\title{
Well-to-Wheels Analysis of Energy Use and Greenhouse Gas Emissions of Plug-In Hybrid Electric Vehicles
}

Energy Systems Division 


\section{About Argonne National Laboratory}

Argonne is a U.S. Department of Energy laboratory managed by UChicago Argonne, LLC under contract DE-AC02-06CH11357. The Laboratory's main facility is outside Chicago, at 9700 South Cass Avenue, Argonne, Illinois 60439. For information about Argonne and its pioneering science and technology programs, see www.anl.gov.

\section{Availability of This Report}

This report is available, at no cost, at http://www.osti.gov/bridge. It is also available on paper to the U.S. Department of Energy and its contractors, for a processing fee, from:

U.S. Department of Energy

Office of Scientific and Technical Information

P.O. Box 62

Oak Ridge, TN 37831-0062

phone (865) 576-8401

fax (865) 576-5728

reports@adonis.osti.gov

\section{Disclaimer}

This report was prepared as an account of work sponsored by an agency of the United States Government. Neither the United States Government nor any agency thereof, nor UChicago Argonne, LLC, nor any of their employees or officers, makes any warranty, express or implied, or assumes any legal liability or responsibility for the accuracy, completeness, or usefulness of any information, apparatus, product, or process disclosed, or represents that its use would not infringe privately owned rights. Reference herein to any specific commercial product, process, or service by trade name, trademark, manufacturer, or otherwise, does not necessarily constitute or imply its endorsement, recommendation, or favoring by the United States Government or any agency thereof. The views and opinions of document authors expressed herein do not necessarily state or reflect those of the United States Government or any agency thereof, Argonne National Laboratory, or UChicago Argonne, LLC 


\section{Well-to-Wheels Analysis of Energy Use and Greenhouse Gas Emissions of Plug-In Hybrid Electric Vehicles}

by

A. Elgowainy, J. Han, L. Poch, M. Wang, A. Vyas, M. Mahalik, and A. Rousseau

Energy Systems Division, Argonne National Laboratory

June 2010 
This page intentionally left blank. 


\section{CONTENTS}

ACKNOWLEDGMENTS ................................................................................. xi

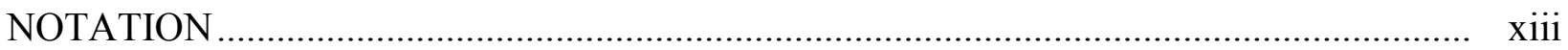

EXECUTIVE SUMMARY .............................................................................

ES.1 CD Operation of Gasoline PHEVs and BEVs ............................................. 2

ES.1.1 Petroleum Displacement ................................................................... 2

ES.1.2 GHG Emissions ............................................................................... 3

ES.1.3 Electric Range of PHEVs and BEVs in Real-World Driving................... 4

ES.2 Combined CD and CS Operation of PHEVs …................................................ 4

ES.2.1 Petroleum Displacement ..................................................................... 4

ES.2.2 GHG Emissions ............................................................................. 5

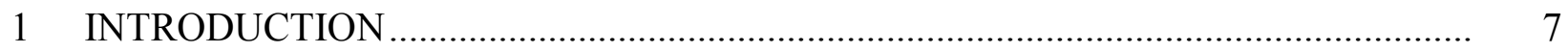

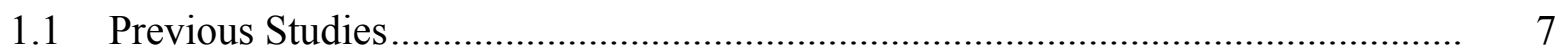

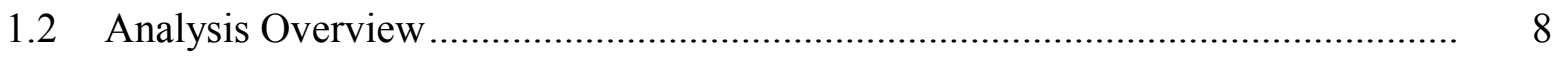

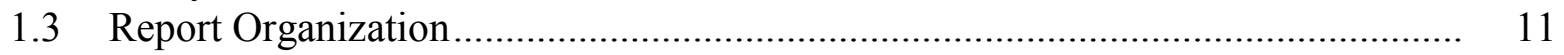

2 FUEL AND ELECTRICITY CONSUMPTION BY PHEVs ..................................... 13

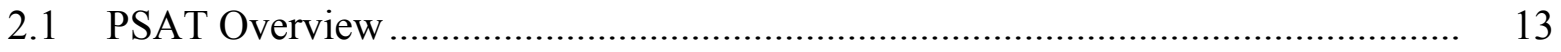

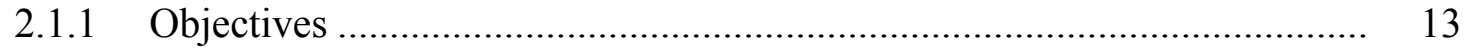

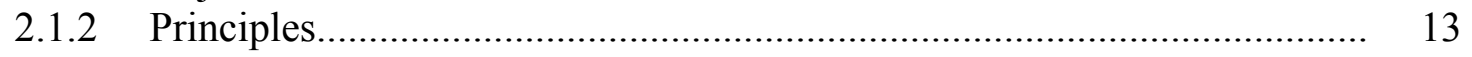

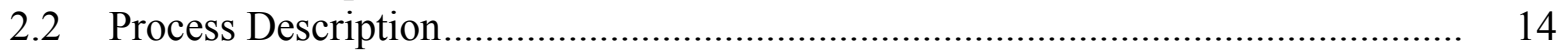

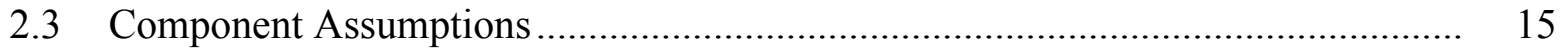

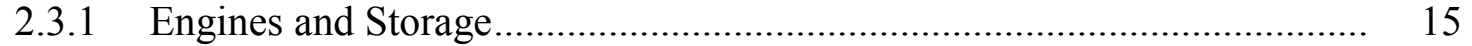

2.3.2 Transmission............................................................................. 18

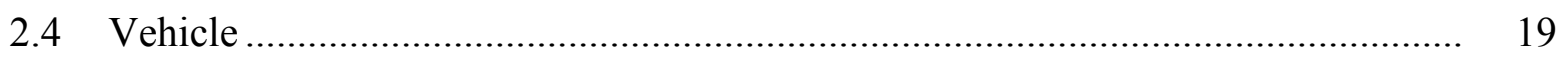

2.4.1 Vehicle Powertrain Assumptions........................................................... 20

2.4.2 Vehicle Architecture Selection ......................................................... 20

2.4.3 Configuration Selection ................................................................... 23

2.5 Vehicle Sizing Process................................................................................. 23

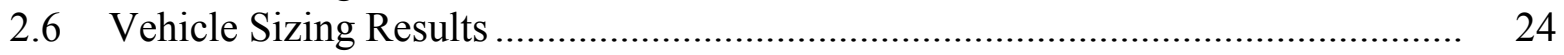

3 ON-ROAD ADJUSTMENT OF FUEL ECONOMY AND

ELECTRICITY CONSUMPTION ..................................................................... 31

3.1 Fuel Economy Adjustment for On-Road Performance..................................... 31

3.1.1 Background ...................................................................................... 31

3.1.2 Conventional ICEVs and HEVs........................................................ 34

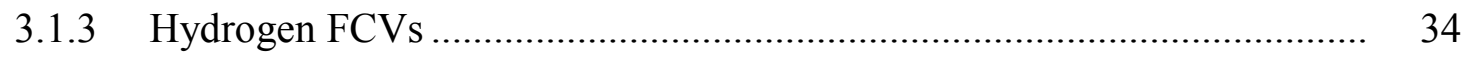




\section{CONTENTS (CONT.)}

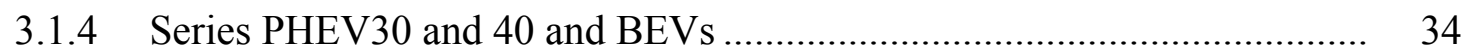

3.1.5 Power-Split PHEV10 and 20 ............................................................ 35

3.2 Battery Charging Losses for PHEVs and BEVs ................................................... 37

3.3 Actual "On-Road" Miles Driven In CD Mode …….............................................. 40

3.4 Vehicle Miles Traveled Split by CD Versus CS Operation.................................... 41

$4 \quad$ PHEV POPULATION AND ELECTRIC LOAD PROFILE …….................................. 45

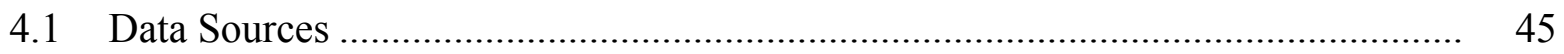

4.2 PHEV Population........................................................................................ 46

4.3 PHEV Charging Scenarios................................................................................. 48

4.4 Summary of PHEV Population and Electric Load Analysis .................................. 52

$5 \quad$ ELECTRIC POWER SYSTEM DISPATCH............................................................... 53

5.1 Modeling Technique and Methodology ............................................................ 53

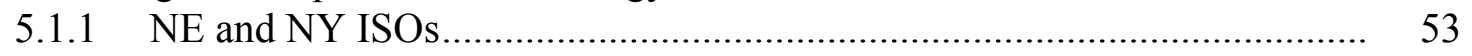

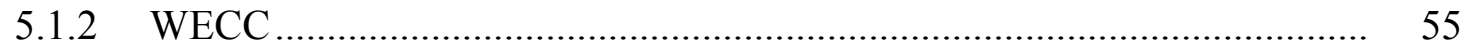

5.1.3 State of Illinois ................................................................................... 57

5.2 Data Collection and Preparation ...................................................................... 59

5.2.1 Inventory of Existing and Proposed Power Plants.................................... 59

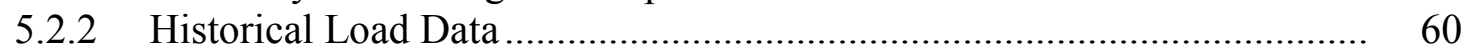

5.2.3 Load Projections ........................................................................... 60

5.2.4 Fuel Price Projections ......................................................................... 60

5.2.5 Expansion Candidate Technology Data .................................................... 60

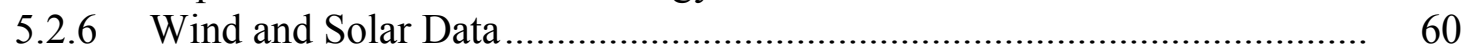

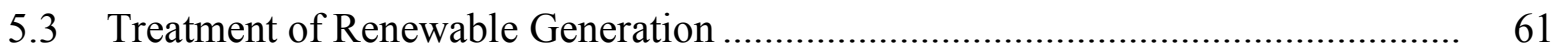

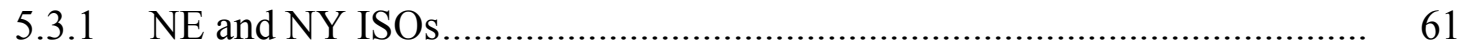

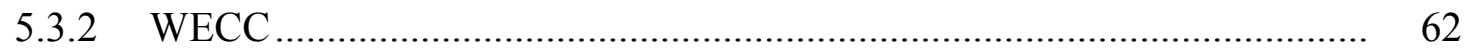

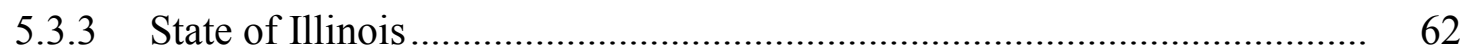

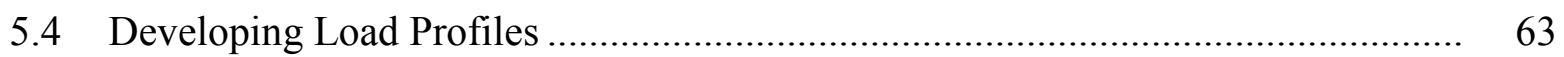

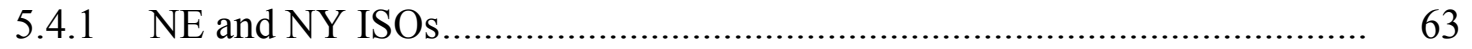

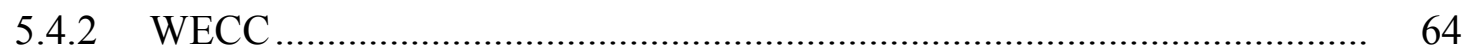

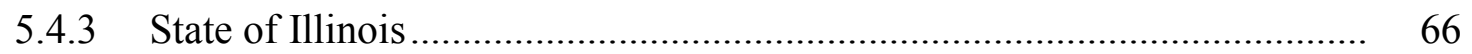

5.4.4 Forecasting PHEV Loads.................................................................... 66

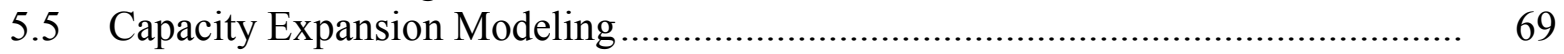

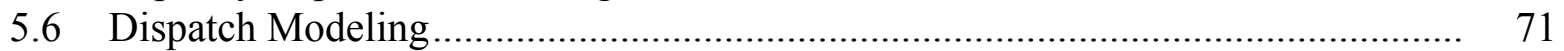

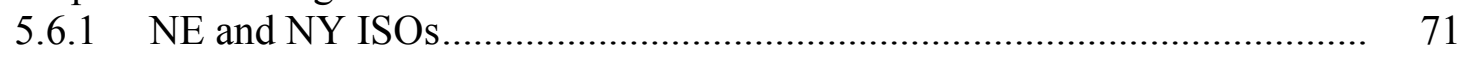

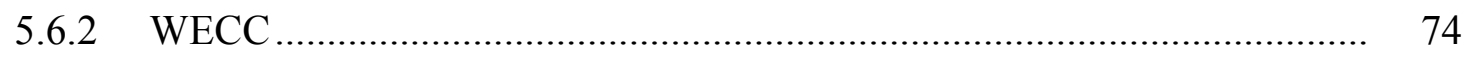

5.6.3 State of Illinois ............................................................................... 76

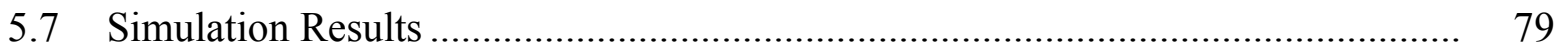

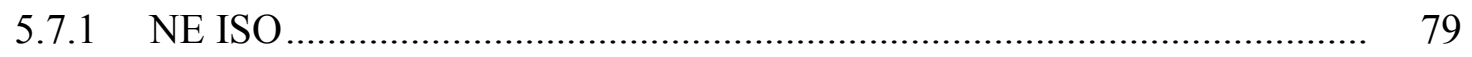

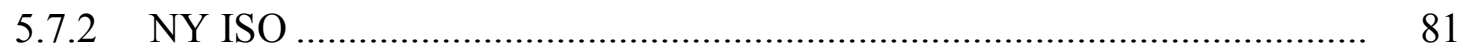




\section{CONTENTS (CONT.)}

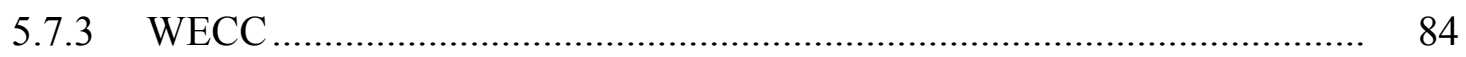

5.7.4 State of Illinois ................................................................................. 88

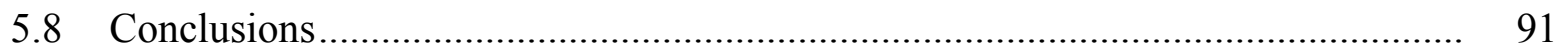

6 GREET WTW ENERGY USE AND GHG EMISSIONS ............................................... 93

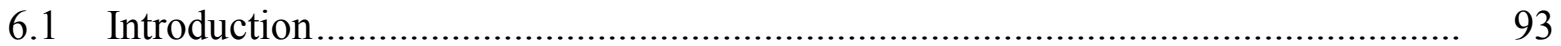

6.2 Well-To-Wheels Simulation Methodology........................................................... 98

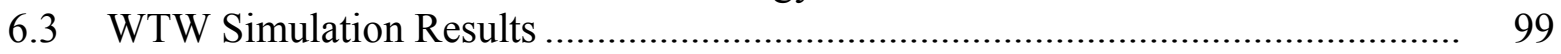

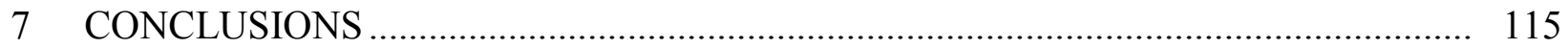

7.1 CD Operation of Gasoline PHEVs and BEVs ................................................ 115

7.1.1 Petroleum Displacement ..................................................................... 115

7.1.2 GHG Emissions ............................................................................. 115

7.1.3 Electric Range of PHEVs and BEVs in Real-World Driving..................... 116

7.2 Combined CD and CS Operation of PHEVs .................................................. 116

7.2.1 Petroleum Displacement .................................................................... 116

7.2.2 GHG Emissions …........................................................................ 117

8 IMPLICATIONS FOR FUTURE ANALYSIS .................................................... 119

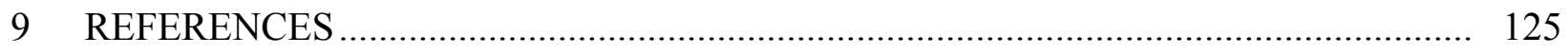

APPENDIX 1: VEHICLE DESCRIPTIONS ………….................................................. 127

\section{FIGURES}

ES.1 WTW Petroleum Use and GHG Emissions for CD Operation of Gasoline PHEVs and BEVs Compared with Baseline Gasoline ICEVs and Regular Gasoline HEVs .......................................................................................................

ES.2 WTW Petroleum Use and GHG Emissions for Combined CD and CS Operation of PHEVs Compared with Baseline Gasoline ICEVs ................................... 5

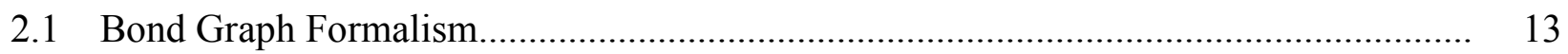

2.2 Simulink Vehicle Model Example........................................................................ 14

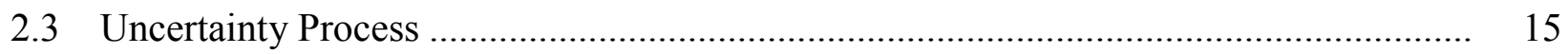




\section{FIGURES (CONT.)}

2.4 Fuel Cell System Efficiency Versus Fuel Cell System Power from the System Map.... 16

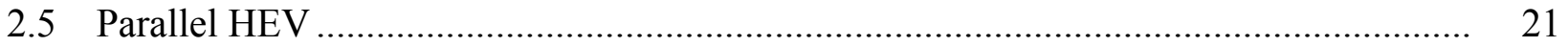

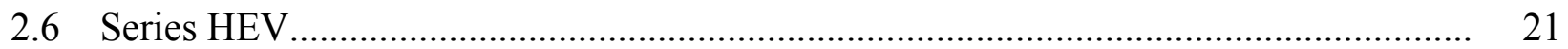

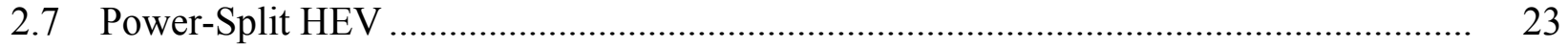

2.8 Process for Sizing PHEV Components............................................................. 24

2.9 Engine Power for Gasoline Powertrains ................................................................... 25

2.10 Electric Machine Power for Gasoline HEVs and PHEVs ....................................... 26

2.11 Fuel Cell Power for Hydrogen Vehicles .......................................................... 26

2.12 Battery Power for Gasoline HEVs and PHEVs ................................................. 27

2.13 Usable Battery Energy for PHEV Midsize Vehicle with Gasoline Engine ................... 27

2.14 Usable Battery Energy for PHEV Midsize Vehicle with Fuel Cell ............................ 28

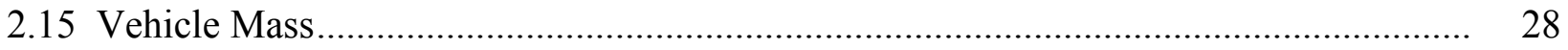

3.1 On-Road Adjustment Factor for Laboratory Fuel Economy Based on EPA's MPG-Based Formulas................................................................................ 33

3.2 On-Road Adjustments of Laboratory Fuel and Electricity Consumption .................... 36

3.3 Electricity and Fuel Consumption in CD Operation of PHEVs and BEVs ................. 38

3.4 Electricity and Fuel Consumption in CD and CS Operation of PHEVs...................... 39

3.5 CD VMT on UDDS from PSAT Simulations..................................................... 40

3.6 CD VMT on HWFET from PSAT Simulations................................................

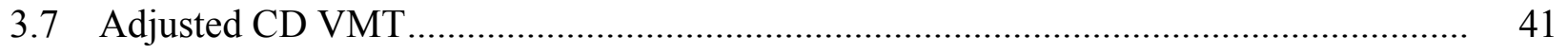

3.8 Percentage of Daily VMT Available for Substitution by a PHEV in CD Mode ............ 43

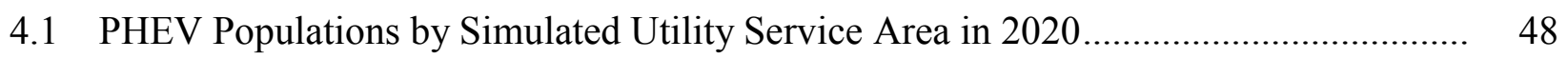




\section{FIGURES (CONT.)}

4.2 Distribution of Vehicles by Last Trip Ending Time for Large MSAs in California........

4.3 Distribution of Vehicles by Last Trip Ending Time for Large MSAs in California, January-March.

4.4 Distribution of Vehicles by Last Trip Ending Time for Large MSAs in California, April-June

4.5 Distribution of Vehicles by Last Trip Ending Time for Large MSAs in California, July-September

4.6 Distribution of Vehicles by Last Trip Ending Time for Large MSAs in California, October-December

5.1 WECC Network Topology

5.2 State of Illinois Network Topology ................................................................. 58

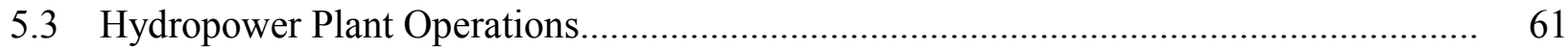

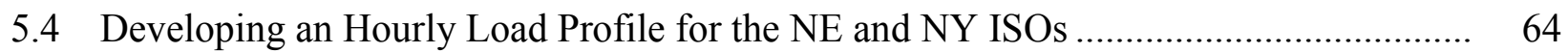

5.5 Developing Hourly Load Profiles for Nodes in WECC …...................................... 65

5.6 Typical Hourly Charging Pattern for All Three PHEV Charging Scenarios................. 70

5.7 Creating a Thermal Unit Inventory for the NE and NY ISOs .................................. 72

5.8 Example for Results of Maintenance Scheduling Routine ...................................... 74

6.1 WTW Total Energy Use for PHEV10 and PHEV40 for Different Fuel/Vehicle Systems

6.2 WTW Fossil Energy Use for PHEV10 and PHEV40 for Different Fuel/Vehicle Systems

6.3 WTW Petroleum Energy Use for PHEV10 and PHEV40 for Different Fuel/Vehicle Systems

6.4 WTW GHG Emissions for PHEV10 and PHEV40 for Different Fuel/Vehicle Systems 


\section{FIGURES (CONT.)}

6.5 WTW GHG Emissions for HEV and CD Operation of PHEV40 with

Different Charging Scenarios in the WECC Region

6.6 WTW GHG Emissions for CD Operation of PHEV40 with

Unconstrained Charging in Different Regions

6.7 WTW Petroleum Energy Use for Combined CD and CS Operations of

PHEVs as a Function of Rated AER

6.8 WTW GHG Emissions for Combined CD and CS Operations of PHEVs in

WECC as a Function of Rated AER

6.9 WTW GHG Emissions for Combined CD and CS Operations of PHEVs in

IL as a Function of Rated AER

6.10 WTW GHG Emissions for Combined CD and CS Operations of PHEVs as a

Function of Rated AER Using the U.S. Average Generation Mix

6.11 WTW GHG Emissions for Combined CD and CS Operations of PHEVs as a Function of Rated AER Using the Northeastern U.S. Average Generation Mix

6.12 WTW GHG Emissions for Combined CD and CS Operations of PHEVs as a Function of Rated AER Using the CA Average Generation Mix

6.13 WTW Petroleum Use and GHG Emissions for CD Operation of PHEVs

6.14 WTW Petroleum Use and GHG Emissions for Combined CD and CS Operation of PHEVs

6.15 WTW Petroleum Use and GHG Emissions for CD Operation of Gasoline Vehicles ....

\section{TABLES}

1.1 Vehicle Technologies, Fuels, and Feedstock Sources ............................................ 9

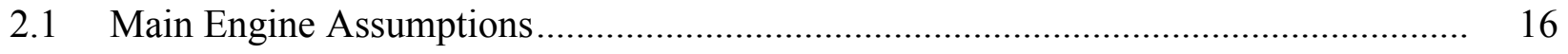

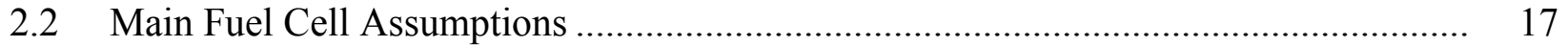

2.3 Main Hydrogen Storage Assumptions ................................................................ 17 


\section{TABLES (CONT.)}

2.4 Main Electric Machine Assumptions............................................................................. 18

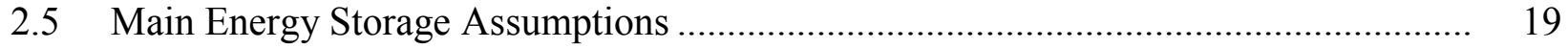

2.6 Main Transmission Assumptions............................................................................... 19

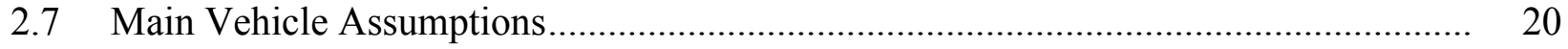

3.1 PSAT Lab-Based Fuel Economy and Electricity Consumption Results ........................ 31

3.2 On-Road Fuel Economy Results............................................................................ 36

3.3 Fuel and Electricity Consumption Calculated from the Adjusted

Fuel Economy and Electricity Consumption in Table 3.2 .......................................... 37

3.4 Share of Daily Vehicle Miles Covered by a Given Distance Range .............................. 42

5.1 Transmission and Distribution Losses by Region ..................................................... 68

5.2 Capacity Additions by Region and PHEV Scenario...................................................... 71

5.3 Baseline Capacity for NE ISO in 2020 .................................................................. 73

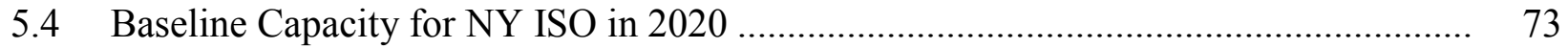

5.5 Baseline Capacity for California and the Rest of WECC in 2020 ................................. 76

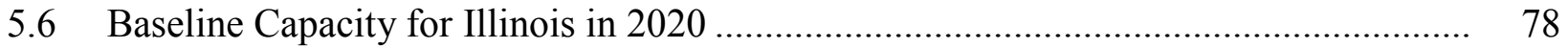

5.7 Baseline Generation Mix for NE ISO in 2020 ........................................................... 79

5.8 Difference in Generation by Fuel Type and Technology between Baseline

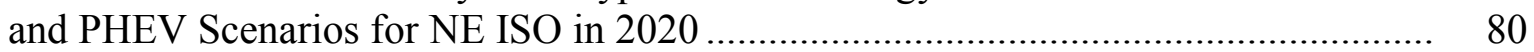

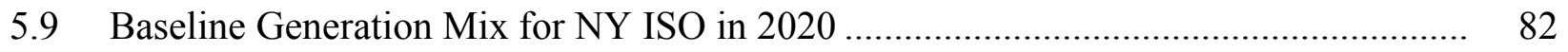

5.10 Difference in Generation by Fuel Type and Technology between Baseline and PHEV Scenarios for NY ISO in 2020 ………..................................... 83

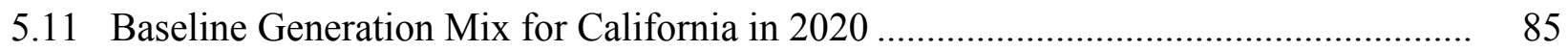

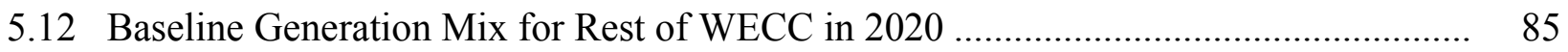




\section{TABLES (CONT.)}

5.13 Difference in Generation by Fuel Type and Technology between Baseline and PHEV Scenarios for California in 2020

5.14 Difference in Generation by Fuel Type and Technology between Baseline and PHEV Scenarios for WECC in 2020.

5.15 Baseline Generation Mix for Illinois in 2020

5.16 Difference in Generation by Fuel Type and Technology between Baseline and PHEV Scenarios for the State of Illinois in 2020.

6.1 Marginal Electricity Generation Mix for Each Charging Scenario, for Each Region

6.2 Marginal Electricity Generation Mix for California, WECC without California, and WECC Total.

6.3 Average Generation Mix for United States, Northeastern United States, and California

6.4 Generation Efficiency for Each Region by Technology for Each Charging Scenario.

6.5 Generation Efficiency for United States, Northeastern United States, and California by Technology

6.6 Electricity Transmission and Distribution Losses 


\section{ACKNOWLEDGMENTS}

This study was supported by the Fuel Cell Technologies Program (U.S. Department of Energy, Assistant Secretary for Energy Efficiency and Renewable Energy) under Contract Number DEAC02-06CH11357. We would like to thank Fred Joseck of the Fuel Cell Technologies Program for his support of this study. We are also grateful to Audun Botterud, Jianhui Wang, Tom Veselka, Guenter Conzelmann, Vladimir Koritarov, Jason Wang, Dan Santini, Mike Duoba, Andrew Burnham, Neeraj Shidore, Theodore Bohn, Aurelien Sergent, and Phil Sharer of Argonne National Laboratory for contributing their knowledge and experience in electricity dispatch modeling, battery performance, and plug-in electric vehicles. 
This page intentionally left blank. 


\section{NOTATION}

\section{ACRONYMS AND ABBREVIATIONS}

AEO

AER

APRF

BDF

$\mathrm{BEV}$

$\mathrm{CD}$

$\mathrm{CH}_{4}$

CI

CMSA

$\mathrm{CO}_{2}$

Cold FTP

CS

DA

DC OPF

DOE

E85

EIA

EMCAS

EPA

EPRI

EV

EVS22

FCV

FERC

FHWA

FOR

FTP

GADS

GDI

GHG

GPRA

GREET

GT

GTMax

GUI
Annual Energy Outlook

all-electric range

Advanced Powertrain Research Facility

bus distribution factor

battery-powered electric vehicle

charge depleting

methane

compression ignition

Consolidated Metropolitan Statistical Area

carbon dioxide

test cycle operating at an ambient temperature of $20^{\circ} \mathrm{F}$

charge sustaining

day ahead

direct-current optimal power flow

U.S. Department of Energy

blend of $85 \%$ ethanol and $15 \%$ gasoline by volume

Energy Information Administration

Electricity Market Complex Adaptive Systems

U.S. Environmental Protection Agency

Electric Power Research Institute

electric vehicle

22nd International Electric Vehicle Symposium

fuel-cell vehicle

Federal Energy Regulatory Commission

Federal Highway Administration

forced outage rate

federal test protocol

Generating Availability Data System

gasoline direct injection

greenhouse gas

Government Performance and Results Act

Greenhouse gases, Regulated Emissions, and Energy use in Transportation gas turbine

Generation and Transmission Maximization

graphical user interface 
GVW

$\mathrm{H}_{2}$

HEV

HWFET

ICC

ICE

ICEV

IGCC

IPCC

IMEP

IPT

ISO

LDC

LDV

LHV

Li-ion

LMP

LSD

MISO

MIT

MSA

MY

$\mathrm{N}_{2} \mathrm{O}$

NE ISO

NEMS

NERC

NG

NGCC

NHTS

NiMH

NRDC

NREL

NY ISO

O\&M

OEM

ORNL

PHEV

PHEV10 and 20

PHEV 30 and 40 gross vehicle weight

hydrogen

hybrid electric vehicle

Highway Federal Emissions Test

Illinois Commerce Commission

internal combustion engine

internal combustion engine vehicle

Integrated Gasification Combined Cycle Power Plant

Intergovernmental Panel on Climate Change

indicated mean effective pressure

integrated powertrain

independent system operator

load duration curve

light-duty vehicle

lower heating value

lithium ion

locational marginal prices

low-sulfur diesel

Midwest Independent Transmission System Operator

Massachusetts Institute of Technology

metropolitan statistical area

model year

nitrous oxide

New England Independent System Operator

National Energy Modeling System

North American Electric Reliability Corporation

natural gas

natural gas combined cycle

National Household Travel Survey

nickel metal hydride

Natural Resources Defense Council

National Renewable Energy Laboratory

New York Independent System Operator

operation and maintenance

original equipment manufacturer

Oak Ridge National Laboratory

plug-in hybrid electric vehicle

PHEV with 10 or 20 miles of all-electric range

PHEV with 30 or 40 miles of all-electric range 


$\begin{array}{ll}\text { PSAT } & \begin{array}{l}\text { Powertrain System Analysis Toolkit } \\ \text { Pump to wheels } \\ \text { PV }\end{array} \\ \text { photovoltaic } \\ \text { RPS } & \begin{array}{l}\text { Renewable Portfolio Standard } \\ \text { real time } \\ \text { RT }\end{array} \\ \text { RTO } & \begin{array}{l}\text { Sogional transmission organization } \\ \text { test cycle operating at an ambient temperature of } 95^{\circ} \mathrm{F}\end{array} \\ \text { SAE } & \text { spark ignition } \\ \text { SC03 } & \begin{array}{l}\text { steam methane reformation } \\ \text { state of charge }\end{array} \\ \text { SMR } & \text { sport utility vehicle } \\ \text { SOC } & \text { Transmission Expansion Planning and Policy Committee } \\ \text { SUV } & \text { Urban Dynamometer Driving Schedule } \\ \text { TEPPC } & \begin{array}{l}\text { utility factor } \\ \text { duty cycle with aggressive highway driving }\end{array} \\ \text { UDDS } & \text { vehicle miles traveled } \\ \text { UF } & \text { Western Electric Coordinating Council } \\ \text { US06 } & \text { well to pump } \\ \text { VMT } & \text { well-to-wheels }\end{array}$

\section{UNITS OF MEASURE}

$\begin{array}{ll}\text { A } & \text { ampere(s) } \\ \text { gal } & \text { gallon(s) } \\ \mathrm{h} & \text { hour(s) } \\ \mathrm{mi} & \text { mile(s) } \\ \mathrm{mpg} & \text { mile(s) per gallon } \\ \text { mpgeg } & \text { mile(s) per gasoline-equivalent gallon } \\ \text { MW } & \text { megawatt(s) } \\ \mathrm{V} & \text { volt } \\ \mathrm{Wh} / \mathrm{mi} & \text { Watt hour(s) per mile }\end{array}$


This page intentionally left blank. 


\title{
WELL-TO-WHEELS ANALYSIS OF ENERGY USE AND GREENHOUSE GAS EMISSIONS OF PLUG-IN HYBRID ELECTRIC VEHICLES
}

\author{
by \\ Amgad Elgowainy, Jeongwoo Han, Leslie Poch, Michael Wang, Anant Vyas, Matthew Mahalik, \\ and Aymeric Rousseau
}

\section{EXECUTIVE SUMMARY}

Plug-in hybrid electric vehicles (PHEVs) are being developed for mass production by the automotive industry. PHEVs have been touted for their potential to reduce the U.S. transportation sector's dependence on petroleum and cut greenhouse gas (GHG) emissions by (1) using off-peak excess electric generation capacity and (2) increasing vehicles' energy efficiency. A well-to-wheels (WTW) analysis - which examines energy use and emissions from primary energy source through vehicle operation - can help researchers better understand the impact of the upstream mix of electricity generation technologies for PHEV recharging, as well as the powertrain technology and fuel sources for PHEVs. For the WTW analysis, Argonne National Laboratory researchers used the Greenhouse gases, Regulated Emissions, and Energy use in Transportation (GREET) model developed by Argonne to compare the WTW energy use and GHG emissions associated with various transportation technologies to those associated with PHEVs.

Argonne researchers estimated the fuel economy and electricity use of PHEVs and alternative fuel/vehicle systems by using the Powertrain System Analysis Toolkit (PSAT) model. They examined two PHEV designs: the power-split configuration and the series configuration. The first is a parallel hybrid configuration in which the engine and the electric motor are connected to a single mechanical transmission that incorporates a power-split device that allows for parallel power paths - mechanical and electrical - from the engine to the wheels, allowing the engine and the electric motor to share the power during acceleration. In the second configuration, the engine powers a generator, which charges a battery that is used by the electric motor to propel the vehicle; thus, the engine never directly powers the vehicle's transmission. The power-split configuration was adopted for PHEVs with a 10- and 20-mile electric range because they require frequent use of the engine for acceleration and to provide energy when the battery is depleted, while the series configuration was adopted for PHEVs with a 30- and 40-mile electric range because they rely mostly on electrical power for propulsion.

Argonne researchers calculated the equivalent "on-road" (real-world) fuel economy on the basis of U.S. Environmental Protection Agency miles per gallon (mpg)-based formulas. The reduction in fuel economy attributable to the "on-road" adjustment formula was capped at 30\% for advanced vehicle systems (e.g., PHEVs, fuel cell vehicles [FCVs], hybrid electric vehicles [HEVs], and battery-powered electric vehicles [BEVs]). Simulations for calendar year 2020 with model year 2015 mid-size vehicles were chosen for this analysis to address the implications of PHEVs within a reasonable timeframe after their likely introduction over the next few years. For 
the WTW analysis, Argonne assumed a PHEV market penetration of $10 \%$ by 2020 in order to examine the impact of significant PHEV loading on the utility power sector. Technological improvement with medium uncertainty for each vehicle was also assumed for the analysis.

Argonne employed detailed dispatch models to simulate the electric power systems in four major regions of the United States: the New England Independent System Operator, the New York Independent System Operator, the State of Illinois, and the Western Electric Coordinating Council. Argonne also evaluated the U.S. average generation mix and renewable generation of electricity for PHEV and BEV recharging scenarios to show the effects of these generation mixes on PHEV WTW results.

Argonne's GREET model was designed to examine the WTW energy use and GHG emissions for PHEVs and BEVs, as well as FCVs, regular HEVs, and conventional gasoline internal combustion engine vehicles (ICEVs). WTW results are reported for charge-depleting (CD) operation of PHEVs under different recharging scenarios. The combined WTW results of $\mathrm{CD}$ and charge-sustaining (CS) PHEV operations (using the utility factor method) were also examined and reported. According to the utility factor method, the share of vehicle miles traveled during CD operation is 25\% for PHEV10 and 51\% for PHEV40.

Argonne's WTW analysis of PHEVs revealed that the following factors significantly impact the energy use and GHG emissions results for PHEVs and BEVs compared with baseline gasoline vehicle technologies: (1) the regional electricity generation mix for battery recharging and (2) the adjustment of fuel economy and electricity consumption to reflect "real-world" driving conditions. Although the analysis predicted the marginal electricity generation mixes for major regions in the United States, these mixes should be evaluated as possible scenarios for recharging PHEVs because significant uncertainties are associated with the assumed market penetration for these vehicles. Thus, the reported WTW results for PHEVs should be directly correlated with the underlying generation mix, rather than with the region linked to that mix. The primary conclusion is that electrification of transportation significantly reduces petroleum energy use, but GHG emissions strongly depend on the electricity generation mix for battery recharging. Sections ES.1 and ES.2 summarize petroleum and GHG emissions results for CD operation of gasoline PHEVs and BEVs, and for combined CD and CS operation of PHEVs, respectively.

\section{ES.1 CD OPERATION OF GASOLINE PHEVS AND BEVS}

\section{ES.1.1 Petroleum Displacement}

In CD operation modes, PHEVs employing the power-split and series configurations could realize reductions in petroleum energy use of more than $60 \%$ and $90 \%$, respectively, because the petroleum share is small in the electricity generation mix for most regions in the United States (Figure ES.1, horizontal axis). BEVs can virtually eliminate the use of petroleum

fuels for each vehicle mile traveled on electricity. 


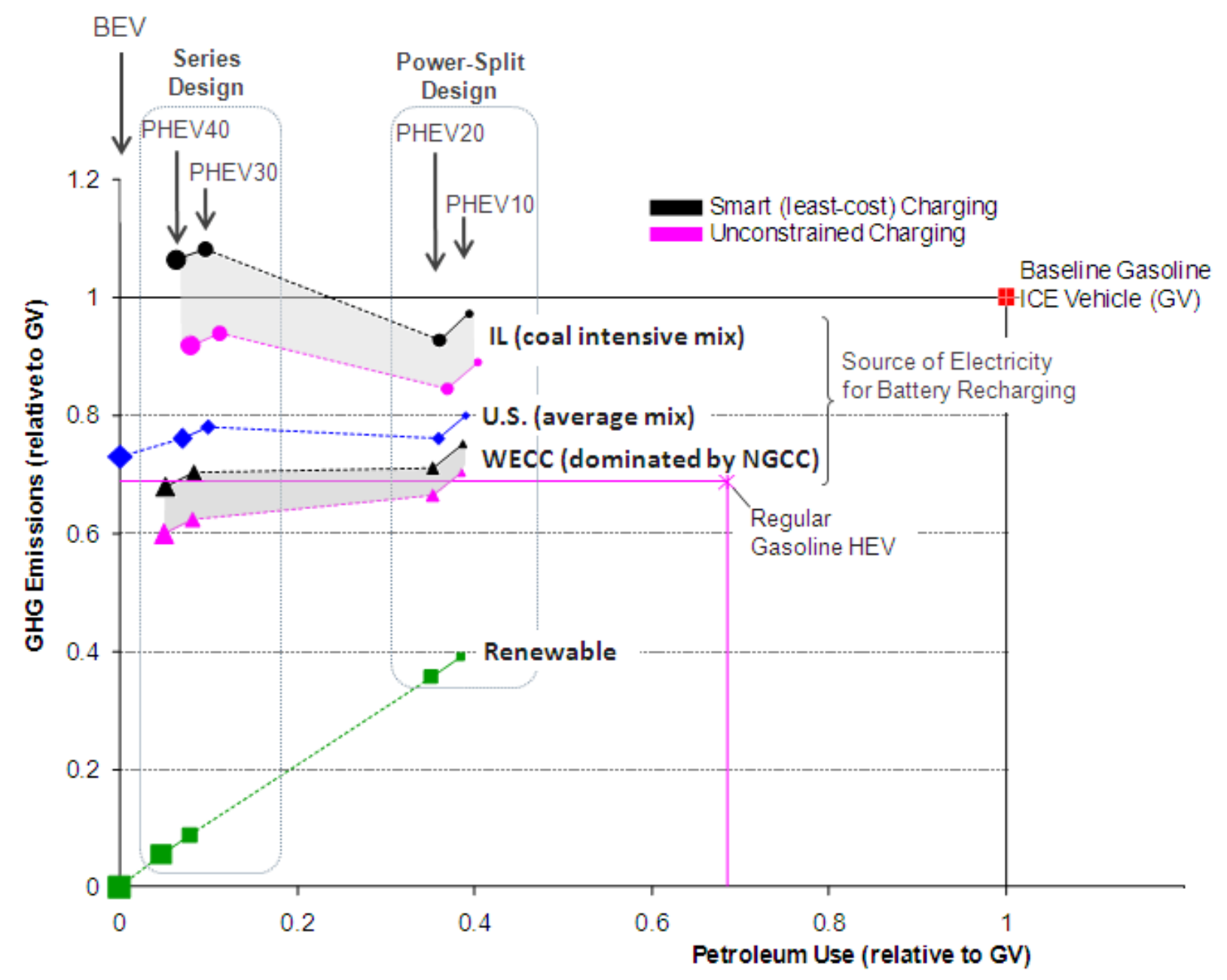

FIGURE ES.1 WTW Petroleum Use and GHG Emissions for CD Operation of Gasoline PHEVs and BEVs Compared with Baseline Gasoline ICEVs and Regular Gasoline HEVs

\section{ES.1.2 GHG Emissions}

- Unconstrained charging (with investments in new generation capacity) reduces GHG emissions (Figure ES.1, vertical axis) compared with smart charging (no needed investment in new capacity) because of the high efficiency and low carbon intensity associated with the added capacity in the unconstrained charging scenario.

- PHEVs recharging from a mix with a large share of coal generation (e.g., Illinois marginal mix) produce GHG emissions comparable to those of baseline gasoline ICEVs (with a range from $-15 \%$ to $+10 \%$ ) but significantly higher than those of gasoline HEVs (with a range from $+20 \%$ to $+60 \%$ ). The range of the results is primarily attributable to the different generation mix for the charging scenarios considered and the different PHEV types (power-split versus series designs). 
- PHEVs recharging from a mix with a large share of efficient electricity generation from natural gas (e.g., natural gas combined-cycle [NGCC] generation in the Western Electric Coordinating Council region) produce GHG emissions comparable to those of gasoline HEVs (with a range from $-15 \%$ to $+10 \%$ ) but significantly lower than those of baseline gasoline ICEVs (with a range from $-25 \%$ to $-40 \%$ ). The range of results is primarily attributable to the different generation mix for the charging scenarios considered and the different PHEV types (power-split versus series designs).

- PHEVs recharging from a generation mix comparable to the U.S. average mix produce lower GHG emissions than baseline gasoline ICEVs (with a range from $-20 \%$ to $-25 \%$ ) but higher than gasoline HEVs (with a range from $+10 \%$ to $+20 \%)$.

- To achieve significant reductions in GHG emissions, PHEVs and BEVs must recharge from a generation mix with a large share of nonfossil sources (e.g., renewable or nuclear power generation). PHEVs recharging from a potential renewable or nonfossil generation mix reduce GHG emissions by more than $60 \%$ for the power-split PHEV configuration and by more than $90 \%$ for the series configuration compared with baseline gasoline ICEVs. BEVs can virtually eliminate GHG emissions (per mile traveled) if recharged from nonfossil electricity generation.

\section{ES.1.3 Electric Range of PHEVs and BEVs in Real-World Driving}

- The actual CD range of PHEVs could be lower or higher than the rated electric range on the standard driving cycles, depending on the powertrain type and the vehicle's control strategy. Power-split PHEVs extend the electric range because the battery receives significant help from the engine, resulting in blended (i.e., blended use of battery and engine) operation in CD mode. The electric range of BEVs and series PHEVs drops below the rated electric range because of the higher battery discharge rate required to meet real-world driving conditions.

\section{ES.2 COMBINED CD AND CS OPERATION OF PHEVS}

\section{ES.2.1 Petroleum Displacement}

- PHEVs powered by petroleum fuels (i.e., gasoline and diesel) reduce petroleum energy use by $40-60 \%$ compared with conventional gasoline ICEVs, while PHEV powered by E85 (blend of $85 \%$ ethanol and $15 \%$ gasoline by volume) reduce petroleum energy use by $80-90 \%$, and PHEVs powered by hydrogen reduce petroleum energy use by greater than $90 \%$ (Figure ES.2, horizontal axis). 


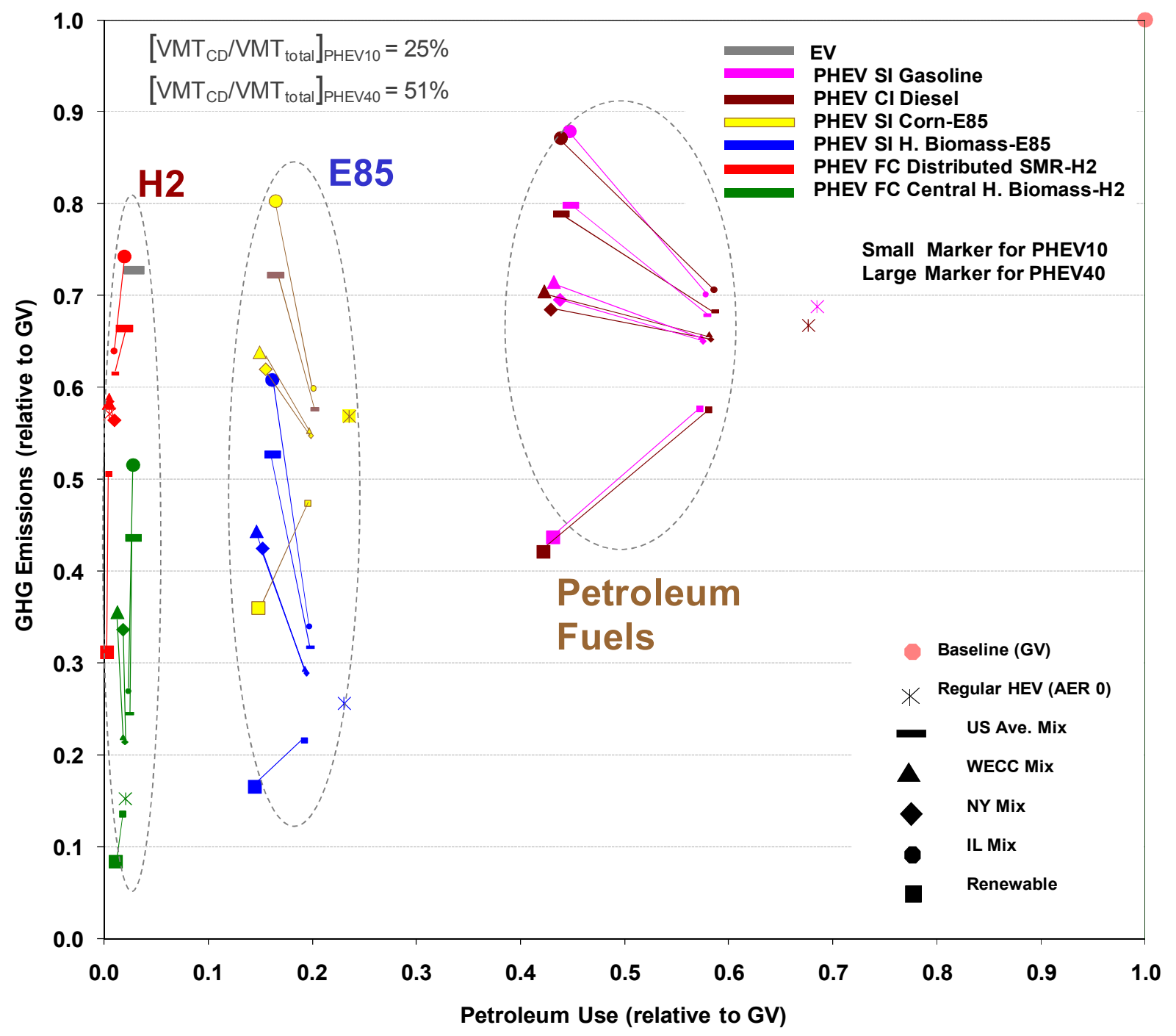

FIGURE ES.2 WTW Petroleum Use and GHG Emissions for Combined CD and CS Operation of PHEVs (unconstrained charging) Compared with Baseline Gasoline ICEVs

\section{ES.2.2 GHG Emissions}

- Compared with conventional gasoline ICEVs, PHEVs powered by petroleum fuels (i.e., gasoline and diesel) reduce GHG emissions by 10-60\%, PHEVs powered by E85 (blend of $85 \%$ ethanol and 15\% gasoline by volume) reduce GHG emissions by $20-80 \%$, and PHEVs powered by hydrogen reduce these emissions by $25-90 \%$. The large range of $\mathrm{GHG}$ emissions reductions is attributable to the variety of feedstock sources considered for producing the fuel and electricity for each vehicle.

- PHEVs achieve greater petroleum energy savings with increased electric range. Conversely, more GHG emissions are produced with increased electric range unless renewable or nonfossil electricity generation is used for recharging. 
- PHEVs employing biomass-based fuels (e.g., E85 or hydrogen from biomass sources) may not achieve GHG emissions benefits compared with conventional HEVs (employing the same fuel) if the electricity generation mix for PHEV recharging is dominated by fossil fuel sources. 


\section{INTRODUCTION}

\subsection{PREVIOUS STUDIES}

Because of increasing concerns about climate change, the growing demand for and declining production of oil, and the associated increase in oil prices, many researchers have investigated the cost and the potential reductions in petroleum use and greenhouse gas (GHG) emissions associated with plug-in hybrid electric vehicles (PHEVs). Kromer and Heywood (2007) evaluated the potential of electric and hybrid electric powertrains - such as PHEVs, gasoline hybrid electric vehicles (HEVs), fuel-cell vehicles (FCVs), and battery-powered electric vehicles (BEVs) - to reduce petroleum use and GHG emissions. Their study showed that a PHEV30 uses only one-third the petroleum of a gasoline-fueled spark-ignition baseline vehicle and one-half that of an HEV, while a PHEV recharging from the average Energy Information Administration (EIA) projection of the electric grid in 2020 offers nearly the same GHGreduction benefits as an HEV. They concluded that the potential of PHEVs, BEVs, and FCVs to offer the sought-after reduction in GHG emissions is constrained by continued reliance on fossil fuels to produce the electricity and hydrogen needed to fuel these vehicles.

An International Energy Agency report examining hybrid and electric vehicle technologies concluded that PHEVs operating in charge-depleting (CD) mode can outperform HEVs in terms of GHG emission reductions if $75 \%$ or more of the required electricity is generated from combined-cycle natural gas (Passier et al. 2007). The Electric Power Research Institute (EPRI) and Natural Resources Defense Council (NRDC) (2007) examined the GHG emissions of potentially large numbers of PHEVs over a time period from 2010 to 2050. Their results revealed that in 2010, even with current coal technologies, a PHEV20 would produce 28$34 \%$ lower GHG emissions compared with a conventional gasoline vehicle and $1-11 \%$ higher GHG emissions compared with an HEV. In 2050, a PHEV20 would generate approximately the same GHG emissions as an HEV powered by electricity from coal-fired power plants that do not capture carbon dioxide $\left(\mathrm{CO}_{2}\right)$ emissions and 37\% lower GHG emissions than an HEV powered by coal-fired power plants equipped with $\mathrm{CO}_{2}$ capture and storage technologies. EPRI and NRDC examined several PHEV and electricity generation technology scenarios for 2050 and concluded that PHEVs would generate lower GHG emissions than either conventional or hybrid vehicles - improvements would range from 40-65\% compared with a conventional vehicle and from $7-46 \%$ compared with an HEV.

Gaines et al. (2008) examined WTW energy use and GHG emissions for several fuel/vehicle systems that used different feedstock sources. They found that, regardless of pathway, when switching to a feedstock other than conventional oil, the best option is a PHEV operating in $\mathrm{CD}$, rather than CS, mode. Morrow et al. (2008) evaluated the charging infrastructure requirements for PHEVs and found that 40 miles of charge-depleting range is necessary for an average PHEV if no infrastructure is available outside of the owner's primary residence; the charge-depleting range can be lowered to 13 miles if public charging infrastructure is available. Morrow and his colleagues highlighted the fact that the availability of a robust charging infrastructure can reduce onboard energy storage requirement (i.e., battery size), as well as the charging time for PHEVs. They concluded that the overall transportation system cost can 
be reduced by providing a robust charging infrastructure, rather than compensating for lean infrastructure with additional battery size and range.

Thomas (2009) examined the cost and benefits of BEVs in comparison to FCVs. He concluded that hydrogen-powered FCVs would use 33-55\% less energy than BEVs in converting natural gas to vehicle fuel with today's electrical power plants. He calculated the ratio of GHG emissions from BEVs (recharging from the U.S. average mix) to those from FCVs (powered by hydrogen from natural gas sources). His results indicated ratios of 1.58 and 1.86 for 200- and 300-mile vehicle range, respectively. Thomas also showed that BEVs with a 300-mile range would have higher GHG emissions compared with conventional gasoline ICEVs. Recently, the National Research Council (2009) released a report assessing the cost and environmental impact of PHEVs. The report concluded that a PHEV10 or a PHEV40 reduce oil consumption by $20 \%$ and $55 \%$, respectively, compared with a gasoline HEV. The report also concluded that a PHEV10 generates fewer GHG emissions compared with conventional (nonhybrid) vehicles, but more than HEVs after accounting for emissions at the generating stations that supply electric power.

\subsection{ANALYSIS OVERVIEW}

This study is an extension of Argonne's earlier analysis of the well-to-wheels (WTW) energy use and GHG emissions associated with the possible introduction of plug-in hybrid electric vehicles (PHEVs) and other alternative vehicle technologies into the marketplace (Elgowainy et al. 2009). At the conclusion of phase I of our previous analysis, we identified two main issues that required further investigation: the per-mile electricity use and fuel consumption of alternative vehicle technologies and the marginal electricity generation mix for PHEVs charging in different U.S. regions. The analysis described in this report addresses these two issues in detail and evaluates their impact on the WTW energy use and GHG emissions in different regions of the United States.

With funding from the U.S. Department of Energy (DOE), researchers in Argonne's Center for Transportation Research use Argonne's Greenhouse gases, Regulated Emissions, and Energy use in Transportation (GREET) model to estimate the full fuel-cycle energy use and emissions for alternative transportation fuels and advanced vehicle systems (Wang 1999). GREET estimates fuel-cycle energy use in British thermal units per mile (Btu/mi) and GHG emissions in grams per mile $(\mathrm{g} / \mathrm{mi})$ for advanced vehicle technologies, including PHEVs. GREET tracks fuel use and emissions from the primary energy source to vehicle operation; such a study is known as a "well-to-wheels" analysis. A WTW analysis is often divided into well-topump (WTP) and pump-to-wheels (PTW) stages. The WTP stage starts with the fuel feedstock recovery, followed by fuel production, and ends with the fuel available at the pump, while the PTW stage represents the vehicle's operation.

The engine/fuel combinations examined in this analysis are a spark ignition (SI) engine fueled by gasoline, an SI engine fueled by a blend of $85 \%$ ethanol and $15 \%$ gasoline (E85), a compression-ignition (CI) engine fueled by low-sulfur diesel (LSD), a fuel cell power system fueled by gaseous hydrogen $\left(\mathrm{H}_{2}\right)$, and a BEV fueled by electricity. The feedstock sources 
considered are corn and switchgrass for E85 and distributed natural gas (NG) steam methane reformation (SMR) and switchgrass (gasification) for $\mathrm{H}_{2}$. Table 1.1 summarizes the vehicle technologies and fuels considered in this analysis, as well as the feedstock sources for these fuels.

A conventional gasoline ICEV and a regular HEV employing an internal combustion engine (ICE) and a fuel cell are compared with a PHEV using the same fuels to examine their relative benefits with respect to energy use and GHG emissions. Simulations for calendar year 2020 with model year (MY) 2015 vehicles are chosen for this analysis to address the implications of PHEVs within a reasonable timeframe after their likely introduction over the next few years.

The fuel economy values for ICEVs and FCVs and the electricity consumption values for CD modes of PHEVs and BEVs were obtained from Argonne's Powertrain System Analysis Toolkit (PSAT) simulations. PSAT is a forward-looking modeling package that can simulate any standard or custom driving cycle for different vehicle configurations in the model's database. PSAT then estimates the fuel consumption by these vehicle technologies on selected driving cycles. Two PHEV design configurations were considered for this analysis: a power-split design for PHEV10 and 20 (i.e., with 10 and 20 miles of all-electric range [AER]) and a series design for PHEV30 and 40 (i.e., with 30 and 40 miles of AER). The power-split design is a parallel hybrid configuration in which the ICE and the electric motor are connected to a single mechanical transmission. The design incorporates a power-split device that allows for power paths from the engine to the wheels that can be either mechanical or electrical, thus decoupling the power supplied by the ICE from the power demanded by the driver. The series design is based on an ICE that powers a generator, which conveys the energy from the engine to power the electric motor that drives the transmission or to charge the battery; the gasoline engine never directly powers the vehicle in this configuration. For the power-split PHEV, the engine is sized to meet the gradeability requirement. The size of the engine in the series PHEV is similar to the one in the power-split PHEV, but with a higher power because of the added inefficiencies of the

TABLE 1.1 Vehicle Technologies, Fuels, and Feedstock Sources

\begin{tabular}{|c|c|c|}
\hline Technology & Fuel & Feedstock \\
\hline \multirow{3}{*}{ SI vehicles } & Gasoline & $\begin{array}{l}\text { Conventional crude }(82 \%) \text { and } \\
\text { oil sand }(18 \%)\end{array}$ \\
\hline & \multirow{2}{*}{ Ethanol } & Corn \\
\hline & & Herbaceous biomass (switchgrass) \\
\hline CI vehicles & Low-sulfur diesel & $\begin{array}{l}\text { Conventional crude }(82 \%) \text { and } \\
\text { oil sand }(18 \%)\end{array}$ \\
\hline BEVs & Electricity & $\begin{array}{l}\text { Mix of fuels for electricity generation } \\
\text { technologies }\end{array}$ \\
\hline \multirow{3}{*}{ FCVs } & \multirow{3}{*}{ Hydrogen } & Natural gas (SMR) \\
\hline & & Electricity (electrolysis) \\
\hline & & Herbaceous biomass (switchgrass) \\
\hline
\end{tabular}


driveline in the series configuration. The battery power for all PHEVs is sized to meet the Urban Dynamometer Driving Schedule (UDDS) in all-electric mode, although the control strategy may limit the use of battery power to maximize fuel efficiency during the blended-mode operation of the power-split PHEVs. The electric machine is sized to meet the UDDS load for the power-split PHEVs and to meet the US06 (cycle with aggressive highway driving) for the series PHEVs. PSAT was employed to estimate the fuel and/or electricity consumption of the selected vehicle technologies on the UDDS and the Highway Federal Emissions Test (HWFET) driving cycles.

One major improvement of this analysis compared with our previous study is the more rigorous examination of the fuel economy adjustment factor for different vehicle technologies (i.e., adjusting the fuel economy and electricity consumption from the UDDS and HWFET values to the actual on-road estimates). In our previous analysis, we adjusted the cycles' fuel economy for all ICEVs, HEVs and FCVs according to the U.S. Environmental Protection Agency (EPA) five-cycle, miles per gallon (mpg)-based formulas, but we did not adjust the cycles' electricity consumption for PHEVs because of a lack of guidance regarding the appropriate adjustment factor. In this analysis, we adjust the electricity consumption of BEVs and series PHEVs in CD operation based on a 0.7 degradation factor, as suggested by EPA and other experts in this area. However, we did not adjust the electricity consumption of the powersplit PHEV design because the additional on-road load (above the cycle load) is assumed to be handled by the engine (in the blended CD mode of operation). In such a case, we assume that the additional load (over the test cycle load) would result in a fuel consumption increase similar to one recorded during CS operation of the same vehicle for the same additional load. As discussed in Section 6 of the report, these adjustment factors for fuel economy and electricity consumption significantly impact the WTW energy use and GHG emissions of PHEVs and BEVs.

The PHEVs will draw electric energy from the national grid. The extent of this electricity demand was estimated by examining patterns of vehicle usage and estimating the potential number of PHEVs that will be plugged in. To conduct utility demand simulations, we estimated daily electricity demands for various PHEVs by analyzing the following four factors: (1) daily vehicle usage; (2) pattern of vehicle arrival at home at the end of the last trip; (3) number of PHEVs of different AERs that will be plugged in each day; and (4) amount of electric power and energy that will be drawn by each PHEV (of different AER), together with time required for charging. For estimating electricity demand by PHEVs, we projected the number of PHEVs that will be on road in 2020. We assumed a high-market-penetration scenario, in which $10 \%$ of all registered light-duty vehicles (LDVs) in 2020 are PHEVs, classifying these vehicles as PHEVs with 10-, 20-, 30-, and 40-mile AERs. Travel data from the 2001 National Household Travel Survey (NHTS) were analyzed to develop distributions of vehicles by the hour of day when the last vehicle trip ended. The time of the last trip ending is potentially the time when the recharging of PHEVs would begin. We estimated the power demand and time required to charge PHEVs of different AERs. Three different charging scenarios were assumed for use in evaluating the impacts of PHEVs on electric utilities.

Another major improvement in this analysis over our previous study is the prediction of the marginal electricity generation mix for PHEVs charging in different U.S. regions. Our previous study relied on an Oak Ridge National Laboratory (ORNL) report by Hadley and Tsvetkova (2008) as source for providing region-specific default marginal generation mixes for 
PHEVs. In this analysis, Argonne employed sophisticated dispatch models to simulate the electric power systems in four regions of the United States: the New England Independent System Operator (NE ISO), the New York Independent System Operator (NY ISO), the State of Illinois, and the Western Electric Coordinating Council (WECC). The NE ISO is a regional electric balancing authority serving all states within the New England region, including Maine, Vermont, New Hampshire, Connecticut, Massachusetts, and Rhode Island. The NY ISO is a regional balancing authority serving all of the loads within the entire State of New York. WECC is a reliability council responsible for coordinating and promoting the bulk power system in all or portions of 14 western states. The State of Illinois is modeled as a single state, but consists of five balancing authorities and two regional reliability councils. These regions were selected because of their large population density, distinct mix of electricity generation technologies, and different climatic conditions.

\subsection{REPORT ORGANIZATION}

The following sections provide an overview of the methodology used by Argonne to obtain the key parameters included in the WTW analysis using GREET. Section 2 provides an explanation of the methodology and assumptions used to obtain the fuel economy values for ICEVs and FCVs and the electricity consumption values for PHEVs and BEVs. Section 3 describes the methodology employed to adjust fuel economy and electricity consumption for onroad performance of the different vehicle technologies considered in this analysis. In section 4, we introduce the PHEV market penetration scenario and explain the methodology behind the PHEV technology mix used in the analysis, as well as the electric load associated with different recharging scenarios. Section 5 describes the electric dispatch modeling technique for the different regions considered in this analysis, the sources for the model's input data, the marginal electricity generation mix obtained for each region and scenario, and key issues and major findings for each region/scenario. In Section 6, we present and discuss the WTW results for the different vehicle technologies. Section 7 provides our conclusion, and Section 8 addresses the remaining issues that need to be addressed in the next phase of WTW analysis. 
This page intentionally left blank. 


\section{FUEL AND ELECTRICITY CONSUMPTION BY PHEVS}

\subsection{PSAT OVERVIEW}

\subsubsection{Objectives}

Because of the time and cost constraints involved in manually building and testing the large number of possible advanced vehicle architectures, Argonne developed PSAT, a state-ofthe-art flexible and reusable simulation package that can be used to meet the requirements of automotive engineers throughout the development process - from modeling to control.

After a thorough assessment, DOE selected PSAT as its primary vehicle simulation tool to support its FreedomCAR and Vehicle Technologies Program. PSAT has been used in numerous studies to guide the U.S. government's advanced vehicle research efforts. Major automotive companies and suppliers are also using PSAT to support their advanced vehicle development programs.

\subsubsection{Principles}

PSAT is a forward-looking (also called "driver-driven") simulation package. A driver model follows any standard or custom driving cycle, sending a power demand to the vehicle controller, which, in turn, sends a demand to the propulsion components. Component models react to the demand and feed back their status to the vehicle controller, and the process iterates to achieve the desired result. Each component model is a Simulink/Stateflow box, which uses the Bond graph formalism, illustrated in Figure 2.1. The components boxes are then "assembled" according to the powertrain configuration chosen by the user in the graphical user interface (GUI) as shown in Figure 2.2.

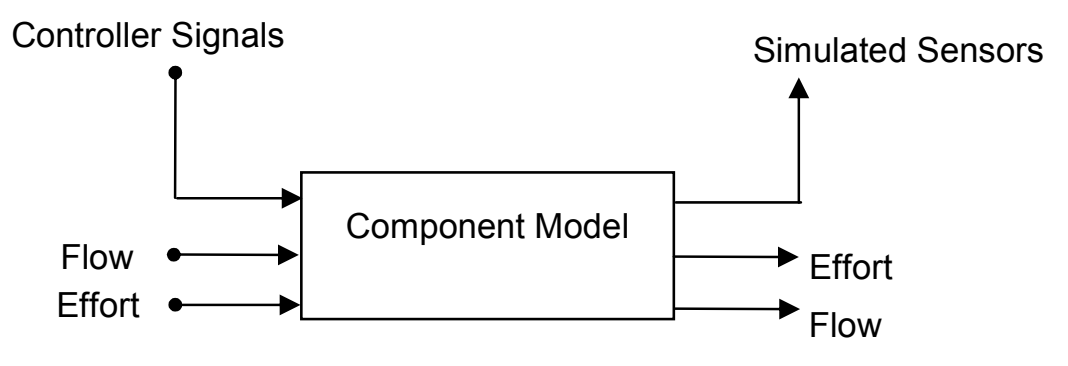

Effort: Torque $(\mathrm{Nm})$ or Voltage $(\mathrm{V})$

Flow: Speed (rad/s) or Current $(\mathrm{A})$

FIGURE 2.1 Bond Graph Formalism 


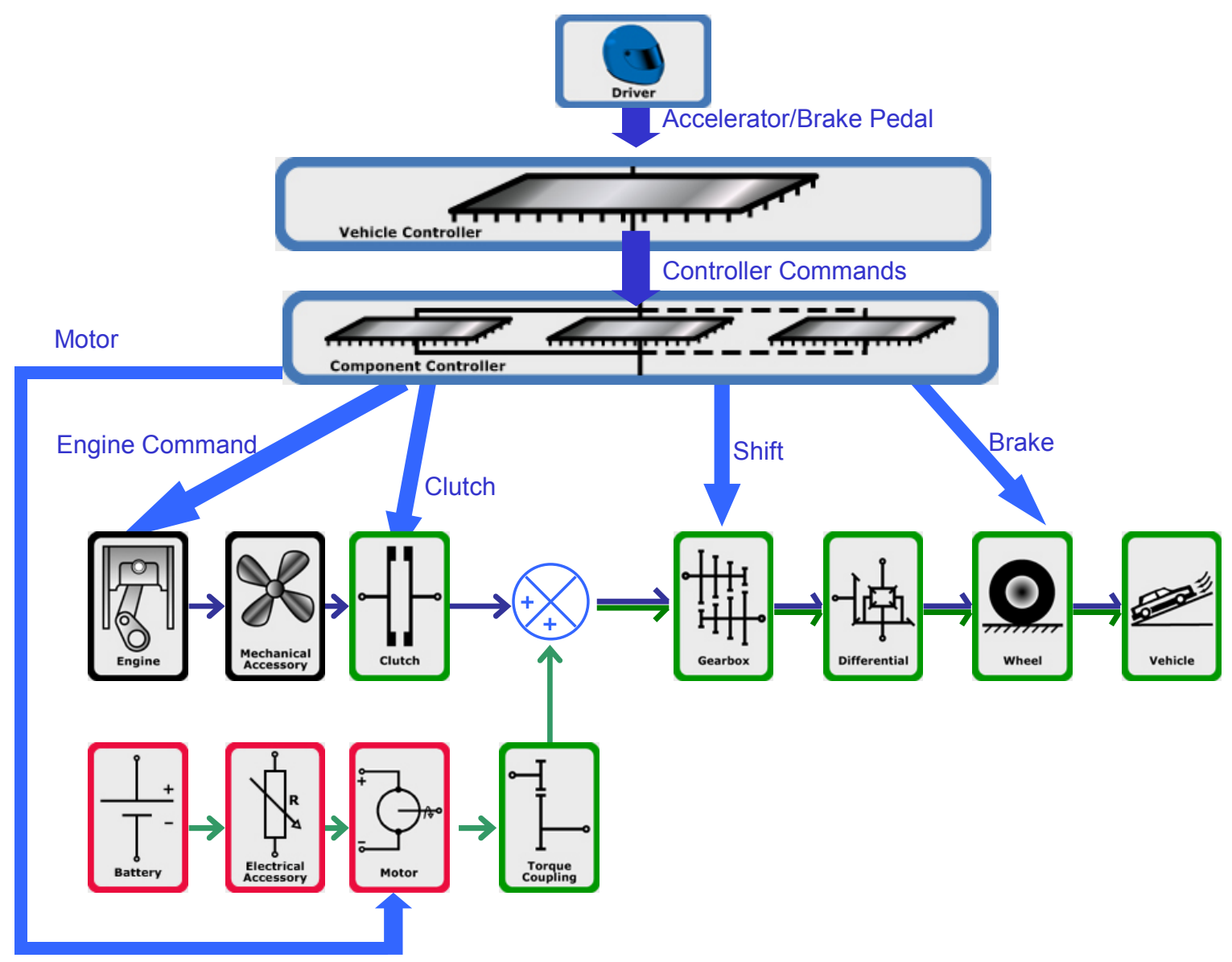

FIGURE 2.2 Simulink Vehicle Model Example

\subsection{PROCESS DESCRIPTION}

To evaluate the fuel efficiency benefits of advanced vehicles, model users design the vehicles on the basis of component assumptions. The fuel efficiency is then simulated on the UDDS and HWFET. The assumptions and results described in this report were generated to support the 2009 Government Performance and Results Act (GPRA) analysis for the light-duty vehicle research conducted at the U.S. DOE from fuel efficiency and cost perspectives. Established in 1993, GPRA holds federal agencies accountable for using resources wisely and achieving program results. A subset of the GPRA study was selected with a midsize car representative of 2015 technologies. To properly assess the benefits of future technologies, the following vehicle configurations and fuels were considered:

- Five powertrain configurations: conventional, HEV, PHEV, fuel cell HEV, and battery electric vehicle (BEV)

- Four fuels: gasoline, diesel, ethanol, and hydrogen 
To address the uncertainties, we employed a triangular distribution approach (low, medium, and high), as shown in Figure 2.3 For each component's assumption (e.g., efficiency, power density), we defined three separate values to represent (1) $90^{\text {th }}$ percentile, (2) $50^{\text {th }}$ percentile and (3) $10^{\text {th }}$ percentile. The $90^{\text {th }}$ percentile means that the technology has a $90 \%$ chance of being available at the time considered. Each set of assumptions is used for each vehicle; note that the most efficient components are not automatically the cheapest ones. As a result, for each vehicle considered, we simulated three options for fuel efficiency. The simulation results for the $50^{\text {th }}$ percentile assumptions, which represent "medium" uncertainty of technological improvement for each vehicle, were used for the WTW analysis.

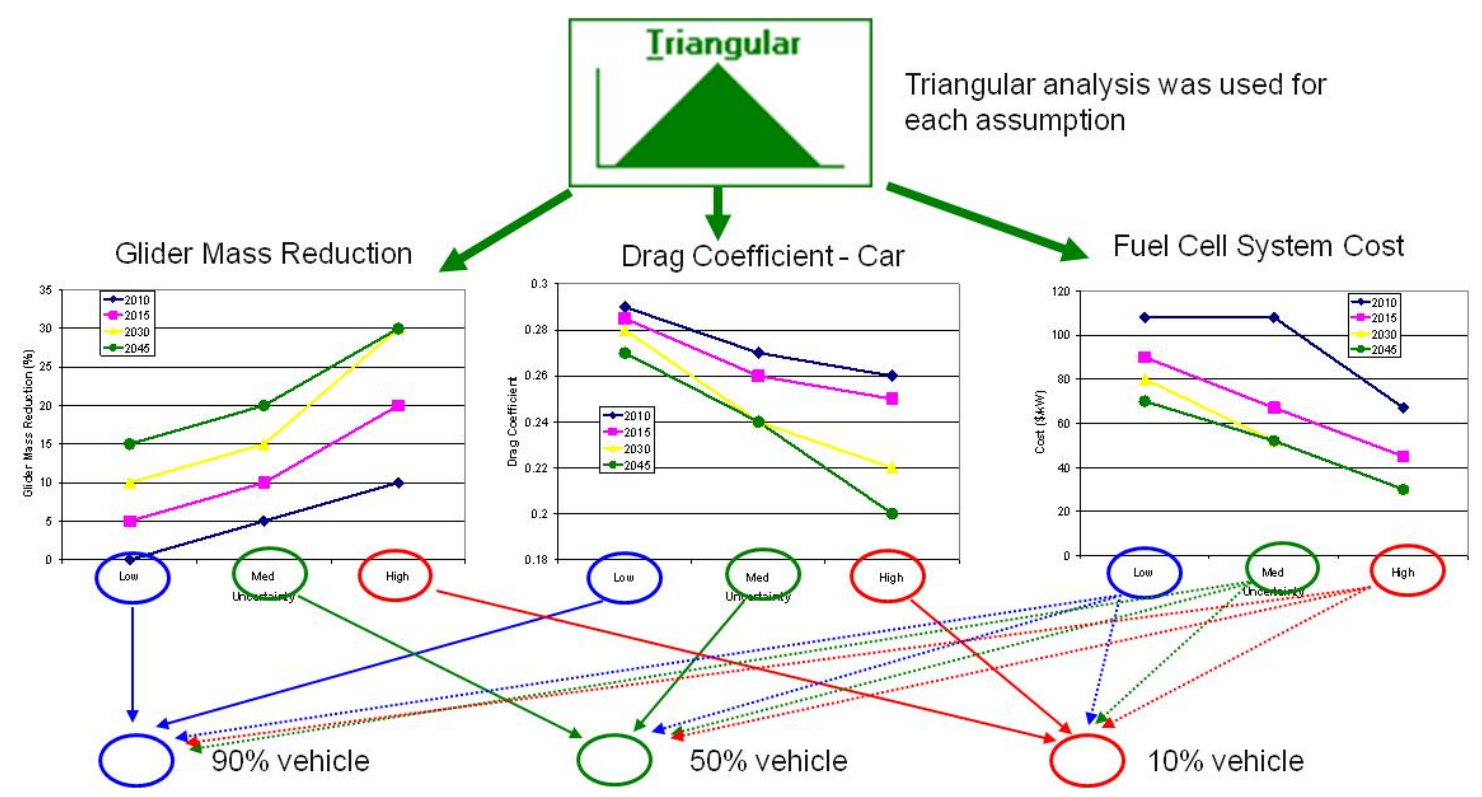

FIGURE 2.3 Uncertainty Process

The following paragraphs describe the assumptions and their associated uncertainties for each component technology.

\subsection{COMPONENT ASSUMPTIONS}

\subsubsection{Engines and Storage}

Several state-of-the-art engines were selected for the fuels considered (gasoline, diesel, E85 flex fuel, and hydrogen). The gasoline, diesel, and E85 flex-fuel engines used for current conventional vehicles were provided by automobile manufacturers. The engines used for HEV and PHEV testing are based on Atkinson cycles that were generated from test data collected at Argonne's dynamometer testing facility (Bohn and Duoba 2005). Different options were considered to estimate the evolution of each engine technology. While linear scaling of 
performance was used for gasoline and E85 HEVs, as well as diesel engines, nonlinear scaling based on AVL's work (Bandel 2006) was used for gasoline and E85 conventional vehicles. For the nonlinear scaling, different operating areas were improved by different amounts, resulting in changes in the constant efficiency contours. Table 2.1 lists the peak efficiencies of the different fuels and technologies.

TABLE 2.1 Main Engine Assumptions

\begin{tabular}{llccc}
\hline & & 2015 Low & 2015 Medium & 2015 High \\
\hline $\begin{array}{l}\text { Gasoline/Flex-fuel ICE for } \\
\text { conventional vehicle }\end{array}$ & Technology & $\begin{array}{c}\text { Spark } \\
\text { Homogeneous }\end{array}$ & $\begin{array}{c}\text { Spark } \\
\text { Homogeneous } \\
+5 \% \text { IMEPa }\end{array}$ & Spray GDI \\
Diesel ICE & Peak efficiency & $41 \%$ & $42 \%$ & $43 \%$ \\
Gasoline ICE for HEVs & Peak efficiency & $38 \%$ & $38.5 \%$ & $39.5 \%$ \\
Flex Fuel ICE for HEVs & Peak efficiency & $36 \%$ & $36.5 \%$ & $37.5 \%$ \\
\hline
\end{tabular}

a IMEP = indicated mean effective pressure; GDI = gasoline direct injection.

\subsubsection{Fuel Cell Systems}

The fuel cell system model is based on the steady-state efficiency map shown in Figure 2.4. The system is assumed to be gaseous hydrogen. In simulation, the additional losses caused by transient operating conditions are not taken into account.

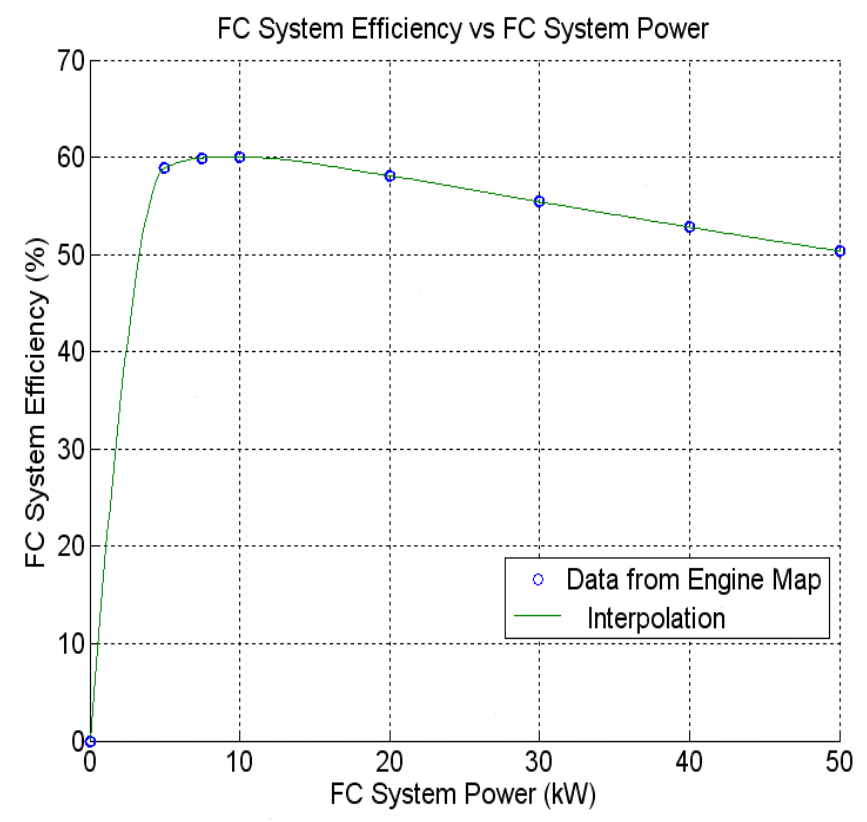

FIGURE 2.4 Fuel Cell System Efficiency Versus Fuel Cell System Power from the System Map 
Table 2.2 shows the peak efficiencies of the fuel cell system, as well as its associated specific power and power density. The peak fuel cell efficiency is assumed to be constant at $60 \%$ because most of the research is expected to focus on reducing cost. The $60 \%$ efficiency has already been demonstrated in laboratories and, consequently, is expected to be implemented soon in vehicles.

TABLE 2.2 Main Fuel Cell Assumptions

\begin{tabular}{lccc}
\hline & & & \\
& 2015 Low & 2015 Medium & 2015 High \\
\hline & & & \\
Specific power (W/kg) & 428 & 519 & 617 \\
Power density (W/L) & 454 & 590 & 818 \\
Peak efficiency (\%) & 60 & 60 & 60 \\
\hline
\end{tabular}

\subsubsection{Hydrogen Storage Systems}

The evolution of hydrogen storage systems is vital to the introduction of hydrogenpowered vehicles. Table 2.3 shows the evolution of the hydrogen storage capacity.

TABLE 2.3 Main Hydrogen Storage Assumptions

\begin{tabular}{lcccc}
\hline & 2015 Low & 2015 Medium & 2015 High \\
\hline & & & \\
System gravimetric capacity $(\mathrm{kWh} / \mathrm{kg})$ & 1.1 & 1.8 & 2.4 \\
System volumetric capacity $(\mathrm{kWh} / \mathrm{L})$ & 0.91 & 1.2 & 1.7 \\
\hline
\end{tabular}

One of the requirements for vehicles in the study is that they be able to travel 320 miles on the UDDS Driving Cycle on a full tank of fuel. However, to simulate 2015 vehicles with a hydrogen storage system allowing a range of 320 miles, the amount of hydrogen needed, and thus the corresponding fuel tank mass, would be excessive. As a result, a range of 250 miles was selected.

\subsubsection{Electric Machines}

Table 2.4 lists the main electric machine characteristics. The values for the current technologies are based on state-of-the-art electric machines currently used in vehicles (Olszewski 2008). The electric machine data from the Toyota Prius and Toyota Camry were used for the power-split HEV applications, while the Ballard integrated powertrain (IPT) was selected for series fuel cell HEVs. 
TABLE 2.4 Main Electric Machine Assumptions

\begin{tabular}{lrrr}
\hline & 2015 Low & 2015 Medium & 2015 High \\
\hline & & & \\
System peak efficiency (\%) & 95 & 96 & 97 \\
Motor specific power (W/kg) & 1,200 & 1,250 & 1,600 \\
Power electronics specific power (W/kg) & 10,000 & 11,000 & 13,000 \\
\hline
\end{tabular}

\subsubsection{Energy Storage System for Electric Vehicles}

Energy storage systems are key components in advanced vehicles. While numerous studies are currently being undertaken with ultracapacitors, only batteries were taken into account in our study. While the current technologies are almost all based on nickel metal hydride (NiMH), the lithium ion (Li-ion) technology is introduced for the medium and high cases in 2015. For HEV applications, the NiMH is based on the Toyota Prius battery pack and the Li-ion battery pack is based on the 6Ah from Saft. For PHEV applications, we characterized the VL41M battery pack from Saft. Because each vehicle is sized to maximize both power and energy, in the case of a PHEV, a sizing algorithm was developed to design the batteries specifically for each application (Sharer et al. 2006).

To ensure that the battery has similar performance at the beginning and end of life, the packs were oversized in terms of both power and energy. However, it should be noted that the additional battery capacity is initially clamped down and is only gradually released by the vehicle's controls as the battery performance degrades with usage and time. In addition, for PHEV applications, the SOC window (difference between maximum and minimum allowable SOC) increases over time, allowing a reduction in the size of the battery pack. Table 2.5 lists the main characteristics of the energy storage systems. The high power applications are used for HEVs while the high energy batteries are dedicated to PHEVs and BEVs. The SOC minimum and maximum in Table 2.5 only apply to the high-energy batteries of PHEVs and BEVs.

\subsubsection{Transmission}

Table 2.6 lists the main assumptions about the transmissions used in the midsize vehicle platform for the conventional powertrains. While most transmissions currently contain four or five gears, it is expected that the number will increase to between five and eight in the near future. The transmissions selected (gearbox and final drive ratios) are based on existing vehicles.

The power-split configurations are based on a single planetary gearset with ratios similar to those of the Toyota Prius. The series configurations are based on a two-speed automated manual transmission (ratios 1.8/1) in order to allow the vehicle to reach the maximum speed (100 mph) without oversizing the components. 
TABLE 2.5 Main Energy Storage Assumptions

\begin{tabular}{lccc}
\hline & 2015 Low & 2015 Medium & 2015 High \\
\hline High-Power Applications for HEVs & & & \\
Technology & NiMH & Li-ion & Li-ion \\
Energy oversize (\%) & 20 & 18 & 16 \\
Power oversize (\%) & 20 & 18 & 16 \\
& & & \\
High-Energy Applications for PHEVs and BEVs & & \\
Technology & Li-ion & Li-ion & Li-ion \\
Energy oversize (\%) & 30 & 28 & 26 \\
Power oversize (\%) & 20 & 18 & 16 \\
SOC max (\%) & 90 & 90 & 95 \\
SOC min (\%) & 30 & 30 & 25 \\
\hline
\end{tabular}

TABLE 2.6 Main Transmission Assumptions (midsize conventional vehicle)

\begin{tabular}{lccc}
\hline & 2015 Low & 2015 Medium & 2015 High \\
\hline & & & \\
Technology & Automatic 5-Speed & Dual-Clutch 6-Speed & Automatic 8-Speed \\
Gearbox ratio & $4.15 / 2.37 / 1.56 / 1.16 /$ & $3.45 / 2.045 / 1.452 /$ & $4.6 / 2.72 / 1.86 / 1.46 /$ \\
& $0.86 / 0.69$ & $1.114 / 1.078 / 0.921$ & $1.23 / 1 / 0.824 / 0.685$ \\
Final drive & 2.74 & 3.29 & 2.47 \\
\hline
\end{tabular}

\subsection{VEHICLE}

As previously discussed, a midsize car with the following characteristics was selected for the 2009 reference:

- $\quad$ Glider mass $=990 \mathrm{~kg}$

- $\quad$ Frontal Area $=2.2 \mathrm{~m}^{2}$

- $\quad$ Tire $=\mathrm{P} 195 / 65 / \mathrm{R} 15$

Because of improvements in materials, the glider mass is expected to significantly decrease over time. The maximum value of $31 \%$ was defined on the basis of previous studies (Stodolsky et al. 1995) that calculated the weight reduction achieved by replacing the entire chassis frame with aluminum. Although frontal area is expected to differ from one vehicle configuration to another (i.e., the electrical components will require more cooling capabilities), the values were considered constant across the technologies. Table 2.7 lists the reductions in both glider mass and frontal area. 
TABLE 2.7 Main Vehicle Assumptions (midsize)

\begin{tabular}{lccc}
\hline & & & \\
& 2015 Low & 2015 Medium & 2015 High \\
\hline & 800 & 740 & 700 \\
Glider mass $(\mathrm{kg})$ & 2.21 & 2.18 & 2.15 \\
Frontal area $\left(\mathrm{m}^{2}\right)$ & 0.295 & 0.28 & 0.265 \\
Drag coefficient & 0.008 & 0.0075 & 0.007 \\
Rolling resistance & 260 & 240 & 220 \\
Electrical load for conventional (W) & 240 & 230 & 220 \\
Electrical load for other configurations (W) & & & \\
\hline
\end{tabular}

\subsubsection{Vehicle Powertrain Assumptions}

All the vehicles have been sized to meet the same requirements:

- $\quad 0-100 \mathrm{~km} / \mathrm{h}$ in $9 \mathrm{sec}+/-0.1$

- Maximum grade of $6 \%$ at $105 \mathrm{~km} / \mathrm{h}$ at gross vehicle weight (GVW)

- Maximum vehicle speed $>160 \mathrm{~km} / \mathrm{h}$

For all cases, the engine or fuel cell is sized to reach the top of the grade without any assistance from the battery. For HEVs, the battery was sized to recuperate the entire braking energy during the UDDS drive cycle. For the PHEV case, the battery power is assumed to be able to follow the UDDS in electric mode, while its energy is calculated to follow the trace for a specific distance. For BEV, the battery was sized to provide a 150-mile range on the UDDS drive cycle. Because of the multitude of vehicles considered, an automated sizing algorithm was defined (Freyermuth et al. 2008).

\subsubsection{Vehicle Architecture Selection}

An HEV — by definition - combines at least two sources of energy. The main types of HEVs are described below, along with their advantages and disadvantages.

\subsubsection{Parallel Hybrid}

Parallel hybrids have mechanical connections to the wheels from both the electric machine and the engine. The electric machine can be located anywhere between the output engine shaft and the wheels (Figure 2.5). These vehicles do not need a dedicated generator; the electric machine can be used as a generator to recharge the batteries. In a parallel HEV, the electric motor can assist the engine during startup and acceleration. 


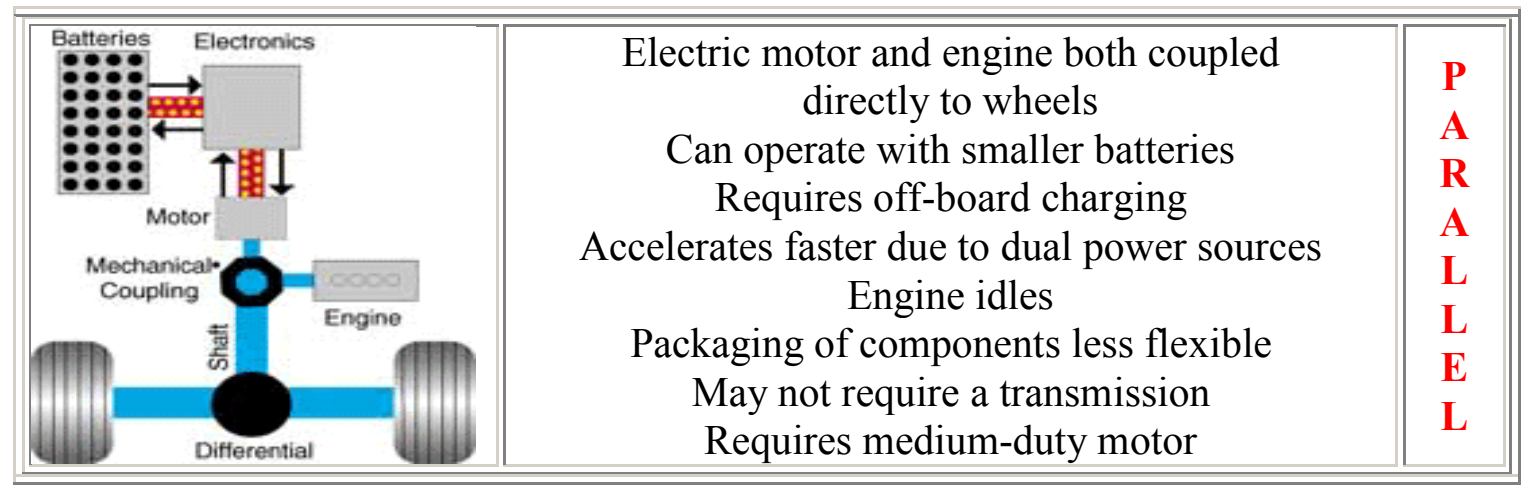

FIGURE 2.5 Parallel HEV

Because the electric machine and the engine are both coupled directly to the wheels, they can share the power during accelerations. Therefore, it is possible to downsize both the engine and the electric machine compared to series hybrids (thus decreasing the vehicle mass). It is also possible to increase the degree of hybridization by decreasing the size of the engine and increasing the size of the electric machine. For some configurations, the engine can operate close to its best efficiency curve (annex), the electric machine assisting it or recharging the battery.

\subsubsection{Series Hybrid}

As shown in Figure 2.6, in a series HEV, an electric generator, coupled with an engine, supplies electricity to the motor to propel the car and to the energy storage system when it needs to be recharged. Generally, the engine/generator set keeps the energy storage system charged between $60-80 \%$ for batteries.

\begin{tabular}{|c|c|c|}
\hline Batteries Electronics Generator & $\begin{array}{c}\text { Entire drive power transmitted electrically } \\
\text { May require larger batteries } \\
\text { Requires on-board charging } \\
\text { Requires some off-board charging } \\
\text { Optimization by separating engine speed } \\
\text { from vehicle speed } \\
\text { Engine never idles, thus reducing overall emissions } \\
\text { May not require a transmission } \\
\text { Requires heavy-duty motor }\end{array}$ & $\begin{array}{l}\mathbf{S} \\
\mathbf{E} \\
\mathbf{R} \\
\mathbf{I} \\
\mathbf{E} \\
\mathbf{S}\end{array}$ \\
\hline
\end{tabular}

FIGURE 2.6 Series HEV 
The main advantage of this configuration is that engine and vehicle speeds are decoupled, and only the electric motor is connected to the wheels. The engine does not need to speed up or slow down as the load varies. As a consequence, the engine can run at optimum performance (best engine efficiency area), greatly improving the fuel economy. Moreover, the engine never idles, thus reducing overall emissions. However, because the electric machine is the only one connected directly to the wheels and the engine/generator set is sized for sustained gradeability, this configuration requires large batteries, motor, and engine. For this system to be viable, it must be highly efficient in terms of total power processing.

\subsubsection{Power-Split Hybrid}

Power split hybrids combine the best features of both series and parallel hybrids to create an extremely efficient system.

As shown in Figure 2.7, this system divides the engine power along two paths: one goes to the generator to produce electricity and one goes through a mechanical gear system to drive the wheels. In addition, a regenerative system uses the kinetic energy of deceleration and braking to produce electricity, which is stored in the battery.

The main components of this configuration are a power-split device (transmission), an electric motor, a generator, and an engine. Depending on the situation, all these elements operate differently. Indeed, the engine is not always "on," and the electricity from the generator may go directly to the wheels to help propel the car or may go through an inverter to be stored in the battery. The different possibilities are as follows:

- When starting out, moving slowly, or when the battery SOC is high enough, the engine is not efficient, so it is turned off, and the motor alone propels the car.

- During normal operation, the engine power is split, with part going to drive the vehicle and part being used to generate electricity. The electricity goes to the motor, which assists in propelling the car.

- During full-throttle acceleration, the battery provides extra power.

- During deceleration or braking, the motor acts as a generator, transforming the kinetic energy of the wheels into electricity. 


\begin{tabular}{|c|c|c|}
\hline Batteries Electronics & Engine can fuel batteries, as well as drive wheels & D \\
\hline
\end{tabular}

FIGURE 2.7 Power-Split (Dual-Mode) HEV

\subsubsection{Configuration Selection}

For the HEV, an input-mode power-split configuration was selected because of its predominance in the marketplace, with vehicles from Toyota and Ford. For the PHEVs with small electric ranges (both the 10- and 20-mile AER on the UDDS), a power-split configuration was selected as well because these vehicles require frequent use of the engine to (1) follow the trace and (2) provide energy when the battery is depleted. Because the PHEVs with large electric ranges (both the 30- and 40-mile AER on the UDDS) rely most of the time on electrical energy to propel the vehicle, the series configuration was selected, with a two-gear transmission to meet the maximum vehicle speed requirement. All the configurations using fuel cell systems are also based on the series configuration.

The vehicle level control strategies employed for each configuration have been defined in previous publications (Rousseau et al. 2006; Pagerit et al. 2005, Sharer et al. 2008; Cao et al. 2007; Karbowski et al. 2006).

\subsection{VEHICLE SIZING PROCESS}

To quickly size the component models of the powertrain, Argonne researchers used an automated sizing process. Figure 2.8 is a flowchart illustrating the sizing process logic. Unlike conventional vehicles, which have only one variable (engine power), PHEVs have two variables (engine power and electric power). In our study, the engine was sized to meet the gradability requirements.

To meet the AER requirements, the battery power was sized to follow each specific driving cycle while in all-electric mode. We also ensured that the vehicle could capture the entire amount of energy from regenerative braking during decelerations. Finally, battery energy was sized to achieve the required AER of the vehicle for the daily driving or trip considered. The AER is defined as the distance the vehicle can travel on the specific cycle until the first engine start. Note that a specific control algorithm was used to simulate the AER. This algorithm forced the engine to remain off throughout the cycle, regardless of the torque request from the driver. 
Vehicle mass was calculated by adding the mass of each component to the mass of the glider. The mass of each component was defined on the basis of its specific power density.

To maintain an acceptable battery voltage (around $200 \mathrm{~V}$ ), a scaling algorithm changes the battery capacity, rather than the number of cells, to meet the AER requirements. The scaling algorithm was developed to properly size the battery for each specific application.

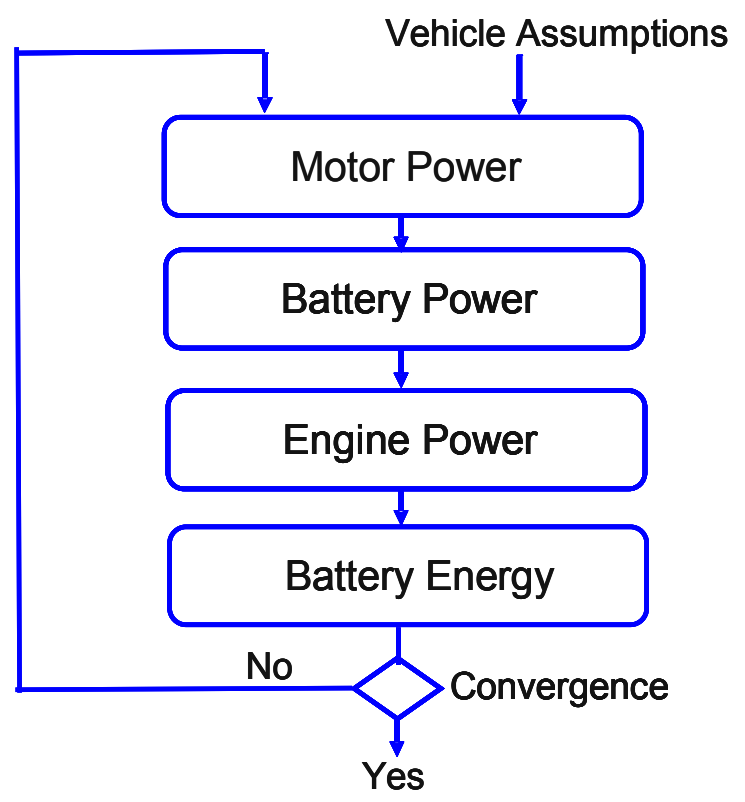

FIGURE 2.8 Process for Sizing PHEV Components

Finally, the PHEV operates in electric-only mode at a higher vehicle speed than regular hybrids. The architecture therefore needs to be able to start the engine at a high vehicle speed. In the power-split configuration, the generator was used to start the engine. Because all of those elements are linked to the wheels via the planetary gear system, the researchers needed to make sure that the generator (the speed of which increases linearly with vehicle speed when the engine is off) still has enough available torque - even at high speed — to start the engine in a timely fashion.

\subsection{VEHICLE SIZING RESULTS}

Figure 2.9 shows the engine peak power for the gasoline powertrain. The difference is attributable to the logic behind the sizing algorithm:

- For the conventional vehicle, the engine has to provide both acceleration and gradeability, with acceleration dictating the power. 
- For HEVs, the engine is also sized to provide both acceleration and gradeability, but the presence of the electric machine allows downsizing.

- For the power-split PHEVs (10-and 20-mile AER), the engine is sized for gradeability because the electric machine power is sized for the UDDS.

- The engine of a series PHEV is sized similar to the engine of a power-split PHEV, but with a higher power only because of the added inefficiencies of the driveline.

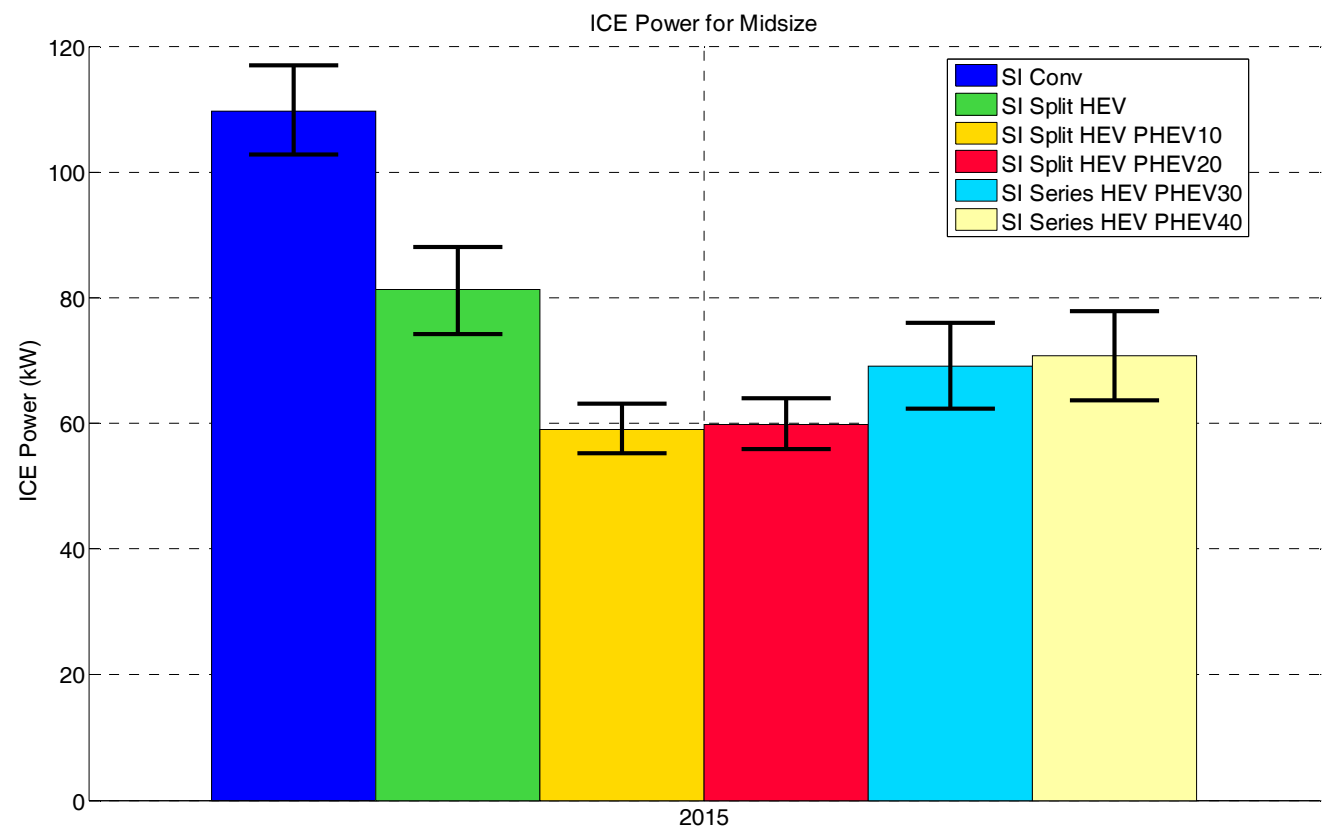

FIGURE 2.9 Engine Power for Gasoline Powertrains

Figure 2.10 shows the electric machine power for the gasoline HEVs and PHEVs. As the figures shows, power-split PHEVs require higher power because one of their requirements is the ability to follow the UDDS in electric mode. It is important to note that, although the vehicles have the ability to drive the UDDS in electric mode, the control strategy employed during fuel efficiency simulation is based on blended operation. The electric machine for the series configuration is sized to follow the US06 in EV mode, thus requiring the highest power.

Figure 2.11 shows the fuel cell system peak power for the different configurations considered. Figure 2.12 shows the battery power requirements for HEV and PHEV applications for the gasoline vehicle. The sensitivity of battery power to vehicle mass increases with the degree of electrification (i.e., higher for PHEV and lower for HEVs). 


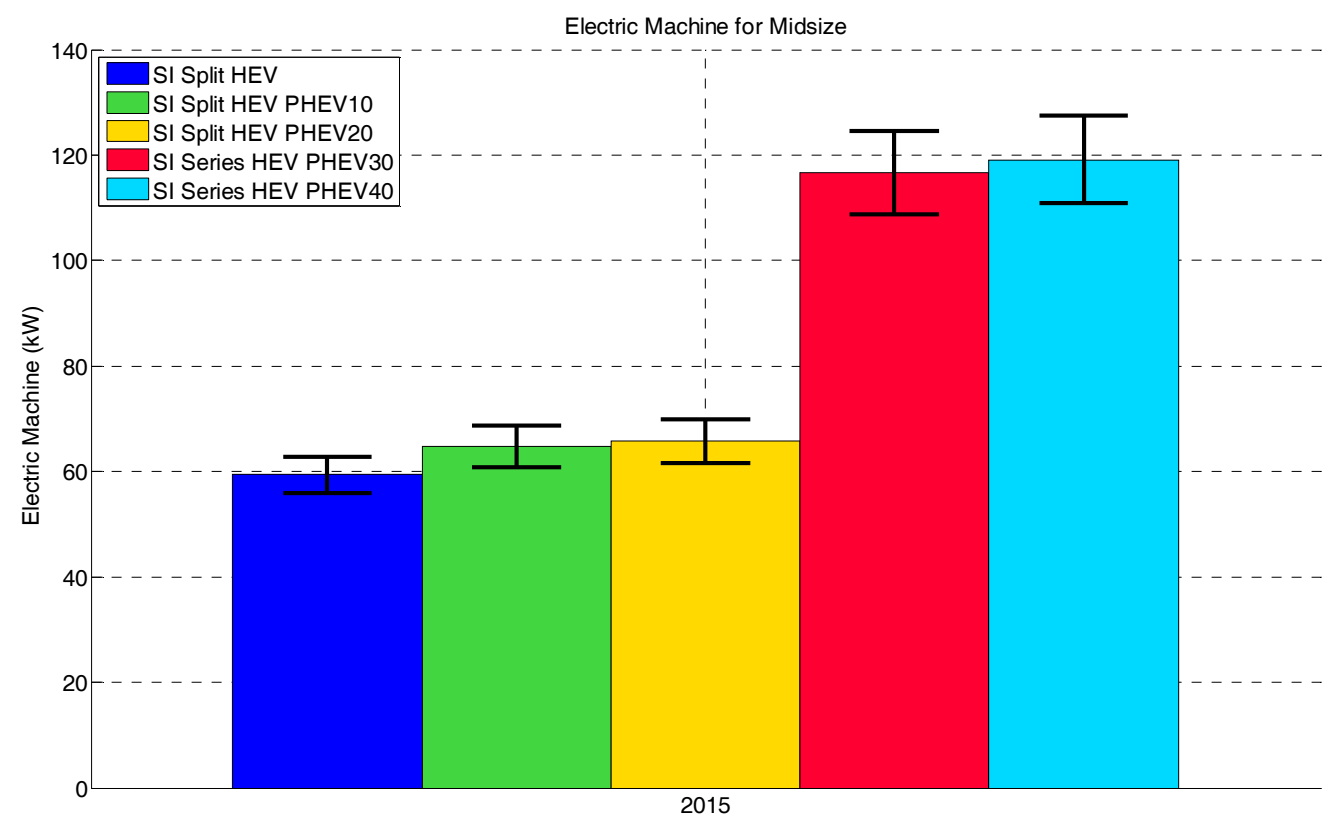

FIGURE 2.10 Electric Machine Power for Gasoline HEVs and PHEVs

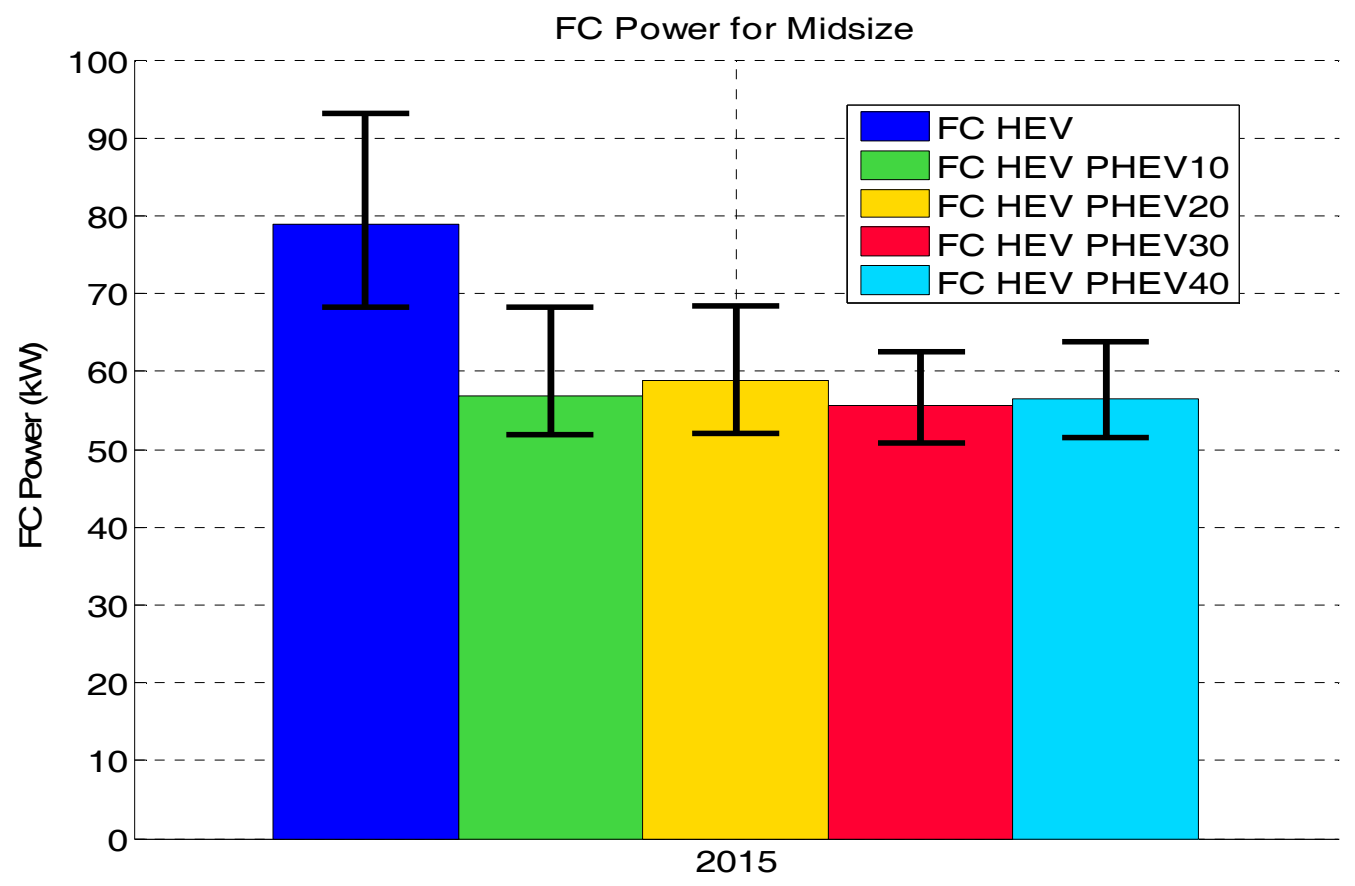

FIGURE 2.11 Fuel Cell Power for Hydrogen Vehicles 


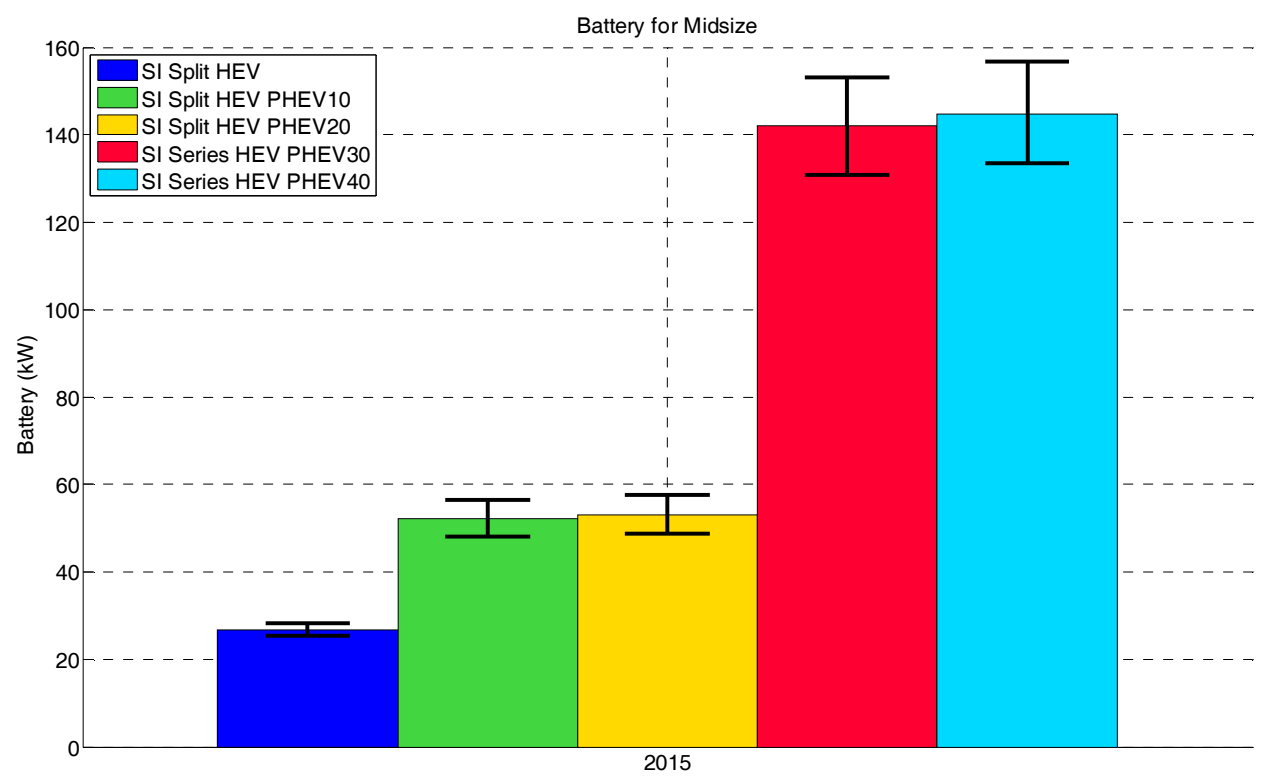

FIGURE 2.12 Battery Power for Gasoline HEVs and PHEVs

The usable battery energy is proportional to the AER of the different PHEVs. If the AER is multiplied by two, the usable battery energy will also be multiplied by two. Figures 2.13 and 2.14 show the usable battery energy for PHEVs with gasoline engines and fuel cell systems.

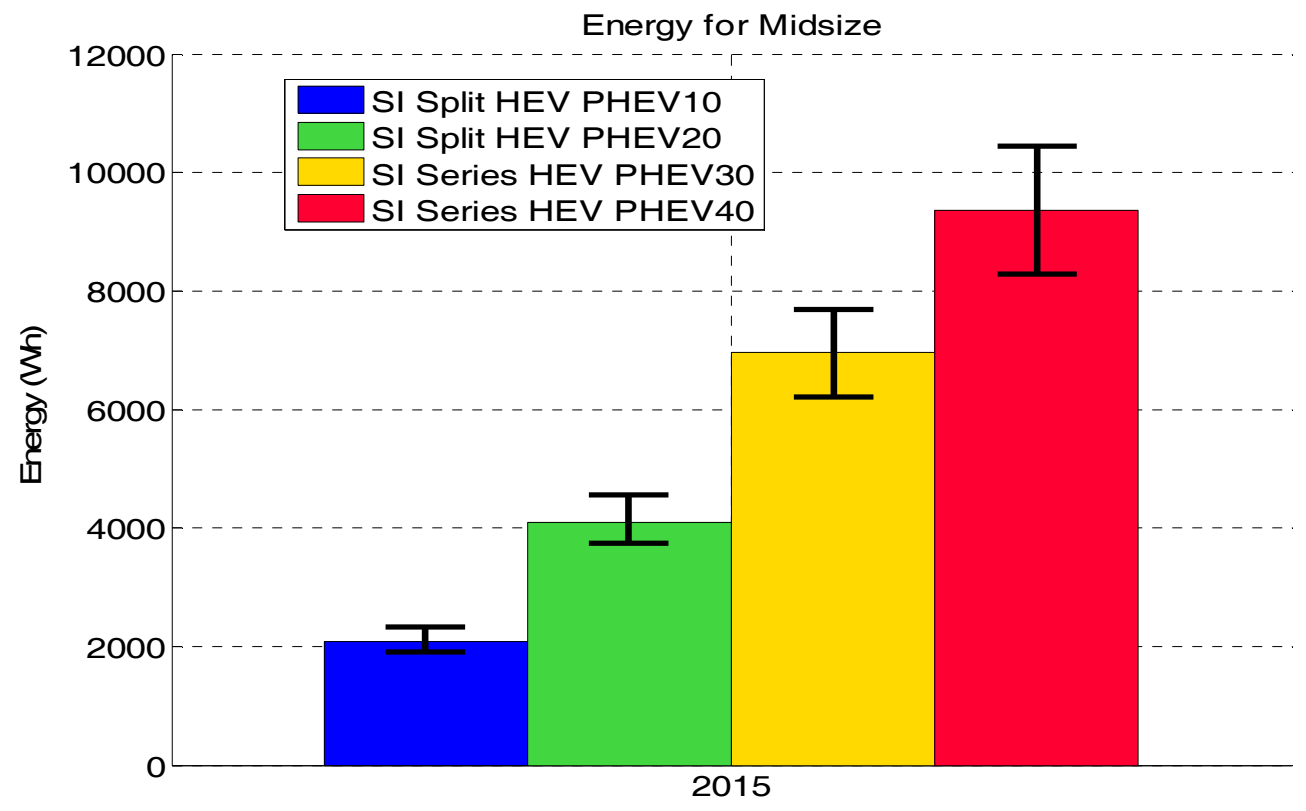

FIGURE 2.13 Usable Battery Energy for PHEV Midsize Vehicle with Gasoline Engine 


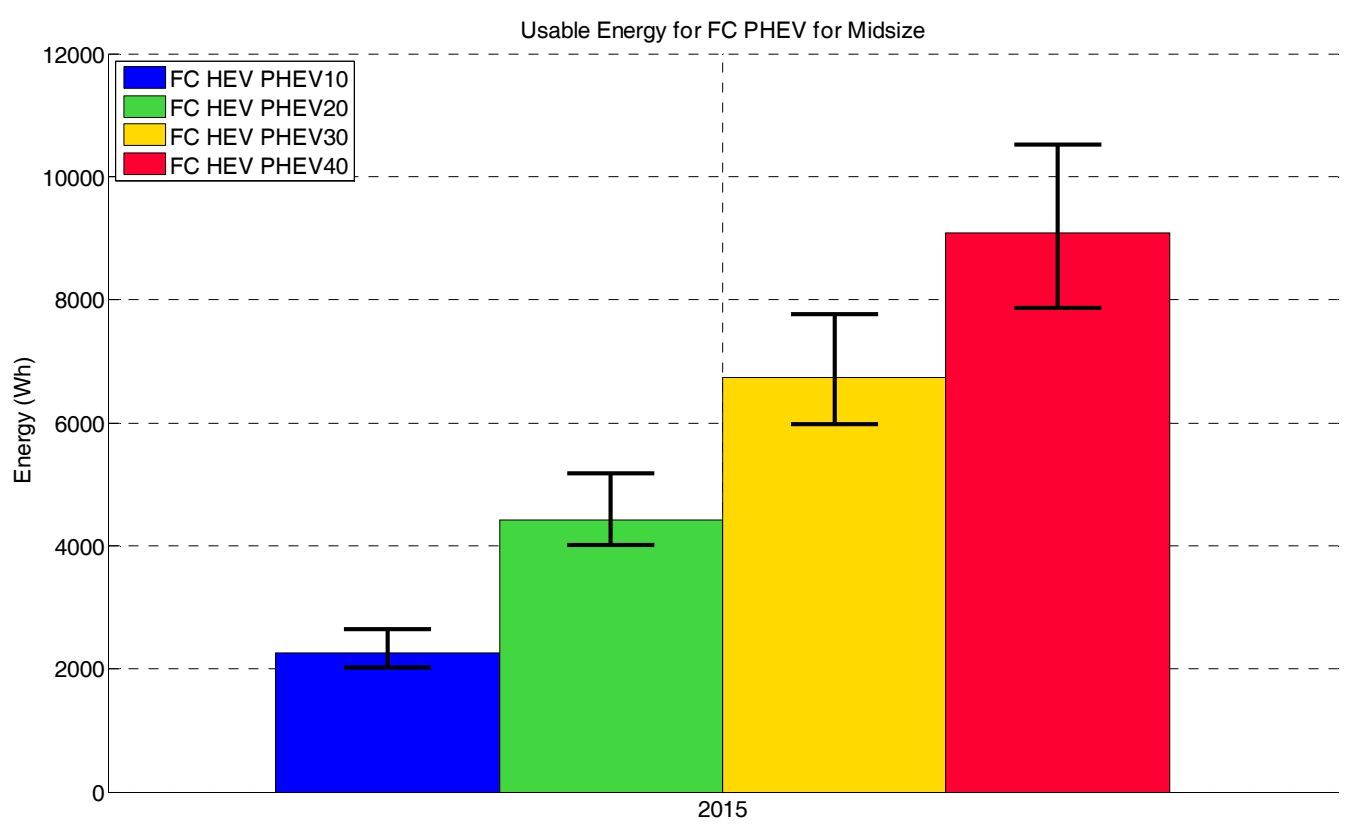

FIGURE 2.14 Usable Battery Energy for PHEV Midsize Vehicle with Fuel Cell

Figure 2.15 shows the vehicle mass for the different configurations. As expected, an increase in electrification leads to higher vehicle weight.

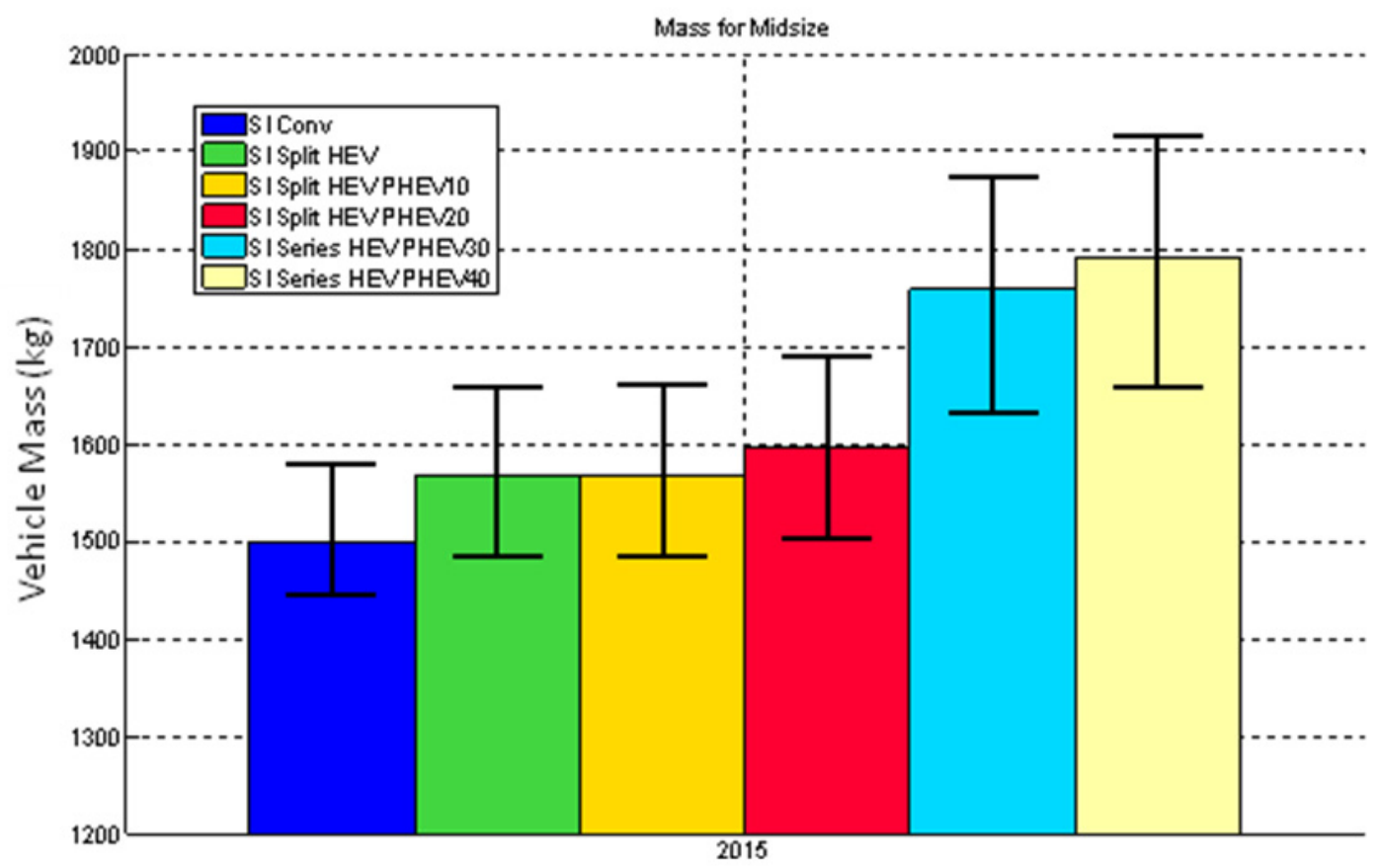

FIGURE 2.15 Vehicle Mass 
Appendix 1 provides the main characteristics (e.g., power, energy, weight) for all of the vehicles. The fuel and electricity consumption results from the PSAT model are provided in Section 3. 
This page intentionally left blank. 


\section{ON-ROAD ADJUSTMENT OF FUEL ECONOMY AND ELECTRICITY CONSUMPTION}

\subsection{FUEL ECONOMY ADJUSTMENT FOR ON-ROAD PERFORMANCE}

\subsubsection{Background}

Estimates of fuel and electricity consumption per VMT on the UDDS and HWFET driving cycles were provided by PSAT (Table 3.1). These test cycle (laboratory) results do not reflect the actual "on-road" fuel and electricity consumption that occurs during "real-world" driving. Limitations of these cycles include the following:

- A top speed of only 60 miles per hour for the highway test,

- Mild climatic conditions $\left(75^{\circ} \mathrm{F}\right)$ for both the city and highway tests,

- Mild acceleration rates for both tests, and

- No use of fuel-consuming accessories, such as air conditioning, for either test.

TABLE 3.1 PSAT Lab-Based Fuel Economy and Electricity Consumption Results ${ }^{\text {a }}$

\begin{tabular}{|c|c|c|c|c|c|c|c|c|c|c|c|c|c|c|c|}
\hline \multicolumn{3}{|c|}{$\begin{array}{l}\text { Unadjusted Wh/mi } \\
\text { and mpgeg }\end{array}$} & \multirow{2}{*}{\begin{tabular}{|c} 
AER \\
$\mathbf{0}$
\end{tabular}} & \multicolumn{3}{|c|}{$\begin{array}{c}\text { AER 10 } \\
\text { Power-Split PHEV }\end{array}$} & \multicolumn{3}{|c|}{$\begin{array}{c}\text { AER 20 } \\
\text { Power-Split PHEV } \\
\end{array}$} & \multicolumn{3}{|c|}{$\begin{array}{c}\text { AER 30 } \\
\text { Series PHEV } \\
\end{array}$} & \multicolumn{3}{|c|}{$\begin{array}{c}\text { AER 40 } \\
\text { Series PHEV } \\
\end{array}$} \\
\hline & & & & $\begin{array}{c}\mathrm{CD} \\
\text { Electric }\end{array}$ & $\begin{array}{c}\mathrm{CD} \\
\text { Engine } \\
\end{array}$ & $\begin{array}{c}\mathrm{CS} \\
\text { Engine } \\
\end{array}$ & $\begin{array}{c}\mathrm{CD} \\
\text { Electric }\end{array}$ & \begin{tabular}{|c|}
$\mathrm{CD}$ \\
Engine \\
\end{tabular} & $\begin{array}{c}\mathrm{CS} \\
\text { Engine } \\
\end{array}$ & $\begin{array}{c}\text { CD } \\
\text { Electric }\end{array}$ & $\begin{array}{c}\mathrm{CD} \\
\text { Engine }\end{array}$ & \begin{tabular}{|c|}
$\mathrm{CS}$ \\
Engine \\
\end{tabular} & $\begin{array}{l}\mathrm{CD} \\
\text { Electric }\end{array}$ & $\begin{array}{c}\mathrm{CD} \\
\text { Engine }\end{array}$ & $\begin{array}{c}\text { CS } \\
\text { Engine }\end{array}$ \\
\hline \multirow{2}{*}{$\begin{array}{l}\text { Gasoline } \\
\text { ICEV }\end{array}$} & UDDS & 32.7 & 62.4 & 182 & 245 & 68.1 & 179 & 231 & 67.8 & 220 & 291 & 46.9 & 228 & 617 & 46.2 \\
\hline & HWFET & 44.1 & 55.9 & 200 & 110.8 & 60.5 & 195 & 149 & 60.0 & 237 & 1234 & 48.1 & 236 & 1280 & 47.6 \\
\hline \multirow{2}{*}{$\begin{array}{l}\text { E85 } \\
\text { ICEV }\end{array}$} & UDDS & & 58.0 & 182 & 229 & 63.6 & 178 & 209 & 63.3 & 220 & 270 & 43.5 & 228 & 570 & 42.8 \\
\hline & HWFET & & 52.0 & 198 & 103.4 & 56.4 & 193 & 136 & 55.9 & 237 & 1162 & 45.1 & 236 & 1202 & 44.6 \\
\hline \multirow{2}{*}{$\begin{array}{l}\text { Diesel } \\
\text { ICEV }\end{array}$} & UDDS & & 65.4 & 182 & 253 & 68.8 & 183 & 229 & 68.4 & 222 & 311 & 50.3 & 231 & 667 & 49.5 \\
\hline & HWFET & & 58.1 & 201 & 114 & 60.6 & 199 & 154 & 59.9 & 239 & 1417 & 49.7 & 241 & 1509 & 49.2 \\
\hline \multirow{2}{*}{$\begin{array}{l}\mathrm{H}_{2} \\
\mathrm{FCV}\end{array}$} & UDDS & & 81.5 & 166 & 233 & 84.3 & 172 & 221 & 83.1 & 221 & 508 & 81.1 & 222 & 964 & 79.8 \\
\hline & HWFET & & 85.4 & 204 & 156 & 85.3 & 198 & 208 & 84.4 & 233 & 1881 & 82.3 & 234 & 1524 & 81.4 \\
\hline \multirow{2}{*}{$\mathrm{EV}$} & UDDS & 237 & & & & & & & & & & & & & \\
\hline & HWFET & 243 & & & & & & & & & & & & & \\
\hline
\end{tabular}

a Results in miles per gasoline-equivalent gallon for fuel economy or $\mathrm{Wh} / \mathrm{mi}$ (shown in red) for electric operation.

Thus, the actual "on-road" fuel and electricity consumption rates per VMT are higher than those obtained from driving test cycles as a result of many factors, including more aggressive driving than the test cycles simulate, air-conditioning use, and cold-weather implications. Before 2008, EPA used "certification" or "laboratory" tests consisting of a federal test protocol (FTP) (a complete UDDS with a cold start followed by a warm start for another 505 seconds) and a HWFET driving cycle to rate vehicle fuel economy (in mpg) using simple adjustment factors of 0.9 and 0.78 for the FTP and HWFET cycle tests, respectively. A weighted 
average of city (55\%) and highway (45\%) fuel economies was used to calculate a combined (composite) "label" fuel economy. However, several independent studies that compared EPA's fuel economy estimates to the real-world experience of consumers concluded that there was considerable variation in real-world fuel economy and that EPA's mileage ratings often overestimated real-world fuel economy.

In the Energy Policy Act of 2005, the U.S. Congress required EPA to revise the fuel economy labeling methods to better reflect a variety of real-world factors that affect fuel economy. Consequently, EPA developed a new approach to estimate the on-road fuel economy based on a five-cycle testing method (EPA 2006). Starting with 2008 MY vehicles, a new EPA method required that vehicles be tested on three additional driving cycles: a high-speed, aggressive driving cycle (US06), a cycle operating at an ambient temperature of $95^{\circ} \mathrm{F}$ (SC03), and a cycle operating at an ambient temperature of $20^{\circ} \mathrm{F}$ (cold FTP). These five cycles are now used to construct a weighted average fuel economy for city and highway driving. Alternatively, manufacturers may calculate equivalent five-cycle fuel economy through MY 2010 using regression lines, known as mpg-based formulas, from the city and highway fuel economy values. Equations 1 and 2 represent the EPA's mpg-based formulas for the city and highway cycles, respectively.

Five-cycle city fuel economy $=1 /(0.003259+1.1805 /$ FTP fuel economy $)$

Five-cycle highway fuel economy $=1 /(0.001376+1.3466 /$ HWFET fuel economy $)$

For MY 2011 and beyond, if the five-cycle city and highway fuel economy values for an emissions data vehicle group are not more than $4 \%$ and $5 \%$ below the mpg-based regression line, respectively, all the vehicle configurations represented by the emissions data vehicle (e.g., all vehicles within the vehicle test group) could continue to use the mpg-based approach. Vehicles within a test group falling more than $5 \%$ below the tolerance band for highway fuel economy values would be required to conduct US06 tests, while those falling more than $4 \%$ below the city fuel economy tolerance band would be required to conduct US06, SC03, and cold FTP tests (EPA 2006). Furthermore, EPA proposed a new harmonic weighting (43/57) of the five-cycle city and highway fuel economies to calculate a combined fuel economy consistent with the recent shift in consumer's driving toward the highway driving style. Finally, it should be noted that, because fuel economy depends on a wide variety of factors, individual consumers will experience higher or lower fuel economy than a given estimate, depending on their real-world driving conditions for any vehicle technology.

While PSAT is capable of simulating the US06 cycle, it cannot accurately simulate vehicle operation with air-conditioning on or in cold weather. So Argonne sought an alternative to the five-cycle testing methodology to adjust the PSAT fuel economy results for engine operation (ICE or fuel cell) and electricity consumption (by the battery in PHEVs and BEVs) on the test driving cycles (UDDS and HWFET) to account for the additional on-road driving load. Figure 3.1 shows the "on-road" adjustment factors, which are based on the mpg-based formulas (equations 1 and 2). The adjustment factor is simply the ratio of the "on-road" fuel economy to the test cycle (laboratory) fuel economy. 


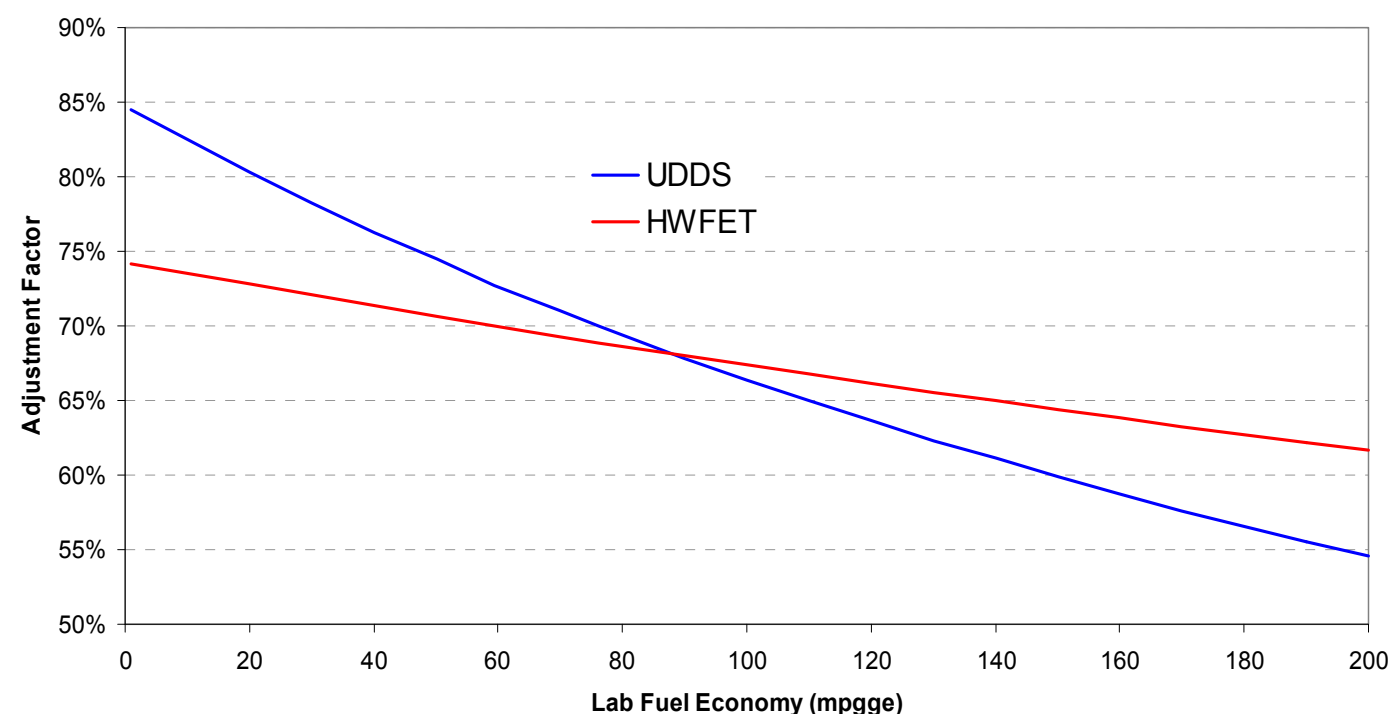

FIGURE 3.1 On-Road Adjustment Factor for Laboratory Fuel Economy Based on EPA's MPG-Based Formulas

Figure 3.1 also shows the rapid decrease in the adjustment factor as the laboratory fuel economy increases, especially for the UDDS cycle. The impact of the adjustment factor for the fuel economy values of hybrid ICEVs, FCVs, and BEVs is more dramatic than that for conventional vehicles. It should be noted, however, that the regression lines for the mpg-based formulas are based on test data for vehicles, the vast majority of which are conventional gasoline ICEVs. Thus, the validity of extrapolating the mpg-based formulas to vehicles that offer much higher fuel economy (e.g., FCVs and BEVs) is questionable and needs further investigation. For example, FCVs (e.g., Honda Clarity and Toyota FCHV) achieve laboratory fuel economies greater than 85 miles per gasoline-equivalent gallon (mpgeg), resulting in an adjustment factor of less than 0.7 if the mpg-based formulas are used. Note that a fuel economy adjustment factor of 0.7 corresponds to a UDDS fuel economy of 76 mpgeg and a HWFET fuel economy of 60 mpgeg, as shown in Figure 3.1. Similarly, the adjustment factor for the more efficient BEVs could fall below 0.65. This trend is consistent with our expectation that the impact of "realworld" driving on more efficient vehicles would be greater than on conventional vehicles, because of many factors, including diminished energy recovery from regenerative breaking under high deceleration rates and increased penalties on powertrain efficiency from airconditioning loads and cold-weather operation.

Whether the mpg-based formulas accurately capture the impact of these factors remains uncertain in the absence of sufficient fuel economy data from on-road operation of these advanced vehicles. This issue posed a significant challenge in our analysis and triggered an extensive literature search and discussion with original equipment manufacturers (OEMs) and other researchers. The objective was to develop an accurate methodology for estimating fuel economy adjustment for the various vehicle technologies considered in this analysis until a formal rule is developed by EPA (in cooperation with other relevant organizations). Our discussions revealed that many OEMs and researchers believe that the mpg-based equations are suitable for estimating on-road fuel economy from city and highway test cycles for HEVs, FCVs, 
and BEVs. Other experts proposed a lower limit of 0.7 on the adjustment factor produced by the mpg-based formulas (i.e., capping the reduction of fuel economy at 30\%), which is consistent with the suggested windows sticker calculation for the Mini-e EV (Weissler 2009). The following sections describe the methodology we adopted for adjusting the laboratory fuel economy and electricity consumption to on-road ("real-world") fuel economy and electricity consumption for conventional ICEVs and HEVs (Section 3.1.2), FCVs (Section 3.1.3), Series PHEV30 and 40 and BEVs (Section 3.1.4), and power-split PHEV10 and 20 (Section 3.1.5).

\subsubsection{Conventional ICEVs and HEVs}

In accordance with EPA's final rule on fuel economy labeling for motor vehicles, we used the mpg-based formulas (equations 1 and 2) to calculate the "on-road" city and highway fuel economies for conventional gasoline ICEVs, as well as all hybrid ICEVs (HEVs) from their laboratory fuel economies (see adjustment arrow a-A in Figure 3.2). The composite city/highway fuel economy was calculated on the basis of new proposed weighting factors of $43 \%$ for city driving and $57 \%$ for highway driving. Table 3.1 shows the adjusted fuel economies for conventional ICEVs and HEVs.

\subsubsection{Hydrogen FCVs}

The on-road fuel economy data for the second-generation hydrogen FCVs (collected as part of DOE hydrogen fleet and infrastructure demonstration and validation projects) indicate an adjustment factor range between 0.66 and 0.70 , which is consistent with the mpg-based equations (Wipke et al., 2009). The label fuel economy for the Honda Clarity also reflects an adjustment factor of 0.7 . For this analysis we used the mpg-based formulas (see adjustment arrow a-A in Figure 3.2) to calculate the on-road fuel economy for all FCVs, but we capped the adjustment factor at 0.7 , which corresponds to a $30 \%$ reduction compared with the fuel economies obtained from city and highway test cycles.

\subsubsection{Series PHEV30 and 40 and BEVs}

For the series-configuration PHEVs, the fuel economy in the CS operational mode was adjusted according to the mpg-based formulas because that mode of operation is similar to the operation of a regular HEV; the engine is the source of all the power needed to satisfy the vehicle's various loads. As we did for regular HEVs, we capped the adjustment factor at 0.7 to correspond to a 30\% reduction compared with the fuel economies from city and highway test cycles. The electricity consumption in the CD operational mode for series PHEVs is assumed to be similar to that of BEVs because the control strategy for series PHEVs maximizes the use of battery power, and the electric machine is sized to meet the US06 cycle (which is more aggressive than typical real-world driving); the on-road load is mostly met by the battery power, with minor assistance from the engine (see Table 3.1). Consequently, we adjusted electricity consumption for series PHEVs using the same adjustment suggested by EPA for the Mini-e EV: a 0.7 adjustment factor (see adjustment arrow b-B in Figure 3.2). We also adjusted the relatively 
small fuel consumption by the same 0.7 factor to account for additional engine load from airconditioning and cold-weather operations.

\subsubsection{Power-Split PHEV10 and 20}

For the power-split PHEVs, we adjusted the fuel economy in the CS operational mode according to the EPA mpg-based formulas because that mode of operation is similar to operation of a regular HEV. For the blended (engine and motor) CD mode of operation for power-split PHEVs, there could be many possible adjustments to fuel and electricity consumption, as illustrated by the two general adjustment directions ( $d-\mathrm{D}_{2,3}$ arrows) in Figure 3.2. The actual onroad adjustment direction depends on many factors: the power rating of the battery, engine, and electric motor; the relative aggressiveness over the laboratory driving cycles; air-conditioning use; cold-weather operation; and the vehicle's control strategy. For vehicle designs that feature larger batteries and electric motors, the adjustment will likely follow the general direction of $\mathrm{d}$ $\mathrm{D}_{3}$ in Figure 3.2 because the additional on-road load would be mostly satisfied by the battery, with some help from the engine.

For vehicle designs that feature smaller battery and electric motors, the adjustment will likely follow the general direction $\mathrm{d}-\mathrm{D}_{2}$ in Figure 3.2 because the additional on-road load would be mostly satisfied by the engine, with little or no help from the battery. Note that electricity consumption (in $\mathrm{Wh} / \mathrm{mi}$ ) decreases in such scenario because the increase in on-road acceleration (compared with accelerations of the test cycle) results in less time elapsed per each driven mile, thus less electricity is consumed per mile for a constant battery discharge rate. This general trend - an increase in fuel consumption and a decrease in electricity consumption - has been observed and reported by many researchers for the power-split PHEV configuration (Duoba et al. 2009; Santini et al. 2008; and Christenson et al. 2009). The degree by which fuel consumption increases and electricity consumption decreases is not well quantified and depends on the many factors mentioned above. Because of this uncertainty, we adopted the adjustment path for the CD blended operation of the power-split design configuration, as shown by the arrow $d-D_{1}$ in Figure 3.2. This path assumes that the additional on-road load (compared with the test cycle load) would result in a fuel consumption increase similar to the increase during CS operation by the same vehicle for the same additional load. This appeared to be the most reasonable assumption because the electric machine of the power-split design is smaller than that of the series PHEV examined in this analysis (see Appendix 1). Therefore, the laboratory fuel consumption in CD mode for power-split PHEVs was adjusted by the same increase in fuel consumption associated with the CS operation of the same vehicle (see magnitude of adjustment arrow d- $\mathrm{D}_{1}$ in Figure 3.2, which equals adjustment arrow a-A for the CS operation of the same vehicle).

The methodology described above for adjusting the fuel economy and electricity consumption was applied to the PSAT simulation results (Table 3.1) for the different vehicle technologies considered in this analysis. Table 3.2 lists the corresponding "adjusted" fuel economy and electricity consumption for on-road performance. Note that the electricity consumption values under the CD electric mode are provided in units of $\mathrm{Wh} / \mathrm{mi}$ (shown in red), while the fuel economy values for ICEVs and FCVs are shown in units of miles per unit of gasoline equivalent gallon (shown in black). 


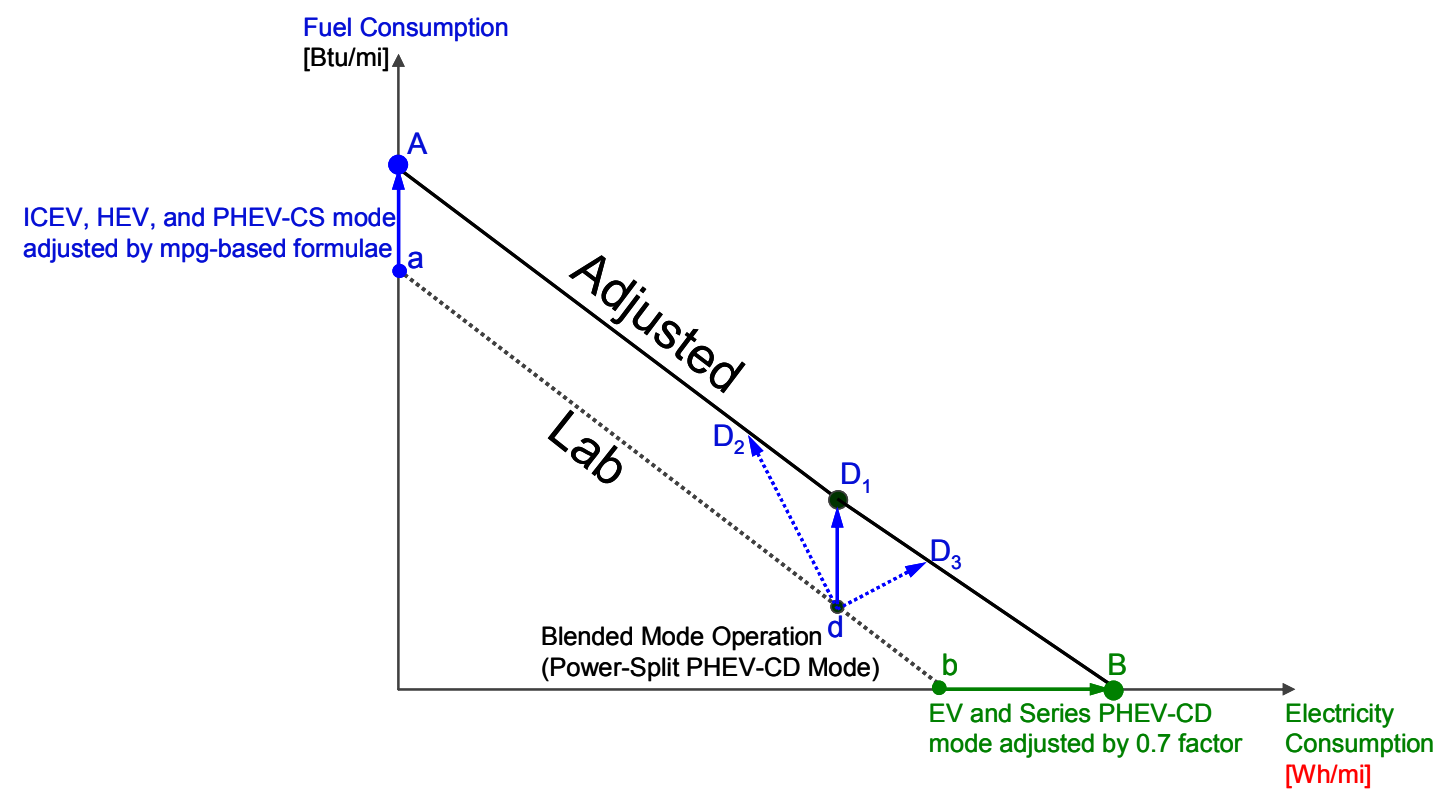

FIGURE 3.2 On-Road Adjustments of Laboratory Fuel and Electricity Consumption

TABLE 3.2 On-Road Fuel Economy Resultsa,b

\begin{tabular}{|c|c|c|c|c|c|c|c|c|c|c|c|c|c|c|c|}
\hline \multicolumn{3}{|c|}{$\begin{array}{c}\text { Adjusted } \mathrm{Wh} / \mathrm{mi} \text { and } \\
\text { mpgeg }\end{array}$} & \multirow{2}{*}{$\begin{array}{l}\text { AER 0 } \\
\text { Regular } \\
\text { Hybrid } \\
\end{array}$} & \multicolumn{3}{|c|}{$\begin{array}{c}\text { AER 10 } \\
\text { Power-Split PHEV } \\
\end{array}$} & \multicolumn{3}{|c|}{$\begin{array}{c}\text { AER 20 } \\
\text { Power-Split PHEV } \\
\end{array}$} & \multicolumn{3}{|c|}{$\begin{array}{c}\text { AER 30 } \\
\text { Series PHEV } \\
\end{array}$} & \multicolumn{3}{|c|}{$\begin{array}{c}\text { AER 40 } \\
\text { Series PHEV } \\
\end{array}$} \\
\hline & & & & $\begin{array}{c}\mathrm{CD} \\
\text { Electric }\end{array}$ & $\begin{array}{c}\mathrm{CD} \\
\text { Engine }\end{array}$ & $\begin{array}{c}\mathrm{CS} \\
\text { Engine } \\
\end{array}$ & $\begin{array}{c}\mathrm{CD} \\
\text { Electric }\end{array}$ & $\begin{array}{c}\mathrm{CD} \\
\text { Engine }\end{array}$ & $\begin{array}{c}\mathrm{CS} \\
\text { Engine }\end{array}$ & $\begin{array}{c}\mathrm{CD} \\
\text { Electric }\end{array}$ & $\begin{array}{c}\mathrm{CD} \\
\text { Engine }\end{array}$ & $\begin{array}{c}\mathrm{CS} \\
\text { Engine }\end{array}$ & $\begin{array}{c}\mathrm{CD} \\
\text { Electric }\end{array}$ & $\begin{array}{c}\mathrm{CD} \\
\text { Engine }\end{array}$ & $\begin{array}{c}\mathrm{CS} \\
\text { Engine } \\
\end{array}$ \\
\hline \multirow{2}{*}{$\begin{array}{l}\text { Gasoline } \\
\text { ICEV }\end{array}$} & UDDS & 25.4 & 45.1 & 182 & 100 & 48.6 & 179 & 98 & 48.4 & 314 & 204 & 35.2 & 326 & 432 & 34.7 \\
\hline & HWFET & 31.4 & 39.3 & 200 & 45.6 & 42.3 & 195 & 78.0 & 42.0 & 338 & 864 & 34.0 & 337 & 896 & 33.7 \\
\hline \multirow{2}{*}{\begin{tabular}{|l} 
E85 \\
ICEV \\
\end{tabular}} & UDDS & & 42.4 & 182 & 96 & 45.9 & 178 & 92 & 45.7 & 314 & 189 & 32.9 & 326 & 399 & 32.4 \\
\hline & HWFET & & 36.7 & 198 & 45.6 & 39.6 & 193 & 76.9 & 39.3 & 339 & 814 & 32.0 & 338 & 841 & 31.7 \\
\hline \multirow{2}{*}{$\begin{array}{l}\text { Diesel } \\
\text { ICEV }\end{array}$} & UDDS & & 47.0 & 182 & 102 & 49.1 & 183 & 98 & 48.8 & 318 & 218 & 37.4 & 330 & 467 & 37.0 \\
\hline & HWFET & & 40.7 & 201 & 48.6 & 42.4 & 199 & 82.4 & 42.0 & 342 & 992 & 35.2 & 344 & 1056 & 34.8 \\
\hline \multirow{2}{*}{$\begin{array}{l}\mathrm{H}_{2} \\
\mathrm{FCV}\end{array}$} & UDDS & & 57.1 & 166 & 107 & 59.0 & 172 & 103 & 58.2 & 315 & 355 & 56.7 & 317 & 674 & 55.8 \\
\hline & HWFET & & 59.8 & 204 & 50.0 & 59.7 & 198 & 86.2 & 59.1 & 333 & 1316 & 57.6 & 335 & 1067 & 57.0 \\
\hline \multirow{2}{*}{ EV } & UDDS & 338 & & & & & & & & & & & & & \\
\hline & HWFET & 347 & & & & & & & & & & & & & \\
\hline
\end{tabular}

a Results in mpgeg for fuel economy or $\mathrm{Wh} / \mathrm{mi}$ (shown in red) for electric operation.

$\mathrm{b}$ Electricity consumption is from the battery, while fuel consumption is from the vehicle's tank. 


\subsection{BATTERY CHARGING LOSSES FOR PHEVS AND BEVS}

To perform WTW energy and GHG emissions calculations in GREET, we processed the adjusted (on-road) fuel economy and electricity consumption results listed in Table 3.2 for inclusion in GREET. The first step was to convert the electricity consumption of the battery and the fuel economy values of the engine (ICE or fuel cell) to per-mile fuel consumption in consistent units (Btu/mi), as listed in Table 3.3. We assumed that the charger and battery charging efficiencies would be $90 \%$ and $97 \%$, respectively, using a $110-\mathrm{V}$ outlet at a rate of $15-$ $20 \mathrm{~A}$, and corresponding efficiencies of $87 \%$ and $95 \%$ using $220-\mathrm{V}$ outlet at a rate of $20-30 \mathrm{~A}$. The charger efficiency reflects the energy losses in the charger circuitry, while the battery charging efficiency reflects the energy losses from the battery while converting the received electric energy into chemical energy for storage. The combined "charging" efficiency is $87 \%$ for the $110-\mathrm{V}$ charging and $83 \%$ for the $220-\mathrm{V}$ charging. Thus, we adopted an average combined charging efficiency of $85 \%$ to calculate the electricity consumption at the wall outlet for charging BEVs and PHEVs.

In accordance with EPA's recommendation, $43 \%$ city $/ 57 \%$ highway VMT weighting values were used to calculate the composite city/highway electricity and fuel consumption for all vehicle technologies (EPA 2008). Table 3.3 includes three fuel consumption types for each PHEV system: grid electricity consumption in CD operation, engine fuel consumption in the blended CD operational mode, and engine fuel consumption in the CS operational mode. The first column in Table 3.3 includes the fuel consumption of the baseline conventional gasoline ICEV and the grid electricity consumption (at the wall outlet) for BEVs. The second column lists the fuel consumption of regular HEVs $(\mathrm{AER}=0)$. The fuel consumption for the baseline gasoline ICEV and the regular HEVs are provided to allow comparison between existing and future powertrain systems.

TABLE 3.3 Fuel and Electricity Consumption Calculated from the Adjusted (on-road) Fuel Economy and Electricity Consumption in Table 3.2 $\mathbf{2}^{\mathrm{a}, \mathrm{b}}$

\begin{tabular}{|c|c|c|c|c|c|c|c|c|c|c|c|c|c|c|}
\hline \multirow[b]{2}{*}{ Fuel } & \multirow[b]{2}{*}{ ICEV } & \multirow[b]{2}{*}{$\begin{array}{r}\text { Regular } \\
\text { Hybrid }\end{array}$} & \multicolumn{3}{|c|}{$\begin{array}{c}\text { AER } 10 \\
\text { Power-Split PHEV }\end{array}$} & \multicolumn{3}{|c|}{$\begin{array}{c}\text { AER } 20 \\
\text { Power-Split PHEV }\end{array}$} & \multicolumn{3}{|c|}{$\begin{array}{c}\text { AER 30 } \\
\text { Series PHEV }\end{array}$} & \multicolumn{3}{|c|}{$\begin{array}{c}\text { AER } 40 \\
\text { Series PHEV }\end{array}$} \\
\hline & & & $\begin{array}{c}\mathrm{CD} \\
\text { Electric }\end{array}$ & $\begin{array}{c}\text { CD } \\
\text { On- } \\
\text { Board }\end{array}$ & CS & $\begin{array}{c}\mathrm{CD} \\
\text { Electric }\end{array}$ & $\begin{array}{c}\text { CD } \\
\text { On- } \\
\text { Board }\end{array}$ & $\mathrm{CS}$ & $\begin{array}{c}\mathrm{CD} \\
\text { Electric }\end{array}$ & $\begin{array}{l}\text { CD On- } \\
\text { Board }\end{array}$ & $\mathrm{CS}$ & $\begin{array}{c}\mathrm{CD} \\
\text { Electric }\end{array}$ & $\begin{array}{c}\text { CD } \\
\text { On- } \\
\text { Board }\end{array}$ & CS \\
\hline Gasoline & 4015 & 2751 & 771 & 1542 & 2554 & 755 & 1408 & 2570 & 1316 & 317 & 3316 & 1334 & 187 & 3354 \\
\hline E85 & & 2939 & 768 & 1634 & 2720 & 749 & 1507 & 2739 & 1317 & 341 & 3534 & 1334 & 201 & 3578 \\
\hline Diesel & & 2648 & 773 & 1517 & 2542 & 771 & 1395 & 2563 & 1331 & 292 & 3170 & 1358 & 167 & 3208 \\
\hline Hydrogen & & 1954 & 753 & 1208 & 1927 & 749 & 1121 & 1950 & 1305 & 188 & 2000 & 1313 & 134 & 2027 \\
\hline $\begin{array}{l}\text { Electricity } \\
\text { (BEV) }\end{array}$ & 1375 & & & & & & & & & & & & & \\
\hline
\end{tabular}


The data in Table 3.3 are plotted in Figures 3.3 and 3.4 for different fuel/vehicle systems. Figure 3.3 reveals the qualitative difference in fuel consumption (by engine or fuel cell) and electricity consumption (at wall outlet) in CD mode of operation between the power-split and the series PHEV design configurations. The power-split design (PHEV10 and 20) exhibits significant fuel consumption by the on-board system (engine or fuel cell) compared with electricity consumption in that (blended) mode of operation. The reverse trend is observed for the series design (PHEV30 and 40), in which the electricity consumption dominates that mode of operation. Figure 3.3 also shows that the electricity consumption of BEVs is comparable to that of the series PHEVs in CD operational mode. Note that the rated AER for the BEV in this analysis is $150 \mathrm{mi}$ on the UDDS cycle, which is not shown on Figure 3.3.

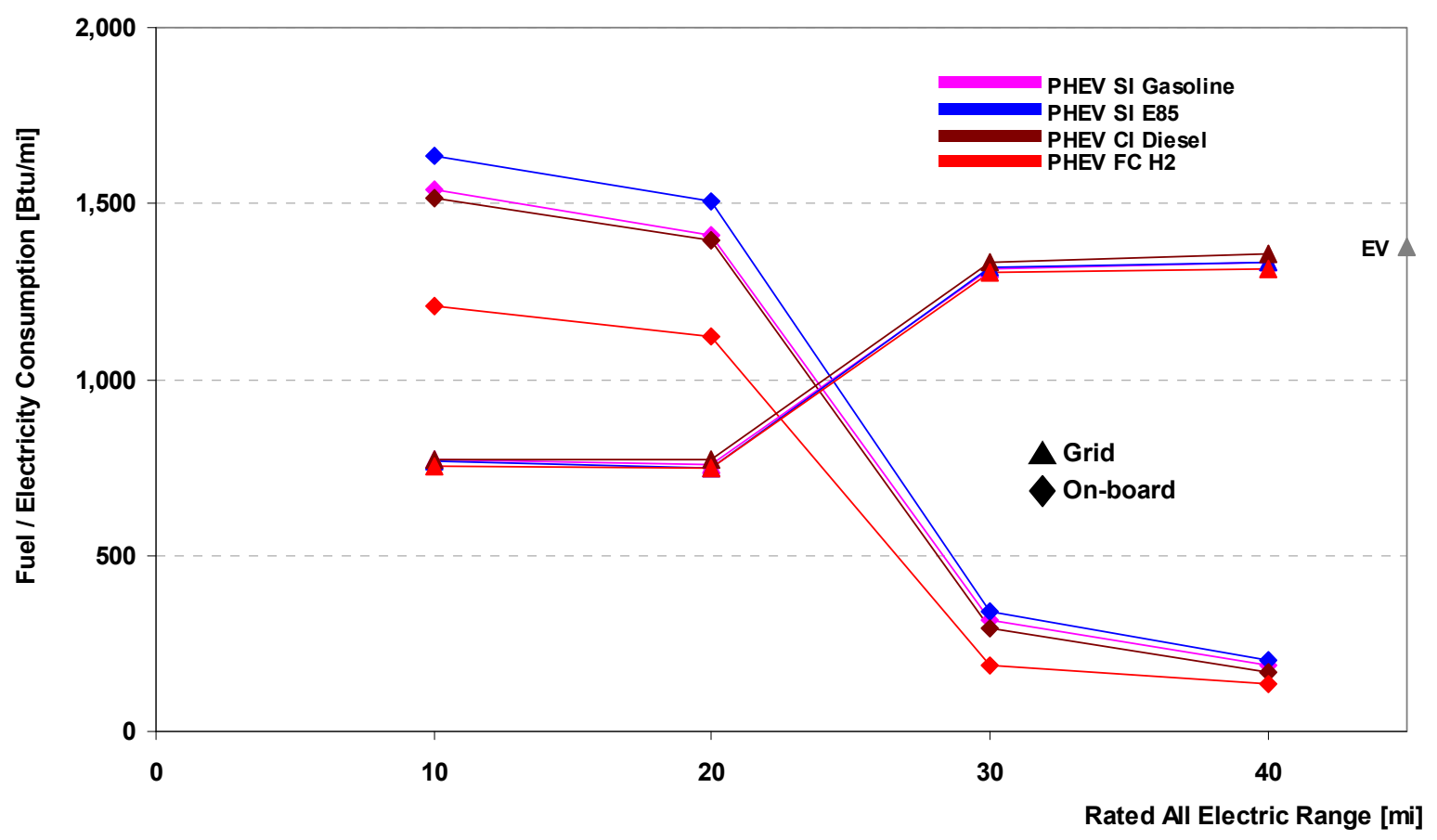

FIGURE 3.3 Electricity (Grid) and Fuel (Engine or Fuel Cell) Consumption in CD Operation of PHEVs and BEVs

Figure 3.4 shows the combined fuel and electricity consumption for CD operation of PHEVs, the fuel consumption for HEVs and CS operation of PHEVs, and the electricity consumption for BEVs. The markers on the vertical axis at $\mathrm{AER}=0$ represent the baseline gasoline ICEV and the regular HEVs. Figure 3.4 shows that, in CS operation mode, the powersplit configuration of PHEV10 and 20 consumes less fuel than the regular HEV for the same fuel. This is because of the larger battery capacity of the PHEVs, which allows for a more effective hybridization with the engine in CS operation. However, the fuel consumption of the series configuration of PHEV30 and 40 is much higher compared with that of the regular HEVs for the same fuel, mainly because of the added inefficiencies of the series configuration 


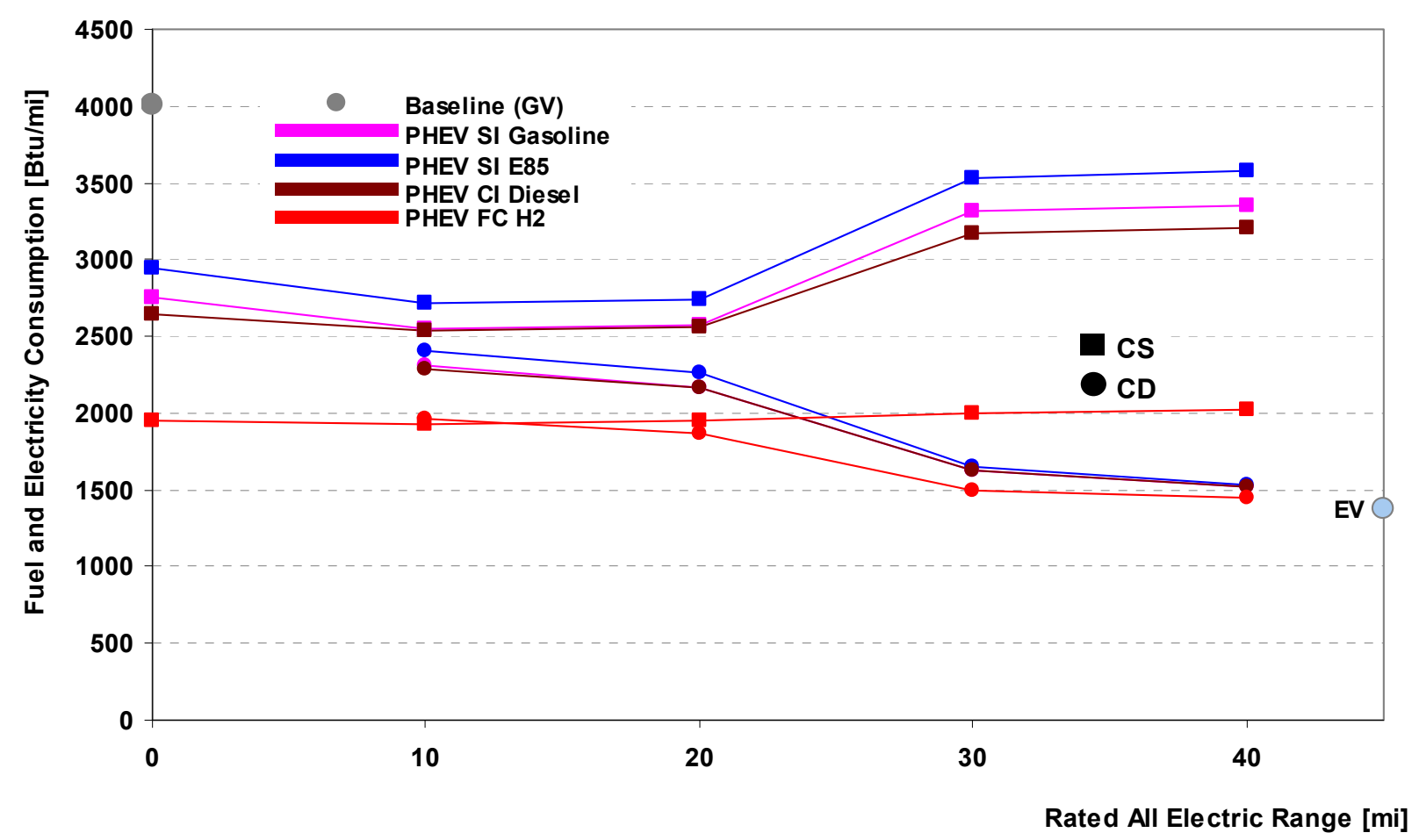

FIGURE 3.4 Electricity and Fuel Consumption in CD and CS Operation of PHEVs

driveline. It should be noted that the fuel consumption of FC-PHEVs in CS operation is comparable to that of the regular FC-HEV because all FCVs adopt the series design configuration.

Figure 3.4 also shows the CD fuel and electricity consumption for PHEVs, as well as the electricity consumption of BEVs. When comparing the electricity consumption of BEVs $(1,375$ $\mathrm{Btu} / \mathrm{mi})$ to the fuel consumption of baseline gasoline ICEV $(4,015 \mathrm{Btu} / \mathrm{mi})$, we find that the electric powertrain is almost three times as efficient as the ICE powertrain. This is not surprising; the conversion efficiency of electric energy to mechanical energy in the electric machine (motor) is several times higher than the corresponding conversion efficiency of fuel energy to mechanical energy in the engine. In other words, the PTW efficiency is much higher for BEVs compared with ICEVs. For the same reason, the total energy consumption in CD operation is lower for the series configuration (PHEV 30 and 40) compared with the power-split configuration (PHEV 10 and 20) because the control strategy of the latter allows for more fuel use in that mode. However, the fuel-to-mechanical-to-electrical-energy conversion losses associated with electricity generation at the power plant and the losses associated with electricity transmission and distribution to the wall outlet are much higher than the losses associated with fuel production and transportation to the pump. In other words, WTP efficiency is much lower for electricity generation and transmission to the vehicle's battery compared with fuel production and transmission to the vehicle's tank. The net impact of the WTP and PTW efficiency will become evident in the WTW results presented in Section 6. 


\subsection{ACTUAL “ON-ROAD” MILES DRIVEN IN CD MODE}

As mentioned in Section 2, the battery of PHEVs and BEVs is sized to achieve the required (rated) AER of the vehicle on the UDDS. However, if the additional "on-road" load (over the test cycle load) is met by the battery's power, the actual (operational) AER of the PHEV would fall short of the rated AER because the usable energy of the battery is fixed for a given PHEV technology. As mentioned above, this is assumed to be the case for the series PHEVs because of the larger electric machine in that design configuration. In this case, the CD VMT (calculated by PSAT on the UDDS) decreases by the same percentage as the decrease in fuel economy for such a mode (i.e., 30\%). In contrast, the additional "on-road" load is met by the engine for the power-split PHEVs because of the smaller electric machine. Thus, the CD VMT calculated by PSAT on the UDDS is unchanged for that design configuration. Figures 3.5 through 3.7 show the unadjusted (UDDS and HWFET) and adjusted (on-road) CD VMT for all PHEV technologies. The adjusted VMT shown in Figure 3.7 is used to calculate the share of CD VMT as a percentage of the total CD and CS VMT, hereafter referred to as the "utility factor." The utility factor (UF) is used to combine the WTW energy use and emissions results of the CD and CS operations. Section 3.4 describes the UF evaluation for the different PHEV technologies considered in this analysis.

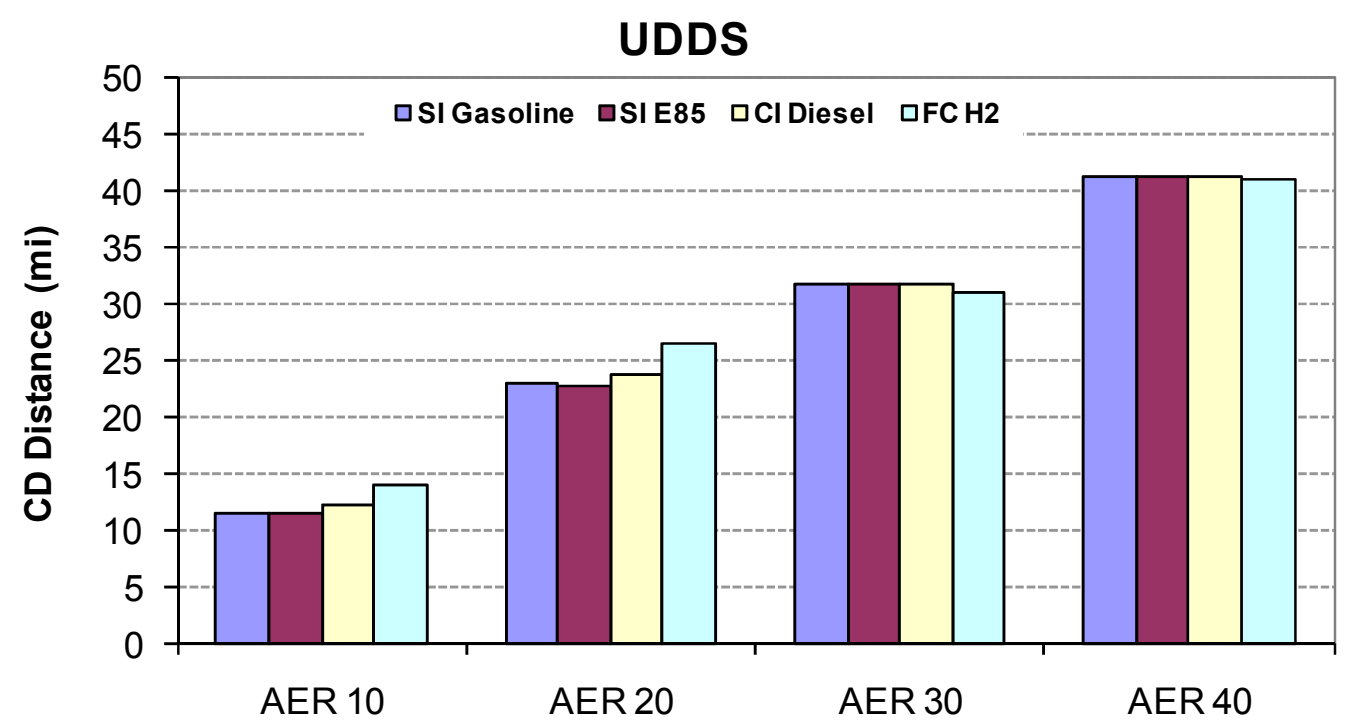

FIGURE 3.5 CD VMT on UDDS from PSAT Simulations 


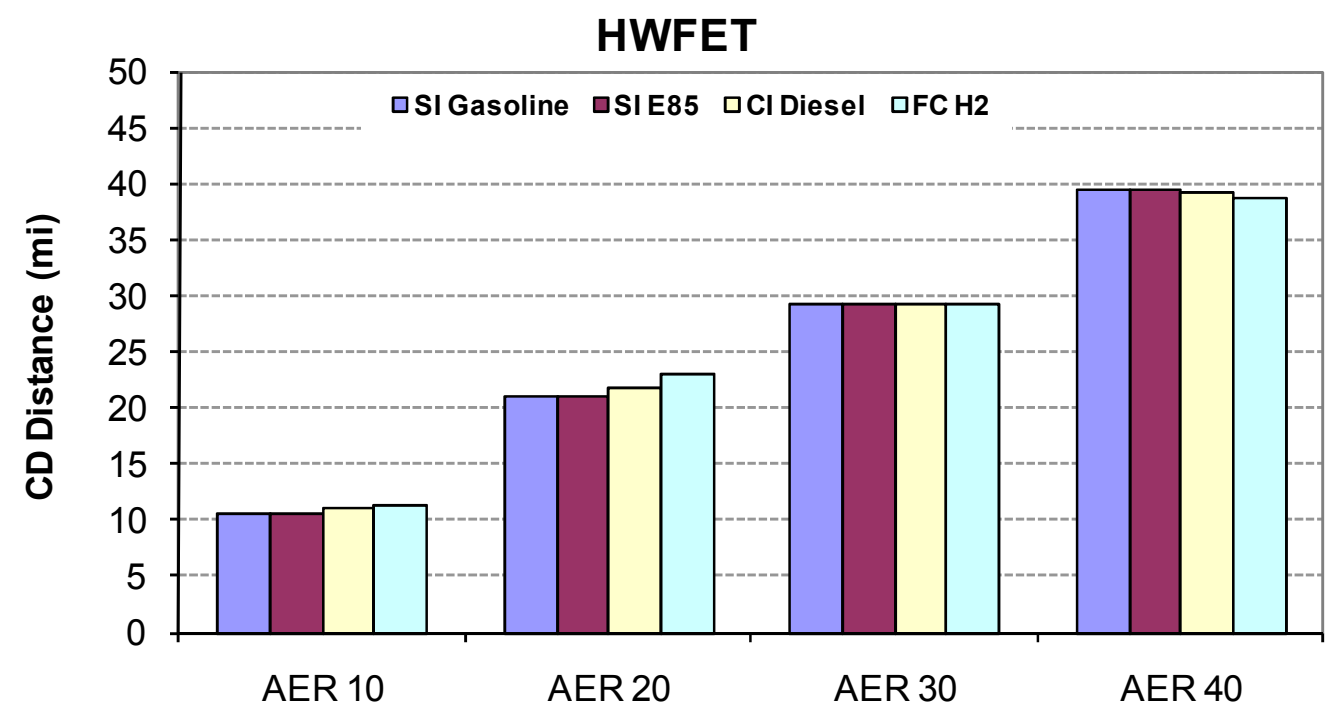

FIGURE 3.6 CD VMT on HWFET from PSAT Simulations

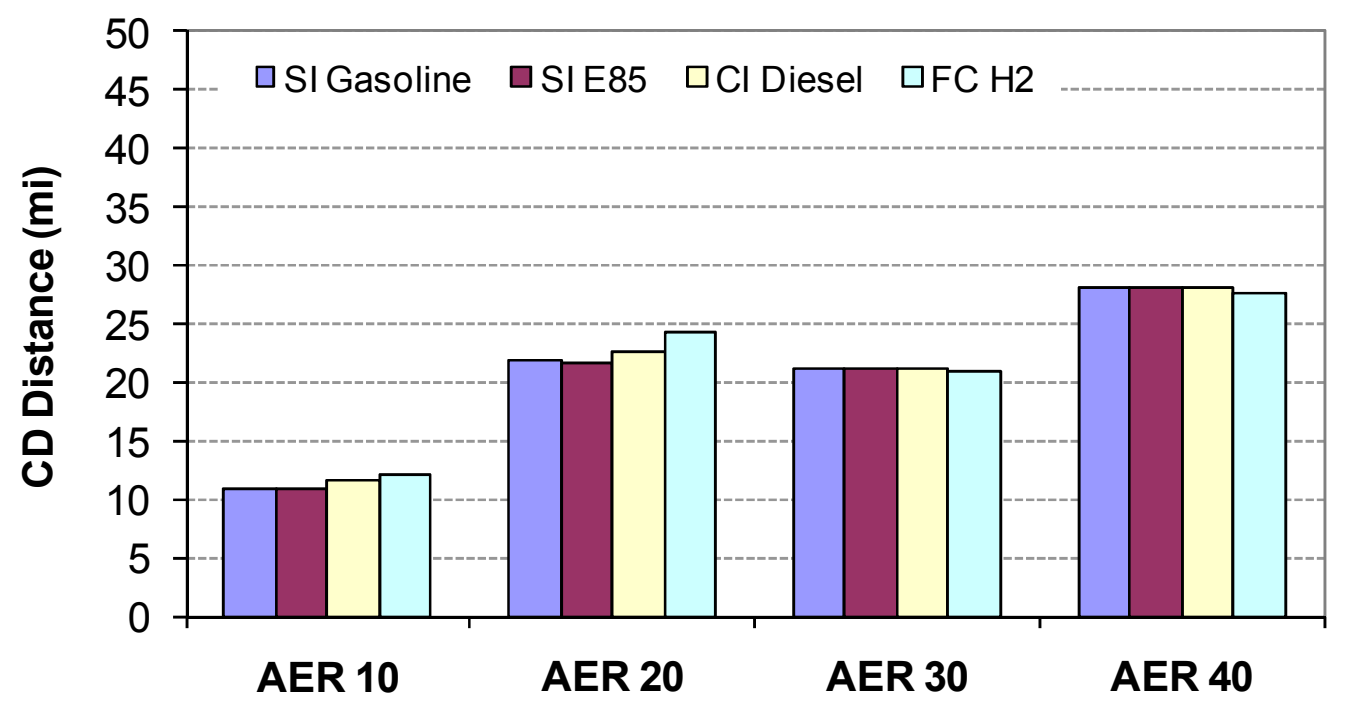

FIGURE 3.7 Adjusted (On-Road) CD VMT

\subsection{VEHICLE MILES TRAVELED SPLIT BY CD VERSUS CS OPERATION}

In order to combine the CD and CS energy use and emissions for PHEVs, we must evaluate the potential of PHEVs to replace miles driven by gasoline-powered vehicles with miles driven by electricity-powered vehicles. Vyas et al. (2007) evaluated the UF, which partitions the average national miles driven into vehicle miles that can be traveled using the PHEV's CD mode and vehicle miles that exceed the rated CD range, based on the 2001 NHTS data. Table 3.4 shows the share of national total VMT contributed by vehicles traveling various ranges per day and the maximum percentage of VMT that could be replaced by CD operation of a PHEV. If a PHEV has an operational AER equal to or larger than the daily VMT, it could travel all those 
miles in CD mode. However, if the vehicle is driven longer than the operational AER, only the first miles driven up to that AER can be electrified. The sum of the gray cells for any given distance range in Table 3.4 represents the VMT share of PHEVs rated for that range, with daily VMT not exceeding their rated AER. The yellow cell for any given distance range in Table 3.4 represents the VMT share of PHEVs rated for that range, with daily VMT that could exceed their rated AER.

TABLE 3.4 Share of Daily Vehicle Miles Covered by a Given Distance Range

\begin{tabular}{lcccccc}
\hline & & \multicolumn{5}{c}{ First VMT\% Covered by Given Distance Range } \\
\cline { 3 - 6 } & & & & & & \\
& & & & & & \\
Daily Travel & VMT Share in & 0 & 30 & 40 & 60 \\
Range of Vehicle & NHTS 2001 (\%) & Miles & Miles & Miles & Miles & Miles \\
\hline & & & & & & \\
Up to 10 Miles & 3.3 & 3.3 & 3.3 & 3.3 & 3.3 & 3.3 \\
10-20 Miles & 8.1 & 5.3 & 8.1 & 8.1 & 8.1 & 8.1 \\
20-30 Miles & 10.0 & 3.9 & 7.9 & 10.0 & 10.0 & 10.0 \\
30-40 Miles & 10.0 & 2.8 & 5.7 & 8.5 & 10.0 & 10.0 \\
40-60 Miles & 16.8 & 3.4 & 6.7 & 10.1 & 13.5 & 16.8 \\
Over 60 Miles & 51.8 & 4.5 & 8.9 & 13.4 & 17.9 & 26.7 \\
Total & 100.0 & 23.2 & 40.6 & 53.4 & 62.8 & 74.9 \\
\hline
\end{tabular}

Figure 3.8 shows a curve fitted to the results shown in Table 3.4. If the PHEV does not operate "all electrically" in CD mode and employs some type of blended-mode strategy (e.g., power-split configuration), the miles to deplete the battery will be extended beyond the rated AER. Thus, when a power-split PHEV (operating under a blended CD mode strategy) travels a distance shorter than or equal to its rated electric range, the usable battery energy will not be fully utilized, and fewer miles will be displaced by electricity compared with a PHEV that uses $100 \%$ electricity in the CD mode (e.g., series design configuration).

This study did construct a market segmentation (not transition) scenario in which consumer PHEV selection among four different choices was matched to "economically appropriate" daily driving patterns (see Chapter 4). The greater the daily distance driven, the higher the CD range of the PHEV presumed to be selected. Recognize, for example, that the average daily distance traveled in the U.S. is about 34 miles per day. If every day of driving were identical to the average, then a PHEV40 would electrify all miles driven. Of course miles driven vary considerably. They vary in an asymmetric way, with a relatively few very long distance intercity trips and very many short intra-urban trips. So, in order for a PHEV40 owner to obtain the full value from regular at home overnight charging, the owner will have to regularly drive over 40 miles in intra-city driving only - not including the days with inter-city driving. Therefore, we assume that only owners with more than average annual driving will select the PHEV40. As the distance driven per day drops, households are assumed to choose less allelectric range - because of the great expense of purchasing more battery electric range than can be used on a regular daily basis. The result is that rough calculations based on the scenario 
utilized here imply a relatively invariant share of daily miles driven in charge depletion mode associated with each PHEV placed "in the field", regardless of CD range. This is not the result that was assumed in many past analyses, which used a share estimate that goes from about $20 \%$ for a PHEV10 to over 50\% for a PHEV40 (as in Fig. 3.8). One critical implicit assumption of the "share of miles electrified" curve used in the past (the "utility factor") was that only one type of PHEV was available for purchase: in our scenario four distinct types are available. Another implicit assumption of the utility factor is that the probability of PHEV purchase is invariant to daily distance driven, or to benefit vs. cost. In order to save oil, PHEVs will have to be purchased and used. How often this happens, and how frequently the pack will be charged and fully discharged remain an area of considerable uncertainty.

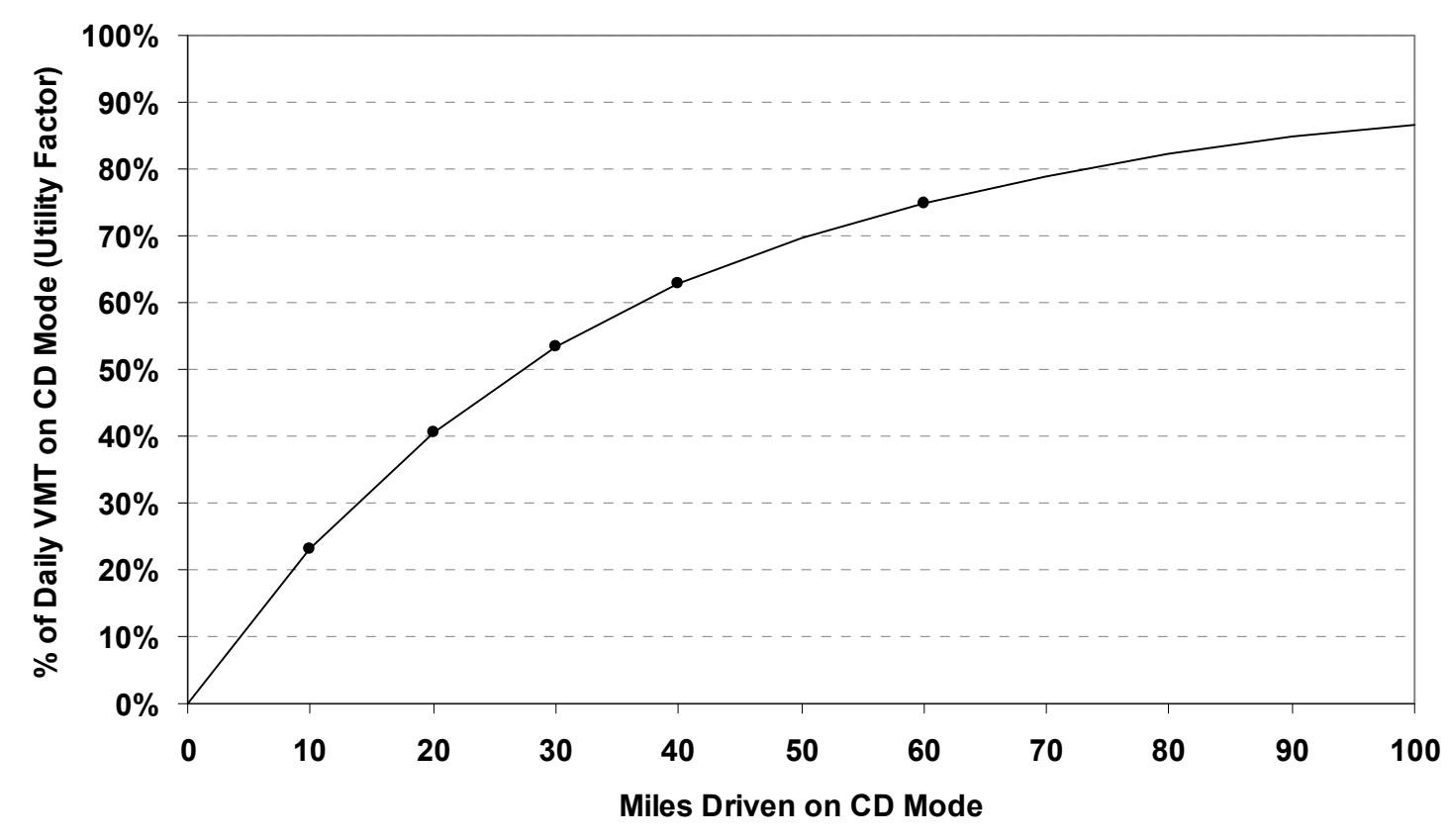

FIGURE 3.8 Percentage of Daily VMT Available for Substitution by a PHEV in CD Mode

Santini et al. (2008) and Vyas et al. (2007) found that, when estimating the potential for national savings in petroleum energy use and GHG emissions, an estimate of the electrifiable VMT share (utility factor) is further complicated by the following issues:

- Large-scale change will be slow because of low fleet turnover (approximately $7-8 \%$ per year).

- PHEVs will not be purchased by everyone.

- PHEVs will likely complement, rather than displace, HEVs, thus expanding the long-term hybrid drivetrain market (i.e., PHEVs may not become a universal powertrain). 
- Various control strategies for utilizing the engine and the electric machine could result in a myriad of VMT shares in CD mode.

- PHEVs will vary in terms of their AER capability and will have different configurations of the electric machine, battery, and engine.

- PHEVs purchased with a nominal range capability (AER rating) will not realize that exact rated value in practice because of variations in driving conditions, driver characteristics, accessory use, etc.

- Batteries for PHEVs may be charged more than once every day.

Because of these issues, we report the WTW energy use and emissions results for the CD mode in addition to the WTW results for the combined CD and CS operations. The utility factor was calculated from Figure 3.8 on the basis of the adjusted CD VMT in Figure 3.7. Then the WTW results for the combined CD and CS operations were calculated on the basis of the utility factor using the following equation:

$$
E_{\text {combined }}=\left(E_{G \text { rid }}+E_{\text {Engine }}\right)_{C D} * U F+E_{C S} *(1-U F)
$$

where E refers to the energy consumption or emissions associated with the fuel and electricity use by PHEVs, as well as those associated with the upstream processes of electricity generation, fuel production, and their transmission and distribution to the vehicles. 


\section{PHEV POPULATION AND ELECTRIC LOAD PROFILE}

PHEVs will draw electric energy from the electric grid. The extent of this electricity demand was estimated by examining patterns of vehicle usage and calculating the potential number of PHEVs that will be plugged in.

\subsection{DATA SOURCES}

To conduct utility demand simulations, we estimated daily electricity demand for various PHEVs, specifically the following characteristics: (1) daily vehicle usage, (2) pattern of vehicle arrival at home at the end of the last trip, (3) number of PHEVs of different AERs that will be plugged in each day, and (4) amount of electric power and energy that will be drawn by each PHEV (with different AERs), and (5) time required for charging.

Travel data from the 2001 NHTS were analyzed to determine the pattern of daily vehicle usage and how much of that travel can potentially rely on electricity. In other words, we examined, under different assumptions, the ending time of the last vehicle trip and the share of VMT that can be electrified. The NHTS was conducted under the sponsorship of the Federal Highway Administration (FHWA), Bureau of Transportation Statistics, and National Highway Traffic Safety Administration (FHWA 2004). The NHTS files contain data on household characteristics, household member characteristics, household vehicle characteristics, and household travel characteristics. For travel data, the survey includes a one-day travel component and a long-distance travel component. Data from the one-day travel component were used for the PHEV analysis presented here. The 2001 NHTS was conducted from March 2001 through May 2002. Each sampled household was assigned a travel day to report all trips made on that day. Travel days covering all seven days of the week (including holidays) were assigned. The travel day began at 4:00 a.m. and ended at 3:59 a.m. of the following day. On a typical day, 4:00 a.m. represents the time when the fewest number of people are in the middle of a trip. Care was taken to have each month of the year and each day represented properly in the survey.

The NHTS covered 69,817 households, 160,758 persons, 139,382 vehicles, and 642,292 person trips on the assigned travel day. Of these 642,292 trips, 387,431 were made by personal vehicles driven by one of the responding drivers and 172,879 were made by passengers in private vehicles. When trips with unreported travel times and travel distances are dropped, 366,084 trips made by 84,916 vehicles are available for further analysis. These trips and vehicles include samples from areas that requested additional sampling. When these add-on samples are removed, 142,111 trips made by 32,022 vehicles remain. The sample without the add-ons is called the "national sample" by the Federal Highway Administration; the national sample is used here because it provides a random representation of national household travel.

Light-duty vehicle projections from EIA's 2009 Annual Energy Outlook (AEO) (EIA 2009a) were used to estimate the number of PHEVs on the road in 2020. EIA is a part of DOE and uses its National Energy Modeling System (NEMS) to project vehicle sales, vehicle stock 
(number of vehicles on the road), and energy demand (EIA 2009b). The AEO provides national projections of cars and light trucks on the road.

Argonne used population data from the U.S. Census Bureau to allocate national vehicle projection to individual states. The Census Bureau projections provide population - by age group - for each state (U.S. Census Bureau 2005). The 2007 state-level vehicle registration data from Highway Statistics published by the FHWA (FHWA 2008) were used, together with the population projections, to allocate EIA's projected national vehicle population to each state. The vehicle registration data were also used to determine the likelihood of each state to have more or fewer vehicles per driving-age person.

\subsection{PHEV POPULATION}

For estimating electricity demand by PHEVs, Argonne estimated the number of PHEVs that will be on road in 2020. Two alternatives were considered: (1) estimate new PHEV market penetration profile for vehicles having 10-, 20-, 30-, and 40-mile AER or (2) assume that a certain percent of registered vehicles in 2020 will be PHEVs and then allocate the resulting vehicles as PHEVs with 10-, 20-, 30-, and 40-mile AERs.

The first approach would require development of detailed vehicle characteristics of PHEVs and competing-technology vehicles to allow us to estimate PHEV market shares through a vehicle choice model. These market shares then can be applied to new vehicle sales, and the resulting new vehicles can be simulated by using a vehicle survival model. Because such a detailed approach would take considerable time and effort, we decided to employ the second approach and assume that $10 \%$ of all vehicles in 2020 will be PHEVs. The assumed 10\% share may appear high, compared with the historical shares by such technologies as diesel vehicles and CS HEVs. However, because the intent of this analysis is to analyze the impact of a high level of market penetration by PHEVs, the assumption of a 10\% market share is justified.

Next, we estimated the $10 \%$ share of 2020 vehicle population as projected in AEO 2009. AEO projections provide separate estimates for car and light truck stock, but not by vehicle type within the light truck category. We assumed that PHEVs will not be offered in all light trucks; only the sport utility vehicle (SUV) segment will offer PHEVs. FHWA's 2007 Highway Statistics provide registrations of light trucks by state and by category (i.e., pickups, vans, SUVs, other light trucks, and farm trucks). The 2007 light truck shares by these vehicle types were computed and were assumed to remain unchanged through 2020 for each state.

We estimated the 2007 light vehicle registration shares per driving-age population for each state and each state's share of the total driving-age population. (Note: for this purpose, the 16- to 84-year-old age group was considered as the driving-age population.) An analysis of the 2007 driving-age population share and vehicle registration share provided each state's propensity to own more or fewer light-duty vehicles per driving-age person. These propensity values were assumed to remain unchanged through 2020 for each state. 
The use of these estimates (2020 driving-age population share by state and each state's propensity to have more or fewer light-duty vehicles per driving-age person) allowed us to allocate national light vehicle estimates from AEO 2009 to each state. We used the SUV share of light truck registrations for each state to arrive at 2020 state-level SUV registrations. These estimates were used the project the 2020 PHEV population in each state.

To analyze the impacts of such PHEV penetration on electric utilities, we selected four study areas: (1) the area within the United States that is served by the WECC, (2) Illinois State, (3) New York State, and (4) states within the U.S. Census Bureau's New England division. To develop detailed characteristics, we further subdivided the first three areas into eight subareas. The state-level PHEV estimates described above were used to estimate PHEV population for the following geographical areas:

1. Metropolitan Statistical Areas (MSAs) within WECC service area (excluding California),

2. Non-MSA areas WECC service area (excluding California),

3. California's large MSAs,

4. Rest of California,

5. Chicago MSA within Illinois,

6. Rest of Illinois,

7. New York City Consolidated Metropolitan Statistical Area (CMSA) within New York State

8. Rest of New York State, and

9. New England states.

The WECC service area (excluding California) in our analysis encompassed Arizona, Colorado, Idaho, Montana, New Mexico, Nevada, Oregon, Utah, Washington, and Wyoming.

We used the travel day data in the 2001 NHTS to allocate total PHEVs in each of these geographical areas by 10-, 20-, 30-, and 40-mile AERs. Vehicles traveling 12-24 miles were used to compute vehicle share by PHEVs with a 10-mile AER; those traveling 24-36 miles were used for PHEVs with a 20-mile AER; those traveling 36-48 miles for were used for PHEVs with a 30-mile AER; and those traveling 48-60 miles were used for PHEVs with a 40-mile AER. The share of vehicles in each AER was determined and applied to PHEV estimates in each of the analysis areas. Figure 4.1 shows 2020 PHEV population by various AER in each of the analysis areas. 


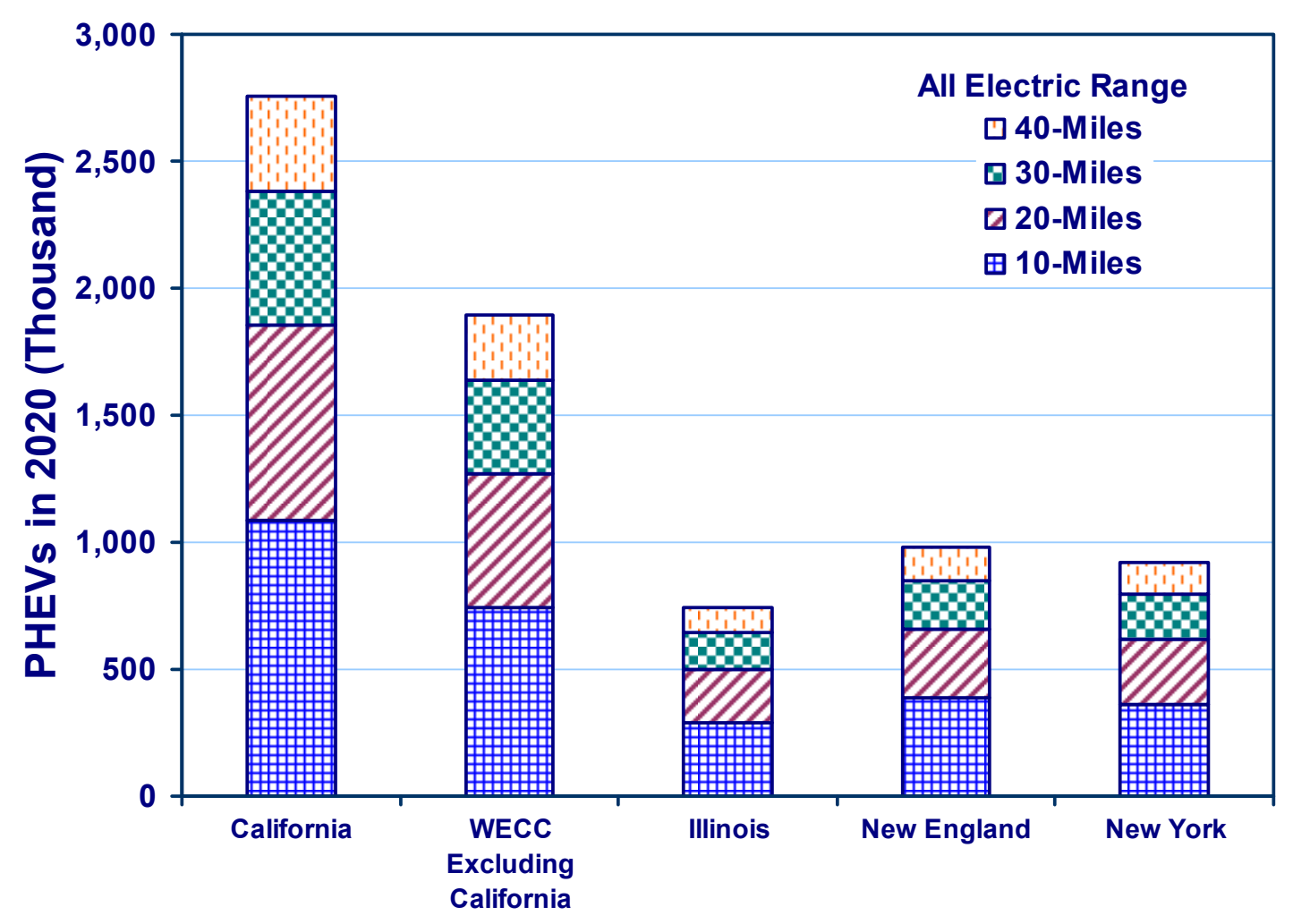

FIGURE 4.1 PHEV Populations by Simulated Utility Service Area in 2020

\subsection{PHEV CHARGING SCENARIOS}

PHEVs with various AERs were assumed to be charged once at the end of a day. Earlier PSAT simulations estimated that the per-charge energy requirements for the four PHEV AERs were $2.4 \mathrm{kWh}$ for a PHEV with a 10-mile AER, $4.8 \mathrm{kWh}$ for a PHEV with a 20-mile AER, 7.2 $\mathrm{kWh}$ for a PHEV with a 30 -mile AER, and $9.6 \mathrm{kWh}$ for a PHEV with a 40 -mile AER. The following three different charging scenarios were simulated:

1. Unconstrained charging,

2. Begin charging 3 hours after the hour in which the last trip ended, and

3. Smart charging to fill valleys in the daily utility demand profile.

We analyzed travel data from the 2001 NHTS to develop distributions of vehicles by the hour of day when the last vehicle trip ended. Because the travel data contained several trips by each vehicle, additional data processing was required. The vehicle trip data were sorted by household identification and vehicle number. We arranged all trips made by a vehicle according to time sequence and created one record for each vehicle. Each vehicle record contained important data items relating to the household, vehicle, and each trip. Finally, we analyzed the resulting file to arrive at distributions of vehicles by the last trip ending time for each area of interest, showing percent of vehicles that ended their last trip at a different time of day. Figure 4.2 shows weekday and weekend distributions of vehicles by last trip ending time for 
California's large MSAs (with a population of 1 million or more). Similar distributions were developed for each area of interest.

The demand for electricity varies by season. Seasons also seem to have some effect on vehicle usage patterns. We analyzed the vehicle usage data in the NHTS to develop distributions of vehicles by the last trip ending time for four quarters of the calendar year. Figures 4.3 through 4.6 show such distributions for large MSAs in California. The figures show some seasonal variations. During January-March (Figure 4.3), the last trip ending time shows a marked peak between 6:00 and 7:00 p.m. For April-June and July-September (Figures 4.4 and 4.5), the last trip ending time peaks between 5:00 and 6:00 p.m. For October-December (Figure 4.6), a nearly flat peak is observed over a three-hour period between 4:00 and 7:00 p.m. The vehicle shares at these peak time periods are also different, with the highest share observed during April-June.

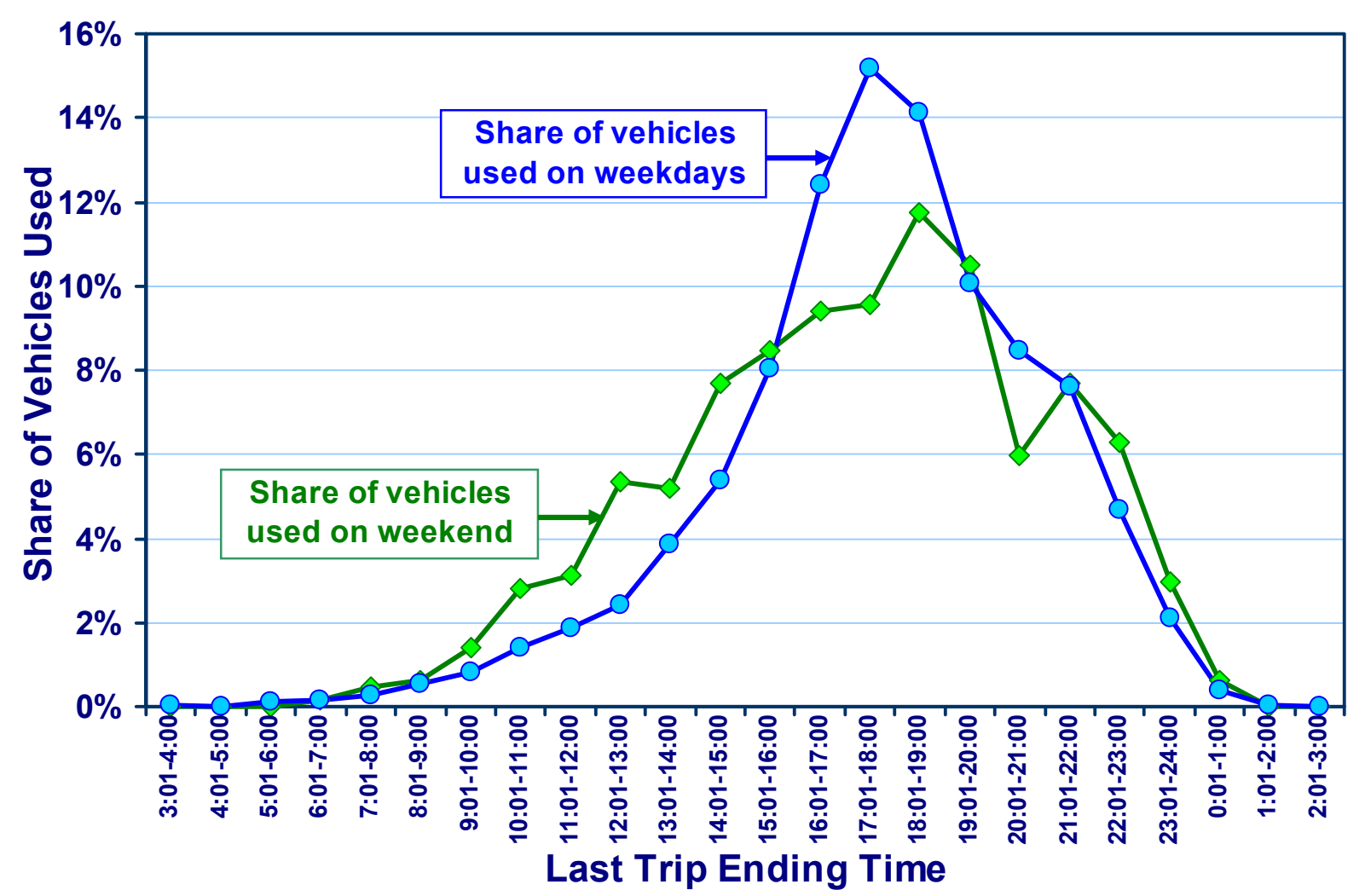

FIGURE 4.2 Distribution of Vehicles by Last Trip Ending Time for Large MSAs in California 


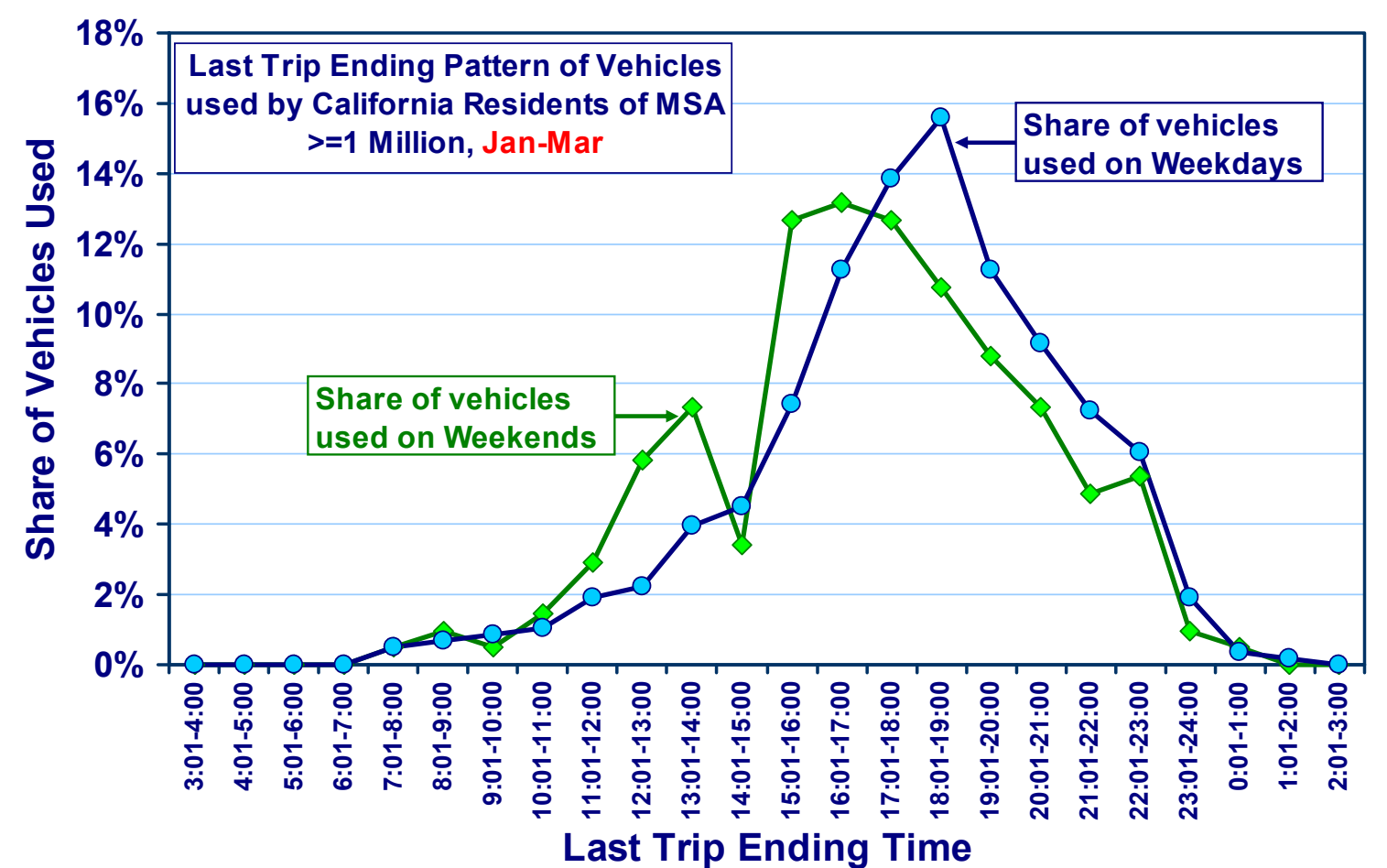

FIGURE 4.3 Distribution of Vehicles by Last Trip Ending Time for Large MSAs in California, January-March

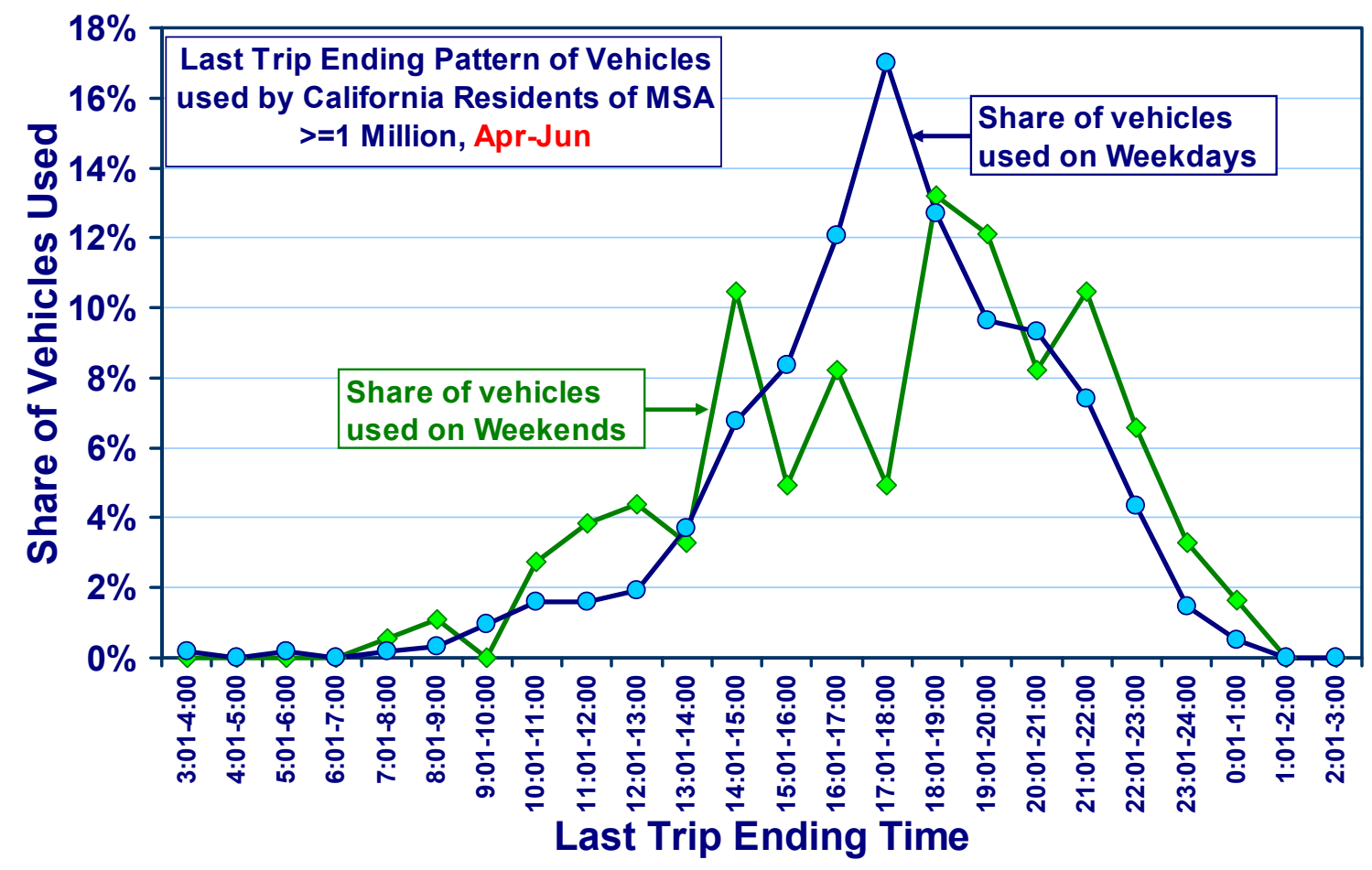

FIGURE 4.4 Distribution of Vehicles by Last Trip Ending Time for Large MSAs in California, April-June 


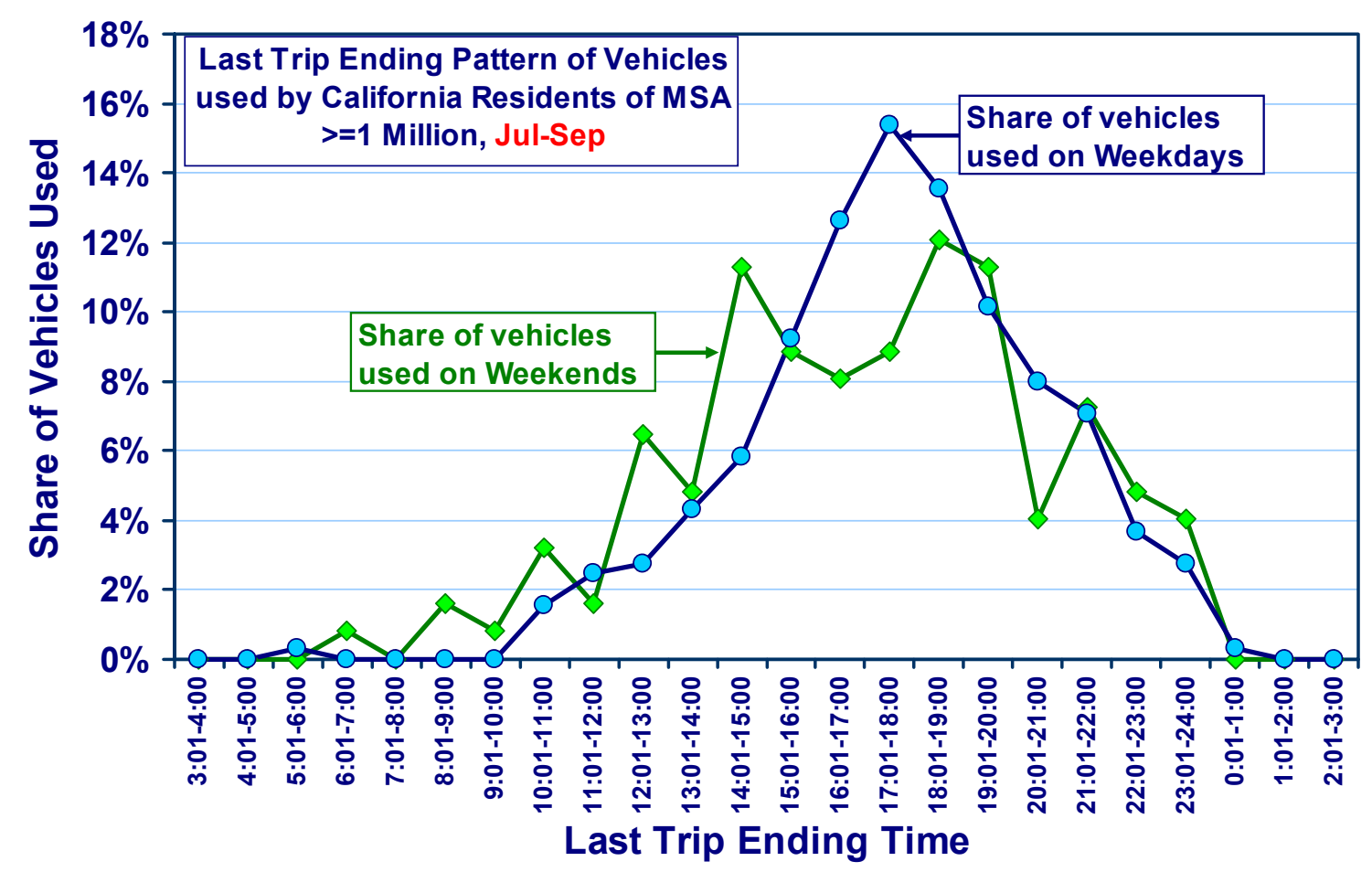

FIGURE 4.5 Distribution of Vehicles by Last Trip Ending Time for Large MSAs in California, July-September

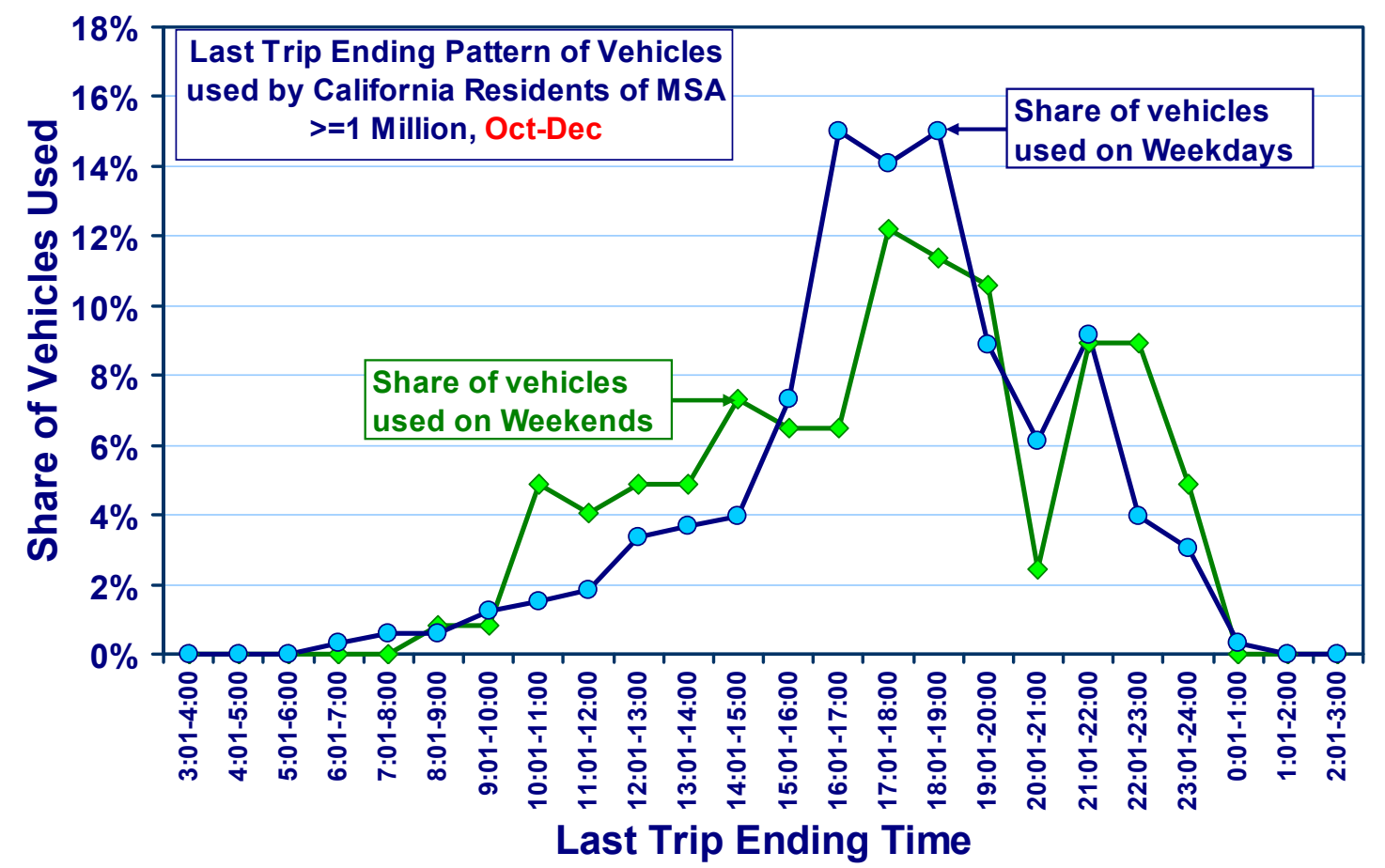

FIGURE 4.6 Distribution of Vehicles by Last Trip Ending Time for Large MSAs in California, October-December 
The next step was to determine the probable charging characteristics for PHEVs of each AER. The NHTS analysis showed that more than $60 \%$ of vehicles end their last trip after 5:00 p.m. and 70\% after 4:00 p.m. Also, 54\% of vehicles begin their first trip between 6:00 and 9:00 a.m. on weekdays. We employed these vehicle-use characteristics to estimate PHEV charging times for the four AERs.

As mentioned earlier, a PHEV with a 10-mile AER would need $2.4 \mathrm{kWh}$ to be fully charged after having depleted its battery pack to the lowest allowable SOC. This demand can be met easily by a $110-$ to $120-\mathrm{V}$ and $15-\mathrm{A}$ (12-A average output) circuit drawing $1.3 \mathrm{~kW}$ on average. A full charge would take nearly 2.1 hours. This estimate assumes a charger efficiency of $90 \%$ and a battery intake efficiency of $97 \%$. Modern chargers are designed to have a near-unity power factor.

The estimated electricity requirements were $4.8 \mathrm{kWh}$ for a PHEV with a 20-mile AER, $7.2 \mathrm{kWh}$ for a PHEV with a 30-mile AER, and $9.6 \mathrm{kWh}$ for a PHEV with a 40-mile AER. A PHEV with a 20-mile AER can be charged through a 110- to $120-\mathrm{V}$ and 15-A (12-A average output) circuit drawing $1.3 \mathrm{~kW}$ on average. A full charge would take 4.2 hours with a charger efficiency of $90 \%$ and a battery intake efficiency of $97 \%$.

A PHEV with a 30-mile AER can be charged through a 110- to $120-\mathrm{V}$ and 20-A circuit in 4.8 hours drawing $1.75 \mathrm{~kW}$, and a PHEV with a 40-mile AER can be charged through a 220- to $240-\mathrm{V}$ and 20 -A circuit in 3.3 hours drawing $3.5 \mathrm{~kW}$. The charger and battery efficiencies for the 220 - to $240-\mathrm{V}$ circuit were assumed to be slightly lower, at $87 \%$ and $95 \%$, respectively.

\subsection{SUMMARY OF PHEV POPULATION AND ELECTRIC LOAD ANALYSIS}

Argonne employed data from various sources in developing the vehicle-related quantitative inputs necessary for this study. Our analytical work can be summarized as follows:

- We estimated populations of PHEVs with 10-, 20-, 30-, and 40-mile AERs in each analysis region and used the U.S. Department of Transportation's NHTS and Highway Statistics publication, DOE's vehicle stock projection, and U.S. Census Bureau population projections.

- We developed distributions of vehicles by ending time of the last trip for each analysis region by using the U.S. Department of Transportation's NHTS.

- We analyzed seasonal variations in the distributions of vehicles by ending time of the last trip by using the U.S. Department of Transportation's NHTS.

- We estimated power demand and time required to charge PHEVs of different AERs and developed three different charging scenarios to evaluate the impacts of PHEVs on electric utilities. 


\section{ELECTRIC POWER SYSTEM DISPATCH}

Argonne's analysis included modeling of electric power systems in four regions of the United States: the New England Independent System Operator (NE ISO), the New York Independent System Operator (NY ISO), the state of Illinois, and the Western Electric Coordinating Council (WECC). The NE ISO is a regional electric balancing authority serving all of the states within the New England region, including Maine, Vermont, New Hampshire, Connecticut, Massachusetts, and Rhode Island. The NY ISO is a regional balancing authority serving all of the loads within the entire state of New York. WECC is a reliability council responsible for coordinating and promoting the bulk power system in all or portions of 14 western states. The State of Illinois is modeled as a single state.

Different modeling techniques and methodologies were used to simulate the electric power system dispatch in these regions on the basis of data that had been collected already on each region and of data that was readily available from public sources. This section will describe the modeling technique and methodology used in each region, the sources of the model's input data, the simulation results for each region and scenario, and key issues and major findings for each region/scenario.

\subsection{MODELING TECHNIQUE AND METHODOLOGY}

\subsubsection{NE and NY ISOs}

Only the generators and loads were modeled for both of these systems. Treating the model components this way assumes that the transmission system has no limitations; that is, it is capable of transmitting any amount of electricity from generators at point A to loads at point B. Therefore, the amount of electricity that a plant could generate at any time was not constrained by the capacity of the transmission lines to which it was connected.

The future generation mix was estimated by simulating the operations of thermal and renewable power plants in each region. Because hydropower provides a small but not insignificant portion of the electric generation in both regions, special attention was paid to interdependencies among hydropower and thermal power plant operations. Hydropower plants currently provide almost $20 \%$ of the generation in New York and about 5\% in New England. Generation from wind power plants was also estimated for both regions. However, wind power currently provides less than $1 \%$ in New York and about $0.2 \%$ in New England.

Thermal power plants were simulated at the unit level. A probabilistic dispatch model was used to simulate thermal power plant production to meet load that is not served by hydropower plants and other renewable resources, such as wind power. The thermal dispatch model was run in the monthly load duration curves (LDCs) mode. In this mode, monthly average capacity factors and generation levels were obtained for each unit in the inventory. Maintenance 
and random forced outages were accounted for at the unit level. Data for unit characteristics came from both ISO and EIA sources.

Hydropower plant generation is determined on an hourly time-step basis. Hydropower is simulated as an aggregate generation resource that serves both base load and peaking duties. Information is compiled for the aggregation from individual plant-level data. The hourly dispatch of the aggregate power plant is based on (1) monthly generation control totals, (2) the amount of water used for base load duties, (3) estimated monthly hydropower capability, and (4) an hourly load profile for each ISO service territory. Section 5.3.1 describes the methodology used to calculate base and peak generation from hydropower in greater detail.

Wind turbines are a nondispatchable resource, meaning that the operator has no control over when the wind turbine generates electricity; turbines generate when the wind is blowing and feed electricity into the grid. Data from the National Renewable Energy Laboratory (NREL) Web site were used to estimate electricity generated from wind turbines. Section 5.3.1 describes the methodology used to calculate electricity generated from wind turbines in greater detail.

Solar power is miniscule in both the NE ISO and NY ISO, and so it was ignored in the study. Other plants using renewable fuel sources (such as geothermal, municipal solid waste, wood, and biomass) were included in the thermal dispatch model because operators can control when these plants produce power. These plants can be dispatched as necessary as opposed to wind or non-storage hydroelectric sources.

An hourly electricity demand profile was constructed from historical hourly demand profiles available on each ISO's Web site (New England, www.iso-ne.com; New York, www.nyiso.com). Forecasts of monthly peak loads and energy use for 2020 were also obtained from forecasting documents available on the two ISOs' Web sites.

The modeling methodology for both regions used several modeling tools. The sequence of operations in the methodology is as follows:

1. Collect and process data and information;

2. Determine hourly generation from renewable resources, including dispatchable and nondispatchable aggregate hydropower and other nondispatchable plants, such as wind;

3. Determine current hourly electricity loads and forecast future load levels;

4. Adjust loads for nondispatchable renewable generation and hydropower plant generation by subtracting nondispatchable renewable generation and peak shaving dispatchable hydropower (such as plants with storage reservoirs or pumped storage plants);

5. Develop a baseline plant inventory for 2020 ; 
6. Run a probabilistic thermal dispatch model to estimate electricity generation by thermal generation units for 2020 ;

7. Obtain monthly unit-level generation values and compute capacity factors;

8. Develop alternative PHEV scenarios;

9. Develop a capacity expansion plan for 2020 to meet additional loads from PHEVs, starting with baseline expansion plan from step 5;

10. Run probabilistic dispatch model for the different scenarios to obtain unit-level generation and compute capacity factors for 2020; and

11. Compare and summarize results.

The source of data for the steps in the above process is described in Section 5.3.

\subsubsection{WECC}

The WECC system encompasses a large geographic area in the western United States; it covers all of the states west of the Rocky Mountains. Because the WECC system's area extends so widely and is known to have transmission congestion issues, its system topology was simulated in finer detail for this study. The transmission system was modeled as a system of nodes, with both loads and resources aggregated at each node. The nodes had links to approximate the flow of power over transmission lines in WECC. Limits were placed on the amount of energy that could be transferred over those links to approximate actual transmission line constraints. For this study, the U.S. portion of WECC consisted of 23 nodes; there were also links to nodes in Canada and Mexico and to other reliability councils in the United States. Figure 5.1 shows the WECC system topology.

The Generation and Transmission Maximization (GTMax) model, developed by Argonne, simulated the operation of both dispatchable and nondispatchable resources and power transfer limitations of the transmission system. Additional details about this model are provided in Section 5.6.2.

Thermal power plants and dispatchable renewable generators, such as geothermal, municipal solid waste, wood, and biomass, were simulated at the unit level. Data for unit characteristics were obtained from both EIA and WECC sources.

Hydroelectric power plays a key role in the WECC system; it can provide as much as $40 \%$ of the WECC load during wet hydrological conditions. Hydroelectric plants were modeled on a plant-level basis. They were assigned to specific nodes within the network, and generation was derived from historical data available in Form EIA-906. Section 5.3.2 describes the methodology used to calculate generation from hydropower in greater detail. 


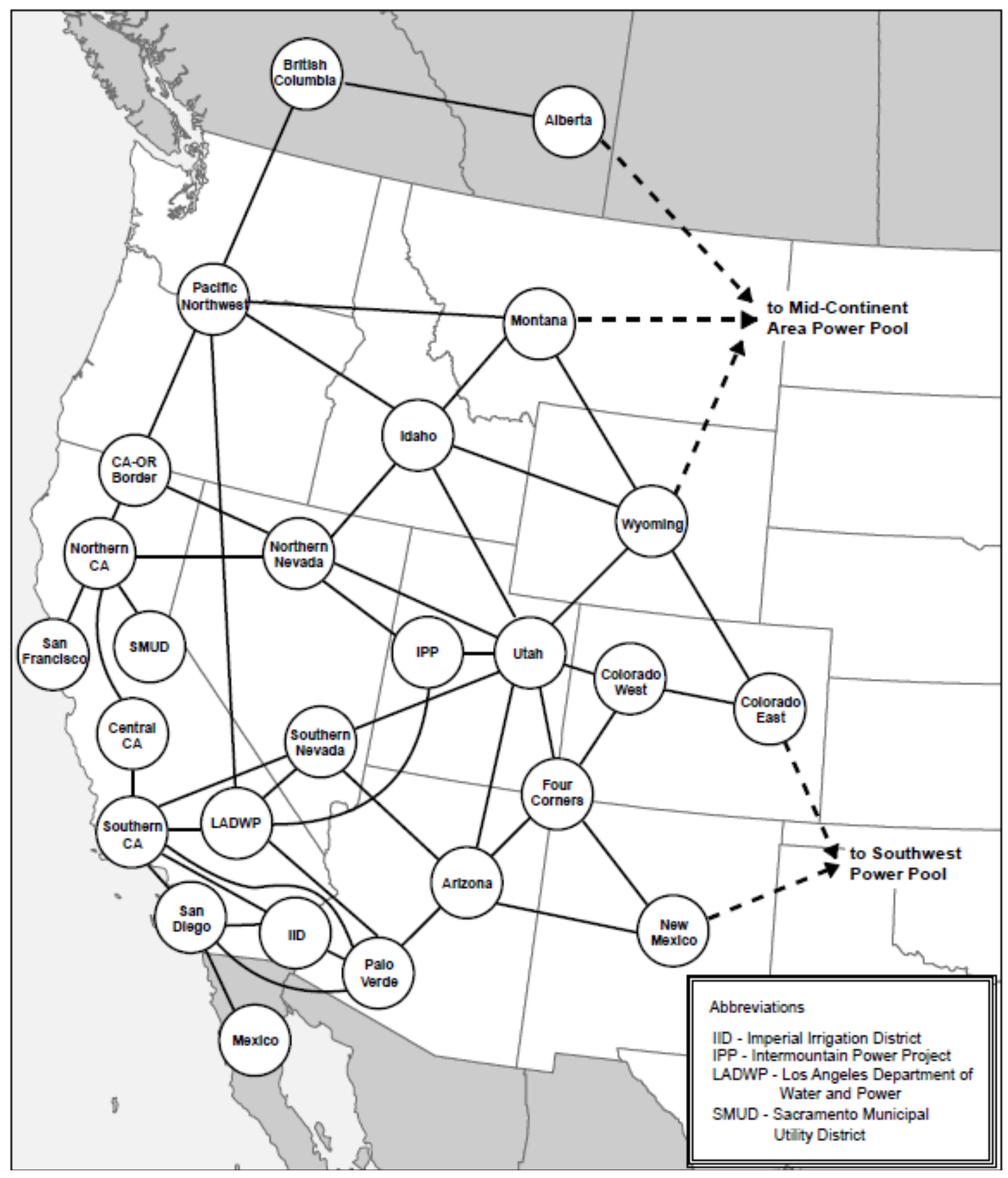

FIGURE 5.1 WECC Network Topology 
Generation from wind and solar plants, both of which are nondispatchable sources, also plays a role in the WECC system. Data from the NREL Web site was used to estimate electricity generated from both wind turbines and solar generators. Section 5.3.2 describes the methodology used to calculate electricity generated from wind and solar in greater detail.

An hourly electricity demand profile was constructed from hourly demand data available from WECC. Forecasts of monthly peak loads and energy use for 2020 were also obtained from forecasting documents available from WECC and supplemented by data from EIA Form-411.

\subsubsection{State of Illinois}

To explore the effect(s) on the transmission system more fully when serving increased loads from PHEVs, the State of Illinois was modeled in the greatest level of detail (i.e., at the bus level). A bus is defined as a nodal point in a transmission system - typically a point at which major loads and generating resources connect. Buses are connected to each other via transmission lines. The Illinois system consisted of more than 1,900 buses and more than 2,500 transmission lines. Figure 5.2 shows the topology of the Illinois electric power system.

In addition to the in-state transmission configuration, the power transfers into and out of Illinois were accounted for in order to obtain an accurate picture of how its electric system would perform. All of the tie lines between Illinois and surrounding states were identified and aggregated into a small set of interconnection points. Eleven interconnection points covered an area including Indiana, Michigan, and parts of Ohio in the east, Tennessee in the south, parts of Missouri served by the Ameren and AECI utilities in the southwest, Iowa and parts of Minnesota in the west, and Wisconsin in the north. These out-of-state connections are also shown in Figure 5.2.

The Electricity Market Complex Adaptive Systems (EMCAS) model, developed by Argonne, was used to simulate operation of the Illinois electric system, including all generating resources and transmission line constraints. EMCAS uses an agent-based modeling structure to simulate the operation of the different entities participating in the electricity market. Additional detail on this model is provided in Section 5.6.3.

Hydroelectric power plays a miniscule role in Illinois's power system, where only one small plant feeds electricity into the Illinois grid. Section 5.3.3 describes in greater detail the methodology used to calculate electricity generated from this unit.

Wind power is likely to play a large role in Illinois by 2020. Data from the NREL Web site were used to estimate electricity generated from wind. Section 5.3.3 describes the methodology used to calculate electricity generated from wind in greater detail.

An hourly electricity demand profile was constructed from hourly demand data available from the Federal Energy Regulatory Commission (FERC) Form 714. Forecasts of monthly peak loads and energy use for 2020 were extrapolated from data available on the PJM Interconnection and Midwest Independent Transmission System Operator (MISO) Web sites. 


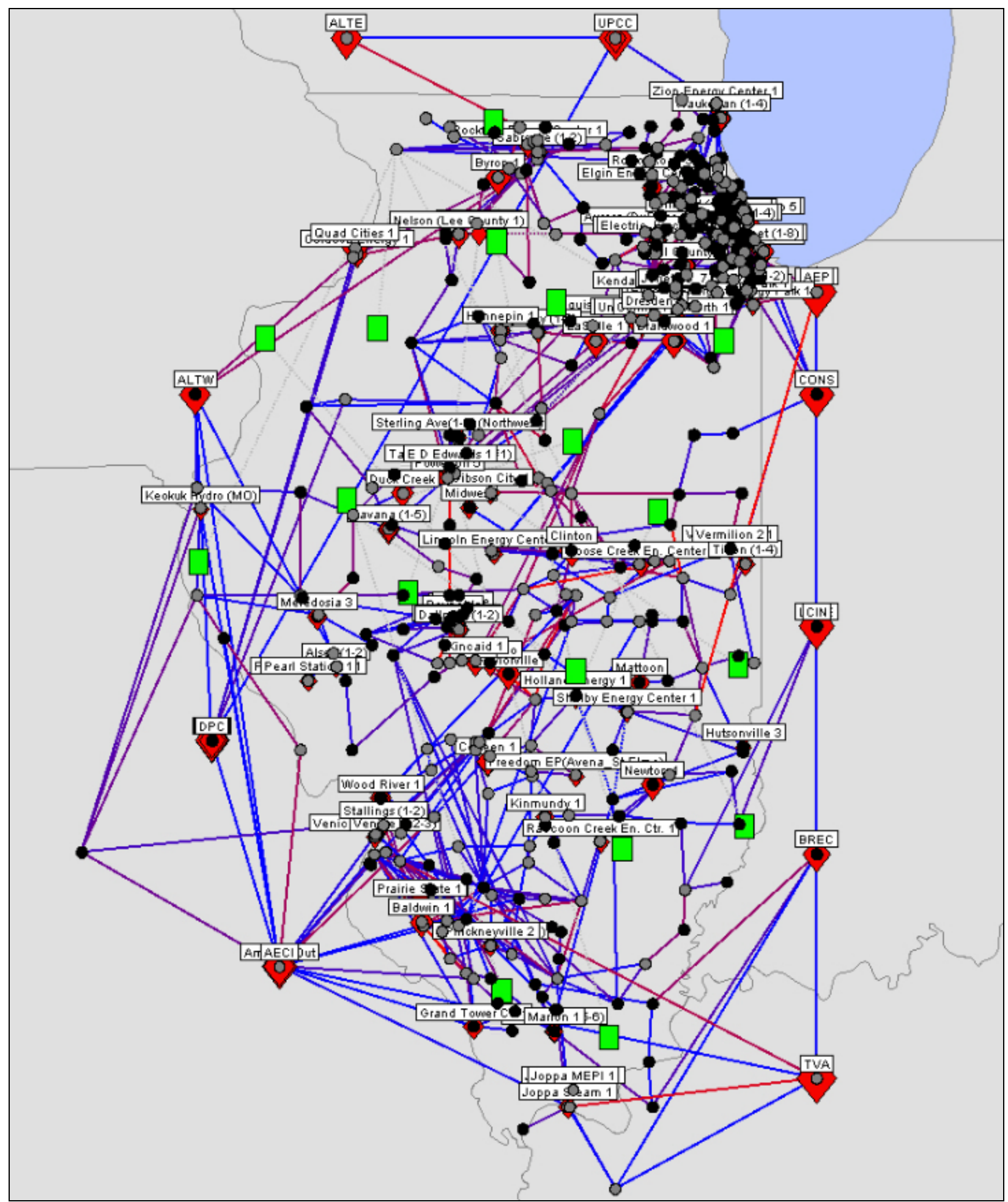

FIGURE 5.2 State of Illinois Network Topology 
Thermal power plants were simulated at the unit level. Data for unit characteristics were obtained from EIA and utility sources.

\subsection{DATA COLLECTION AND PREPARATION}

The baseline analysis makes use of information from an extensive set of sources. Underlying data were compiled from various sources; a considerable data validation effort helps to ensure data consistency. The following is a list of the information sources used to compile the inventory of existing and proposed power plants, hourly load profiles, load projections, fuel price projections, and technology data.

\subsubsection{Inventory of Existing and Proposed Power Plants}

- Form EIA-860 (Annual Electric Generator Report 2007) (EIA 2007) 2008-2017 Capacity, Energy, Loads, and Transmission Report (NE ISO 2008a) - for NE ISO data 2008 Load and Capacity Data "Gold Book" (NY ISO 2008b) — for NY ISO data

- Identifies the generator location

- Identifies the generator owner(s)

- Provides information on summer and winter generating capability

- Identifies the type of primary mover

- Identifies the fuel type(s) used by the generator

- Form EIA-423 (Monthly Cost and Quality of Fuels Report 2007) (EIA 2007)

- Provides information on the price of the fuel(s) used by generator

- Provides information on the sources of the fuel(s) used by the generator

- Provides information on the quality of the fuel(s) used by the generator (e.g., sulfur content, ash content, and higher heating value)

- Form EIA-906 (Power Plant Report 2007) (EIA 2007)

- Provides information on monthly fuel consumption levels by generator

- Provides information on monthly generation levels by generator

- Used to compute generator heat rates

- North American Electric Reliability Corporation (NERC), Generating Availability Data System (GADS) (NERC 2008)

- Provides scheduled maintenance outage rates by type of technology

- Provides random outages by type of technology

- Power plant expansion plans from regional transmission organizations (RTOs)

- MISO Web site (www.midwestiso.com)

- PJM Interconnection Web site (www.pjm.com) 


\subsubsection{Historical Load Data}

- NE ISO Web site (www.iso-ne.com)

NY ISO Web site (www.nyiso.com)

MISO Web site (www.midwestiso.com)

PJM Interconnection Web site (www.pjm.com)

Data used to prepare the WECC 2007 Transmission Expansion Planning and

Policy Committee (TEPPC) Annual Report (TEPPC 2008)

FERC Form 714 (Annual Electricity Balancing Authority Area and Planning Area

Report) (FERC 2009)

- Provides information on hourly load data for the entire region and various subregions

\subsubsection{Load Projections}

- $\quad$ NE ISO Web site (www.iso-ne.com)

NY ISO Web site (www.nyiso.com)

Data used to prepare the WECC 2007 TEPPC Annual Report (TEPPC 2008) - received from WECC in April 2009

Form EIA-411 (Coordinated Bulk Power Supply Program Report) - WECC load forecasts

FERC Form 714 (Annual Electricity Balancing Authority Area and Planning Area Report) (FERC 2009)

- Provides data used to make annual load projections for 2020

\subsubsection{Fuel Price Projections}

- Annual Energy Outlook 2009 (EIA 2009a) projections

- Provides annual fuel price escalation rates by fuel type until 2030

\subsubsection{Expansion Candidate Technology Data}

- Assumptions to the Annual Energy Outlook 2008 (EIA 2008)

- Provides information on technical and economic performance parameters of representative power-generation technologies

\subsubsection{Wind and Solar Data}

- $\quad$ NREL/3TIER Western Wind Resources Dataset (NREL 2009a)

NREL Eastern Wind Dataset (NREL 2009b)

- Has locations of wind power monitoring sites and historical time series of observed wind power 
- National Solar Radiation Database (NREL 2009c)

- Has locations of wind power monitoring sites and historical time series of observed wind power

\subsection{TREATMENT OF RENEWABLE GENERATION (HYDRO, WIND, AND SOLAR)}

\subsubsection{NE and NY ISOs}

It was assumed for both systems that generation from wind turbines, which are nondispatchable, will always serve load before hydropower and dispatchable renewable and thermal power plants. Solar generation is not modeled because little if any capacity is expected to be in service by 2020 in either region. Generation supplied by wind turbines is subtracted from system loads, and remaining loads will be served by hydropower plants and dispatchable renewable and thermal power plants, in that order.

Hourly wind generation for the simulation year was estimated from data on the NREL Web site (NREL 2009b). NREL has collected wind speed data at 10-minute intervals for numerous sites around the United States. The dataset also estimates electric generation output for those wind speeds on the basis of a power curve for a wind turbine of a standard capacity. The data can be scaled up or down depending on the wind capacity installed at that site. Because wind turbines in both the NE ISO and NY ISO make up a very small percentage of the total installed capacity, one site for each region was used to represent the wind generation for the entire region. The hourly wind profile from 2005 was used to develop generation from wind in both New England and New York in 2020. The hourly wind generation is subtracted from the hourly ISO load.

After wind turbines, hydropower plants are the next group of units to serve load, so their patterns of hourly generation were estimated next. To model the hourly generation pattern from dispatchable hydropower plants (i.e., plants with reservoirs or storage capabilities), a peak shaving approach was used, as follows: monthly hydropower generation patterns were estimated for individual hydropower plants by using information from the two ISOs' Web sites and Form EIA-906. Data from various sources were also used to disaggregate power plant capabilities obtained from Form EIA-860 into base load and peaking duties. Total monthly hydropower generation levels and plant capabilities were then computed. Next, the hourly hydropower dispatch was simulated by using a peak shaving algorithm that minimized the peak load

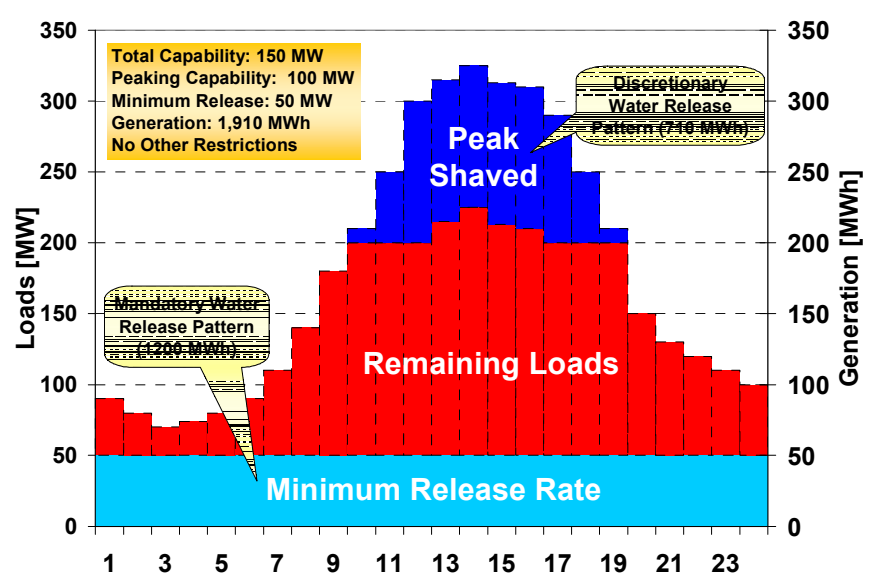

FIGURE 5.3 Hydropower Plant Operations 
that the thermal system must serve, subject to monthly hydropower capacity and energy constraints, spinning reserve duties, hourly ramping constraints, and daily change limitations (see Figure 5.3). The loads remaining after peak shaving were input to the thermal dispatch model.

\subsubsection{WECC}

Because hydropower provides a significant portion of electric generation in WECC, this resource was modeled carefully in GTMax. Hydroelectric power was modeled on a plant-level basis; each plant was assigned to a specific node in the network on the basis of WECC data. Historical data from 1985 to 2005 in Form EIA-906 were used to develop an average monthly capacity and energy value for each plant. Plants were categorized as providing baseload generation (run-of-river plants), intermediate generation, or peaking generation. This information was used to determine the amounts of both capacity and energy that would be available at different times during the day. The data were summed for each node and input to the GTMax model.

Wind and solar supply a smaller — but still significant — amount of electricity in WECC. An inventory of wind and solar power plants was developed from EIA and WECC data. This data identified capacity additions up to 2011. Projections of wind and solar capacity additions from 2011 to 2020 were obtained from data in AEO 2009 (EIA 2009a). Capacity projections were specified in each of four WECC subregions. Capacity was then assigned to specific nodes on the basis of the node's proportion of new capacity within the subregion.

Hourly wind and solar power profiles were developed from data available on the NREL Web site. The NREL/3TIER Western Wind Resources Dataset was used for wind (NREL 2009a), and the National Solar Radiation Database (NREL 2009c) was used for solar. Data are available for numerous sites throughout the United States. Each dataset estimated electric generation output for a wind or solar generating unit of a specific size based upon its performance curve. The data were then scaled to the amount of wind and solar capacity assigned to each node. Because nodes covered a wide geographic area, the generation at each node was represented by the average of two sites that were highly rated for their wind potential and located in different areas within the node. Wind and solar profiles from 2005 were used to develop generation from both resources for WECC in 2020.

\subsubsection{State of Illinois}

The Illinois electric system has only a single hydroelectric power plant, which is located near Keokuk, Iowa, on the Mississippi River. It has no reservoir storage and is considered a runof-river plant. It has an installed capacity of about $112 \mathrm{MW}$. Because this plant contributes only a small amount to the total Illinois generation, the plant was modeled as a thermal plant with fuel costs equal to zero. Its capacity was set to $36 \mathrm{MW}$, which approximated the average capacity factor of the plant. 
The State of Illinois has enacted a Renewable Portfolio Standard (RPS), which specifies through 2025 that an annually increasing amount of electric generation must be obtained from renewable resources. In 2020, the RPS calls for $17.5 \%$ of Illinois's energy to be supplied by renewable resources, with a minimum of $75 \%$ coming from wind and $1 \%$ coming from solar photovoltaic (PV). Because only a negligible amount of solar will be required by then, solar energy was not modeled in this study. Although hydropower counts toward satisfying the RPS requirement, the amount of hydropower in Illinois is miniscule. Therefore, it was decided that wind alone would be used to comply with the RPS.

Using the NREL wind dataset, a site with strong wind potential was chosen from each of four general geographic regions in Illinois (north, central, east, and west) to represent output from wind turbines located in that region. NREL data showed hourly generation output at each site for a wind turbine of a specific size. The hourly wind profile from 2005 was used to develop generation from wind for 2020. Knowing the load profile for 2020, the hourly wind energy in each region, and the RPS goal, an iterative technique was used to "build" new wind capacity to meet the RPS goal. An initial determination of the wind turbine capacity installed in each geographic region was made such that the annual generation summed from all regions and all hours met the annual RPS goal. This regional wind capacity was then placed geographically at existing wind project sites and at proposed sites that have been publicly announced (IWEA 2009). Wind turbines were connected to the grid at the nearest bus in the EMCAS topology. If several buses were in close proximity to the wind site, the total wind turbine capacity was divided equally among all nearby buses.

After placing the total installed wind turbine capacity, EMCAS was run to investigate the amount of wind output that would be curtailed because of transmission congestion issues. Where moderate congestion was observed, transmission line capability was increased by an amount equal to the line's capacity or 1,000 MW, whichever was smaller. Where excessive curtailment was observed, wind capacity allocations were revised, moved to a different location, and/or connected to a different bus. Several wind turbine capacity allocations and transmission line capacity adjustments were made so that there was only a minor amount of wind curtailment in the final configuration chosen for use in EMCAS.

\subsection{DEVELOPING LOAD PROFILES}

\subsubsection{NE and NY ISOs}

Figure 5.4 shows the process used to develop hourly load data for 2020 for both ISOs. Historical hourly load data and future load forecasts were available on each ISO's Web site.

Historical loads from 2000 to 2008 were used for the New England ISO and from 2001 to 2008 for the New York ISO. A model was used to determine which of those historical years was most representative; that year was then used as the load shape for 2020. 


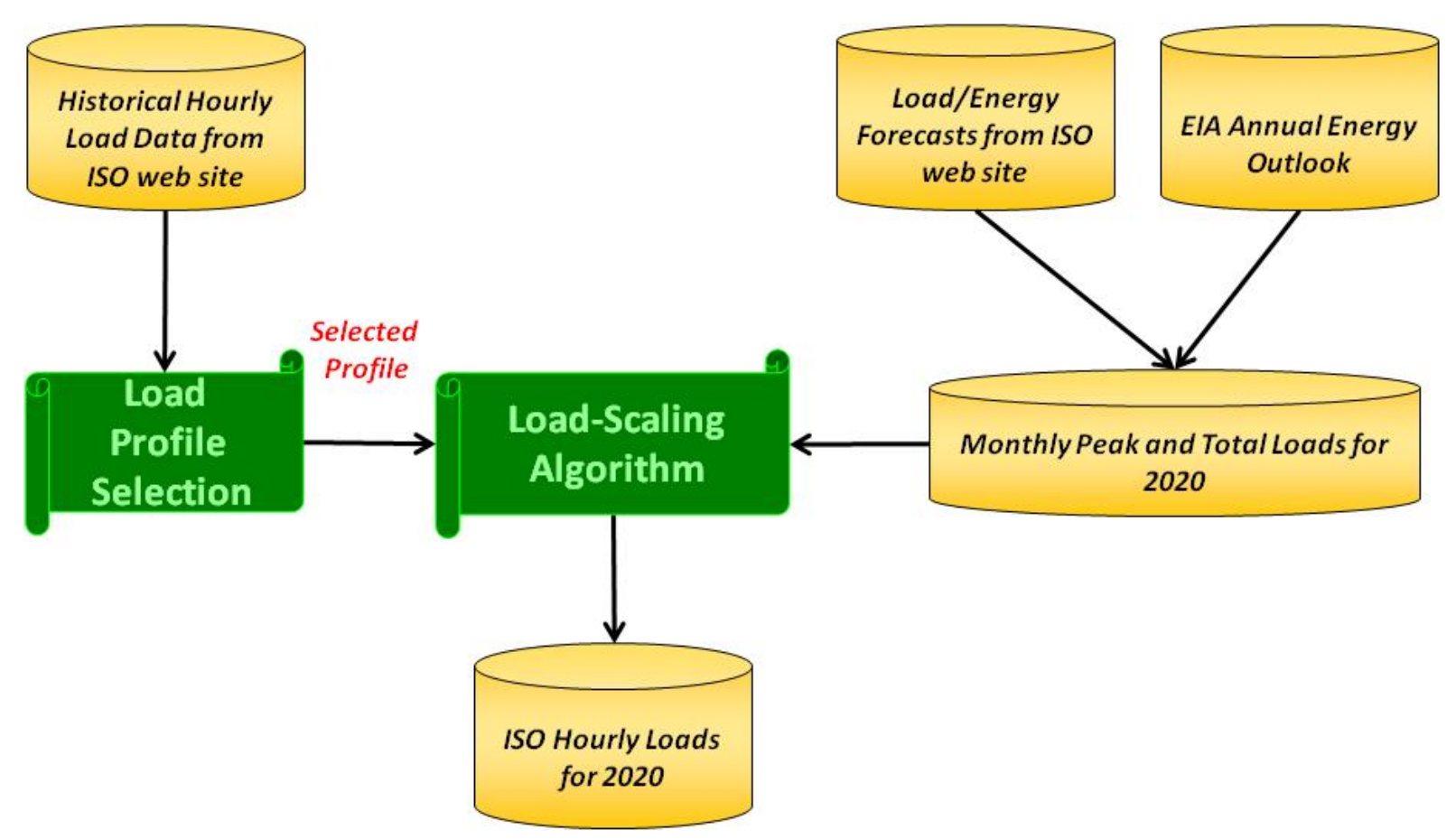

FIGURE 5.4 Developing an Hourly Load Profile for the NE and NY ISOs

The model first calculated an average hourly load for all hours in a year based upon the historical year's input. After computing an average hourly load profile, the model compared each hour's average to the corresponding hour from each input historical load profile. The year that had the lowest sum of squared differences relative to the average year was chosen to represent the hourly load profile for 2020 .

Forecasts of monthly peak loads and energy were also derived from forecast documents on each ISO's Web site. A load-scaling algorithm was used to adjust the representative hourly load profile so that it would exactly match the forecast monthly peak and total load values for 2020 .

\subsubsection{WECC}

Hourly load data projections were available from WECC for 2017. The Transmission Expansion Planning Policy Committee (TEPPC) within WECC produces an annual Synchronized Study Plan (TEPPC 2008). This data and data from EIA Form-411 were used as the basis to construct hourly loads for each of the 23 nodes in the WECC network.

Figure 5.5 shows the process used to develop hourly data for the WECC network. Because the hourly data were projected for the year 2017 and were disaggregated for a different number of nodes (i.e., 42 versus 23 used in this study), two conversions were needed. First, the 


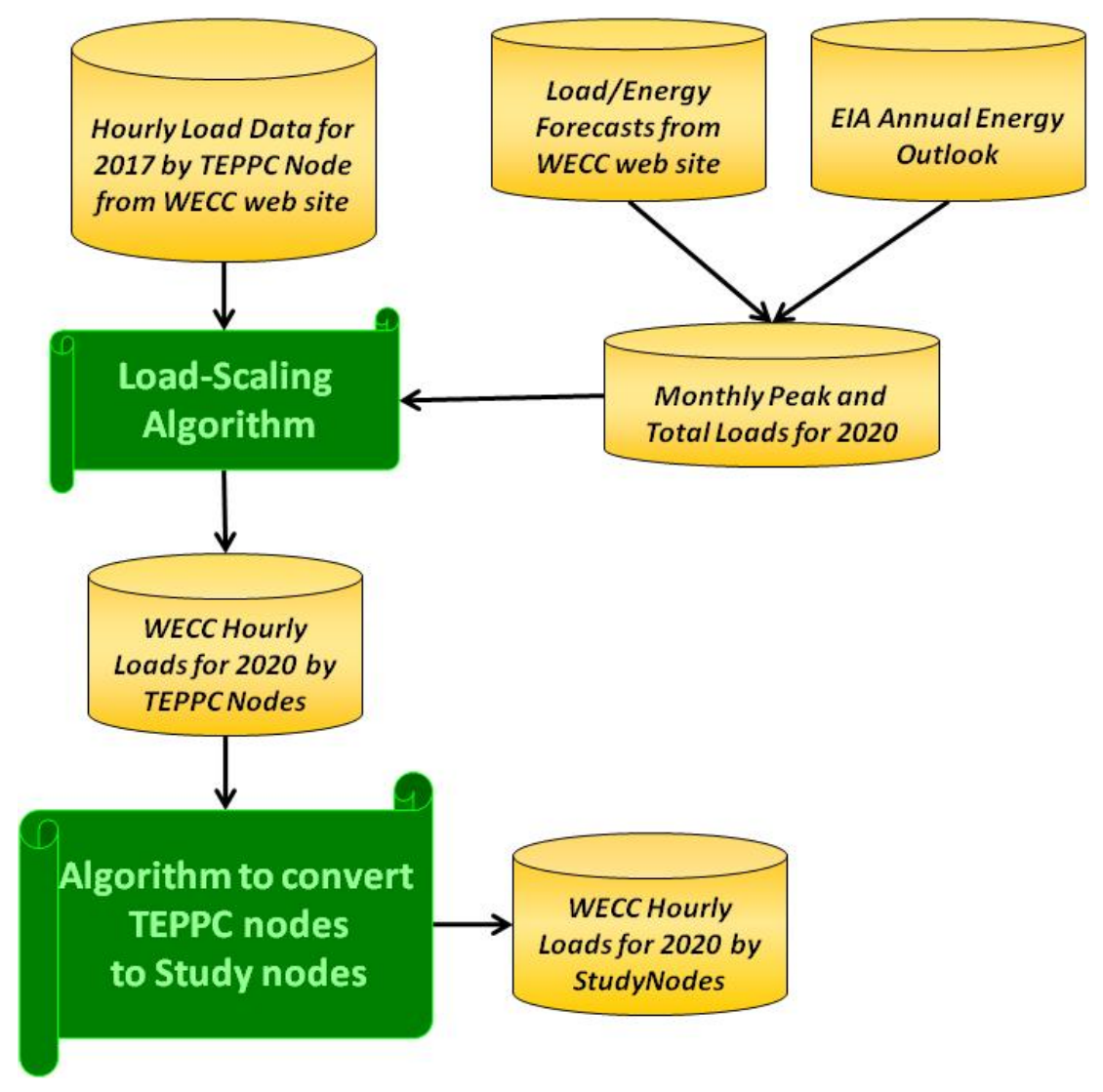

FIGURE 5.5 Developing Hourly Load Profiles for Nodes in WECC

hourly data for the 42 nodes were projected from 2017 to 2020. A load-scaling algorithm with load projections from WECC and EIA's Annual Energy Outlook (EIA 2009a) was used to exactly match the forecast monthly peak and total load values for 2020.

Loads from the TEPPC nodes were then reallocated to the nodes in the study. Of the 42 TEPPC nodes, 39 were inside the United States, two were in Canada, and one was in Mexico. In both nodal systems, the foreign nodes were identical. There were seven study nodes that matched up to TEPPC nodes on a one-to-one basis. Four of the study nodes encompassed two or more TEPPC nodes entirely. In these cases, the hourly loads from the TEPPC nodes were summed to form the hourly load profile for the study node.

There were eight study nodes that had no exact match for TEPPC nodes. For these cases, data from WECC publications posted on its Web site were used to allocate fractional portions of loads in TEPPC nodes to study nodes. For example, one study node may consist of $88 \%$ of the load from one TEPPC node and 50\% from another TEPPC node. Therefore, fractions of hourly loads were summed to form the hourly load profile for those study nodes. 


\subsubsection{State of Illinois}

Hourly load data for each bus was developed by first generating an hourly load profile based upon historical data and then scaling that to match 2020 load and energy use projections. As part of the original study for the Illinois Commerce Commission (ICC) (Cirillo et al. 2006), hourly data were obtained from FERC Form 714, which contains total control area loads for all hours of an historical year. This form also contains 10-year forecasts of seasonal peak loads and total annual loads. To project hourly loads for a control area for the year 2007, historic hourly loads were scaled such that the total annual load and both summer and winter peaks match the Form 714 projection. This method produces results that exactly match the annual load factor predicted by the reporting control areas.

Hourly loads at a bus are based on a bus distribution factor (BDF) that indicates the portion of the total control area load assigned to that specific bus. The BDFs remain constant throughout the simulation year and are based on input data for a peak load day using the PowerWorld Simulator. PowerWorld Simulator is an interactive power system package designed to simulate high-voltage power system operation. A BDF is multiplied by the hourly control area load to obtain the hourly bus load; that is, the FERC Form 714 data that were scaled to the projection year. This methodology assumed that the relative load contribution that a bus makes to the control area total is constant throughout the year and will not change in the future. (Those assumptions are reasonable for this type of study.) The procedure is described in greater detail in Cirillo et al. (2006).

In order to extrapolate the load data for 2007 to year 2020, we first adjusted the 2007 load data based on historical electricity sales from Illinois for that year. We then used peak load forecasts from ComEd and the central region of the MISO to extrapolate the loads to 2020 by multiplying the original hourly loads with a constant growth rate. In total, the hourly loads for the ComEd region and the rest of Illinois were assumed to increase by $31 \%$ and $19 \%$, respectively, compared to the original study of Illinois. The growth rate for loads outside of the state was assumed to be the same as for the rest of Illinois (i.e., 19\%).

\subsubsection{Forecasting PHEV Loads}

For each study region, a set of three PHEV charging load profiles was developed; an "unconstrained" scenario, a "constrained" scenario, and a "smart charge" scenario. Each profile specifies the hourly amount of energy needed to charge PHEVs. This section describes how these PHEV charging load profiles were developed. Load profiles for PHEV charging were developed for a typical week in each of four seasons. PHEV charging loads were added to the baseline scenario loads to determine the final load profiles for each scenario. It should be noted that while each of the three scenarios use different amounts for PHEV hourly loads, the total weekly PHEV load is the same.

Data used to calculate the PHEV charging profiles were presented in Chapter 3 and include: (1) projections of the number of cars and SUVs on the road in each region; (2) the hourly distribution of household vehicles arriving home after their last trips of the day; and 
(3) the time required to charge PHEVs depending upon battery size. PHEVs were assumed to comprise $10 \%$ of the vehicle fleet in 2020 .

The number of vehicles on the road in each region was disaggregated by subregion based upon U.S. Census data. In New England, data were aggregated for the whole region. In New York, vehicle data were divided into the number of vehicles in the New York City metropolitan statistical area (MSA) and the number of vehicles outside of New York City. In WECC, vehicle data were divided into four WECC subregions: (1) California MSAs having a population greater than 1 million; (2) vehicles in California MSAs having a population less than 1 million, including rural areas; (3) vehicles in MSAs within WECC but outside of California; and (4) vehicles in non-MSAs within WECC but outside of California. In Illinois, vehicle data were divided into the number of vehicles in the Chicago MSA and the number of vehicles in the rest of Illinois.

PHEV charging loads were generated for a typical week in each of four seasons. To generate hourly load profiles for the scenarios with PHEVs, seasonal PHEV hourly loads were added to the baseline loads for that season.

\subsubsection{Unconstrained Scenario}

This scenario assumes that charging begins as soon as PHEVs arrive home after the final trip of the day. The number of PHEVs by battery size was determined from the number of conventional vehicles in a region and the distribution of PHEVs by battery size.

The hourly PHEV charging load is the sum of the load from PHEVs that arrived home in that hour plus the load from PHEVs that arrived home in previous hours. Depending upon the PHEV range (or battery type), a PHEV arriving home 1 to 4 hours earlier would still be charging. Another consideration is that in the final hour of charge, the amount of energy needed is less than that required in earlier hours. Therefore, a multiplier is used to modify the energy needed in the final charging hour compared to earlier hours.

To determine PHEV charging load from vehicles that have arrived home, the total number of PHEVs on the road by battery type is multiplied by the charge fraction. The charge fraction is the distribution of vehicles arriving home after the last trip of the day for an entire day. The charge fraction varies by season and type of day; namely, by weekday and weekend day. Then, the number of vehicles arriving home in that hour is multiplied by the energy needed to charge those vehicles. This multiplier varies by the type of electric service used at a household; namely, voltage (V) and amperage (A). It was assumed that PHEV10 and PHEV20 owners have 110-V, 15-A service; PHEV30 owners have 110-V, 20-A service; and PHEV40 owners have $220-\mathrm{V}, 20-\mathrm{A}$ service.

To account for transmission losses and determine the load that the electric system must serve, the PHEV hourly charging sum is divided by the transmission and distribution loss factor. That factor varies by region, and the values used in this study are shown in Table 5.1. 
TABLE 5.1 Transmission and Distribution Losses by Region

\begin{tabular}{lc}
\hline \multicolumn{1}{c}{ Region } & $\begin{array}{c}\text { Transmission \& } \\
\text { Distribution Loss } \\
(\%)\end{array}$ \\
\hline New England ISO & 6.55 \\
New York ISO & 6.55 \\
Illinois & 5.54 \\
California & 7.96 \\
WECC, excluding California & 7.57 \\
\hline Source: EIA (2009b). &
\end{tabular}

For the NE ISO case, the hourly PHEV charging profile was added to the baseline load profile to determine the hourly load profile for this scenario. For the NY ISO case, hourly profiles were developed for vehicles in the New York City MSA and for vehicles in the rest of New York state. Both profiles were added to the baseline load profile to determine the hourly load profile for this scenario.

In the WECC case, load profiles were developed for vehicles in each of the four subregions. A methodology was developed to assign PHEV loads to appropriate nodes in the network. The 23 nodes were grouped into three categories: namely, California urban, California rural, and rest of WECC (i.e., no distinction between urban and rural). In California, it was clear which nodes were urban and which rural; in the rest of WECC, however, some nodes had characteristics of both profiles because of the fact that those nodes represented a wider geographic area than those in California.

The PHEV charging load profiles developed for California urban MSAs (i.e., those with a population greater than 1 million) were assigned to California urban nodes, and load profiles for California suburban MSAs (i.e., those with a population of less than 1 million, including rural) were assigned to California rural nodes. The PHEV load fraction assigned to each node equaled its fraction of total California urban or rural baseline load.

The PHEV charging load profiles developed for the rest of the WECC MSAs and the rest of the WECC non-MSAs were combined into one load profile. The PHEV load fraction assigned to each rest-of-WECC node equaled its fraction of the total rest-of-WECC baseline load .

In the Illinois case, load profiles were developed for vehicles in each of 2 subregions. Buses were categorized as either within the Chicago MSA or outside of Chicago (i.e., the rest of Illinois). PHEV load profiles were assigned to the appropriate bus in the same proportion as the bus's contribution to the total baseline load for either the Chicago MSA or the rest of Illinois. Loads in the nodes outside of Illinois were increased in the same proportions as the PHEV load growth in the rest of Illinois. 


\subsubsection{Constrained Scenario}

This scenario assumes charging begins 3 hours after the PHEV arrives home after the final trip of the day. Determining the PHEV charging load in each hour of a typical seasonal week is performed in the same way as in the unconstrained scenario; the hours to which the load is assigned occur 3 hours later.

\subsubsection{Smart Charge Scenario}

This scenario assumes that smart meters are located in every home with a PHEV, and PHEV charging is only performed during the hours with the lowest system loads. A load-shaping algorithm was used on the baseline load profile for each region studied to determine when the low load hours occurred and how much of the total load should be assigned to that hour to charge PHEVs. This process is also known as "valley filling."

Figure 5.6 compares the load profiles from all three scenarios in a typical week. It should be noted that the area under the curves (i.e., the energy required to charge PHEVs in that week) is the same for all scenarios.

\subsection{CAPACITY EXPANSION MODELING}

Both the unconstrained and constrained PHEV scenarios in each region had peak loads that exceeded the peak loads in the base case. Because the Smart Charge scenario restricted PHEV charging to only the lowest load hours of the day, it is the only scenario where the peak load was the same as in the base case. Since peak loads increased in two scenarios, the impact on system reliability was examined to determine whether additional capacity was needed to serve this new load.

When deciding on new capacity additions, electric system operators are guided by the reserve margin needed to maintain system reliability and the amount of new energy needed within the time period. Operators add enough capacity to maintain a $15 \%$ reserve margin, that is, an amount of installed capacity that is greater than the anticipated system peak load by $15 \%$. The overall capacity factor of the new additions is used to guide the selection of the type(s) of units needed. Capacity factor is a measure of the plant's actual output over a period of time compared to the output it could generate if it operated at its maximum capacity over that same time period. 


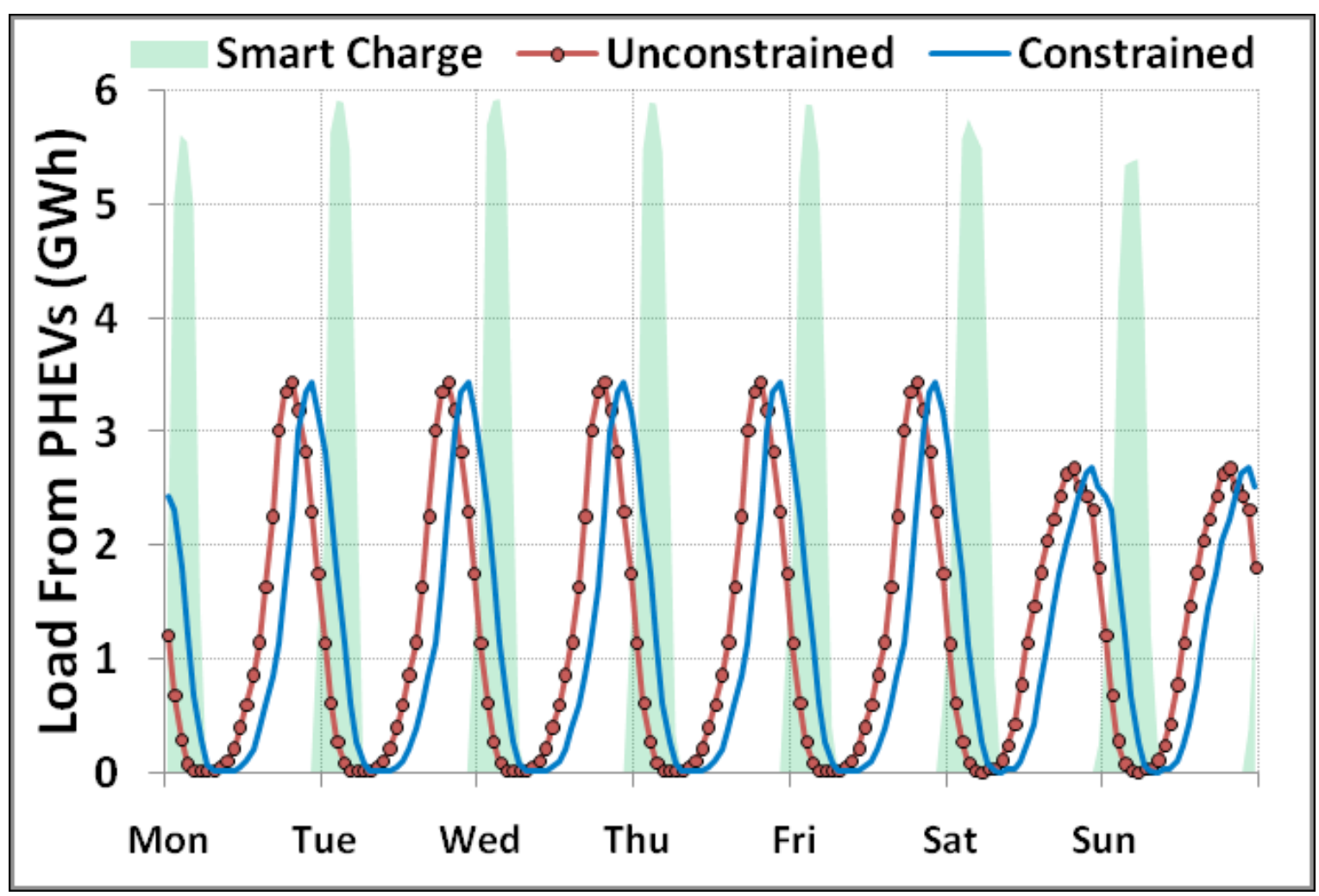

FIGURE 5.6 Typical Hourly Charging Pattern for All Three PHEV Charging Scenarios (week runs from Monday through Sunday)

For this study, if the additional PHEV energy required that plants operate at a capacity factor of about $30 \%$ or less, the least-cost solution for the system would be to add gas turbine (GT) capacity. On the other hand, if the capacity factor is higher than $30 \%$, then a mix of GT and natural gas combined cycle (NGCC) capacity is appropriate. For capacity factors of $50 \%$ or more, NGCCs would be the best solution.

It should be noted that the above capacity factor ranges are considered guidelines and not cutoff points, as all of the analyzed systems already have a plant mix containing both baseload and peaking units. Since the amount of new energy that the PHEVs require in all regions is small compared to the region's total energy, new additions change the composition of the existing plant mix very little. Again, it is important to remember that the new PHEV loads will be served by the entire system, not just by new capacity additions.

Using the aforementioned criteria for capacity expansion, the numbers, sizes, and types of new capacity were determined for each region and scenario. Table 5.2 summarizes the results. 
TABLE 5.2 Capacity Additions by Region and PHEV Scenario

\begin{tabular}{|c|c|c|c|}
\hline \multirow[b]{2}{*}{ Region } & \multicolumn{3}{|c|}{ PHEV Scenario } \\
\hline & Unconstrained & Constrained & Smart Charge \\
\hline New England ISO & $\begin{array}{c}1 \text { 400-MW NGCC \& } \\
1230-M W \text { GT }\end{array}$ & 1 230-MW GT & No Addition \\
\hline New York ISO & 1 400-MW NGCC & 1 230-MW GT & No Addition \\
\hline State of Illinois & 1 400-MW NGCC & 1 230-MW GT & No Addition \\
\hline WECC & 5 400-MW NGCCs & 2 400-MW NGCCs & No Addition \\
\hline
\end{tabular}

Because the transmission systems of the New England ISO and New York ISO were not modeled, the locations of the new additions were not specified. However, it was necessary to locate the additional units for the State of Illinois and WECC cases.

In both scenarios where new units were added in the State of Illinois, they were located at a bus near Chicago. This location was chosen because PHEV loads were highest in the Chicago area, and that location had similar types of units.

Locations of new units in the WECC region were chosen on the basis of the node marginal prices determined after running the baseline scenario. In the unconstrained scenario, 5 NGCCs were needed, so one NGCC was placed in each of the five largest marginal price nodes. In the constrained scenario, one NGCC was placed in each of the top two highest marginal price nodes.

Table 5.2 shows that only small amounts of new capacity are needed in each region to maintain the $15 \%$ reserve margin and generate additional energy required for the PHEVs. No new additions beyond what was already forecast for the base case were needed in the Smart Charge scenario, because the peak load did not increase from the base case. The Smart Charge scenario allowed PHEV charging only in the lowest load hours of the day. Characteristics such as heat rates and outage rates of the new capacity were assumed to be average values for those types of units already operating in the region.

\subsection{DISPATCH MODELING}

\subsubsection{NE and NY ISOs}

After accounting for loads served by nondispatchable renewable and peaking hydroelectric energy, the remaining loads would be served by dispatchable thermal power plants in the ISO's system. A thermal dispatch model was used to determine how the thermal power plants would be operated to serve these loads. 
This first step in dispatch modeling is creating a validated unit inventory for the entire ISO. As shown in Figure 5.7, data on the ISOs' web sites and Form EIA-860 were the starting points. Other data used included Form EIA-423 to determine fuel prices, Form EIA-906 to obtain estimates for unit heat rates, the GADS database (NERC 2008) for information on forced outages, and the AEO 2008 tables for variable operation and maintenance (O\&M) costs (EIA 2008). Plant additions/retirements/upgrades that have been announced and are likely to be in place by 2020 were accounted for in developing the inventory.

Both ISOs have contracts with neighboring electric systems to purchase a specific amount of capacity, if needed, during peak loads. Both also have a demand response program whereby a certain amount of load can be interrupted at times of capacity shortage. Capacity from both purchases and demand response programs were modeled as dispatchable units. The characteristics of these "plants" were adjusted so that they would be loaded after all other units in the inventory.

The baseline unit inventories in 2020 for both the New England ISO and the New York ISO are shown in Tables 5.3 and 5.4, respectively.

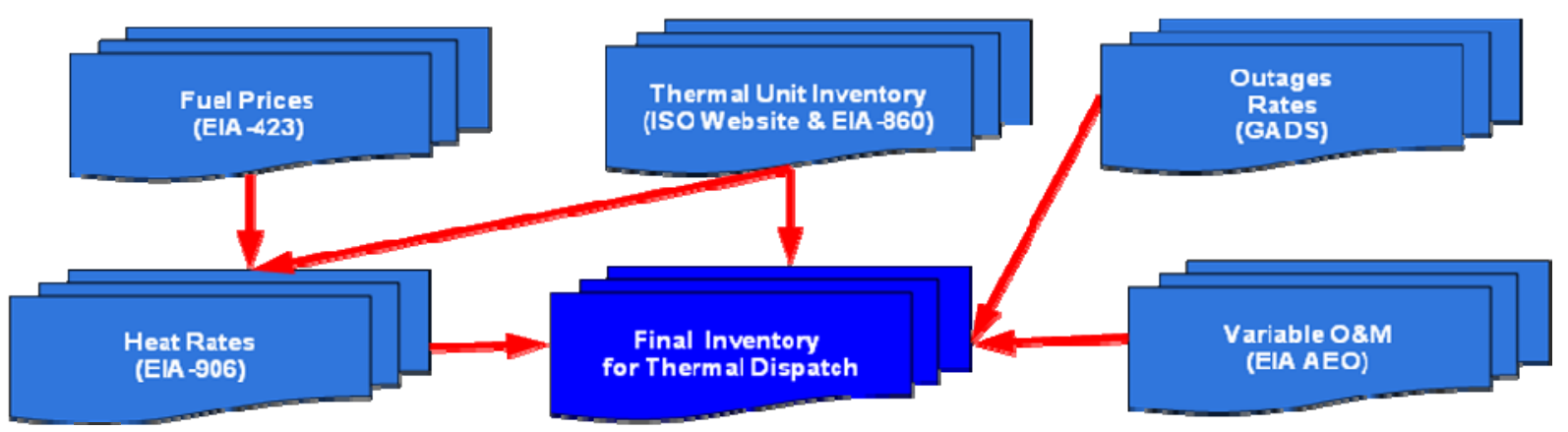

FIGURE 5.7 Creating a Thermal Unit Inventory for the NE and NY ISOs 
TABLE 5.3 Baseline Capacity for NE ISO in 2020

\begin{tabular}{lrr}
\hline \multicolumn{1}{c}{ Fuel \& Technology } & $\begin{array}{c}\text { Baseline } \\
\text { Capacity (MW) }\end{array}$ & $\begin{array}{r}\text { \% of Total } \\
\text { Capacity }\end{array}$ \\
\hline Coal & & \\
$\quad$ Steam Turbine & 2,821 & 7.6 \\
Natural Gas & & \\
$\quad$ Steam Turbine & 67 & 0.2 \\
$\quad$ Combined Cycle & 11,789 & 31.6 \\
Combustion Turbine & 1,378 & 3.7 \\
$\quad$ Internal Combustion & 1 & 0.0 \\
Light Fuel Oil & & \\
$\quad$ Steam Turbine & 2 & 0.0 \\
$\quad$ Simple Gas Turbine & 1,130 & 3.0 \\
Internal Combustion & 158 & 0.4 \\
Heavy Fuel Oil & 6,217 & 16.6 \\
Nuclear Steam Turbine & 4,023 & 10.8 \\
Biofuel & 1,063 & 2.8 \\
Hydroelectric & 3,387 & 9.1 \\
Wind & 89 & 0.2 \\
Demand Response & 2,937 & 7.9 \\
Purchases & 2,298 & 6.2 \\
TOTAL & 37,360 & 100.0 \\
\hline
\end{tabular}

TABLE 5.4 Baseline Capacity for NY ISO in 2020

\begin{tabular}{lcc}
\hline \multicolumn{1}{c}{ Fuel \& Technology } & $\begin{array}{c}\text { Baseline } \\
\text { Capacity (MW) }\end{array}$ & $\begin{array}{r}\text { \% of Total } \\
\text { Capacity }\end{array}$ \\
\hline Coal & & \\
$\quad$ Steam Turbine & 2,802 & 6.7 \\
Natural Gas & & \\
$\quad$ Steam Turbine & 4,219 & 10.1 \\
$\quad$ Combined Cycle & 9,171 & 21.9 \\
$\quad$ Combustion Turbine & 2,100 & 5.0 \\
$\quad$ Internal Combustion & 11 & 0.0 \\
Light Fuel Oil & & \\
$\quad$ Simple Gas Turbine & 2,594 & 6.2 \\
$\quad$ Internal Combustion & 81 & 0.2 \\
Heavy Fuel Oil & 6,770 & 16.2 \\
Nuclear Steam Turbine & 5,433 & 13.0 \\
Biofuel & 397 & 0.9 \\
Hydroelectric & 5,674 & 13.6 \\
Wind & 151 & 0.4 \\
Demand Response & 1,936 & 4.6 \\
Purchases & 460 & 1.1 \\
TOTAL & 41,799 & 100.0 \\
\hline
\end{tabular}


Upon completing the inventory, a unit-level hourly thermal dispatch model simulated operation of the thermal units in the system. The model used a probabilistic technique to account for forced outages and scheduled maintenance. It estimated future maintenance schedules by using a routine that maximized the minimum reserve margin. Figure 5.8 shows sample results for the maintenance scheduler in combination with a forced outage scenario. The dispatch model utilizes a convolution process in which the loads that a unit serves include (1) the original LDC and (2) loads that could not be served by units loaded before it because of forced outages.

The results of the dispatch model were generation amounts for each unit and generation prices summarized by simulation month. Hydropower plants in this analysis were modeled as an aggregate generation resource serving base load and peaking duties. The hourly dispatch of the aggregate power plant is based on monthly generation control totals, the amount of water used for base load duties, estimated monthly hydropower capability, and an ISO hourly load profile as discussed in Section 5.3.1.

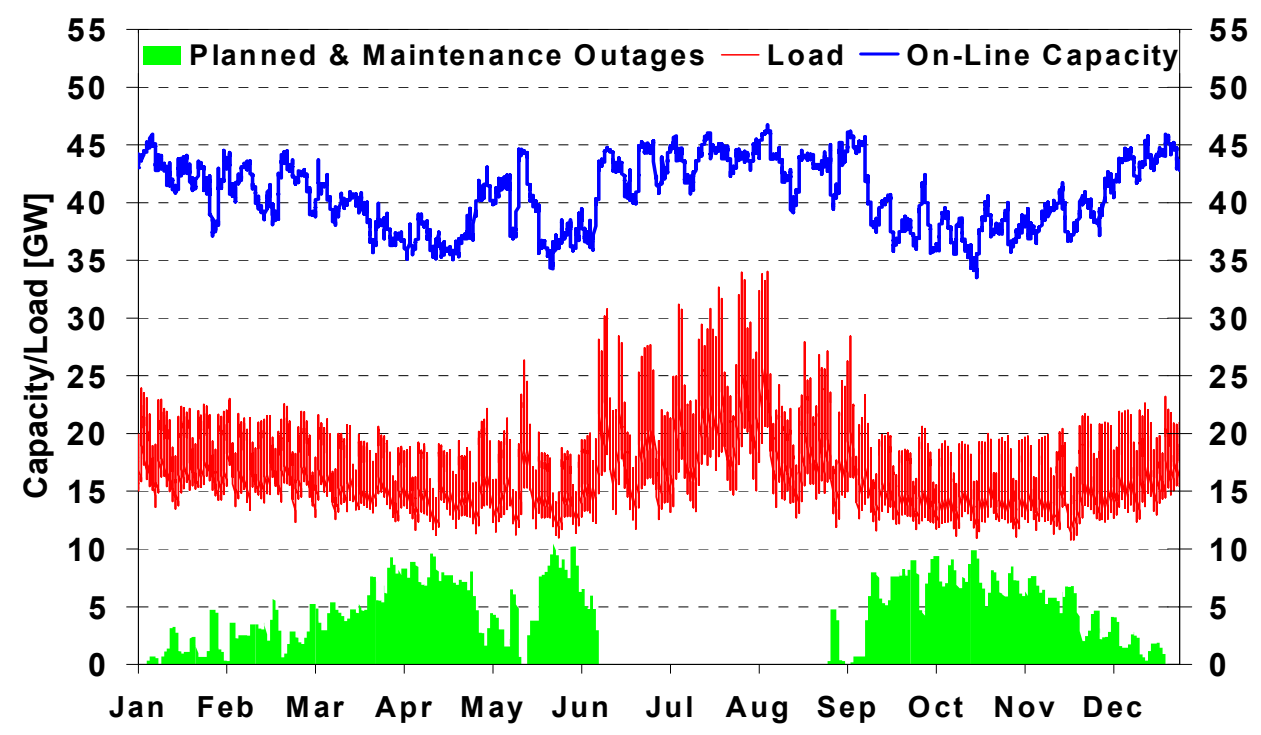

FIGURE 5.8 Example for Results of Maintenance Scheduling Routine

\subsubsection{WECC}

The GTMax model was used to simulate the operation of the entire WECC electric system, including both dispatchable and nondispatchable resources and the transmission system. GTMax takes into account the electric power system topology, interconnection transfer capabilities, chronological hourly loads, and differences in electricity generation costs; its objectives are to simultaneously optimize power transactions while minimizing overall operating costs in the region.

To maintain reasonable model run times, the analysis was carried out for four typical weeks in 2020 (with one week each occurring in the winter, spring, summer, and autumn). 
GTMax simulated hourly system operations during the second week of the months of January, April, July, and October of 2020.

Simulating operation of WECC's electric system on an hour-by-hour basis for an entire week (168 consecutive hours) was considered very important in order to capture the operational behavior of hydropower and pumped-storage power plants. Most hydropower plants in the region have at least daily regulation capabilities and operate differently during the peak and offpeak hours (e.g., during the day and during the night). Also, in the case of hydro plants with greater storage capabilities, there are significant differences between their operation during the weekdays and during the weekends.

To develop a validated unit inventory of thermal and dispatchable renewable power plants to input to GTMax, a strategy similar to the New England and New York ISO cases was used. Data from the WECC Web site and Form EIA-860 were the starting points. Fuel price data were obtained from Form EIA-423, heat rates were estimated from Form EIA-906, forced outage data from the GADS database, and O\&M costs from AEO 2008 tables. Plant additions/retirements/upgrades that have been announced and are likely to be in place by 2020 were accounted for in developing the inventory. The baseline unit inventories in 2020 that are disaggregated by generators located in California and those located in the rest of WECC are shown in Table 5.5.

Because of the large number of generating units in the WECC inventory, the dataset was input to GTMax as a supply curve rather than as individual units. The generating units were aggregated at the node to which they were assigned and represented as a curve of cost as a function of capacity.

Data were input to GTMax for renewable generators such as hydroelectric, wind, and solar by using the methodology described in Section 5.3.2.

Because the GTMax model does not automatically plan a maintenance schedule for thermal units, a schedule was determined exogenously using a maintenance scheduler routine, which was the same routine from the dispatch model used for the New England and New York ISO cases (see Section 5.6.1). The thermal generating unit inventory was input, along with annual hourly load data for 2020. The maintenance schedule was determined such that the minimum reserve margin was maximized. After the maintenance schedule was determined, the unit inventory input to GTMax was adjusted such that units were not allowed to operate in time periods simulated by GTMax when the maintenance scheduler had determined that they would be on maintenance.

Another point to consider is that the GTMax model does not automatically account for forced outages at thermal plants. To adjust for this condition, the unit size was derated in proportion to its forced outage rate (FOR); for example, if a plant's FOR was 5\%, its capacity was reduced by $5 \%$. 
TABLE 5.5 Baseline Capacity for California and the Rest of WECC in 2020

\begin{tabular}{|c|c|c|c|c|}
\hline \multirow[b]{2}{*}{ Fuel \& Technology } & \multicolumn{2}{|c|}{ California } & \multicolumn{2}{|c|}{ Rest of WECC } \\
\hline & $\begin{array}{c}\text { Baseline } \\
\text { Capacity } \\
(\mathrm{MW})\end{array}$ & $\begin{array}{c}\% \text { of Total } \\
\text { Capacity }\end{array}$ & $\begin{array}{l}\text { Baseline } \\
\text { Capacity } \\
(\mathrm{MW})\end{array}$ & $\begin{array}{c}\% \text { of Total } \\
\text { Capacity }\end{array}$ \\
\hline \multicolumn{5}{|l|}{ Coal } \\
\hline Steam Turbine & 317 & 0.4 & 46,953 & 35.0 \\
\hline \multicolumn{5}{|l|}{ Natural Gas } \\
\hline Steam Turbine & 16,181 & 19.9 & 2,416 & 1.8 \\
\hline Combined Cycle & 18,741 & 23.0 & 27,593 & 20.6 \\
\hline Combustion Turbine & 6,374 & 7.8 & 7,666 & 5.7 \\
\hline Internal Combustion & 119 & 0.1 & 387 & 0.3 \\
\hline \multicolumn{5}{|l|}{ Light Fuel Oil } \\
\hline Simple Gas Turbine & 595 & 0.7 & 155 & 0.1 \\
\hline Nuclear Steam Turbine & 4,390 & 5.4 & 5,073 & 3.8 \\
\hline Biofuel & 1,246 & 1.5 & 312 & 0.2 \\
\hline \multicolumn{5}{|l|}{ Petroleum Coke } \\
\hline Steam Turbine & 120 & 0.1 & 55 & 0.0 \\
\hline Geothermal & 2,606 & 3.2 & 561 & 0.4 \\
\hline Hydroelectric & 10,768 & 13.2 & 29,125 & 21.7 \\
\hline Solar & 8,233 & 10.1 & 26 & 0.0 \\
\hline Wind & 11,661 & 14.3 & 13,773 & 10.3 \\
\hline TOTAL & 81,351 & 100.0 & 134,095 & 100.0 \\
\hline
\end{tabular}

\subsubsection{State of Illinois}

The EMCAS model was used to simulate the operation of the entire electric system in Illinois, including both dispatchable and nondispatchable resources and the transmission system. EMCAS is an agent-based simulation model that enables analysis of the interactions among all major agents in a restructured electricity market, including generating companies, transmission companies, distribution companies, demand companies, consumers, the system operator, and the regulator. The model, which was developed at Argonne, includes a detailed representation of the bidding, dispatch, and settlement in day-ahead and real-time (balancing) electricity markets. A detailed description of the EMCAS model and its applications is available at http://www.dis.anl.gov/projects/emcas.html. The most relevant features for the case study of Illinois presented in this report are as follows:

- Chronological hourly simulation of day-ahead (DA) scheduling, and real-time (RT) dispatch and calculation of locational marginal prices (LMPs) over short or long time periods; 
- Hourly transmission-constrained market clearing by using a Direct-Current Optimal Power Flow (DC OPF) algorithm in day-ahead and real-time markets;

- Inclusion of planned outages and random forced outages in market simulations;

- Possibility of specifying different market rules (e.g., regarding congestion management, price caps and bid caps in the energy market);

- Calculation of prices and profits based on the "two-settlement system" (i.e., DA price for DA schedule, and RT price for deviations between RT dispatch and DA schedule);

- Calculation of generation and emissions by generation unit, generating company, and fuel type; and

- Calculation of cost, revenues, and profits for all market participants (agents).

The Illinois power system was simulated assuming a competitive electricity market into which all generation is bid into the market based on its marginal production cost. Hence, the simulated power system is dispatched according to a least-cost objective. The focus is placed on how an increase in electric loads that results from charging PHEVs changes the dispatch and operation of the system.

Similar to the WECC case, the analysis was carried out for four typical weeks in 2020 (one week each during the seasons of winter, spring, summer, and autumn) to maintain reasonable model run times. EMCAS simulated hourly system operations during the second week of the months of January, April, July, and October of 2020.

The same unit inventory of thermal power plants as in the original ICC study (Cirillo et. al. 2006) was used as a starting point for this analysis. Fuel prices were updated based on EIA projections for 2020. Plant additions/retirements/upgrades that have been announced and are likely to be in place by 2020 were accounted for in developing the inventory. Furthermore, because buses and transmission lines were explicitly modeled, new transmission lines and upgrades to existing lines that are likely to be in place by 2020 were estimated. The baseline unit inventory in 2020 for Illinois is shown in Table 5.6.

Data were input to EMCAS for renewable generators, such as hydroelectric and wind, using the methodology described in Section 5.3.3. Generating capacity outside of Illinois was represented in a simplified manner, similar to the representation in the original Illinois study (Cirillo et al. 2006). Hence, all the generation capacity in each out-of-state node was represented as an aggregate supply curve with multiple cost steps. The total capacity of each curve was increased according to the assumed growth for out-of-state load (i.e., by 19\%) to a total out-ofstate capacity of 201,600 MW. The costs of each supply step on the aggregated curves were also adjusted according to the assumed fuel prices for 2020. The aggregate out-of-state supply curves 
TABLE 5.6 Baseline Capacity for Illinois in 2020

\begin{tabular}{lcc}
\hline \multicolumn{1}{c}{ Fuel \& Technology } & $\begin{array}{c}\text { Baseline } \\
\text { Capacity (MW) }\end{array}$ & $\begin{array}{r}\text { \% of Total } \\
\text { Capacity }\end{array}$ \\
\hline Coal & & \\
$\quad$ Steam Turbine & 18,175 & 31.0 \\
$\quad$ IGCC & 275 & 0.5 \\
Natural Gas & & \\
$\quad$ Steam Turbine & 1,777 & 3.0 \\
$\quad$ Combined Cycle & 3,594 & 6.1 \\
$\quad$ Combustion Turbine & 10,853 & 18.5 \\
Light Fuel Oil - Gas Turbine & 632 & 1.1 \\
Heavy Fuel Oil & 438 & 0.7 \\
Nuclear Steam Turbine & 11,683 & 19.9 \\
Hydroelectric & 36 & 0.1 \\
Wind & 11,145 & 19.0 \\
TOTAL & 58,608 & 100.0 \\
\hline a Integrated gasification combined cycle power plant. &
\end{tabular}

do not differentiate between generation technologies other than through different cost segments on the supply curve. Note that the out-of-state generating capacity is almost four times as large as the generating capacity within Illinois.

EMCAS accounts for maintenance and forced outage rates in the following manner. It schedules maintenance outages sequentially, one unit at a time, in a pre-specified order. Units are ordered according to average production costs in terms of $\$ / \mathrm{MWh}$, such that less expensive units are scheduled first and those with the highest costs are scheduled last.

The maintenance algorithm first computes reserve margins for each hour of the year under the assumption that all units are always available for service. The unit with the lowest average production cost is then taken off-line for a continuous maintenance outage for a length of time that is consistent with the average downtime for units of that specific type. The maintenance outage period is selected to maintain the minimum reserve margin. After recomputing hourly reserve margins, we determined the planned outage period for the unit with the next-lowest production cost. All units are scheduled for maintenance sequentially by using the same rule. The end result is to "valley fill" the low-load period with maintenance, thus reducing variability in hourly reserve margins among seasons of the year. The duration of the maintenance period was obtained from GADS data.

Forced outages occur at random as the result of component failures. Outage durations range from a few hours to several days as a function of the cause of the failure. Consistent with GADS statistics, the forced outage algorithm determines the number of outages, by cause, that the entire fleet of units will encounter. The algorithm also determines the approximate number of 
hours that each unit is forced out of service based on GADS cumulative frequency distributions. This methodology results in a pattern of outages in which there is diversity among units in terms of the number of hours that each one is out of service during a given year. A Monte Carlo simulation approach was used to generate a set of forced outage patterns from which the one used here was selected. Note that in order to produce consistent results, the same set of maintenance and forced outages are used in all of the scenarios in the analysis. Furthermore, no outages were assumed for the new plants added to the system, including both thermal plants and wind power plants. The concept of derating was used to represent outages in the out-of-state generation; that is, the available capacity of the supply curves were reduced according to assumed total outage rates.

\subsection{SIMULATION RESULTS}

This section will discuss, in detail, the simulation results for all four regions studied.

\subsubsection{NE ISO}

After adjusting loads to account for energy supplied by wind and hydropower, the thermal dispatch model was run first for the baseline scenario in 2020 to determine the generation mix against which all other scenarios would be compared. The generation mix by fuel and technology type is shown in Table 5.7.

TABLE 5.7 Baseline Generation Mix for NE ISO in 2020

\begin{tabular}{lrr}
\hline \multicolumn{1}{c}{ Fuel \& Technology } & $\begin{array}{c}\text { Generation } \\
(\mathrm{GWh})\end{array}$ & $\begin{array}{c}\% \text { Total } \\
\text { Generation }\end{array}$ \\
\hline Coal & & \\
$\quad$ Steam Turbine & 21,200 & 14.6 \\
Natural Gas & & \\
$\quad$ Steam Turbine & 200 & 0.1 \\
$\quad$ Combined Cycle & 68,500 & 47.1 \\
$\quad$ Combustion Turbine & 3,700 & 2.5 \\
$\quad$ Internal Combustion & 0 & 0.0 \\
Light Fuel Oil & & \\
$\quad$ Steam Turbine & 100 & 0.0 \\
$\quad$ Simple Gas Turbine & 0 & 0.1 \\
$\quad$ Internal Combustion & 5,400 & 0.0 \\
Heavy Fuel Oil & 31,800 & 3.7 \\
Nuclear Steam Turbine & 7,700 & 21.9 \\
Biofuel & 6,400 & 5.3 \\
Hydro/pumped Storage & 300 & 4.4 \\
Wind & 100 & 0.2 \\
Other (Purchases) & 145,400 & 100.1 \\
TOTAL & &
\end{tabular}


Natural gas combined cycle power plants provide more than $47 \%$ of the electricity generation, while nuclear and coal plants provide almost $22 \%$ and $15 \%$, respectively. Biofuel and hydroelectric power plants provide $5.3 \%$ and $4.4 \%$ of the generation, respectively.

Results from the three PHEV charging scenarios are shown next. It should be noted that for each of the three PHEV charging scenarios, the total charging loads remained the same. The only difference between the scenarios was the time of day during which charging occurred. NE ISO loads increased by about 2.22 MWh or $1.5 \%$ as a result of PHEV charging.

Table 5.8 shows differences in generation mix between the baseline scenario and the three PHEV scenarios. The "total" value in the last row of the table equals the PHEV load. Differences in capacity mix between the baseline scenario and the PHEV scenarios are as follows:

- Unconstrained charging scenario - one 400-MW NGCC plant and one 230MW combustion turbine;

- Constrained charging scenario - one 230-MW combustion turbine; and,

- Smart charge scenario - same capacity mix as baseline scenario.

TABLE 5.8 Difference in Generation by Fuel Type and Technology between Baseline and PHEV Scenarios for NE ISO in 2020

\begin{tabular}{lccc}
\hline & \multicolumn{2}{c}{ Change in Generation from Baseline (GWh) } \\
\cline { 2 - 4 } & $\begin{array}{c}\text { Unconstrained } \\
\text { Charge }\end{array}$ & $\begin{array}{c}\text { Constrained } \\
\text { Charge }\end{array}$ & $\begin{array}{c}\text { Smart Charge } \\
\text { Scenario }\end{array}$ \\
\hline Scenario & Scenario & \\
Coal Technology & & & 0 \\
Steam Turbine & 0 & 0 & \\
Natural Gas & & & 0 \\
Steam Turbine & -10 & 0 & 2,100 \\
Combined Cycle & 2,270 & 1,250 & 90 \\
Combustion Turbine & 510 & 750 & 0 \\
Internal Combustion & 0 & 0 & 0 \\
Light Fuel Oil & 0 & 0 & 0 \\
Steam Turbine & -10 & 0 & 0 \\
Simple Gas Turbine & 0 & 0 & 30 \\
Internal Combustion & -520 & 220 & 0 \\
Heavy Fuel Oil & 0 & 0 & 10 \\
Nuclear Steam & 0 & 10 & 0 \\
Biofuel & 0 & 0 & 0 \\
Hydro/pumped Storage & 0 & 0 & 0 \\
Wind & -10 & 0 & 2,230 \\
Other (Purchases) & 2,230 & 2,230 & \\
TOTAL & & & \\
\hline
\end{tabular}


The following observations were made after comparing differences in the generation mix between the baseline scenario and the PHEV charging scenarios. In the unconstrained scenario, generation from natural gas-fired plants, particularly NGCCs, increased significantly; slightly more than the load increased from PHEV charging. Baseloaded plants, such as coal and nuclear, did not increase generation relative to the baseline. Generation from non-baseload plants, such as those fueled by heavy fuel oil, decreased.

The reason that coal and nuclear plants were unable to increase generation in this scenario can be seen by examining their capacity factors in the baseline scenario. Their capacity factors were between $86 \%$ and $90 \%$, which meant they were already fully loaded. Therefore, they could not generate additional energy to serve new PHEV loads. Generation from hydropower and wind turbines did not increase because those resources are limited.

NGCC plants were able to increase generation significantly because these plants operated at less-than-full capacity in the baseline scenario; their average capacity factor was about $65 \%$. Operation of NGCC plants is generally the most economical after nuclear and coal plants. This scenario also had one additional NGCC plant compared to the baseline scenario.

Generation from combustion turbines also increased partially due to operating at a capacity factor of about $30 \%$. Gas turbines typically generate during peak loads, and since some PHEV loads occurred during peak afternoon hours, these plants were able to pick up the slack. This scenario also had one additional combustion turbine compared to the baseline scenario.

In the constrained scenario, only a single 230 -MW combustion turbine was added to the inventory. As in the unconstrained scenario, natural gas-fired plants significantly increased their generation. Plants using heavy fuel oil and biofuel increased generation only slightly. Generation from baseload plants and plants using resource-constrained renewable fuels did not increase similar to the unconstrained scenario. The reasons these generation patterns occurred were the same as in the unconstrained scenario.

In the smart charge scenario, no new capacity was added. Natural gas-fired plants generated $98 \%$ of the increase resulting from PHEV charging, with NGCC plants alone generating almost $95 \%$. As in the unconstrained and constrained scenarios, increased generation from NGCCs was expected because they are efficient, have moderate production costs, and are not fully loaded, especially at night when the PHEV charging occurs in this scenario. Therefore, they are available to generate the electricity needed at a reasonable cost.

\subsubsection{NY ISO}

After adjusting loads to account for energy supplied by wind and hydropower, the thermal dispatch model was run first for the baseline scenario in 2020 to determine the generation mix against which all other scenarios would be compared. The generation mix by fuel and technology type is shown in Table 5.9. 
TABLE 5.9 Baseline Generation Mix for NY ISO in 2020

\begin{tabular}{lrc}
\hline Fuel \& Technology & $\begin{array}{c}\text { Generation } \\
(\mathrm{GWh})\end{array}$ & $\begin{array}{c}\text { \% Total } \\
\text { Generation }\end{array}$ \\
\hline Coal & & \\
$\quad$ Steam Turbine & 21,000 & 11.9 \\
Natural Gas & & \\
$\quad$ Steam Turbine & 20,360 & 11.6 \\
$\quad$ Combined Cycle & 58,780 & 33.4 \\
$\quad$ Combustion Turbine & 4,640 & 2.6 \\
$\quad$ Internal Combustion & 10 & 0.0 \\
Light Fuel Oil & & \\
$\quad$ Simple Gas Turbine & 90 & 0.1 \\
$\quad$ Internal Combustion & 0 & 0.0 \\
Heavy Fuel Oil & 2,330 & 1.3 \\
Nuclear Steam Turbine & 42,830 & 24.3 \\
Biofuel & 30 & 0.0 \\
Hydro/pumped Storage & 25,520 & 14.5 \\
Wind & 450 & 0.3 \\
Other (Purchases) & 10 & 0.0 \\
TOTAL & 176,050 & 100.0 \\
\hline
\end{tabular}

Natural gas-fired power plants provide $45 \%$ of the total electric generation; combined cycle plants alone provide more than $33 \%$ of that total. Nuclear and coal plants provide about $24 \%$ and $12 \%$, respectively, while hydroelectric power plants provide almost $15 \%$ of the system generation.

Results from the three PHEV charging scenarios are shown next. It should be noted that for each of the three PHEV charging scenarios, the total charging loads remained the same. The only difference between the scenarios was the time of day during which charging occurred. NY ISO loads increased by about $2.09 \mathrm{MWh}$ or $1.2 \%$ as a result of PHEV charging.

Table 5.10 shows differences in generation mix between the baseline scenario and the three PHEV scenarios. The "total" value in the last row of the table equals the PHEV load. Differences in capacity mix between the baseline scenario and the PHEV scenarios are as follows:

- Unconstrained charging scenario - one 400-MW NGCC plant;

- Constrained charging scenario - one 230-MW combustion turbine; and,

- Smart charge scenario - same capacity mix as baseline scenario. 
TABLE 5.10 Difference in Generation by Fuel Type and Technology between Baseline and PHEV Scenarios for NY ISO in 2020

\begin{tabular}{|c|c|c|c|}
\hline \multirow[b]{2}{*}{ Fuel \& Technology } & \multicolumn{3}{|c|}{ Change in Generation from Baseline (GWh) } \\
\hline & $\begin{array}{c}\text { Unconstrained } \\
\text { Charge } \\
\text { Scenario } \\
\end{array}$ & $\begin{array}{c}\text { Constrained } \\
\text { Charge } \\
\text { Scenario } \\
\end{array}$ & $\begin{array}{c}\text { Smart Charge } \\
\text { Scenario }\end{array}$ \\
\hline \multicolumn{4}{|l|}{ Coal } \\
\hline Steam Turbine & 0 & 0 & 0 \\
\hline \multicolumn{4}{|l|}{ Natural Gas } \\
\hline Steam Turbine & -270 & 220 & 610 \\
\hline Combined Cycle & 2,400 & 190 & 1,180 \\
\hline Combustion Turbine & -70 & 1,620 & 280 \\
\hline Internal Combustion & 0 & 0 & 0 \\
\hline \multicolumn{4}{|l|}{ Light Fuel Oil } \\
\hline Simple Gas Turbine & 0 & 0 & 0 \\
\hline Internal Combustion & 0 & 0 & 0 \\
\hline Heavy Fuel Oil & 20 & 50 & 10 \\
\hline Nuclear Steam & 0 & 0 & 0 \\
\hline Biofuel & 0 & 0 & 0 \\
\hline Hydro/pumped Storage & 0 & 0 & 0 \\
\hline Wind & 0 & 0 & 0 \\
\hline Other (Purchases) & 0 & 0 & 0 \\
\hline TOTAL & 2,080 & 2,080 & 2,080 \\
\hline
\end{tabular}

The following observations were made after comparing differences in the generation mix between the baseline scenario and the PHEV charging scenarios. In the unconstrained scenario, generation by NGCC plants increased more than the load increased as a result of PHEV charging. Generation from baseloaded plants, such as coal and nuclear, did not increase relative to the baseline. Generation by non-baseloaded plants decreased, except for plants fueled by heavy fuel oil, which had only a marginal increase in generation.

The reason that coal and nuclear plants were unable to increase generation in this scenario can be seen by examining their capacity factors in the baseline scenario. Their capacity factors were between $85 \%$ and $90 \%$, which meant they were already fully loaded. Therefore, they could not generate additional energy to serve new PHEV loads. Generation from hydropower and wind turbines did not increase because those resources are limited.

NGCC plants were able to increase generation significantly because these plants operated at less-than-full capacity in the baseline scenario; their average capacity factor was about $70 \%$. Operation of NGCC plants is generally the most economical after nuclear and coal plants. This scenario also had added one NGCC plant compared to the baseline scenario. Generation from 
NGCCs also displaced generation from other natural gas-fired plants, whose generation decreased in this scenario, because operation of NGCCs is more economical.

In the constrained scenario, only a single 230-MW combustion turbine was added to the inventory. In this scenario, natural gas-fired plants significantly increased their generation, but most of that increase came from combustion turbines. This result was expected because a combustion turbine was added to the unit inventory. Generation from NGCC plants increased because their operation is economical and their capacity was not fully utilized, as seen from the capacity factors in the baseline scenario.

In the smart charge scenario, no new capacity was added. Natural gas-fired plants again generated more than $99 \%$ of the increase resulting from PHEV charging, with NGCC plants alone generating almost $57 \%$. As in the unconstrained and constrained scenarios, generation increase from NGCCs was expected because they are efficient, have moderate production costs, and are not fully loaded, especially at night when the PHEV charging occurs in this scenario. Other natural gas-fired plants increased generation because they also had excess capacity and a moderate production cost.

\subsubsection{WECC}

The GTMax model was run first for the baseline scenario in 2020 to determine the generation mix against which all other scenarios would be compared. Because California imports a significant quantity of electricity from other areas of the WECC, the generation mix is disaggregated into two subareas: (1) California including imports; and (2) the rest of WECC, excluding California exports. The generation mixes by fuel and technology type for these two areas are shown in Table 5.11 and Table 5.12, respectively. Because the model calculated results for a typical week in each of four seasons, results for each season were estimated by multiplying weekly results by approximately 13.0357. This factor was used to scale the results from a week, which consists of 168 hours, to a season, which consists of 2,190 hours, assuming seasons are of equal length. Values for all four seasons were then summed to obtain annual generation estimates.

More than half of California's electric generation is supplied by natural gas plants, including more than 38\% from NGCCs, $12 \%$ from steam turbines, and about $2 \%$ from combustion turbines. Nuclear power plants supply more than $11 \%$ of the generation, while wind turbines and hydropower supply about $10 \%$ each. Coal-fired power plants supply about $6 \%$ and geothermal about $5 \%$.

In the rest of WECC, more than 53\% of the load is served by coal-fired power plants and almost $25 \%$ by hydropower. Nuclear plants serve about $7 \%$, and natural gas-fired plants serve only $3 \%$. The remaining generating sources serve less than $1 \%$ of the load. 
TABLE 5.11 Baseline Generation Mix for California in 2020 (including imports)

\begin{tabular}{lrc}
\hline \multicolumn{1}{c}{ Fuel \& Technology } & $\begin{array}{c}\text { Generation } \\
(\mathrm{MWh})\end{array}$ & $\begin{array}{c}\text { \% Total } \\
\text { Generation }\end{array}$ \\
\hline Coal & & \\
$\quad$ Steam Turbine & 21,000 & 6.2 \\
Natural Gas & & \\
$\quad$ Steam Turbine & 40,900 & 12.0 \\
$\quad$ Combined Cycle & 130,000 & 38.1 \\
$\quad$ Combustion Turbine & 7,300 & 2.2 \\
$\quad$ Internal Combustion & 100 & 0.0 \\
Light Fuel Oil & & \\
$\quad$ Gas Turbine & 0 & 0.0 \\
Nuclear Steam Turbine & 37,700 & 11.1 \\
Biofuel & 3,600 & 1.1 \\
Petroleum Coke & 900 & 0.3 \\
Geothermal & 17,200 & 5.0 \\
Hydro/pumped Storage & 32,600 & 9.6 \\
Solar & 14,500 & 4.2 \\
Wind & 35,400 & 10.4 \\
TOTAL & 341,200 & 100.0 \\
\hline
\end{tabular}

TABLE 5.12 Baseline Generation Mix for Rest of WECC (excluding California exports) in $\mathbf{2 0 2 0}$

\begin{tabular}{lrc}
\hline \multicolumn{1}{c}{ Fuel \& Technology } & $\begin{array}{c}\text { Generation } \\
(\mathrm{GWh})\end{array}$ & $\begin{array}{c}\text { \% Total } \\
\text { Generation }\end{array}$ \\
\hline Coal & & \\
$\quad$ Steam Turbine & 302,400 & 53.3 \\
Natural Gas & & \\
$\quad$ Steam Turbine & 4,600 & 0.8 \\
$\quad$ Combined Cycle & 11,300 & 2.0 \\
$\quad$ Combustion Turbine & 1,000 & 0.2 \\
$\quad$ Internal Combustion & 0 & 0.0 \\
Nuclear Steam Turbine & 40,400 & 7.1 \\
Biofuel & 200 & 0.04 \\
Petroleum Coke & 200 & 0.03 \\
Geothermal & 3,900 & 0.7 \\
Hydro/pumped Storage & 140,500 & 24.7 \\
Solar & 100 & 0.0 \\
Wind & 63,200 & 11.1 \\
TOTAL & 567,800 & 100.0 \\
\hline
\end{tabular}


The model was run next with data for each of the three PHEV charging scenarios. It should be noted that the total weekly charging load for all three PHEV scenarios was the same. The only difference between the scenarios was the time of day during which charging occurred. WECC loads in California increased by about $6.34 \mathrm{MWh}$ or $1.9 \%$ as a result of PHEV charging; the rest of the WECC loads increased by about $4.34 \mathrm{MWh}$ or almost $0.8 \%$ as a result of PHEV charging.

Tables 5.13 and 5.14 show differences in generation mix between the baseline scenario and the three PHEV scenarios for California loads and the rest of the WECC loads, respectively. The "total" value in the last row of the table is the PHEV load. Differences in the capacity mix between the baseline scenario and the PHEV scenarios are as follows:

- Unconstrained charging scenario - five 400-MW NGCC plants: four assigned to California nodes and one to a node outside of California;

- Constrained charging scenario - two 400-MW NGCC plants: one assigned to a California node and one to a node outside of California; and,

- Smart charge scenario - same capacity mix as baseline scenario.

TABLE 5.13 Difference in Generation by Fuel Type and Technology between Baseline and PHEV Scenarios for California in 2020

\begin{tabular}{lrcr}
\hline & \multicolumn{2}{c}{ Change in Generation from Baseline (GWh) } \\
\cline { 2 - 4 } & $\begin{array}{c}\text { Unconstrained } \\
\text { Fuel \& Technology }\end{array}$ & $\begin{array}{c}\text { Constrained Charge } \\
\text { Charge Scenario }\end{array}$ & $\begin{array}{c}\text { Smart Charge } \\
\text { Scenario }\end{array}$ \\
\hline Coal & & & \\
$\quad$ Steam Turbine & $-1,750$ & $-2,030$ & $-2,550$ \\
Natural Gas & & & \\
$\quad$ Steam Turbine & 760 & 800 & 640 \\
$\quad$ Combined Cycle & 530 & 6,940 & 7,690 \\
$\quad$ Combustion Turbine & 10 & 700 & 470 \\
$\quad$ Internal Combustion & 0 & 20 & 10 \\
Light Fuel Oil & -20 & 0 & 0 \\
$\quad$ Simple Gas Turbine & -20 & -40 & 10 \\
Nuclear Steam & 0 & -50 & 10 \\
Biofuel & 0 & 0 & 0 \\
Petroleum Coke & 0 & 0 & 0 \\
Geothermal & 0 & 0 & 0 \\
Hydro/pumped Storage & 0 & 0 & 6,340 \\
Solar & 6,340 & 0,340 & \\
Wind & & & 0 \\
TOTAL & & & \\
\hline
\end{tabular}


TABLE 5.14 Difference in Generation by Fuel Type and Technology between Baseline and PHEV Scenarios for WECC (excluding California) in 2020

\begin{tabular}{lccc}
\hline & \multicolumn{2}{c}{ Change in Generation from Baseline (GWh) } \\
\cline { 2 - 4 } \multicolumn{1}{c}{ Fuel \& Technology } & $\begin{array}{c}\text { Unconstrained } \\
\text { Charge Scenario }\end{array}$ & $\begin{array}{c}\text { Constrained Charge } \\
\text { Scenario }\end{array}$ & $\begin{array}{c}\text { Smart Charge } \\
\text { Scenario }\end{array}$ \\
\hline Coal & & & \\
$\quad$ Steam Turbine & 1,830 & 2,460 & 4,010 \\
Natural Gas & 0 & 0 & 0 \\
$\quad$ Steam Turbine & 2,490 & 1,910 & 380 \\
$\quad$ Combined Cycle & 20 & -20 & -40 \\
$\quad$ Combustion Turbine & 0 & 0 & 0 \\
$\quad$ Internal Combustion & 0 & 0 & 0 \\
Light Fuel Oil & 0 & 0 & 0 \\
$\quad$ Simple Gas Turbine & 0 & 0 & 0 \\
Nuclear Steam & 0 & 0 & 0 \\
Biofuel & 0 & 0 & 0 \\
Petroleum Coke & 0 & 0 & 0 \\
Geothermal & 0 & 0 & 0 \\
Hydro/pumped Storage & 0 & 0 & 4,340 \\
Solar & 4,340 & 4,340 & \\
Wind & & & \\
TOTAL & & & \\
\hline
\end{tabular}

The following observations can be made after comparing differences in the generation mix between the baseline scenario and the PHEV charging scenarios. In the unconstrained scenario for California, natural gas-fired power plants are virtually the only plants that increased generation compared to the baseline scenario; there was either no change in generation from other plants or there were only marginal changes. Generation from natural gas-fired plants increased more than the load increase as a result of PHEV charging in California.

Examining details at the node level revealed that the reduction in coal generation serving California loads was attributable to a combination of higher loads in the rest of WECC and transmission congestion. Coal makes up less than $0.5 \%$ of the generation capacity located in California, although more than $6 \%$ of the generation in the baseline scenario is from coal; the majority is imported. However, in the unconstrained PHEV scenario, all of the WECC had higher loads as a result of PHEV charging: that source of low-cost generation served nearby loads and therefore was not available for export to California. Transmission congestion also played a role; transmission lines reached their capacity limits, and therefore cheaper coal plants could not export power to California. In one instance, an excess of wind turbine capacity caused an "over supply" pocket, which did not allow generation from low-cost coal plants to be exported to California. Therefore, natural gas plants increased generation to serve the increased loads. Furthermore, four of the five NGCCs that were added in this scenario were assigned to nodes in California. 
In the unconstrained scenario for the rest of WECC, coal and natural gas plants were the only two fuel types that increased generation to serve the additional load. Natural gas plants served about $58 \%$ of the load increase while coal plants served the remaining $42 \%$. The increase in NGCC generation was partially attributable to the addition of an NGCC unit at a node outside of California.

In both California and the rest of the WECC cases, the amount of load served by nuclear power plants did not increase; there was only a marginal decrease in California. Examination of nuclear plant capacity factors in the baseline scenario showed that they were operating at a maximum capacity factor and could not generate any additional energy to serve the new PHEV charging load. The slight decrease in nuclear power plant generation in the California case may be attributable to modeling "noise" and transmission congestion.

Similar results were found in the constrained and smart charge scenarios. In the California case, coal generation decreased sharply while natural gas generation, particularly from NGCC plants, increased sharply. Generation from natural gas plants increased by more than the increase from PHEV charging to compensate for coal imports lost because of transmission congestion and for higher loads served in the locations outside of California. California had one additional NGCC plant in the constrained scenario than it had in the baseline scenario, although no capacity was added in the smart charge scenario.

In the rest of WECC, coal generation increased sharply in the constrained and smart charge scenarios, providing $57 \%$ and $92 \%$, respectively, of the increased generation. The remainder was provided by increased generation from NGCC plants. The rest of WECC had one additional NGCC plant in the constrained scenario compared to the baseline scenario, although no capacity was added in the smart charge scenario.

Finally, nuclear power plants could not increase generation in either the constrained or smart charge scenarios. As in the unconstrained case, these plants had no excess capacity with which to serve the additional load.

\subsubsection{State of Illinois}

The model was run first for the baseline scenario in 2020 to determine the generation mix against which all other scenarios would be compared. The generation mix by fuel and technology type is shown in Table 5.15. Because the model calculated results for a typical week in each of four seasons, results for each season was estimated by multiplying weekly results by 13.0357 . This factor was used to scale the results from a week, which consists of 168 hours, to a season, which consists of 2,190 hours (assuming seasons are of equal length). Values for all four seasons were then summed to obtain annual generation estimates.

Coal-fired and nuclear power plants are the two largest types of electricity generators in Illinois in 2020 , providing more than $44 \%$ and nearly $35 \%$ of the electric power generation, respectively. Wind turbines provide another $17 \%$ of the electric generation. 
TABLE 5.15 Baseline Generation Mix for Illinois in 2020

\begin{tabular}{lrc}
\hline \multicolumn{1}{c}{ Fuel \& Technology } & $\begin{array}{c}\text { Generation } \\
(\text { GWh })\end{array}$ & $\begin{array}{c}\% \text { Total } \\
\text { Generation }\end{array}$ \\
\hline Coal & & \\
$\quad$ Steam Turbine & 94,570 & 44.1 \\
$\quad$ IGCC & 640 & 0.3 \\
Natural Gas & & \\
$\quad$ Steam Turbine & 160 & 0.1 \\
$\quad$ Combined Cycle & 3,090 & 1.4 \\
$\quad$ Combustion Turbine & 4,250 & 2.0 \\
Light Fuel Oil & & \\
$\quad$ Combustion Turbine & 70 & 0.0 \\
Heavy Fuel Oil & 130 & 0.1 \\
Nuclear Steam Turbine & 74,660 & 34.8 \\
Hydro/pumped Storage & 240 & 0.1 \\
Wind & 36,850 & 17.2 \\
Total IL Generation & 214,660 & 100.0 \\
IL Load & 202,220 & \\
Net IL Export & 12,440 & \\
\hline
\end{tabular}

Results from the three PHEV charging scenarios are shown next. It should be noted that for each of the three PHEV charging scenarios, the total weekly charging loads remained the same. The only difference between the scenarios was the time of day during which PHEV charging occurred. Loads in Illinois increased by about $1,660 \mathrm{GWh}$ or $0.8 \%$ as a result of PHEV charging.

Table 5.16 shows differences in generation mix between the baseline scenario and the three PHEV scenarios. The "IL Load" value at the bottom of the table equals the PHEV load. Differences in the capacity mix between the baseline scenario and the PHEV scenarios are as follows:

- Unconstrained charging scenario: one 400-MW NGCC plant: assigned to a bus in metropolitan Chicago;

- Constrained charging scenario: one 230-MW combustion turbine: assigned to a bus in metropolitan Chicago; and,

- Smart charge scenario: same capacity mix as baseline scenario. 
TABLE 5.16 Difference in Generation by Fuel Type and Technology between Baseline and PHEV Scenarios for the State of Illinois in 2020

\begin{tabular}{|c|c|c|c|}
\hline \multirow[b]{2}{*}{ Fuel \& Technology } & \multicolumn{3}{|c|}{ Change in Energy from Baseline (GWh) } \\
\hline & $\begin{array}{c}\text { Unconstrained } \\
\text { Charge } \\
\text { Scenario }\end{array}$ & $\begin{array}{c}\text { Constrained } \\
\text { Charge } \\
\text { Scenario }\end{array}$ & $\begin{array}{c}\text { Smart Charge } \\
\text { Scenario }\end{array}$ \\
\hline \multicolumn{4}{|l|}{ Coal } \\
\hline Steam Turbine & 1,950 & 1,730 & 1,110 \\
\hline IGCC & 80 & 70 & 0 \\
\hline \multicolumn{4}{|l|}{ Natural Gas } \\
\hline Steam Turbine & 20 & 20 & 0 \\
\hline Combined Cycle & 690 & 280 & 0 \\
\hline Combustion Turbine & 260 & 200 & 0 \\
\hline \multicolumn{4}{|l|}{ Light Fuel Oil } \\
\hline Combustion Turbine & 20 & 10 & 0 \\
\hline Heavy Fuel Oil & 20 & 20 & 0 \\
\hline Nuclear Steam & 10 & 10 & 0 \\
\hline Hydro/pumped Storage & 0 & 0 & 0 \\
\hline Wind & -30 & -20 & 10 \\
\hline Total IL Generation & 3,020 & 2,320 & 1,120 \\
\hline IL PHEV Load & 1,660 & 1,660 & 1,660 \\
\hline Net IL Export a & 1,360 & 660 & -540 \\
\hline
\end{tabular}

a Amount of export increase or decrease relative to baseline export of $12,440 \mathrm{GWh}$.

The following observations were made after comparing the differences in the generation mix between the baseline scenario and the PHEV charging scenarios. In the unconstrained scenario, virtually all plants, except for wind turbines, increased their generation, with coal plants accounting for more than $67 \%$ of the increase. The increase in NGCC generation accounted for more than $23 \%$ of the increase. Coal plants, which account for $31 \%$ of the installed capacity in 2020, increased their generation because they have a very low operating cost and were not fully loaded, so they were able to produce additional electricity economically. In the baseline scenario, coal plants have an average capacity factor of about $60 \%$. The generation increase from NGCC plants was attributable to their excess capacity; in the baseline scenario, their capacity factor is less than $40 \%$. Also, the unit inventory in this scenario had one additional 400-MW NGCC plant compared to the baseline scenario.

As in the WECC case, nuclear power plants did not increase their generation significantly to serve the PHEV load. Results from the baseline scenario showed that nuclear power plants were already fully loaded, with a capacity factor of almost $90 \%$, and could not generate more power. There was a very slight increase, which could be attributed to modeling noise and transmission congestion. 
Generation in Illinois increased by more than was necessary to serve the increase in Illinois loads arising from PHEV charging, partially because of the way the Illinois system was modeled and the underlying assumptions. As described earlier, nodes outside of Illinois were modeled, and, in general, Illinois is a net exporter of electricity. The loads at the out-of-state nodes were increased to account for increased loads because of PHEV charging, but no new plants were added to the inventory of out-of-state generators. Therefore, generators in Illinois stepped in to fill the generation gap. In fact, almost $46 \%$ of the generation increase in this scenario was exported.

In the constrained scenario, only a single 230-MW combustion turbine was added to the inventory. In this scenario, all plants, except for wind turbines, increased generation. Again, while coal and natural gas-fired plants significantly increased their generation, it was to a lesser extent than the increases in the constrained scenario. Coal generated slightly less in this scenario than in the unconstrained scenario but accounted for $75 \%$ of the increase, while NGCC plants accounted for $12 \%$ of the increase. Almost $29 \%$ of the generation increase in this scenario was exported.

In the smart charge scenario, no new capacity was added. Energy to serve additional PHEV load comes from plants increasing their generation in Illinois and decreasing their exports outside Illinois. New generation serves about $67 \%$ of the additional system load; $99 \%$ of the increased generation comes from coal plants. Wind turbines provided about $1 \%$ of the increased generation. Although the same wind output profile is used for all scenarios, generation from wind was higher in this scenario because there was less transmission congestion compared with the other two scenarios. The remaining 33\% (or $540 \mathrm{GWh}$ ) of the additional system load is served by plants whose energy was exported under the baseline scenario. Illinois exports slightly less energy under the smart charge scenario compared with the baseline scenario, but is - in all cases - a net exporter.

\subsection{CONCLUSIONS}

A number of important conclusions can be drawn from this study concerning how PHEV charging affects an electric power system, such as effects on the mix of generators serving the load and on the transmission network. The results from simulations of electric power system operations showed that plants supplying base load generation will often be unable to increase generation if they are already operating at high capacity factors before loads increase from PHEV charging. The plants that are able to serve the additional PHEV load are normally operated at less than their maximum capacity factor and have the lowest operating costs after the baseload plants. In many parts of the United States, this role is served by natural gas plants, particularly NGCC plants.

An example of this conclusion can be seen by comparing results in Illinois to those in the New England and New York ISOs. Coal plants in the New England and New York ISOs were unable to generate more electricity to serve the new PHEV load because their capacity factors exceeded $80 \%$ in the baseline scenario. However, in Illinois, coal plants had a capacity factor of less than $70 \%$ in the baseline scenario and therefore were able to generate more electricity. 
Limitations on transmission line transfer capabilities can have a major impact on the operation of power plants within the system. In this analysis, it was observed that transmission congestion can constrain generation from plants that are connected to those transmission lines; that is, the plants can generate the needed electricity, but limitations on the power transfer capacity of the transmission lines prevent the plant from doing so. Therefore, plants whose operations may be less economical than those of the constrained plants - but whose generation is not limited by congestion in the transmission network - increase their generation to serve the new load.

In electric systems that extend over a wide geographic area, individual regions that import large amounts of energy can also be adversely affected by system-wide load increases. In this analysis, it was observed that imports from coal-fired power plants into California were greatly reduced in the PHEV scenarios as compared to the baseline scenario. This reduction resulted in a significant increase in natural gas generation, particularly by NGCC plants, to serve California's loads. This phenomenon was partially the result of loads increasing in regions closer to where the coal plants were located and also because of transmission congestion. Therefore, regions relying heavily on imports to serve their load may see a significant shift in their generation mix under higher load scenarios. 


\section{GREET WTW ENERGY USE AND GHG EMISSIONS}

\subsection{INTRODUCTION}

Table 1.1 (in Section 1) lists the vehicle technologies and the feedstock sources for the fuels considered in this analysis. The selected vehicle platform for the WTW analysis is a MY 2015 mid-size vehicle. Although the PHEV penetration scenario considered a mix of PHEV classes and technologies, we examined the impact of the combined PHEV load on the WTW energy use and GHG emissions for each PHEV technology (e.g., 10-, 20-, 30-, and 40-mile AERs). The fuel economy for each vehicle technology was based on components' efficiencies with a $50 \%$ chance of being available at the time of vehicle production (2015). This approach represents a "medium" uncertainty of technological improvement for each of the vehicles analyzed.

The marginal electricity generation mixes considered for this WTW analysis include those in WECC, Illinois, New York, and New England. For each of these regions, we examined three scenarios for PHEV recharging: smart charging (i.e., charging at lowest cost, which occurs during the lowest electricity demand period at night), unconstrained charging (i.e., PHEVs start recharging as soon as the last daily trip is completed), and unconstrained charging delayed by 3 hours (i.e., recharging starts 3 hours after the last daily trip is completed). We also studied the impact of average electricity generation mixes in California, the Northeastern United States, and the entire United States on WTW energy use and GHG emissions and the impact of charging PHEVs with electricity from potential renewable or nonfossil sources ( e.g., wind and nuclear).

Year 2020 was chosen for the simulations in order to address the implications of PHEVs within a reasonable timeframe after their likely introduction in the next few years. This analysis assumed a 10\% PHEV market penetration for the on-road fleet by 2020. Because, on average, the midpoint for U.S. light-duty vehicles is about five years, we adopted the fuel economy values for vehicles' MY 2015 (i.e., five years ahead of the calendar year targeted for simulation [2020]).

Table 6.1 lists the marginal generation mix for the unconstrained charging scenario, the unconstrained 3-hour delay charging scenario, and the smart charging scenario. The table shows that the dispatch model predicts a marginal mix with significant coal share for Illinois, while predicting that NG technologies will dominate the marginal mix for all other regions (WECC, NY ISO, and NE ISO). A negative share for a generation technology represents a displacement of that share in the marginal mix by newly added generation capacity to satisfy PHEV load. Table 6.2 lists the marginal mix in California and the rest of WECC (excluding California). Table 6.3 lists the average generation mix for California, the Northeast United States, and the entire United States. The efficiency for each generation technology in each region is shown in Table 6.4 for each of the three charging scenarios. The source for the generation efficiency is EIA form 906 (2007). The generation efficiencies are converted to a lower heating value (LHV) basis for use in this analysis. Table 6.4 reveals wide variation in the generation efficiency between regions for biomass-based power generation. Depending on the biomass feedstock type, the generation efficiency could range from below $10 \%$ to over $30 \%$. The low generation efficiency for biomass power generation in NE and NY is attributed to the larger share of 
municipal solid waste and wood waste in these regions. Table 6.5 lists the generation efficiencies for the technologies associated with the average generation scenarios. The losses associated with the average and marginal electricity transmission and distribution in each region, based on EIA's Annual Energy Outlook 2009 projections, are shown in Table 6.6.

Although the marginal generation mixes were produced by means of detailed and careful dispatch modeling for selected regions, the actual mix for PHEV recharging could be significantly different depending on many factors, including the following:

- The actual penetration of PHEVs over time;

- The impact of policy development at the state and federal levels (e.g., renewable energy standards, energy efficiency and emissions standards, carbon tax or cap and trade) on technology adopted for generation capacity expansion and actual electricity pricing;

- The impact of future fuel prices (e.g., natural gas) on generation technology selection for capacity expansion; and

- The impact of number of charges per day, as well as the time of recharging for the actual technology being dispatched for the PHEV load.

Because significant uncertainties are associated with the predicted marginal mix for the regions considered in this analysis, the predicted marginal mixes should be evaluated as possible scenarios for recharging PHEVs. Thus, the objectives of this analysis are to evaluate (1) the impact of key factors on the marginal electricity generation mix and (2) the impact of a variety of possible generation mixes on the relative WTW performance of PHEVs compared with other vehicle technologies. The WTW results for PHEVs in this analysis should be directly correlated with the underlying generation mix rather than the region or state associated with that mix. 
TABLE 6.1 Marginal Electricity Generation Mix for Each Charging Scenario, for Each Region

\begin{tabular}{|c|c|c|c|c|c|c|c|c|c|c|c|c|c|}
\hline \multicolumn{2}{|c|}{ Charging Scenario } & \multicolumn{4}{|c|}{ Unconstrained Charging (\%) } & \multicolumn{4}{|c|}{$\begin{array}{c}\text { Unconstrained (3h-delay) } \\
\text { Charging }(\%) \\
\end{array}$} & \multicolumn{4}{|c|}{ Smart Charging (\%) } \\
\hline Fuel & Technology & WECC & IL & NY-ISO & NE-ISO & WECC & IL & NY-ISO & NE-ISO & WECC & IL & NY-ISO & NE-ISO \\
\hline Coal & Utility Boiler / IGCC & 0.7 & 67.2 & 0.0 & 0.0 & 4.1 & 77.8 & 0.0 & 0.0 & 13.7 & 99.5 & 0.0 & 0.0 \\
\hline \multirow[t]{3}{*}{ Natural Gas } & Utility Boiler & 7.1 & 0.7 & -12.8 & -0.5 & 7.5 & 0.7 & 10.8 & 0.2 & 5.9 & 0.0 & 29.5 & 0.1 \\
\hline & Combined Cycle & 87.2 & 22.6 & 115.2 & 102.0 & 82.8 & 11.9 & 9.2 & 56.3 & 75.6 & 0.0 & 56.8 & 94.7 \\
\hline & Combustion Turbine & 5.3 & 8.8 & -3.5 & 23.1 & 6.5 & 8.7 & 77.7 & 33.6 & 4.2 & 0.0 & 13.3 & 3.7 \\
\hline Residual Oil & Utility Boiler & 0.0 & 1.2 & 1.1 & -23.9 & 0.0 & 1.2 & 2.3 & 9.8 & 0.0 & 0.0 & 0.4 & 1.3 \\
\hline Nuclear & & -0.2 & 0.4 & 0.0 & 0.0 & -0.4 & 0.4 & 0.0 & 0.0 & 0.5 & 0.0 & 0.0 & 0.0 \\
\hline Biomass & Utility Boiler / IGCC & -0.2 & 0.0 & 0.0 & -0.1 & -0.5 & 0.0 & 0.0 & 0.2 & 0.1 & 0.0 & 0.0 & 0.2 \\
\hline Other & Renewable & 0.0 & -0.9 & 0.0 & -0.6 & 0.0 & -0.7 & -0.1 & -0.1 & 0.0 & 0.5 & 0.0 & 0.0 \\
\hline Total & & 100 & 100 & 100 & 100 & 100 & 100 & 100 & 100 & 100 & 100 & 100 & 100 \\
\hline
\end{tabular}


TABLE 6.2 Marginal Electricity Generation Mix for California, WECC without California, and WECC Total

\begin{tabular}{|c|c|c|c|c|}
\hline \multicolumn{2}{|c|}{ Charging Scenario } & \multicolumn{3}{|c|}{ Unconstrained Charging (\%) } \\
\hline Fuel & Technology & CA & WECC without CA & WECC Total \\
\hline Coal & Utility Boiler / IGCC & -27.6 & 42 & 0.7 \\
\hline \multirow[t]{3}{*}{ Natural Gas } & Utility Boiler & 11.9 & 0.1 & 7.1 \\
\hline & Combined Cycle & 107.7 & 57.3 & 87.2 \\
\hline & Combustion Turbine & 8.6 & 0.5 & 5.3 \\
\hline Residual Oil & Utility Boiler & 0.0 & 0.0 & 0.0 \\
\hline Nuclear & & -0.3 & 0.0 & -0.2 \\
\hline Biomass & Utility Boiler / IGCC & -0.4 & 0.0 & -0.2 \\
\hline Other & Renewable & 0.0 & 0.0 & 0.0 \\
\hline Total & & 100 & 100 & 100 \\
\hline
\end{tabular}

TABLE 6.3 Average Generation Mix for United States, Northeastern United States, and California

\begin{tabular}{|c|c|c|c|c|}
\hline Fuel & Technology & $\begin{array}{l}\text { U.S. Ave. } \\
\text { Mix (\%) }\end{array}$ & $\begin{array}{l}\text { NE U.S. Ave. } \\
\text { Mix (\%) }\end{array}$ & $\begin{array}{l}\text { CA Ave. } \\
\text { Mix (\%) }\end{array}$ \\
\hline \multirow[t]{3}{*}{ Coal } & Utility Boiler / IGCC & 48.6 & 28.7 & 14.2 \\
\hline & Utility Boiler & 2.5 & 2.8 & 5.2 \\
\hline & Combined Cycle & 6.9 & 7.6 & 14.0 \\
\hline Nuclear & & 19.7 & 32.0 & 19.3 \\
\hline Biomass & Utility Boiler / IGCC & 2.6 & 6.9 & 1.1 \\
\hline Total & & 100 & 100 & 100 \\
\hline
\end{tabular}


TABLE 6.4 Generation Efficiency for Each Region by Technology for Each Charging Scenario

\begin{tabular}{|c|c|c|c|c|c|c|c|c|c|c|c|c|}
\hline & \multicolumn{3}{|c|}{ WECC $(\%)$} & \multicolumn{3}{|c|}{ IL $(\%)$} & \multicolumn{3}{|c|}{ NY-ISO (\%) } & \multicolumn{3}{|c|}{ NE-ISO (\%) } \\
\hline & Unconst. & $\begin{array}{c}\text { 3-h- } \\
\text { delayed }\end{array}$ & $\begin{array}{c}\text { Smart } \\
\text { charging }\end{array}$ & Unconst. & $\begin{array}{c}\text { 3-h- } \\
\text { delayed }\end{array}$ & $\begin{array}{c}\text { Smart } \\
\text { charging }\end{array}$ & Unconst. & $\begin{array}{c}\text { 3-h- } \\
\text { delayed }\end{array}$ & $\begin{array}{c}\text { Smart } \\
\text { charging }\end{array}$ & Uncons. & $\begin{array}{c}\text { 3-h- } \\
\text { delayed }\end{array}$ & $\begin{array}{c}\text { Smart } \\
\text { charging }\end{array}$ \\
\hline \multicolumn{13}{|l|}{ Coal-Fired Power Plants } \\
\hline Utility boiler & 30.2 & 33.1 & 33.4 & 21.2 & 22.1 & 27.1 & 34.5 & 34.5 & 34.5 & 35.2 & 35.2 & 35.2 \\
\hline IGCC & N/A & N/A & N/A & $\mathrm{N} / \mathrm{A}$ & $\mathrm{N} / \mathrm{A}$ & N/A & N/A & $\mathrm{N} / \mathrm{A}$ & N/A & $\mathrm{N} / \mathrm{A}$ & N/A & N/A \\
\hline \multicolumn{13}{|l|}{ Natural Gas Power Plants } \\
\hline Utility boiler & 33.8 & 33.8 & 35.9 & 27.0 & 27.0 & 27.0 & 33.9 & 32.2 & 33.2 & 31.5 & 31.5 & 31.5 \\
\hline Combined-cycle gas turbine & 50.4 & 50.4 & 50.4 & 53.0 & 46.8 & 45.4 & 48.2 & 48.2 & 48.2 & 46.6 & 43.3 & 44.4 \\
\hline Combustion turbine & 35.5 & 35.2 & 38.1 & 34.9 & 35.4 & 38.0 & 37.7 & 36.6 & 35.0 & 37.6 & 36.6 & 35.7 \\
\hline \multicolumn{13}{|l|}{ Residual Oil Power Plants } \\
\hline \multicolumn{13}{|l|}{ Biomass Power Plants } \\
\hline Utility boiler & 25.3 & 26.5 & 23.8 & N/A & N/A & N/A & 19.7 & 21.5 & 22.2 & 12.1 & 15.3 & 16.0 \\
\hline IGCC & N/A & N/A & $\mathrm{N} / \mathrm{A}$ & $\mathrm{N} / \mathrm{A}$ & $\mathrm{N} / \mathrm{A}$ & N/A & $\mathrm{N} / \mathrm{A}$ & $\mathrm{N} / \mathrm{A}$ & N/A & $\mathrm{N} / \mathrm{A}$ & N/A & $\mathrm{N} / \mathrm{A}$ \\
\hline
\end{tabular}


TABLE 6.5 Generation Efficiency for United States, Northeastern United States, and California by Technology

\begin{tabular}{lc}
\hline & $\begin{array}{c}\text { U.S., Northeastern U.S., and California Average } \\
\text { Generation Efficiency (\%) }\end{array}$ \\
\hline Coal-Fired Power Plants Default)
\end{tabular}

TABLE 6.6 Electricity Transmission and Distribution Losses

\begin{tabular}{lc}
\hline \multicolumn{1}{c}{ Region } & 2020 Loss (\%) \\
\hline & \\
NE-ISO & 8.0 \\
NY-ISO & 8.0 \\
IL & 6.8 \\
WECC & 9.4 \\
CA & 9.7 \\
U.S., NE U.S., and CA Average & 8.0 \\
Generation (GREET Default) & \\
\hline
\end{tabular}

\subsection{WELL-TO-WHEELS SIMULATION METHODOLOGY}

We employed Argonne's GREET model to evaluate the WTW energy use and GHG emissions by tracking their occurrences from the primary energy source (well) to the vehicle's wheels for each vehicle technology (Wang 1999). The WTW analysis of PHEVs in GREET is separated into three distinct parts: grid electricity use in CD operation, fuel use in CD operation, and fuel use in CS operation. It should be noted that the combined operation of the electric motor and engine contribute to the same VMT in CD blended mode; thus their per-mile energy use and emissions must be added to properly characterize the PHEV in CD operation. The data listed in Table 3.3 represent only the energy use in the PTW (vehicle operation) stage. The PTW GHG emissions are calculated based on the carbon content of the fuel and the engine's emissions characteristics. The electricity use by the vehicle does not produce any GHG emissions because 
all emissions have already occurred upstream of the vehicle, during the electric power generation and transmission stage (WTP). Thus, the WTP energy use and emissions must be calculated to account for their occurrences during electricity generation, as well as during fuel production and transportation to the refueling (or recharging) location. For each of the WTP and PTW stages, GREET calculates total energy use, fossil energy use (combining petroleum, natural gas, and coal), petroleum energy use, and carbon dioxide $\left(\mathrm{CO}_{2}\right)$-equivalent $\mathrm{GHG}$ emissions. The $\mathrm{GHG}$ emissions calculation combines $\mathrm{CO}_{2}$, methane $\left(\mathrm{CH}_{4}\right)$, and nitrous oxide $\left(\mathrm{N}_{2} \mathrm{O}\right)$ with their global warming potentials of 1,25 , and 298, respectively, as recommended by the latest Intergovernmental Panel on Climate Change for a 100-year time horizon (IPCC 2008).

We examined the CS operational mode separately from the CD mode for all PHEVs. For the CS mode, we calculated and combined the energy use and emissions associated with the fuel production and transportation to the pump (WTP) with the energy use and emissions by the vehicle (PTW) in the form of a stacked bar that represents the WTW result for that mode of operation. The PTW results are arbitrarily stacked on top of the WTP results in all graphical representations in Section 6.3. The CD mode involves both fuel and electricity use that together contribute to the same VMT in that mode. For the CD mode of operation, we calculated the WTP energy use and emissions for fuel use and for electricity use and combined them with the PTW energy use and emissions in the form of a stacked bar. Note that there is only energy use — but no emissions - associated with the electricity use by PHEVs. Thus, the WTW energy use bar for CD mode comprises four components, while the WTW emissions bar comprises only three components. Finally, we combined the WTW results of the CD and CS modes by employing the utility factor method, as explained in Section 3.4.

\subsection{WTW SIMULATION RESULTS}

Figures 6.1 show the WTW total energy use for PHEV10 (power-split configuration) and PHEV40 (series configuration) side-by-side for different fuel/vehicle systems. The WECC marginal mix for the unconstrained charging scenario was assumed for PHEV recharging in Figure 6.1. As shown in Table 6.1, the marginal generation mix for the WECC region is dominated by a low-carbon fuel ( $>99 \%$ natural gas) — the majority of which $(88 \%)$ is provided by the efficient NGCC technology. Two stacked bars for CD and CS operations are shown in Figure 6.1 for each vehicle technology. The stacked bar for the CD operation consists of four components representing the vehicle's (PTW) electricity and fuel use, followed by the upstream (WTP) stages of electricity generation and fuel production, from top to bottom, respectively. The

stacked bar for the CS operation consists of the engine's fuel consumption, followed by the upstream stage of the fuel production. Note that the total energy includes fossil energy (e.g., petroleum, natural gas, and coal) as well as nonfossil energy (e.g., nuclear and renewables). For example, the WTW total energy for E85 includes the renewable energy of the corn kernels that is embedded in the ethanol fuel.

In Figure 6.1, the top component of the CD bar represents the amount of electricity acquired from the grid to recharge the batteries of PHEVs. It is interesting to note that the series design (PHEV40) allows for more electricity use per VMT in CD mode compared with the power-split design (PHEV10) because of better utilization of the battery's energy by the 
vehicle's control strategy. Because the marginal electricity generation efficiency is relatively high for the WECC region, the WTW total energy use is lower for CD operation of the series PHEV compared with the split design in that region. However, even with such an efficient pathway for electricity generation, the CD operation of the gasoline series PHEV barely matches the regular gasoline HEV with respect to WTW efficiency. Conversely, CS operation of the gasoline series PHEV has lower WTW efficiency (i.e., higher total energy use) compared with the regular gasoline HEV and much lower WTW efficiency compared with the power-split PHEV because of the driveline inefficiencies associated with CS operation of the series PHEV configuration. The power-split gasoline PHEV has higher WTW efficiency compared with the regular gasoline HEV because of the higher usable energy of PHEV battery that allows for a more efficient hybridization.

The fossil energy use shown in Figure 6.2 exhibits a trend similar to that of total energy use, except for E85, which discounts the renewable energy embedded in the bioethanol fuel. Figure 6.3 shows the petroleum energy use for the different PHEV fuel/vehicle systems. For gasoline and diesel, the electricity use in CD operation reduces petroleum use relative to CS operation, and the series design (PHEV40) uses less petroleum than the power-split design (PHEV10) in the CD mode. PHEVs using E85 exhibit some petroleum dependence because of the $15 \%$ gasoline (by volume) in the E85 blend. All hydrogen PHEV systems almost eliminate dependence on petroleum energy sources. The gasoline and diesel PHEV40 use more petroleum compared with gasoline HEV in CS mode because of the inefficiency of the driveline in the series PHEV configuration.

The WTW GHG emissions for the marginal mix of the WECC region in Figure 6.4 exhibit a similar trend to that of fossil energy use for all PHEV fuel/vehicle systems. All PHEVs recharging from the WECC marginal mix provide significant GHG emission reductions compared with conventional gasoline ICEVs. While the GHG emissions associated with CD operation of the gasoline PHEV10 are only slightly lower than those of the gasoline HEV, the gasoline PHEV40 in CD mode reduces GHG emissions by $15 \%$ compared with the gasoline $\mathrm{HEV}$. The figure also shows that CS operation of the power-split design (PHEV10) produces fewer GHG emissions than CD operation of the series design (PHEV40) across all fuel/vehicle systems for the marginal mix of the WECC region. All operation modes of E85 and $\mathrm{H}_{2} \mathrm{FC}$ PHEVs reduce GHG emissions compared with gasoline HEVs.

Figure 6.5 shows the WTW GHG emissions associated with operation of PHEV40 in CD mode for the marginal mix of WECC under different charging scenarios. The GHG emissions increase when the recharging of PHEVs is delayed by 3 hours compared with the unconstrained case, and they increase further by delaying the recharging to fill the valley of the electric load (during the off-peak hours). The increase in GHG emissions is attributed to the increase in coal power generation share in the marginal mix as the recharging is delayed to occur at off-peak hours (see Table 6.1). The same trend is expected for the State of Illinois because the share of coal in the marginal mix also increases with delay of PHEV recharging to off-peak hours. While the unconstrained charging in WECC results in a 15\% decrease in GHG emissions for the gasoline PHEV40 in CD mode compared with the gasoline HEV, the smart charging scenario eliminates that advantage because of the increased coal share in the marginal mix of that scenario. 


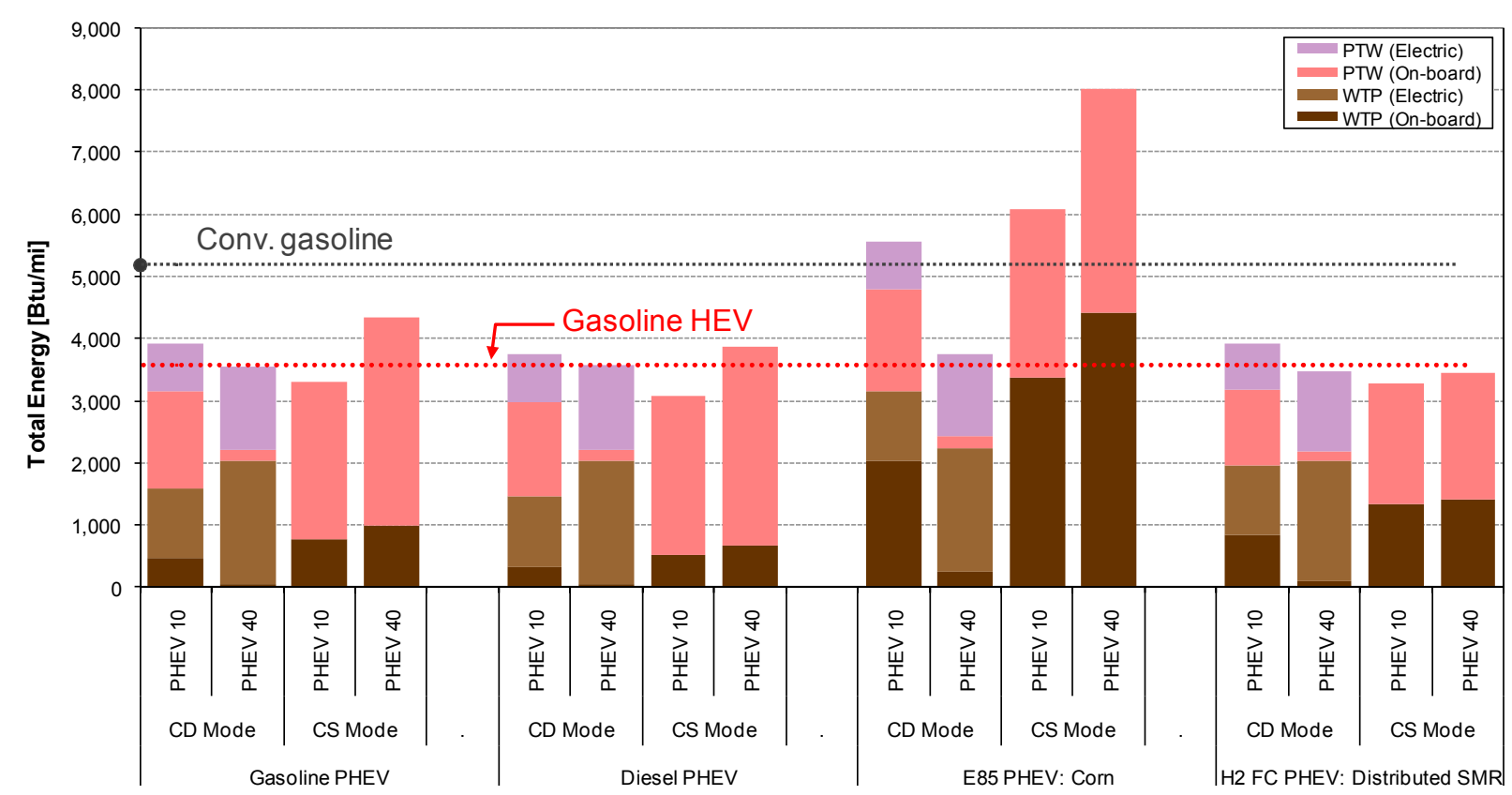

FIGURE 6.1 WTW Total Energy Use for PHEV10 and PHEV40 for Different Fuel/Vehicle Systems (WECC, unconstrained charging)

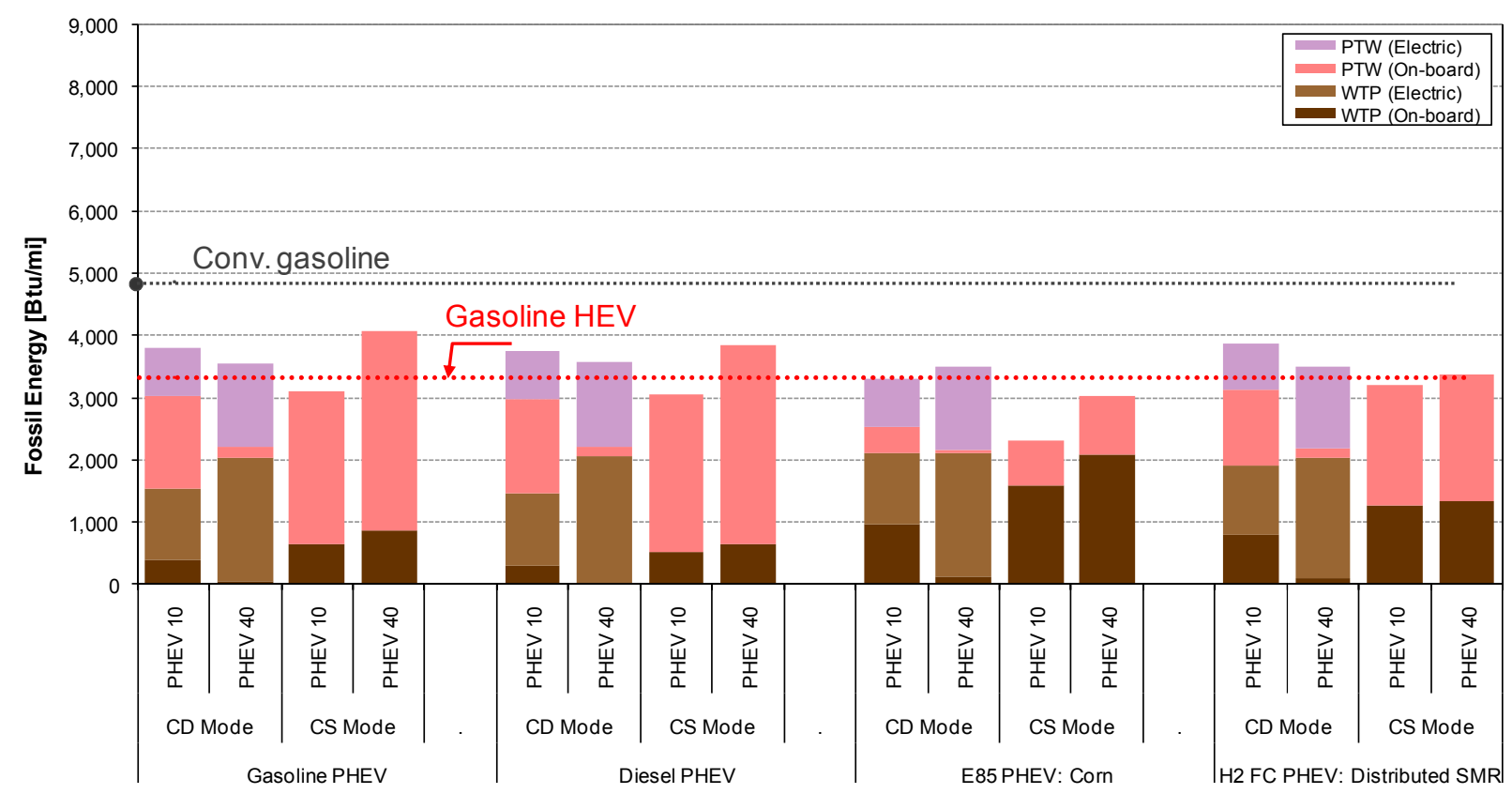

FIGURE 6.2 WTW Fossil Energy Use for PHEV10 and PHEV40 for Different Fuel/Vehicle Systems (WECC, unconstrained charging) 


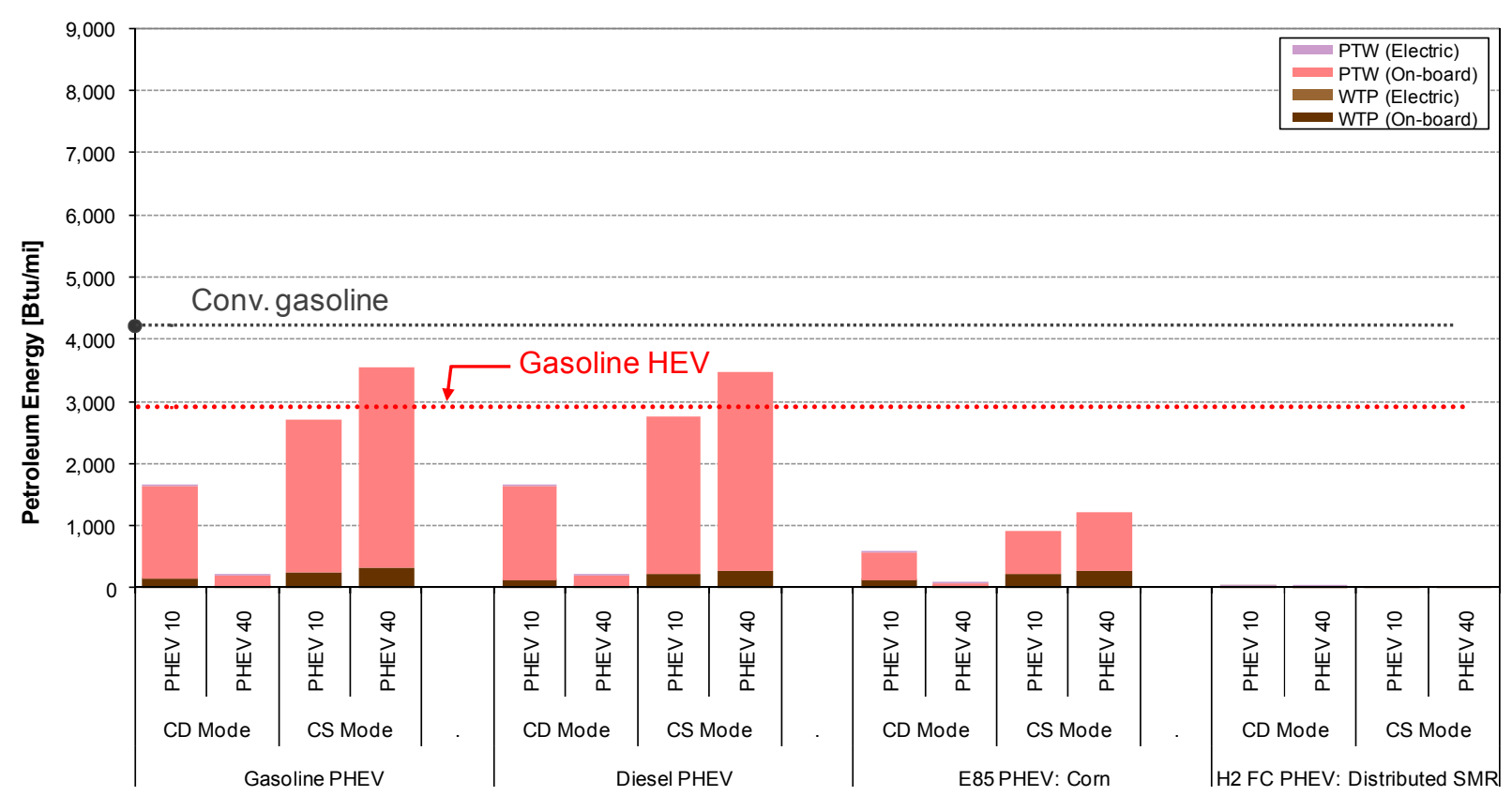

FIGURE 6.3 WTW Petroleum Energy Use for PHEV10 and PHEV40 for Different Fuel/Vehicle Systems (WECC, unconstrained charging)

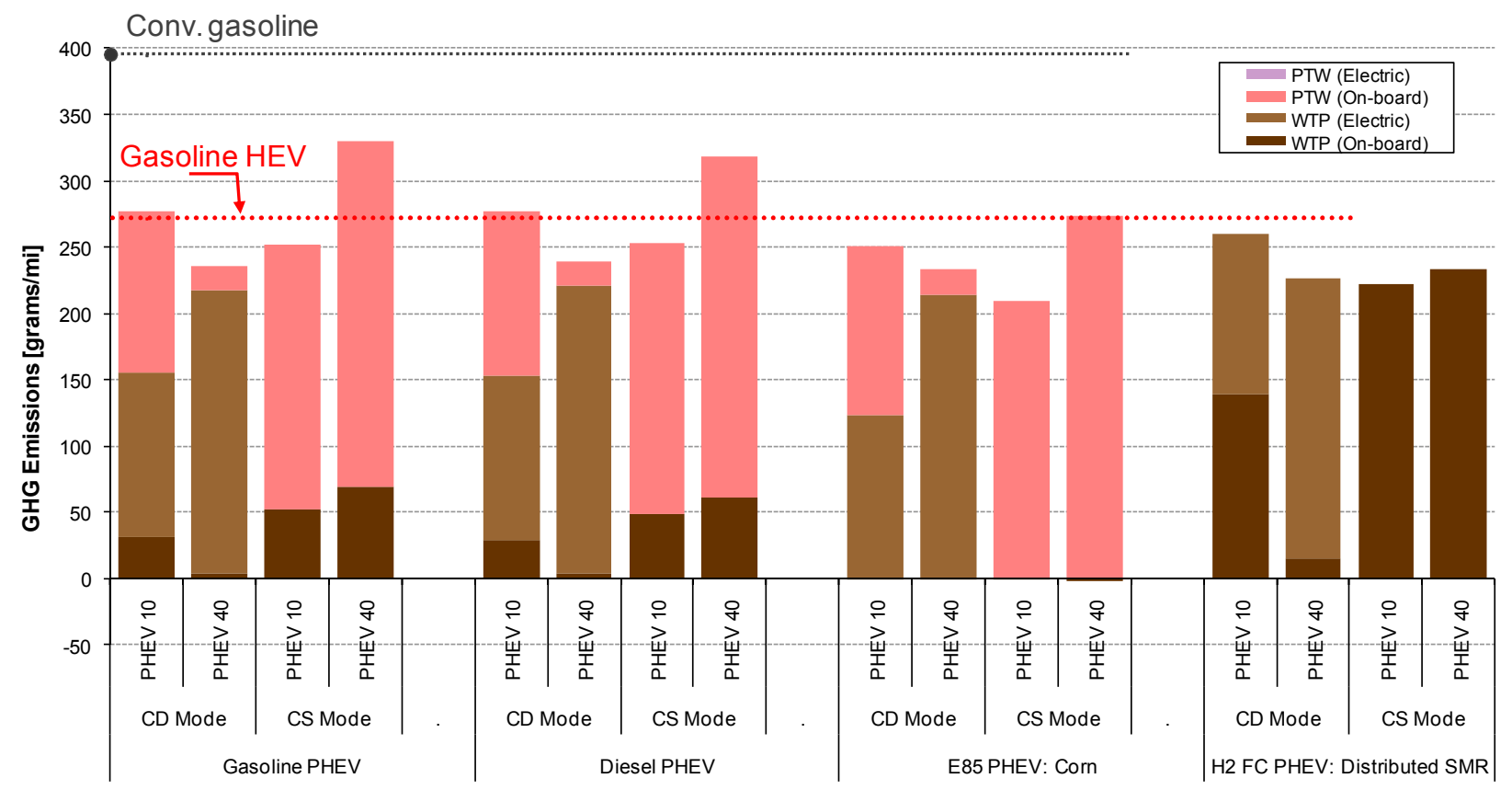

FIGURE 6.4 WTW GHG Emissions for PHEV10 and PHEV40 for Different Fuel/Vehicle Systems (WECC, unconstrained charging) 


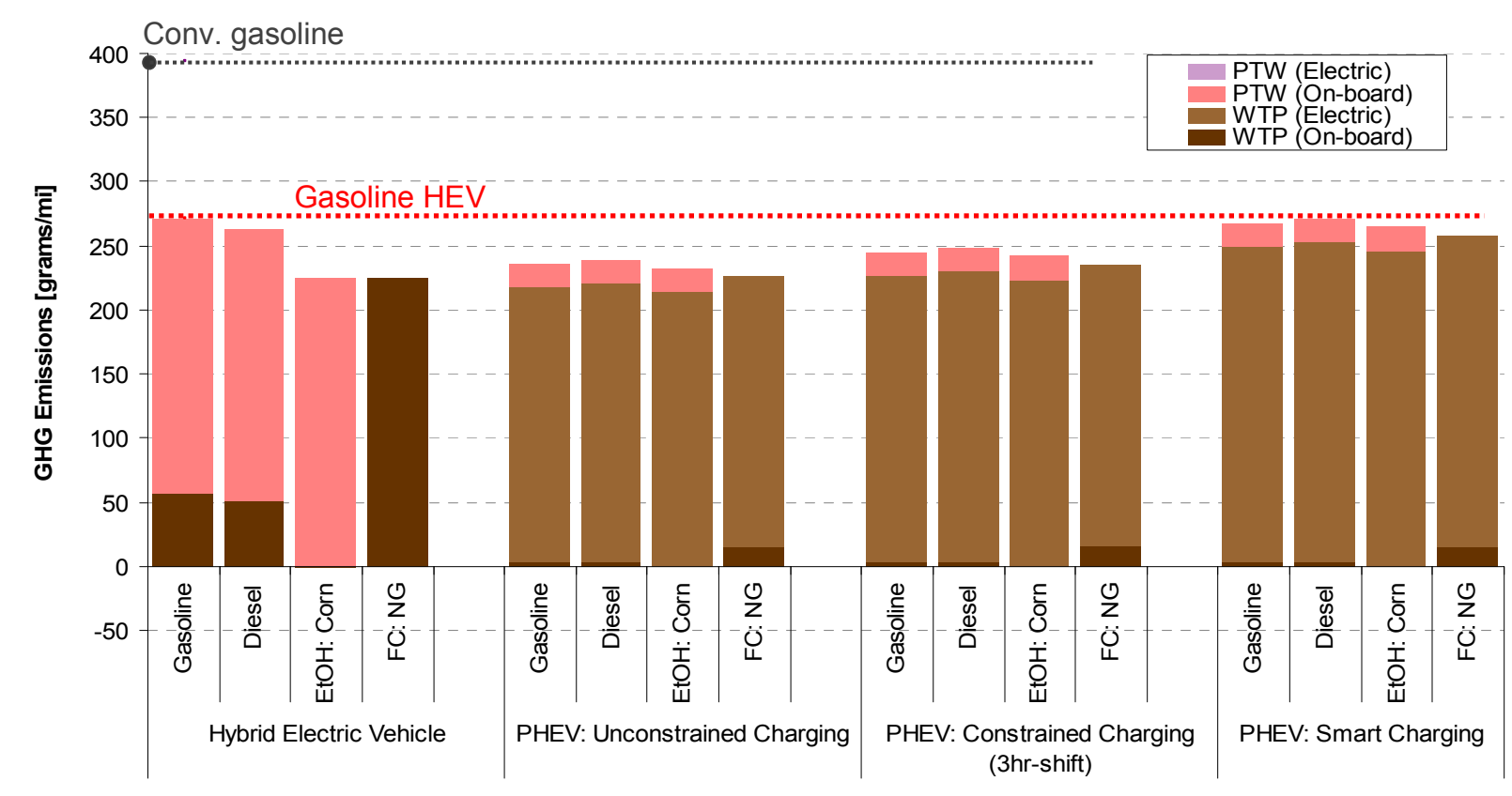
FIGURE 6.5 WTW GHG Emissions for HEV and CD Operation of PHEV40 with Different
Charging Scenarios in the WECC Region

Figure 6.6 highlights the impact of the marginal generation mix on the GHG emissions associated with the CD operation of PHEVs. For the unconstrained charging scenario, the marginal mix in New York, California, and WECC is dominated by natural gas generation technologies, while the marginal mix is dominated by coal in Illinois (see Table 6.1). The WECC marginal generation mix is less efficient compared with New York because of the lower share of NGCC (see Table 6.3), resulting in slightly higher GHG emissions per kWh of electricity generated for PHEV recharging. While California is part of WECC, it exhibits significantly fewer GHG emissions compared with WECC as a whole, which implies that the remainder of WECC (excluding California) would experience higher GHG emissions compared with California and WECC. This is because the coal generation that would otherwise have been exported to California from the rest of WECC has been used to satisfy the load increase due to PHEVs in that region, while the California PHEV load is served by generation from newly added NGCC capacity in California (Section 5), resulting in lower GHG emissions for California but much higher GHG emissions for the rest of WECC. This result highlights the possibility of GHG emissions displacement within interconnected regions due to PHEV load in these regions. Thus, the system boundary for WTW analysis should be expanded to include the combined GHG emissions for interdependent regions, which is the entire WECC region in this case.

Figure 6.7 shows the WTW petroleum energy use for combined CD and CS operations of PHEVs as a function of rated AER. The UFs for combining the CD and CS WTW results are $25 \%, 43 \%, 42 \%$, and $51 \%$ for PHEV 10, 20, 30, and 40, respectively. The WTW results at $\mathrm{AER}=0$ represents the regular HEVs. As expected, the petroleum energy use decreases significantly with a corresponding increase in AER for petroleum-based fuels (e.g., gasoline and 


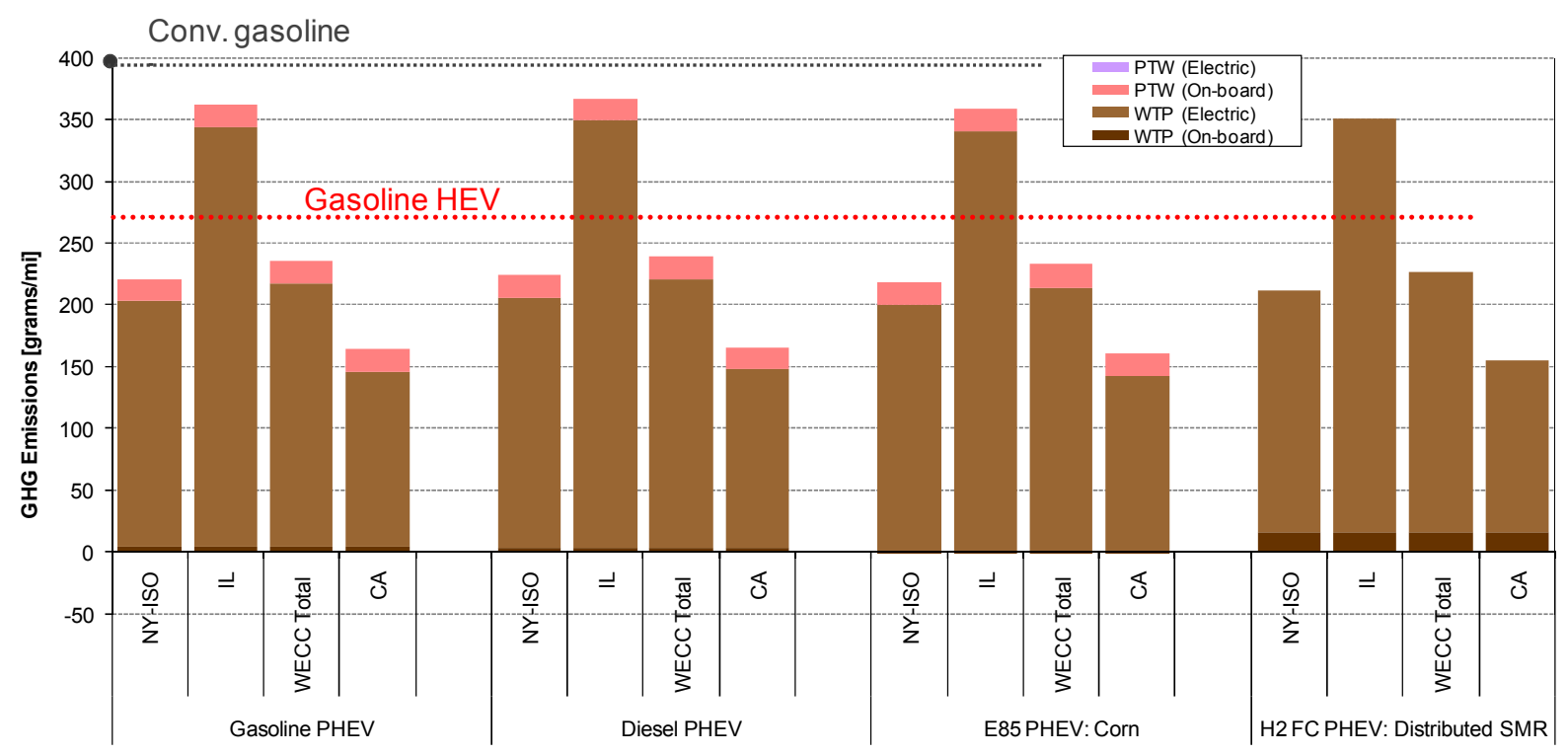

FIGURE 6.6 WTW GHG Emissions for CD Operation of PHEV40 with Unconstrained Charging in Different Regions

diesel), mainly because of the displacement of petroleum fuels with electricity generated from non-petroleum sources. A gasoline or diesel PHEV 40 provides an approximately $60 \%$ reduction in petroleum energy use compared with a conventional gasoline ICEV. It should be noted that the trend shown in Figure 6.7 is insensitive to the generation mix as long as the mix of fuels for electricity generation is mainly from non-petroleum sources, which is the case for the WECC, Illinois, New York, and U.S. mixes. The reduction in petroleum energy use with the increase in AER is less significant for the E85 PHEVs because of the 15\% share of gasoline in the E85 blend. All hydrogen fuel cell PHEVs are nearly free of petroleum energy use because the feedstock sources of the hydrogen fuel are non-petroleum-based. For all AER ratings, including $\mathrm{AER}=0$ (regular HEV), the petroleum use is significantly reduced relative to the conventional (baseline) gasoline ICEV.

Figures 6.8 and 6.9 show GHG emissions associated with PHEV operation for the best case (WECC, unconstrained charging) and worst case (Illinois, smart charging) recharging scenarios, as predicted by the dispatch modeling simulations, respectively. Figure 6.8 shows a slight decrease in the WTW GHG emissions for the power-split PHEV design (AER10 and 20) compared with the regular HEV (shown as AER0) using petroleum and corn-E85 fuels and recharging from the WECC marginal generation mix (unconstrained scenario). An opposite trend is observed for the series PHEV design (AER30 and 40) because of the driveline inefficiencies in CS operation (as explained earlier). All PHEVs employing fuels produced from biomass sources (e.g., E85 and hydrogen produced from switchgrass) exhibit a significant increase in GHG emissions as AER increases, regardless of the PHEV design configuration. This trend is attributed to much lower carbon emissions associated with these bio-based fuel options, which favors the use of the biofuel rather than the electricity generated from fossil fuels, even if the fossil fuel for electricity generation is a low carbon fuel (i.e., natural gas) and the generation 


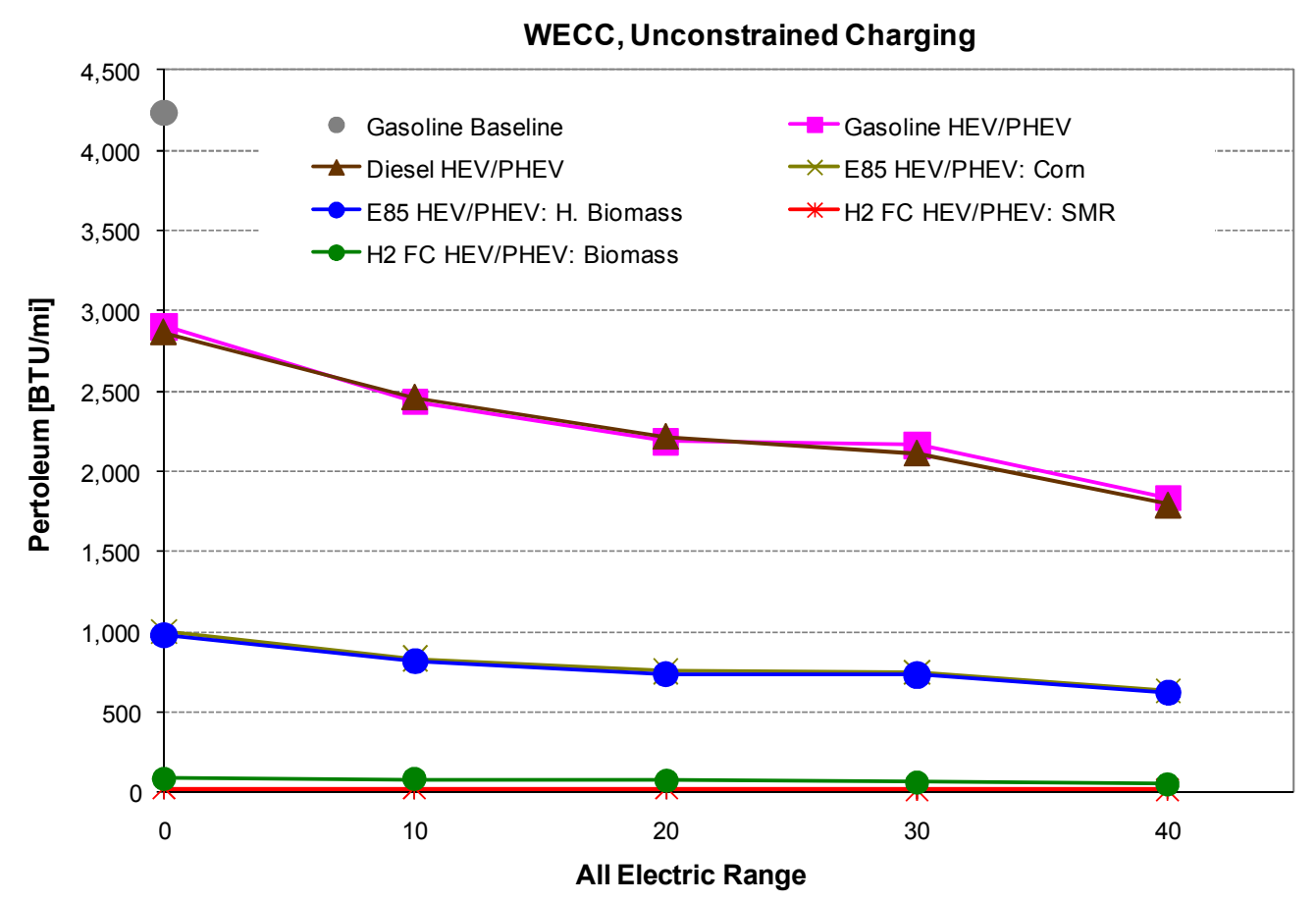

Figure 6.7 WTW Petroleum Energy Use for Combined CD and CS Operations of PHEVs as a Function of Rated AER (Note: Regular HEV and conventional gasoline ICEV are represented at AER=0)

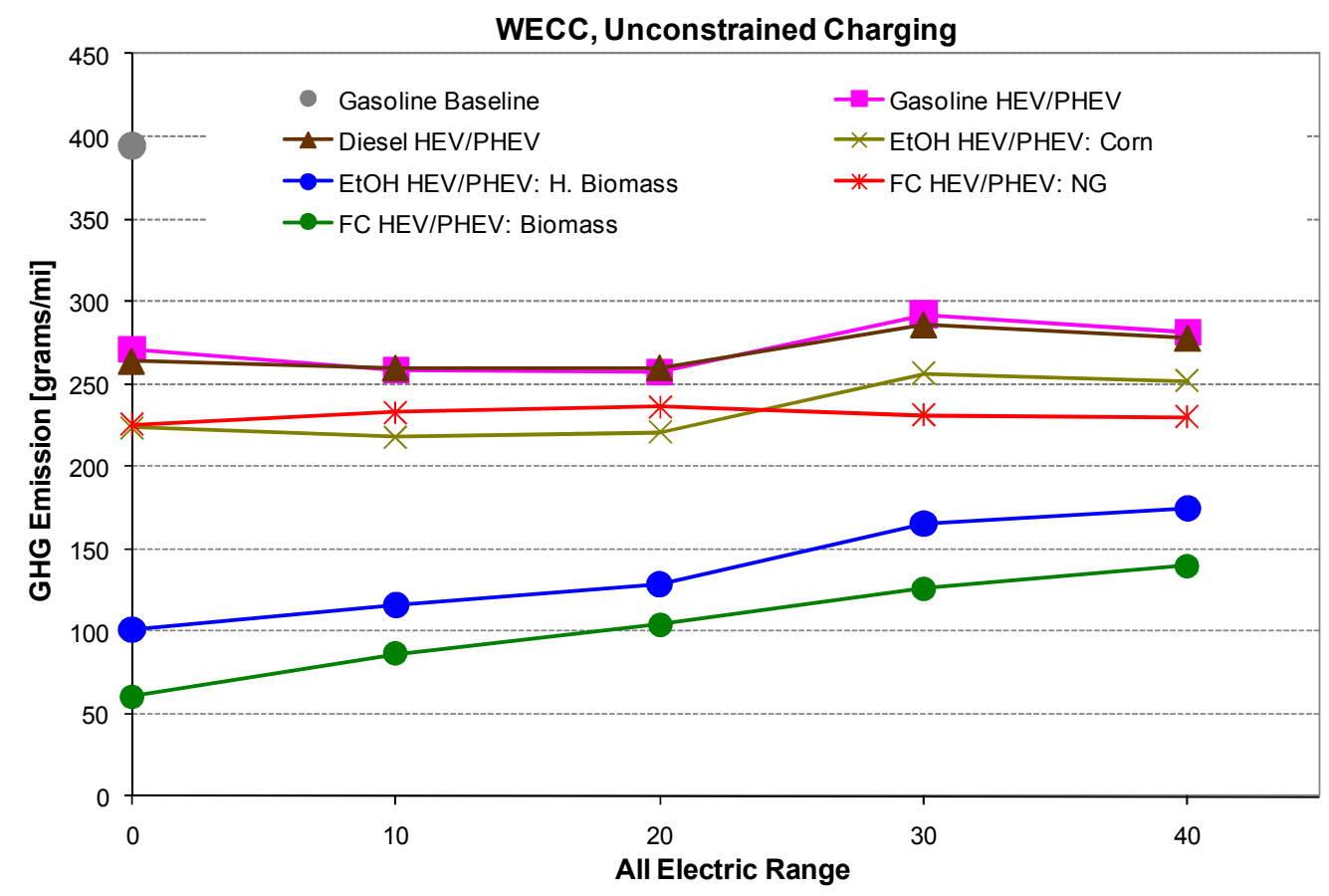

FIGURE 6.8 WTW GHG Emissions for Combined CD and CS Operations of PHEVs in WECC (unconstrained charging scenario) as a Function of Rated AER (Note: Regular HEV and conventional gasoline ICEV are represented at $\mathrm{AER}=0$ ) 


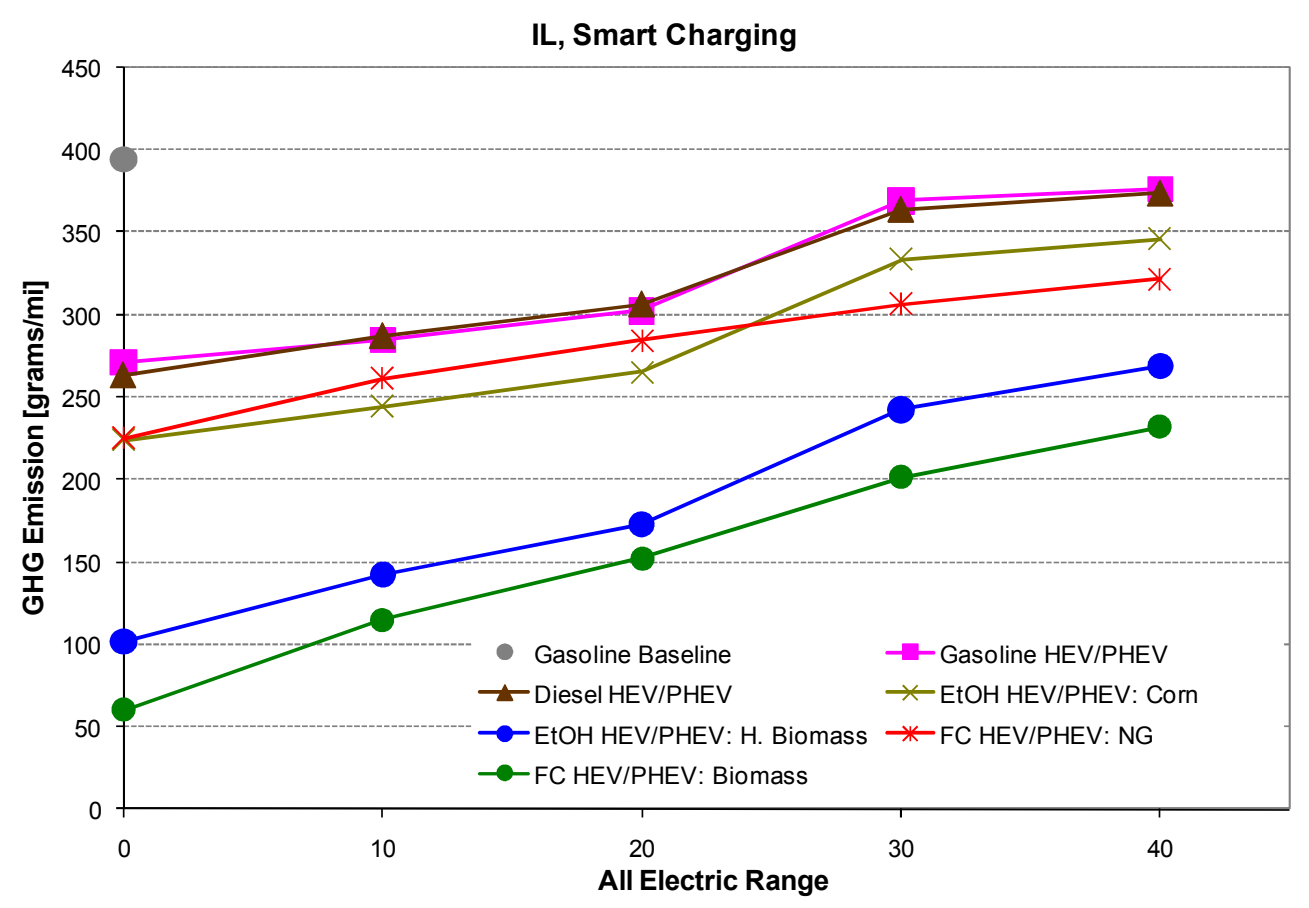

FIGURE 6.9 WTW GHG Emissions for Combined CD and CS Operations of PHEVs in IL (smart charging scenario) as a Function of Rated AER (Note: Regular HEV and conventional gasoline ICEV are represented at $\mathrm{AER}=0$ )

efficiency is high $(\sim 50 \%)$ - the case in the WECC region. Thus, PHEVs that employ biomassbased fuels (e.g., biomass-E85 and biomass-hydrogen) may not realize GHG emissions benefits compared with regular HEVs if the marginal generation mix is dominated by fossil sources.

Figure 6.9 shows that all PHEVs recharging from the Illinois marginal generation mix (smart charging scenario) exhibit significant increases in GHG emissions compared with the regular HEVs because coal dominates that generation mix $(99.5 \%$ coal). The GHG emissions of PHEVs increase proportionally with AER with a jump in emissions observed for the series configuration (PHEV30 and 40). The GHG emissions of the gasoline PHEV40 are shown to approach those of conventional gasoline ICEV for that generation mix.

Figures 6.10 through 6.12 show the GHG emissions associated with the combined CD and CS operation of PHEVs, as well as the CD operation of BEVs for the U.S. average mix, the Northeastern U.S. average mix, and the California average mix, respectively. Please note that we could only examine BEVs with these average generation mixes since we did not consider any BEV market penetration in our utility dispatch simulations. Figure 6.10 for the U.S. average mix shows that GHG emissions from the power-split design of gasoline, diesel, and corn-E85 PHEVs are only slightly lower than those of the regular HEVs, while the corresponding series designs exhibit significantly more WTW GHG emissions compared with the regular HEVs. This is attributed to the high share of coal in the U.S. generation mix (see Table 6.3). All PHEVs powered by biomass-based fuels (e.g., E85 and $\mathrm{H}_{2}$ from switchgrass) show significant increases 


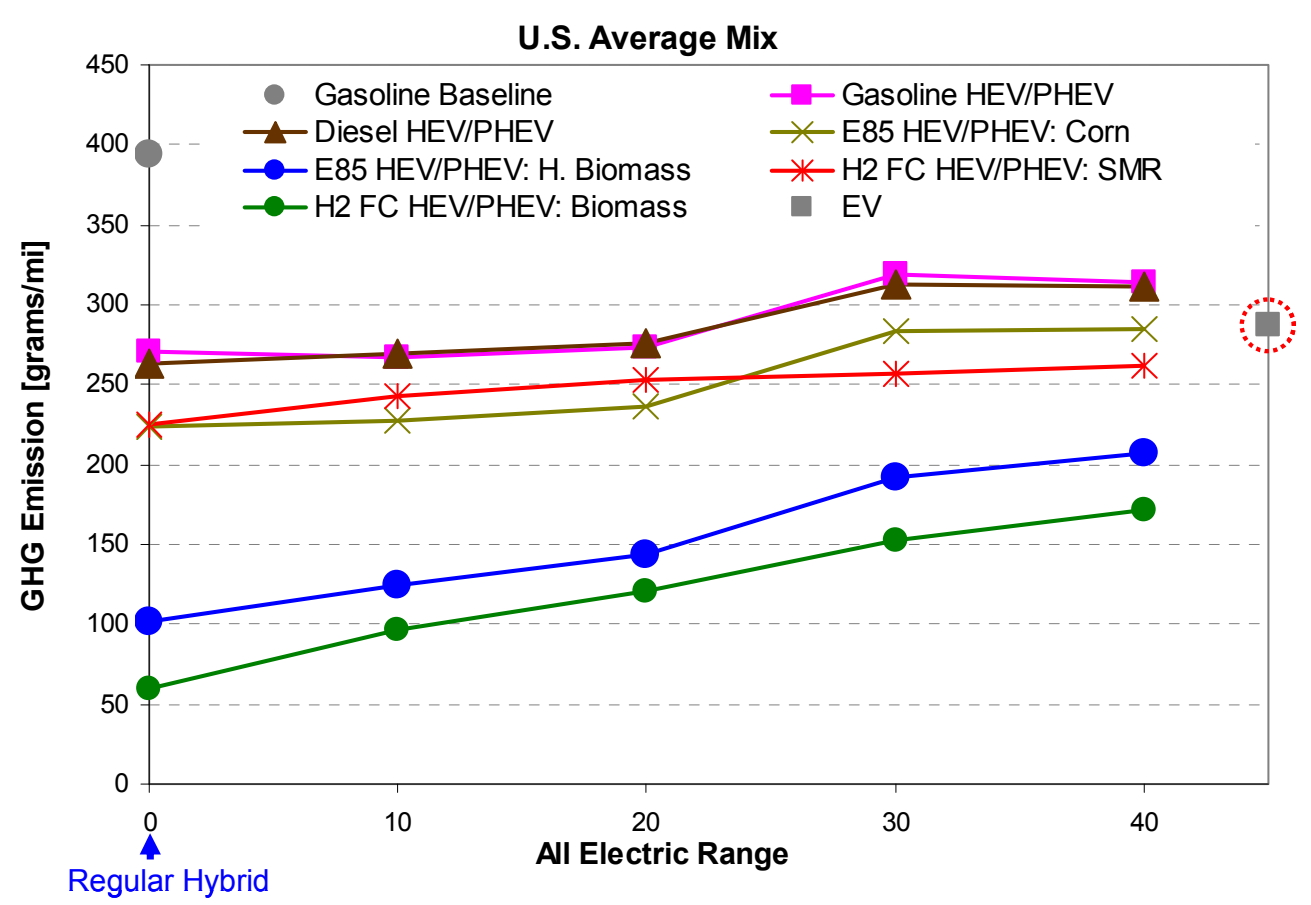

FIGURE 6.10 WTW GHG Emissions for Combined CD and CS Operations of PHEVs as a Function of Rated AER Using the U.S. Average Generation Mix

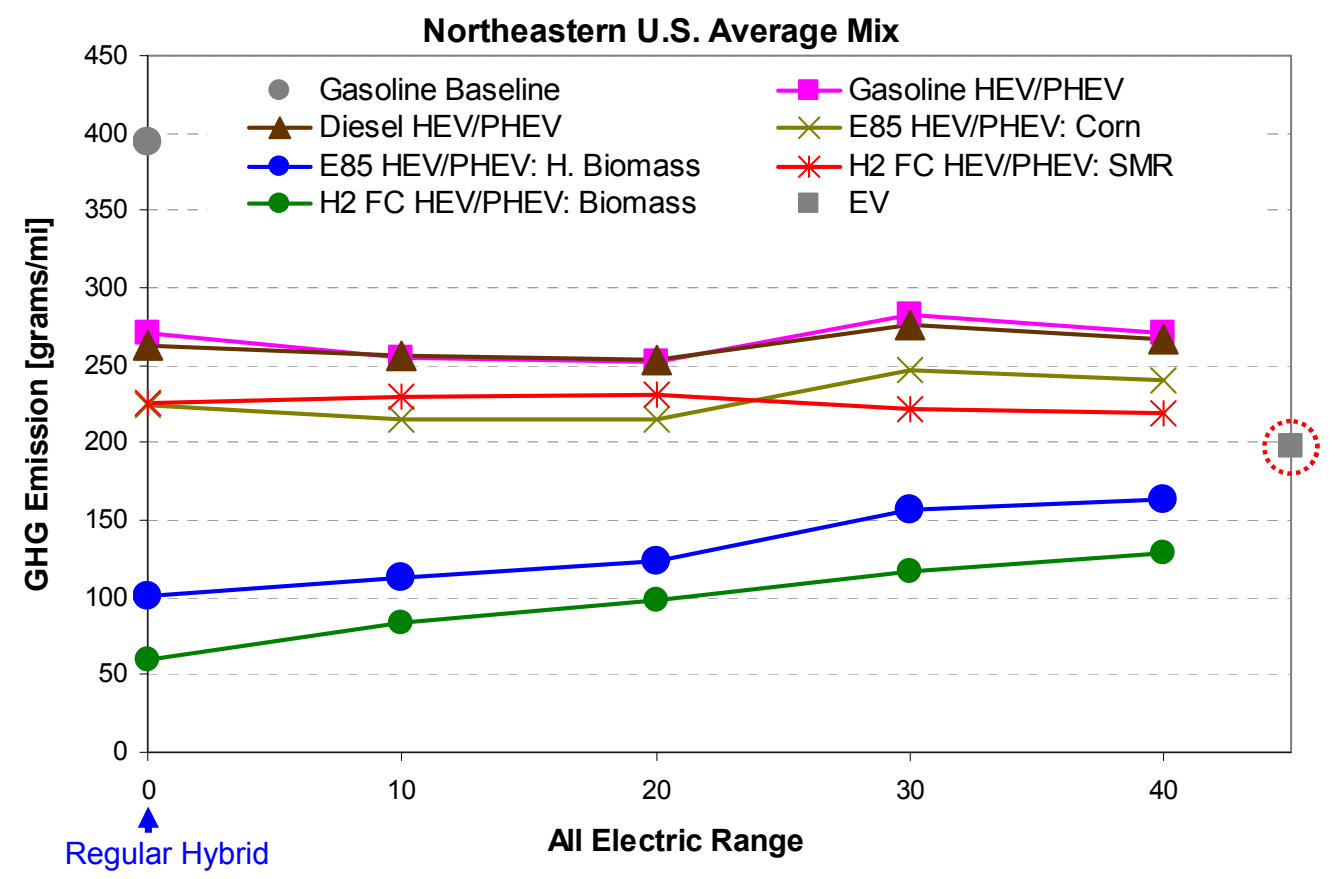

Figure 6.11 WTW GHG Emissions for Combined CD and CS Operations of PHEVs as a Function of Rated AER Using the Northeastern U.S. Average Generation Mix 


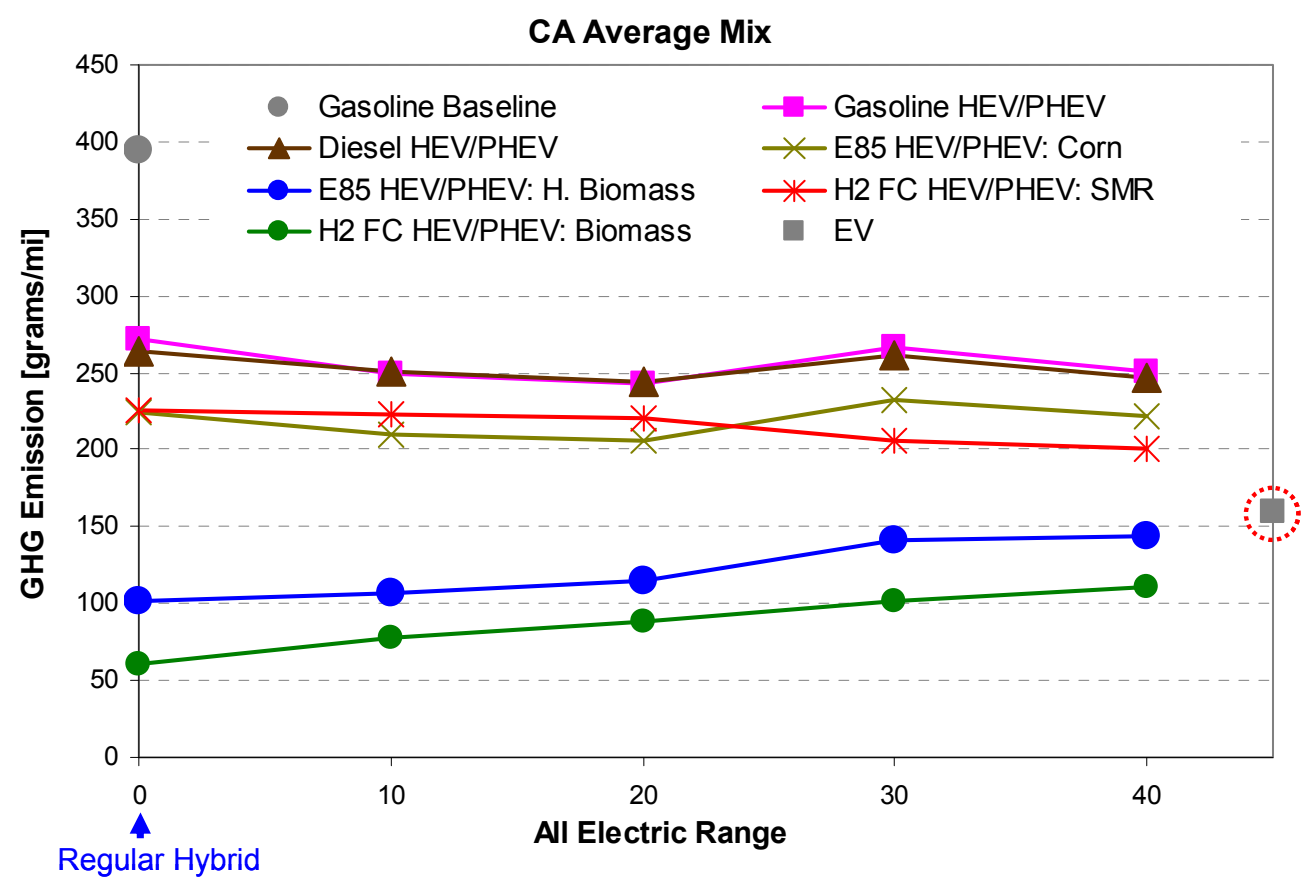

FIGURE 6.12 WTW GHG Emissions for Combined CD and CS Operations of PHEVs as a Function of Rated AER Using the CA Average Generation Mix

in GHG emissions, proportional with their rated AER. Figure 6.10 also shows that WTW GHG emissions for BEVs (recharging from the U.S. average mix) are 30\% lower than those of the baseline gasoline ICEV, but higher than those of all HEVs. For PHEVs employing petroleum fuels and corn-E85 and recharging from the Northeastern U.S. average mix, the WTW GHG emissions are marginally lower for the power-split design, but higher for the series design relative to the corresponding HEVs, as shown in Figure 6.11. The WTW GHG emissions of BEVs for the average mix in the Northeastern U.S. region are lower than those of all HEVs and PHEVs because of the smaller coal share and larger nuclear share in the average generation mix of that region (see Table 6.3). For the California average mix (Figure 6.12), the WTW GHG emissions for power-split PHEVs are similar to those recharging from the Northeastern U.S. average mix, but the series PHEVs and BEVs exhibit much lower emissions because of the much smaller share of coal and much larger share of renewable energy sources in the California average mix.

Figure 6.13 summarizes the most significant WTW results for CD operation of PHEVs, HEVs, and the baseline gasoline ICEV. The figure includes WTW results for the marginal generation mixes of WECC, New York, and Illinois (unconstrained scenario), in addition to the U.S. average generation mix and a renewable mix scenario. The WTW petroleum energy use and GHG emissions of all alternative fuel/vehicle systems are normalized by the per-mile petroleum energy use and GHG emissions of the baseline conventional gasoline ICEV. Similarly, Figure 6.14 summarizes the WTW results for the combined CD and CS operations of PHEVs using the UF method. The figure shows these results for the combined CD and CS operations by employing 25\% and 51\% UFs for the PHEV 10 and PHEV 40, respectively. Before discussing 
the WTW results in Figures 6.13 and 6.14, we provide the following guidelines to facilitate easier interpretation of these two figures.

- The reference point for comparison with all PHEVs is $(1,1)$, which represents the baseline conventional gasoline ICEV's petroleum energy use and GHG emissions as the comparison basis.

- The color of the marker represents a particular PHEV fuel/vehicle technology.

- The shape of the marker represents the marginal generation mix used for recharging the PHEV batteries.

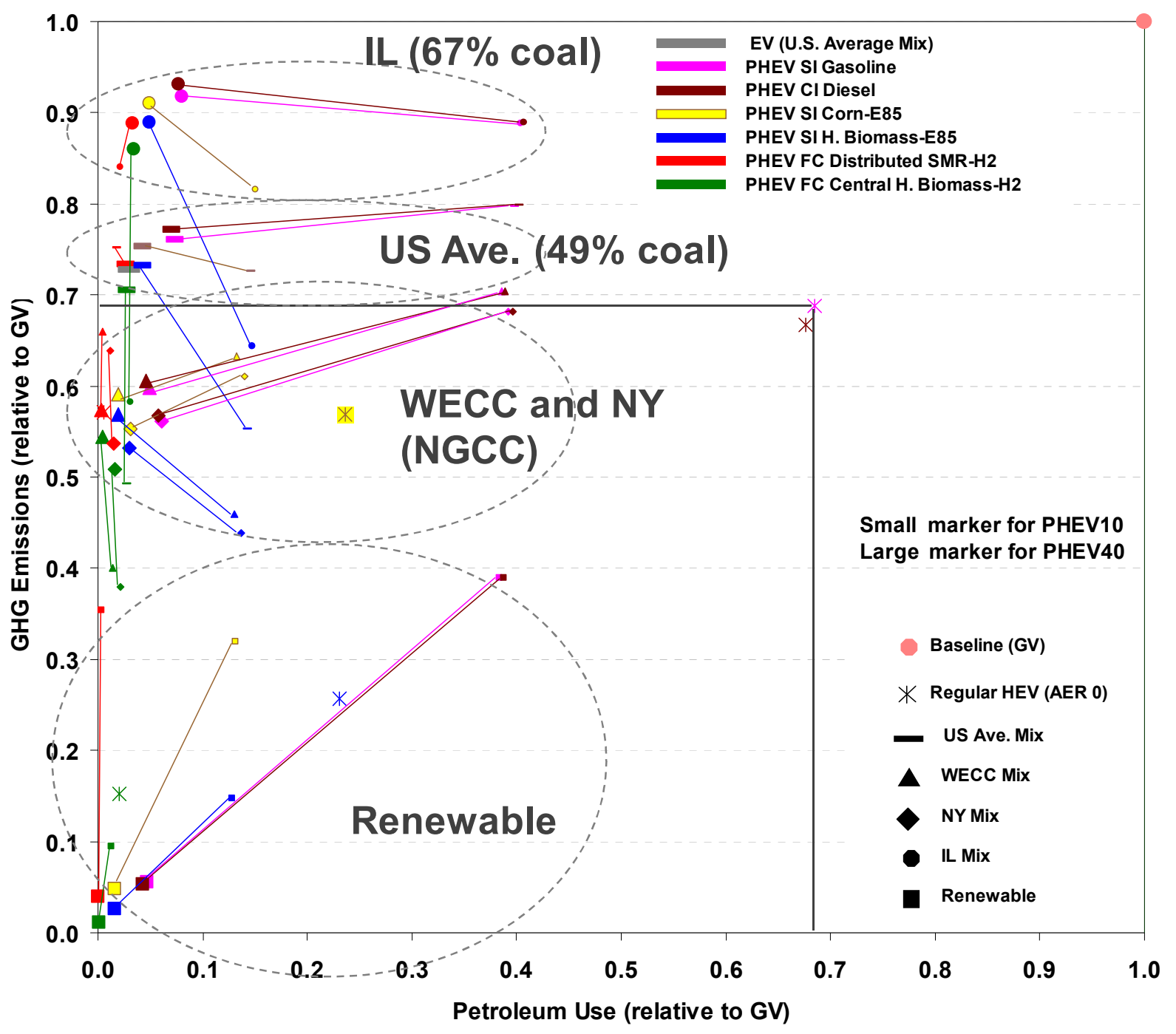

FIGURE 6.13 WTW Petroleum Use and GHG Emissions for CD Operation of PHEVs (unconstrained charging) 


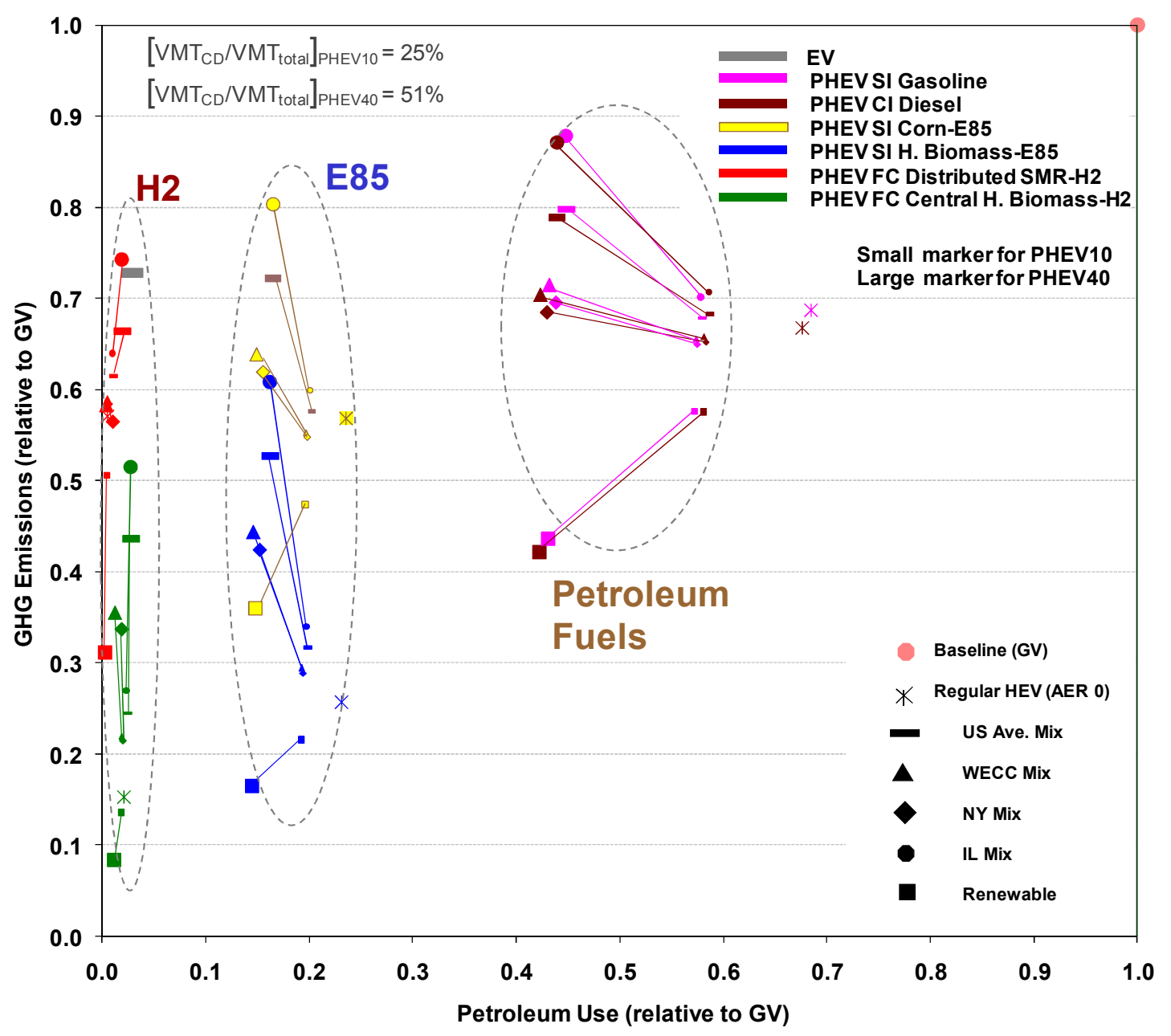

FIGURE 6.14 WTW Petroleum Use and GHG Emissions for Combined CD and CS Operation of PHEVs (unconstrained charging)

- The size of the marker represents the AER rating of that PHEV (small marker for powersplit PHEV10 and large marker for series PHEV40).

- A line connects the PHEV10 marker to the PHEV40 marker to indicate the incremental petroleum energy use and GHG emissions associated with the change in PHEV type from power-split design for PHEV10 to series design for PHEV40. The relative change in petroleum energy use and GHG emissions with PHEV type and AER can be represented by the respective horizontal and vertical components of a vector extending from the PHEV10 marker to the PHEV40 marker.

- The scattered markers represent the HEVs, as well as the baseline gasoline ICEV.

- All fuel/vehicle systems that fall inside the frame bounded by the two points $(0,0)$ and $(1,1)$ provide a reduction in per-mile petroleum energy use and GHG emissions relative to the conventional gasoline ICEV. 
- All fuel/vehicle systems that fall inside the frame bounded by the two points $(0,0)$ and $(0.69,0.69)$ provide a reduction in per-mile petroleum energy use and GHG emissions relative to the gasoline $\mathrm{HEV}$.

- The vehicle technology is less dependent on petroleum energy if its marker is closer to the vertical coordinate. Similarly, the vehicle technology produces less GHG emissions as its marker gets closer to the horizontal coordinate.

The implication of the electricity generation mix resides in the electricity generation stage (WTP). In general, the electricity WTP energy use and GHG emissions increase progressively as the marginal mix becomes less efficient and dominated by a larger share of oil or coal. It should be noted that the petroleum share is insignificant in all considered generation mixes; thus, any contribution of grid-electricity to PHEV's VMT would result in a proportional reduction in petroleum energy use.

Figure 6.13 shows the WTW results of PHEVs only for the CD mode of operation (unconstrained charging scenario). The WTW results for CD operation of PHEVs (relative to the gasoline baseline ICEV and HEV) can be grouped by the type of generation mix used for PHEV recharging. Recharging from a mix with a large share of coal generation (e.g., 67\% share in Illinois and 49\% share in the U.S. average mix) results in WTW GHG emissions higher than those of the gasoline HEV but lower than those of the gasoline ICEV. For example, a PHEV40 recharging from the Illinois marginal mix (unconstrained charging) produces WTW GHG emissions that are approximately 10\% lower than those of the gasoline ICEV but 30\% higher than those of the gasoline HEV. Recharging from a mix with a large share of natural gas generation (e.g., WECC and New York marginal generation mix) results in WTW GHG emissions comparable to or less than those of gasoline HEV, but much lower compared with the gasoline ICEV. For example, a PHEV40 recharging from NGCC produces WTW GHG emissions that are 15-20\% lower compared with the gasoline HEV and 40-45\% lower than those of the gasoline ICEV. However, the power-split gasoline PHEV10 produces WTW GHG emissions similar to those of the gasoline HEV. Figure 6.13 shows that the power-split design (AER10) for all PHEVs reduces petroleum use by more than $60 \%$, while the series design (AER40) reduces it by more than $90 \%$. If a renewable or nonfossil generation mix is employed to recharge PHEVs, the power-split configuration could realize reductions in WTW petroleum use and GHG emissions of more than $60 \%$, while the series configuration could realize reductions of more than $90 \%$ in both. The impact of grid decarbonization on the per-mile GHG emissions is demonstrated by the slope of the lines connecting PHEV10 markers to PHEV40 markers.

The WTW results shown in Figure 6.14 for the combined CD and CS operations of PHEVs (relative to the gasoline baseline ICEV and HEV) can be grouped by the type of fuel. Figure 6.14 shows three fuel groups (petroleum, E85, and hydrogen) with distinct petroleum energy use and GHG emissions. The PHEVs that employ petroleum fuels, E85, and hydrogen offer $40-60 \%, 80-90 \%$, and more-than-90\% reductions in petroleum energy use, respectively, compared with the conventional gasoline ICEV. The corresponding reductions in GHG emissions for PHEVs that employ petroleum fuels, E85, and hydrogen are 10-60\%, 20-80\%, and $25-90 \%$, respectively. The spread of the WTW GHG emissions among the different fuel 
groups is much higher compared with the spread of petroleum energy use, mainly because of the wide variation in the electricity generation mix considered for PHEVs in this analysis. This spread of GHG emissions is more apparent for E85 and hydrogen because of the diverse production technologies and feedstock sources considered in this analysis for these fuels. Overall, more petroleum energy savings are realized as the AER of the PHEVs increases. Conversely, more WTW GHG emissions are produced with increased AER, except when a renewable or nonfossil generation mix is used for PHEV recharging. The increase in GHG emissions with AER for the combined CD and CS operations is opposite to the trend observed in Figure 6.13 for CD operation, where GHG emissions are reduced with AER in WECC, New York, and the U.S. average mix. The opposite trend for these generation mixes highlights the impact of the much lower fuel economy in CS mode for the series design (PHEV40) compared with the power-split design (PHEV10), as explained in Section 3.

Figure 6.15 shows the WTW results for CD operation of gasoline power-split and series PHEVs (for both the unconstrained and smart charging scenarios), in addition to the baseline conventional and regular hybrid gasoline vehicles. For the same PHEV powertrain (i.e., powersplit or series design), more petroleum savings and GHG emission reduction are realized with an increase in AER. Furthermore, when the charging of PHEV occurs from a low-carbon generation mix (e.g., NGCC in WECC and NY) or from a renewable source, the series design of PHEV provides significantly more petroleum savings and GHG emissions reduction compared to the power-split design. Figure 6.15 also shows that the unconstrained charging scenario (with investment in new generation capacity) provide less GHG emissions compared to the smart charging scenario (which requires no investment in new capacity) mainly due to the high efficiency and low carbon intensity of the added capacity in the unconstrained charging scenario. 


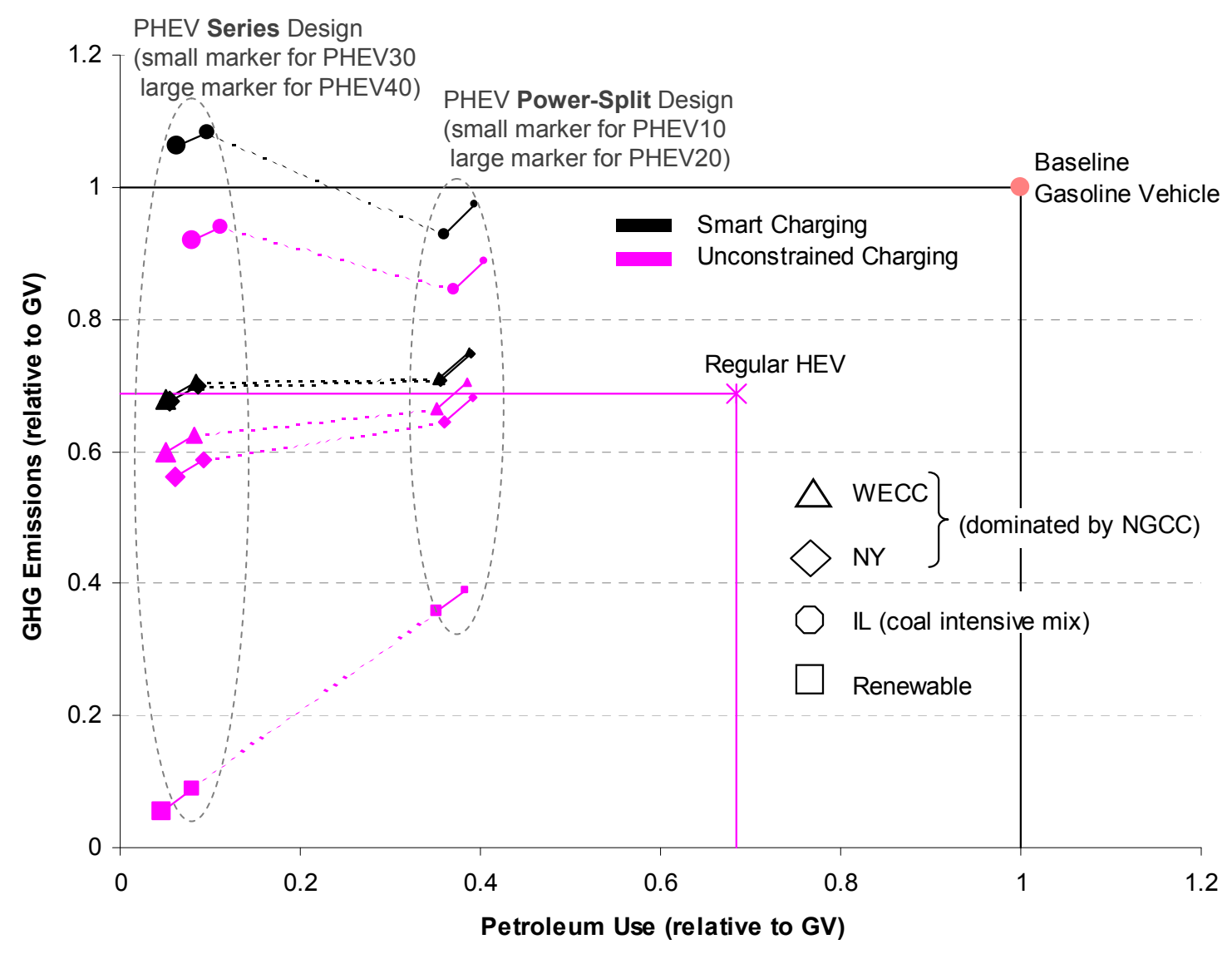

FIGURE 6.15 WTW Petroleum Use and GHG Emissions for CD Operation of Gasoline Vehicles (Conventional, HEV, and PHEVs) 
This page intentionally left blank. 


\section{CONCLUSIONS}

Argonne's WTW analysis of PHEVs revealed that the following factors significantly impact the energy use and GHG emissions results for PHEVs and BEVs compared with baseline gasoline vehicle technologies: (1) the regional electricity generation mix for battery recharging and (2) the adjustment of fuel economy and electricity consumption to reflect "real-world" driving conditions. Although the analysis predicted the marginal electricity generation mixes for major regions in the United States, these mixes should be evaluated as possible scenarios for recharging PHEVs because significant uncertainties are associated with the assumed market penetration for these vehicles. Thus, the reported WTW results for PHEVs should be directly correlated with the underlying generation mix, rather than with the region linked to that mix. The primary conclusion is that electrification of transportation significantly reduces petroleum energy use, but GHG emissions strongly depend on the electricity generation mix for battery recharging. Sections 7.1 and 7.2 summarize petroleum and GHG emissions results for CD operation of gasoline PHEVs and BEVs, and for combined CD and CS operation of PHEVs, respectively.

\subsection{OPERATION OF GASOLINE PHEVS AND BEVS}

\subsubsection{Petroleum Displacement}

In $\mathrm{CD}$ operation modes, PHEVs employing the power-split and series configurations could realize reductions in petroleum energy use of more than $60 \%$ and $90 \%$, respectively, because the petroleum share is small in the electricity generation mix for most regions in the United States. BEVs can virtually eliminate the use of petroleum fuels for each vehicle mile traveled on electricity.

\subsubsection{GHG Emissions}

- Unconstrained charging (with investments in new generation capacity) reduces GHG emissions (Figure ES.1, vertical axis) compared with smart charging (no needed investment in new capacity) because of the high efficiency and low carbon intensity associated with the added capacity in the unconstrained charging scenario.

- PHEVs recharging from a mix with a large share of coal generation (e.g., Illinois marginal mix) produce GHG emissions comparable to those of baseline gasoline ICEVs (with a range from $-15 \%$ to $+10 \%$ ) but significantly higher than those of gasoline HEVs (with a range from $+20 \%$ to $+60 \%$ ). The range of the results is primarily attributable to the different generation mix for the charging scenarios considered and the different PHEV types (power-split versus series designs). 
- PHEVs recharging from a mix with a large share of efficient electricity generation from natural gas (e.g., natural gas combined-cycle [NGCC] generation in the Western Electric Coordinating Council region) produce GHG emissions comparable to those of gasoline HEVs (with a range from $-15 \%$ to $+10 \%$ ) but significantly lower than those of baseline gasoline ICEVs (with a range from $25 \%$ to $-40 \%$ ). The range of results is primarily attributable to the different generation mix for the charging scenarios considered and the different PHEV types (power-split versus series designs).

- PHEVs recharging from a generation mix comparable to the U.S. average mix produce lower GHG emissions than baseline gasoline ICEVs (with a range from $-20 \%$ to $-25 \%$ ) but higher than gasoline HEVs (with a range from $+10 \%$ to $+20 \%)$.

- To achieve significant reductions in GHG emissions, PHEVs and BEVs must recharge from a generation mix with a large share of nonfossil sources (e.g., renewable or nuclear power generation). PHEVs recharging from a potential renewable or nonfossil generation mix reduce GHG emissions by more than $60 \%$ for the power-split PHEV configuration and by more than $90 \%$ for the series configuration compared with baseline gasoline ICEVs. BEVs can virtually eliminate GHG emissions (per mile traveled) if recharged from nonfossil electricity generation.

\subsubsection{Electric Range of PHEVs and BEVs in Real-World Driving}

- The actual CD range of PHEVs could be lower or higher than the rated electric range on the standard driving cycles, depending on the powertrain type and the vehicle's control strategy. Power-split PHEVs extend the electric range because the battery receives significant help from the engine, resulting in blended (i.e., blended use of battery and engine) operation in CD mode. The electric range of BEVs and series PHEVs drops below the rated electric range because of the higher battery discharge rate required to meet real-world driving conditions.

\subsection{COMBINED CD AND CS OPERATION OF PHEVS}

\subsubsection{Petroleum Displacement}

- PHEVs powered by petroleum fuels (i.e., gasoline and diesel) reduce petroleum energy use by $40-60 \%$ compared with conventional gasoline ICEVs, while PHEVs powered by E85 (blend of $85 \%$ ethanol and $15 \%$ gasoline by volume) reduce petroleum energy use by $80-90 \%$, and PHEVs powered by hydrogen reduce petroleum energy use by greater than $90 \%$. 


\subsubsection{GHG Emissions}

- Compared with conventional gasoline ICEVs, PHEVs powered by petroleum fuels (i.e., gasoline and diesel) reduce GHG emissions by 10-60\%, PHEVs powered by E85 (blend of $85 \%$ ethanol and 15\% gasoline by volume) reduce GHG emissions by $20-80 \%$, and PHEVs powered by hydrogen reduce these emissions by $25-90 \%$. The large range of $\mathrm{GHG}$ emissions reductions is attributable to the variety of feedstock sources considered for producing the fuel and electricity for each vehicle.

- PHEVs achieve greater petroleum energy savings with increased electric range. Conversely, more GHG emissions are produced with increased electric range unless renewable or nonfossil electricity generation is used for recharging.

- PHEVs employing biomass-based fuels (e.g., E85 or hydrogen from biomass sources) may not achieve GHG emissions benefits compared with conventional HEVs (employing the same fuel) if the electricity generation mix for PHEV recharging is dominated by fossil fuel sources. 
This page intentionally left blank. 


\section{IMPLICATIONS FOR FUTURE ANALYSIS}

Although the WTW results for PHEVs in this report addressed many of the outstanding issues in our earlier report (Elgowainy at al. 2009), there are remaining issues that require further analysis. The following paragraphs address these remaining issues and their implications for future WTW analyses of PHEVs.

It is not clear what PHEV technology, i.e., power-split or series configuration or both, and what electric range will gain consumer acceptance and attain significant market penetration. Also, it is not clear whether the EPA mpg-based formulas for "on-road" adjustment of fuel economy accurately capture the impact of "real-world" driving for advanced vehicle technologies such as FCVs, PHEVs, and BEVs. Until a solid empirical basis is established to capture the real-world driving fuel and electricity consumption for these vehicle technologies, uncertainty in the on-road adjustment estimates will persist.

Other subtle, but important, complications include the rate of technological advancement that will be made in the critical components of each vehicle technology, e.g., batteries and fuel cells, and the specific control strategy adopted by each OEM for the combined operation of the electric motor and engine of PHEVs. Such uncertainties associated with vehicle technologies and operation impact the projection of fuel and electricity demand for vehicle operation which, in turn, impacts the WTW results for each fuel/vehicle pathway.

In addition to the direct impact of PHEV's electricity use, the impact of the generation mix of technologies and their "operating" (rather than nameplate) efficiencies on the WTW results is crucial. Although many researchers argue that cross-sectional marginal analysis applied to limited time intervals - such as that described here - is the appropriate methodology to capture the impact of PHEV recharging from the grid, such analysis poses many challenges. Also, by its nature, this method cannot account for changes in the generation mix induced by an expanding PHEV fleet over time. Some of the challenges associated with the marginal analysis method were overcome in our analysis, while others require further study. One of the biggest challenges to marginal analysis is the market penetration of the mix of different PHEV and BEV technologies in a given region and a given year. This is a complex subject that could be further examined by using a market transition analysis.

One critical implicit assumption of the "share of miles electrified" (the "utility factor") is that the probability of PHEV purchase is invariant to daily distance driven or to benefit vs. cost. In order to save oil, PHEVs will have to be purchased and used. How often this will happen, and how frequently the pack will be charged and fully discharged, remain topics of considerable uncertainty.

Other uncertainties that impact the electricity dispatch modeling (which calculates the share of electricity generation technologies dispatched to satisfy the vehicles' electric load, i.e., the marginal generation mix) include the rate at which charging occurs, the number of charges per day, and the time of day for each charge. All of these significantly impact the vehicles' charging profiles which, in turn, impact the generation technology dispatched to satisfy the 
additional load and the determination of whether generation capacity expansion is needed to satisfy a specific reserve margin.

Adoption of a specific generation technology for capacity expansion is another complication that depends, not only on the economics of each technology, but also on the evolving regulations and standards - both at the local and national levels. Existing and evolving policies aimed at reducing electricity demand, GHG emissions, and other criteria pollutants (e.g., Energy Efficiency Resource Standard [EERS] and Renewable Energy or Portfolio Standard [RES or RPS], mercury regulations, and Clean Air Interstate Rule [CAIR], carbon tax) impact the economics and - ultimately - the retirement of existing generation technologies, as well as the selection of future generation technologies. While wind is a likely overnight renewable source for battery recharging, its generation is intermittent (varies by time and region) and it must be backed up by another generation source with a high ramping rate. Thus, the attainable share of wind-electricity in the marginal mix and its complementary generation technology require further analysis. While some of these issues could be addressed in further electric utility dispatch simulations, others that are related to future electric utility operations are subject to policy and behavior uncertainties. The latter may have to be addressed by using scenario analysis. 


\section{REFERENCES}

Bandel, W., 2006, "The Turbocharged GDI Engine: Boosted Synergies for High Fuel Economy plus Ultra-Low Emissions," SAE paper 2006-01-1266, SAE World Congress, Detroit, MI, April.

Bohn, T., and M. Duoba, 2005, "Implementation of a Non-Intrusive In-Vehicle Engine Torque Sensor for Benchmarking the Toyota Prius HEV," SAE paper 2005-01-1046, SAE World Congress, Detroit, MI, April.

Cao, Q., S. Pagerit, R. Carlson, and A. Rousseau, 2007, "PHEV Hymotion Prius Model Validation and Control Improvements," 23rd International Electric Vehicle Symposium (EVS23), Anaheim, CA, Dec.

Christenson, M., R. Shinomiya, and D. Karman, 2009, "PHEV Laboratory Test Results: Energy Consumption and Emissions in Cold Climate," PHEV'09 Conference, Sept. 28-30, Montreal, Canada.

Cirillo, R.R., P. Thimmapuram, T. Veselka, V. Koritarov, G. Conzelmann, C. Macal, G. Boyd, M. North, T. Overbye, and X. Cheng, 2006, "Evaluating the Potential Impact of Transmission Constraints on the Operation of a Competitive Electricity Market in Illinois," Report ANL 16/06, Argonne National Laboratory, April.

Duoba, M., R. Carlson, F. Jehlik, J. Smart, and S. White, 2009, "Correlating Dynamometer Testing to In-Use Fleet Results of Plug-In Hybrid Electric Vehicles," EVS24 International Battery, Hybrid and Fuel Cell Electric Vehicle Symposium, Stavanger, Norway, May 13-16.

EIA: See Energy Information Administration.

Electric Power Research Institute and Natural Resources Defense Council, 2007, Environmental Assessment of Plug-In Hybrid Electric Vehicles, Volume 1: Nationwide Greenhouse Gas Emissions, EPRI Report\# 1015325, July.

Elgowainy, A., A. Burnham, M. Wang, J. Molburg, and A. Rousseau, 2009, Well-to-Wheels Energy Use and Greenhouse Gas Emissions Analysis of Plug-In Hybrid Electric Vehicles, ANL_ESD_09-2, Center for Transportation Research, Argonne National Laboratory, Argonne, IL, Feb.

Energy Information Administration, 2007, EIA-411 - Coordinated Bulk Power Supply Program Report, Form EIA-423 - Monthly Cost and Quality of Fuels for Electric Plants Report; Form EIA-767 - Steam-Electric Plant Operation and Design Report; Form EIA-860 - Annual Electric Generator Report; and Form EIA-906 - Power Plant Report available at http://www.eia.doe.gov/oss/forms.html, accessed Feb. 2009. 
Energy Information Administration, 2008, Assumptions to the Annual Energy Outlook 2008: Electricity Market Module, Report Number DOE/EIA-0554(2008), U.S. Department of Energy, June, available at [http://www.eia.doe.gov/oiaf/aeo/assumption/pdf/electricity.pdf], accessed Feb. 2009.

Energy Information Administration, 2009a, Annual Energy Outlook 2009: Updated Reference Case, April 2009, DOE/EIA-0383(2009), U.S. Department of Energy, Washington, D.C. (Detailed tables were obtained from EIA.)

Energy Information Administration, 2009b, The National Energy Modeling System: An Overview, DOE/EIA-0581(2009), U.S. Department of Energy, Washington, D.C.

EPA: see U.S. Environmental Protection Agency.

EPRI and NRDC: see Electric Power Research Institute and Natural Resources Defense Council.

Federal Energy Regulatory Commission, 2009, FERC Form 714 - Annual Electric Balancing Authority Area and Planning Area Report, updated Jan. 8, available at [http://www.ferc.gov/ docs-filing/eforms/form-714/overview.asp], accessed Feb. 2009.

Federal Highway Administration, 2008, Highway Statistics 2007, U.S. Department of Transportation, Washington, D.C., available at [http://www.fhwa.dot.gov/policyinformation/ statistics/2007//], accessed (Tables MV-1 and MV-9) March 2010.

Federal Highway Administration, 2004, The 2001 National Household Travel Survey: Compact Disk and User's Guide, U.S. Department of Transportation, Washington, D.C.

FERC: see Federal Energy Regulatory Commission.

Freyermuth, V., E. Fallas, and A. Rousseau, 2008, Comparison of Powertrain Configuration for Plug-In HEVS from a Fuel Economy Perspective, SAE paper 2008-01-0461, SAE World Congress, Detroit, MI, April.

FHWA: see Federal Highway Administration.

Gaines, L., A. Burnham, A. Rousseau, and D. Santini, 2008, "Sorting through the Many TotalEnergy-Cycle Pathways Possible with Early Plug-in Hybrids," The World Electric Vehicle Journal, Volume 2, Sept.

Hadley, S., and A. Tsvetkova, 2008, Potential Impacts of Plug-in Hybrid Electric Vehicles on Regional Power Generation, ORNL/TM-2007/150, Oak Ridge National Laboratory, Oak Ridge, TN, Jan.

Intergovernmental Panel on Climate Change, 2008, 2008, Climate Change 2007: Technical Summary, Cambridge University Press, Cambridge, UK. 
IPCC: see Intergovernmental Panel on Climate Change.

IWEA: see Illinois Wind Energy Association.

Karbowski, J.D., A. Rousseau, S. Pagerit, and P. Sharer, 2006, "Plug-In Vehicle Control Strategy: From Global Optimization to Real-Time Application," EVS22, Yokohama, Japan, Oct., available at [http://windforillinois.com/maps.php], accessed March 2010.

Kromer, M.A., and J.B. Heywood, 2007, Electric Powertrains: Opportunities and Challenges in the U.S. Light-Duty Vehicle Fleet, Massachusetts Institute of Technology (MIT), Publication No. LFEE 2007-03 RP, May.

Morrow, K., D. Karner, and J. Francfort, 2008, Plug-in Hybrid Electric Vehicle Charging Infrastructure Review, INL/EXT-08-15058, Idaho National Laboratory, Nov.

National Renewable Energy Laboratory, 2009a, Western Wind Resources Dataset, available at http://wind.nrel.gov/Web_nrel/, accessed in March 2010.

National Renewable Energy Laboratory, 2009b, NREL Western Wind and Solar Integration Project, available at [http://mercator.nrel.gov/wwsi/], accessed in June 2009.

National Renewable Energy Laboratory, 2009c, National Solar Radiation Data Base 1991-2005 Update, available at [http://rredc.nrel.gov/solar/old_data/nsrdb/1991-2005/hourly/list_by_ USAFN.html], accessed in June 2009.

National Research Council, 2009, Transitions to Alternative Transportation Technologies Plug-in Hybrid Electric Vehicles, The National Academies Press, Washington D.C., ISBN: 0309-14851-0.

NE ISO: see New England Independent System Operator.

NERC: see North American Electric Reliability Corporation.

New England Independent System Operator, 2008a, 2008-2017 Forecast Report of Capacity, Energy, Loads, and Transmission, April, available at [http:/www.iso-ne.com/trans/celt/ report/2008/index.html], accessed March 2009.

New York Independent System Operator, 2008b, 2008 Load and Capacity Data (Gold Book), April, available at http://www.nyiso.com/public/markets_operations/services/planning/document ments/index.jsp, accessed in March 2009.

North American Electric Reliability Corporation, 2008, Generating Availability Data System (GADS), [http://www.nerc.com/page.php?cid=4\%7C43], accessed April 2009.

NRC: see National Research Council. 
NREL: see National Renewable Energy Laboratory.

NY ISO: see New York Independent System Operator.

Olszewski, M., 2008, Evaluation of the 2007 Toyota Camry Hybrid Synergy Drive System, DOE report, Jan.

Pagerit, S., A. Rousseau, and P. Sharer, 2005, "Global Optimization to Real-Time Control of HEV Power Flow: Example of a Fuel Cell Hybrid Vehicle," 20th International Electric Vehicle Symposium (EVS20), Monaco, April.

Passier, G., F.V. Conte, S. Smets, F. Badin, A. Brouwer, M. Alaküla, D. Santini, and M. Alexander, 2007, Status Overview of Hybrid and Electric Vehicle Technology, MON-RPT-033DTS-2007-02955, International Energy Agency, Dec.6.

Rousseau, A., P. Sharer, S. Pagerit, and M. Duoba, 2006, "Integrating Data, Performing Quality Assurance, and Validating the Vehicle Model for the 2004 Prius Using PSAT," SAE paper 200601-0667, SAE World Congress, Detroit, MI, April.

Santini, D., and A. Vyas, 2008, "More Complications in Estimation of Oil Savings via Electrification of Light Duty Vehicles," Plug-In 2008 Conference, San Jose, CA, July 21-24.

Sharer, P., A. Rousseau, D. Karbowski, and S. Pagerit, 2008, "Plug-in Hybrid Electric Vehicle Control Strategy: Comparison between EV and Charge-Depleting Options," SAE paper 2008-010460, SAE World Congress, Detroit, MI, April.

Sharer, P., A. Rousseau, P. Nelson, and S. Pagerit, 2006, "Vehicle Simulation Results for PHEV Battery Requirements," 22nd International Electric Vehicle Symposium (EVS22), Yokohama, Japan, Oct.

Stodolsky, F., A. Vyas, R. Cuenca, and L. Gaines, 1995, "Life-Cycle Energy Savings Potential from Aluminum- Intensive Vehicles," 1995 Total Life Cycle Conference \& Exposition, Oct., Vienna, Austria.

TEPPC: see Transmission Expansion Planning and Policy Committee.

Thomas, C.E., 2009, "Cost-Benefit Analyses of Alternative Light-Duty Transportation Options for the 21st Century," National Hydrogen Association Conference, Columbia, SC, March 31.

Transmission Expansion Planning and Policy Committee, 2008, 2008 Annual Report of the Transmission Expansion Planning Policy Subcommittee, WECC, March.

U.S. Census Bureau, 2005, State Interim Population Projections by Age and Sex: 2004-2030, Detailed Data File 2, U.S. Department of Commerce, Washington, D.C., available at [http://www.census.gov/population/www/projections/projectionsagesex.html], accessed March 2010. 
U.S. Environmental Protection Agency, 2006, Fuel Economy Labeling of Motor Vehicle Revisions to Improve Calculation of Fuel Economy Estimates, Final Technical Support Document, EPA420-R-06-017, Dec., available at [http://www.epa.gov/fueleconomy/fe-labelingfinal-rule.pdf], accessed March 2010.

U.S. Environmental Protection Agency, 2008, Light-Duty Automotive Technology and Fuel Economy Trends: 1975 through 2008, EPA420-R-08-015, Sept. available at [http://www.epa.gov/oms/cert/mpg/fetrends/fetrends-archive.htm], accessed March 2010.

Vyas, A., D. Santini, M. Duoba, and M. Duvall, 2007, "Plug-In Hybrid Electric Vehicles: How Does One Determine Their Potential for Reducing U.S. Oil Dependence?" Proceedings of the Electric Vehicle Symposium 23, Anaheim, CA, Dec. 2-5.

Wang, M., 1999, GREET 1.5 - Transportation Fuel-Cycle Model, ANL/ESD-39, Center for Transportation Research, Argonne National Laboratory, Argonne, IL, Aug.

Weissler, P., 2009, "Many Factors Figure in EV Fuel-Economy Calculation," CURRENTEVENTS, Vol. 41, No. 8, Aug., available at [http://www.eaaev.org/CurrentEvents/ pdf/2009/CurrentEvents200908.pdf], accessed March 2010.

Wipke, K., S. Sprik, J. Kurtz, and T. Ramsden, 2009, Controlled Hydrogen Fleet Infrastructure Demonstration and Validation Project, NREL/TP-560-45451, March 13, National Renewable Energy Laboratory, Golden, CO. 
This page intentionally left blank. 


\section{APPENDIX 1: VEHICLE DESCRIPTIONS}

\section{Component Power}

\begin{tabular}{|c|c|c|c|c|c|}
\hline & & \multicolumn{4}{|c|}{ Component Power (W) } \\
\hline & & \multirow{2}{*}{$\begin{array}{c}2008 \\
\text { Reference }\end{array}$} & \multicolumn{3}{|c|}{2015} \\
\hline & & & Low & Average & High \\
\hline \multirow[t]{5}{*}{ Gasoline SI Conv } & ICE Power & 120472 & 116993 & 109611 & 102785 \\
\hline & Electric Machine & & & & \\
\hline & $\mathrm{MC} 2 / \mathrm{GC}$ & & & & \\
\hline & Battery & & & & \\
\hline & Specific Power & 76.25 & 74.14 & 73.07 & 71.13 \\
\hline \multirow[t]{5}{*}{ Diesel CI Conv } & ICE Power & 112837 & 110000 & 103673 & 98747 \\
\hline & Electric Machine & & & & \\
\hline & $\mathrm{MC} 2 / \mathrm{GC}$ & & & & \\
\hline & Battery & & & & \\
\hline & Specific Power & 68.59 & 66.91 & 66.16 & 65.22 \\
\hline \multirow[t]{5}{*}{ E85 Conv } & ICE Power & 121988 & 120359 & 114374 & 106250 \\
\hline & Electric Machine & & & & \\
\hline & $\mathrm{MC} 2 / \mathrm{GC}$ & & & & \\
\hline & Battery & & & & \\
\hline & Specific Power & 77.16 & 76.18 & 76.10 & 73.43 \\
\hline \multirow[t]{5}{*}{ Gasoline SI Split HEV } & ICE Power & 88869 & 88132 & 81212 & 74211 \\
\hline & Electric Machine & 63506 & 62801 & 59368 & 55932 \\
\hline & $\mathrm{MC} 2 / \mathrm{GC}$ & 51429 & 51002 & 46998 & 42946 \\
\hline & Battery & 28733 & 28334 & 26738 & 25341 \\
\hline & Specific Power & 69.71 & 70.20 & 68.89 & 67.04 \\
\hline \multirow{5}{*}{$\begin{array}{l}\text { Gasoline SI Split HEV } \\
\text { PHEV10 }\end{array}$} & ICE Power & 63723 & 63096 & 58990 & 55290 \\
\hline & Electric Machine & 69500 & 68696 & 64694 & 60811 \\
\hline & $\mathrm{MC} 2 / \mathrm{GC}$ & 36877 & 36514 & 34138 & 31997 \\
\hline & Battery & 56979 & 56355 & 52082 & 48062 \\
\hline & Specific Power & 71.51 & 71.92 & 70.84 & 69.64 \\
\hline \multirow{5}{*}{$\begin{array}{l}\text { Gasoline SI Split HEV } \\
\text { PHEV20 }\end{array}$} & ICE Power & 64607 & 63952 & 59783 & 55822 \\
\hline & Electric Machine & 70544 & 69934 & 65765 & 61594 \\
\hline & $\mathrm{MC} 2 / \mathrm{GC}$ & 37388 & 37009 & 34597 & 32304 \\
\hline & Battery & 57790 & 57473 & 52986 & 48743 \\
\hline & Specific Power & 71.20 & 71.81 & 70.66 & 69.57 \\
\hline
\end{tabular}




\begin{tabular}{|c|c|c|c|c|c|}
\hline \multirow{8}{*}{$\begin{array}{l}\text { Gasoline SI Series HEV } \\
\text { PHEV30 }\end{array}$} & & \multicolumn{4}{|c|}{ Component Power (W) } \\
\hline & & \multirow{2}{*}{$\begin{array}{c}2008 \\
\text { Reference }\end{array}$} & \multicolumn{3}{|c|}{2015} \\
\hline & & & Low & Average & High \\
\hline & ICE Power & 77511 & 76037 & 69137 & 62271 \\
\hline & Electric Machine & 126935 & 124468 & 116672 & 108694 \\
\hline & $\mathrm{MC} 2 / \mathrm{GC}$ & 75186 & 73756 & 67063 & 60403 \\
\hline & Battery & 156120 & 153121 & 142017 & 130834 \\
\hline & Specific Power & 65.74 & 66.42 & 66.37 & 66.64 \\
\hline \multirow{5}{*}{$\begin{array}{l}\text { Gasoline SI Series HEV } \\
\text { PHEV40 }\end{array}$} & ICE Power & 79497 & 77901 & 70682 & 63701 \\
\hline & Electric Machine & 129935 & 127429 & 119064 & 110960 \\
\hline & $\mathrm{MC} 2 / \mathrm{GC}$ & 77112 & 75564 & 68562 & 61790 \\
\hline & Battery & 159736 & 156706 & 144871 & 133437 \\
\hline & Specific Power & 65.86 & 66.51 & 66.44 & 66.92 \\
\hline \multirow[t]{5}{*}{ Diesel CI Split HEV } & ICE Power & 78299 & 76983 & 71722 & 65009 \\
\hline & Electric Machine & 68729 & 67470 & 64478 & 60358 \\
\hline & $\mathrm{MC} 2 / \mathrm{GC}$ & 65528 & 64426 & 60024 & 54406 \\
\hline & Battery & 30330 & 29731 & 28334 & 26738 \\
\hline & Specific Power & 60.89 & 61.05 & 60.38 & 58.36 \\
\hline \multirow{5}{*}{$\begin{array}{l}\text { Diesel CI Split HEV } \\
\text { PHEV10 }\end{array}$} & ICE Power & 67488 & 66747 & 62474 & 58508 \\
\hline & Electric Machine & 67928 & 66369 & 63255 & 59602 \\
\hline & $\mathrm{MC} 2 / \mathrm{GC}$ & 56480 & 55860 & 52284 & 48965 \\
\hline & Battery & 53221 & 52432 & 48948 & 45544 \\
\hline & Specific Power & 67.47 & 67.75 & 66.88 & 65.94 \\
\hline \multirow{5}{*}{$\begin{array}{l}\text { Diesel CI Split HEV } \\
\text { PHEV20 }\end{array}$} & ICE Power & 67574 & 66776 & 63975 & 59627 \\
\hline & Electric Machine & 69078 & 67499 & 64318 & 60363 \\
\hline & $\mathrm{MC} 2 / \mathrm{GC}$ & 56552 & 55884 & 53540 & 49901 \\
\hline & Battery & 54016 & 53321 & 49648 & 46100 \\
\hline & Specific Power & 66.81 & 67.13 & 67.11 & 66.08 \\
\hline \multirow{5}{*}{$\begin{array}{l}\text { Diesel CI Series HEV } \\
\text { PHEV30 }\end{array}$} & ICE Power & 78703 & 77106 & 70177 & 63272 \\
\hline & Electric Machine & 128774 & 126169 & 118314 & 110347 \\
\hline & $\mathrm{MC} 2 / \mathrm{GC}$ & 76342 & 74793 & 68072 & 61374 \\
\hline & Battery & 158378 & 155206 & 144013 & 132818 \\
\hline & Specific Power & 65.43 & 66.06 & 66.02 & 66.31 \\
\hline \multirow{5}{*}{$\begin{array}{l}\text { Diesel CI Series HEV } \\
\text { PHEV40 }\end{array}$} & ICE Power & 80628 & 79001 & 71812 & 64731 \\
\hline & Electric Machine & 131766 & 129171 & 120859 & 112650 \\
\hline & $\mathrm{MC} 2 / \mathrm{GC}$ & 78209 & 76631 & 69658 & 62789 \\
\hline & Battery & 161992 & 158834 & 147039 & 135466 \\
\hline & Specific Power & 65.52 & 66.14 & 66.12 & 66.58 \\
\hline \multirow[t]{5}{*}{ E85 Split HEV } & ICE Power & 87862 & 86031 & 80131 & 73438 \\
\hline & Electric Machine & 64608 & 63286 & 60276 & 57251 \\
\hline & $\mathrm{MC} 2 / \mathrm{GC}$ & 50846 & 49786 & 46372 & 42499 \\
\hline & Battery & 28733 & 28135 & 26538 & 25341 \\
\hline & Specific Power & 69.03 & 68.90 & 68.12 & 66.52 \\
\hline
\end{tabular}




\begin{tabular}{|c|c|c|c|c|c|}
\hline \multirow{8}{*}{ E85 Split HEV PHEV10 } & \multirow[b]{4}{*}{ ICE Power } & \multicolumn{4}{|c|}{ Component Power (W) } \\
\hline & & \multirow{3}{*}{$\begin{array}{c}\mathbf{2 0 0 8} \\
\text { Reference } \\
63723\end{array}$} & \multicolumn{3}{|c|}{2015} \\
\hline & & & Low & Average & High \\
\hline & & & 63096 & 58990 & 55290 \\
\hline & Electric Machine & 69677 & 68871 & 64856 & 61020 \\
\hline & $\mathrm{MC} 2 / \mathrm{GC}$ & 36877 & 36514 & 34138 & 31997 \\
\hline & Battery & 57315 & 56678 & 52388 & 48490 \\
\hline & Specific Power & 71.70 & 72.11 & 71.03 & 69.93 \\
\hline \multirow[t]{5}{*}{ E85 Split HEV PHEV20 } & ICE Power & 64636 & 63952 & 59754 & 55878 \\
\hline & Electric Machine & 71251 & 70110 & 65765 & 61805 \\
\hline & $\mathrm{MC} 2 / \mathrm{GC}$ & 37405 & 37009 & 34580 & 32337 \\
\hline & Battery & 58874 & 57805 & 53063 & 49137 \\
\hline & Specific Power & 71.81 & 72.00 & 70.73 & 69.78 \\
\hline \multirow{5}{*}{$\begin{array}{l}\text { E85 Series HEV } \\
\text { PHEV30 }\end{array}$} & ICE Power & 77511 & 76037 & 69137 & 62271 \\
\hline & Electric Machine & 126935 & 124468 & 116672 & 108694 \\
\hline & $\mathrm{MC} 2 / \mathrm{GC}$ & 75186 & 73756 & 67063 & 60403 \\
\hline & Battery & 156120 & 153121 & 142017 & 130834 \\
\hline & Specific Power & 65.74 & 66.42 & 66.37 & 66.64 \\
\hline \multirow{5}{*}{$\begin{array}{l}\text { E85 Series HEV } \\
\text { PHEV40 }\end{array}$} & ICE Power & 79497 & 77901 & 70682 & 63701 \\
\hline & Electric Machine & 129935 & 127429 & 119064 & 110960 \\
\hline & $\mathrm{MC} 2 / \mathrm{GC}$ & 77112 & 75564 & 68562 & 61790 \\
\hline & Battery & 159736 & 156706 & 144871 & 133437 \\
\hline & Specific Power & 65.86 & 66.51 & 66.44 & 66.92 \\
\hline \multirow[t]{5}{*}{ FC HEV } & FC Power & 91596 & 93081 & 78904 & 68251 \\
\hline & Electric Machine & 106708 & 106703 & 94330 & 83807 \\
\hline & $\mathrm{MC} 2 / \mathrm{GC}$ & & & & \\
\hline & Battery & 29531 & 29531 & 26938 & 25341 \\
\hline & Specific Power & 59.51 & 58.98 & 59.63 & 58.20 \\
\hline \multirow[t]{5}{*}{ FC HEV PHEV10 } & FC Power & 68104 & 68236 & 56932 & 51933 \\
\hline & Electric Machine & 104379 & 104880 & 93016 & 84619 \\
\hline & $\mathrm{MC} 2 / \mathrm{GC}$ & & & & \\
\hline & Battery & 57045 & 57280 & 49584 & 44610 \\
\hline & Specific Power & 59.14 & 59.22 & 59.74 & 59.22 \\
\hline \multirow[t]{5}{*}{ FC HEV PHEV20 } & FC Power & 67653 & 68432 & 58789 & 52038 \\
\hline & Electric Machine & 107296 & 107267 & 94322 & 86255 \\
\hline & $\mathrm{MC} 2 / \mathrm{GC}$ & & & & \\
\hline & Battery & 58044 & 58523 & 50625 & 45273 \\
\hline & Specific Power & 59.58 & 59.26 & 59.28 & 59.45 \\
\hline \multirow[t]{5}{*}{ FC HEV PHEV30 } & FC Power & 62365 & 62539 & 55592 & 50811 \\
\hline & Electric Machine & 123876 & 123982 & 112616 & 103735 \\
\hline & $\mathrm{MC} 2 / \mathrm{GC}$ & & & & \\
\hline & Battery & 152359 & 152513 & 137085 & 124858 \\
\hline & Specific Power & 65.23 & 65.25 & 67.07 & 67.98 \\
\hline
\end{tabular}




\begin{tabular}{|c|c|c|c|c|c|}
\hline & & \multicolumn{4}{|c|}{ Component Power (W) } \\
\hline & & 2008 & & 2015 & \\
\hline & & Reference & Low & Average & High \\
\hline \multirow[t]{5}{*}{ FC HEV PHEV40 } & FC Power & 63535 & 63735 & 56502 & 51438 \\
\hline & Electric Machine & 127032 & 127236 & 115214 & 106034 \\
\hline & $\mathrm{MC} 2 / \mathrm{GC}$ & & & & \\
\hline & Battery & 156179 & 156454 & 140193 & 127511 \\
\hline & Specific Power & 65.38 & 65.32 & 67.18 & 68.41 \\
\hline \multirow[t]{5}{*}{ BEV } & ICE Power & & & & \\
\hline & Electric Machine & 154191 & 151520 & 137529 & 119779 \\
\hline & $\mathrm{MC} 2 / \mathrm{GC}$ & & & & \\
\hline & Battery & 187219 & 184430 & 166866 & 143655 \\
\hline & Specific Power & 88.69 & 89.40 & 88.01 & 86.07 \\
\hline
\end{tabular}




\section{Battery Energy}

\begin{tabular}{|c|c|c|c|c|c|}
\hline & & \multicolumn{4}{|c|}{ Battery Energy (Wh) } \\
\hline & & \multirow{2}{*}{$\begin{array}{c}2008 \\
\text { Reference }\end{array}$} & \multicolumn{3}{|c|}{2015} \\
\hline & & & Low & Average & High \\
\hline \multirow[t]{2}{*}{ SI Split HEV } & Total Energy & 1123.2 & 1107.6 & 1045.2 & 990.6 \\
\hline & Usable Energy & & & & \\
\hline \multirow[t]{2}{*}{ SI Split HEV PHEV10 } & Total Energy & 3866.7 & 3863.0 & 3474.6 & 2715.2 \\
\hline & Usable Energy & 2320.0 & 2317.8 & 2084.8 & 1900.6 \\
\hline \multirow[t]{2}{*}{ SI Split HEV PHEV20 } & Total Energy & 7534.6 & 7595.7 & 6829.6 & 5344.9 \\
\hline & Usable Energy & 4520.8 & 4557.4 & 4097.8 & 3741.4 \\
\hline \multirow[t]{2}{*}{ SI Series HEV PHEV30 } & Total Energy & 13066.1 & 12810.6 & 11593.9 & 8855.2 \\
\hline & Usable Energy & 7839.6 & 7686.4 & 6956.4 & 6198.6 \\
\hline \multirow[t]{2}{*}{ SI Series HEV PHEV40 } & Total Energy & 17627.2 & 17393.3 & 15593.6 & 11840.2 \\
\hline & Usable Energy & 10576.3 & 10436.0 & 9356.2 & 8288.2 \\
\hline \multirow[t]{2}{*}{ CI Split HEV } & Total Energy & 1185.6 & 1162.2 & 1107.6 & 1045.2 \\
\hline & Usable Energy & & & & \\
\hline \multirow[t]{2}{*}{ CI Split HEV PHEV10 } & Total Energy & 4199.0 & 4184.4 & 3698.2 & 2928.4 \\
\hline & Usable Energy & 2519.4 & 2510.7 & 2218.9 & 2049.9 \\
\hline \multirow{2}{*}{ CI Split HEV PHEV20 } & Total Energy & 8041.7 & 7992.8 & 7201.0 & 5702.0 \\
\hline & Usable Energy & 4825.0 & 4795.7 & 4320.6 & 3991.4 \\
\hline \multirow[t]{2}{*}{ CI Series HEV PHEV30 } & Total Energy & 13206.7 & 13045.0 & 11739.5 & 8983.8 \\
\hline & Usable Energy & 7924.0 & 7827.0 & 7043.7 & 6288.6 \\
\hline \multirow[t]{2}{*}{ CI Series HEV PHEV40 } & Total Energy & 17848.6 & 17584.1 & 15812.2 & 12020.6 \\
\hline & Usable Energy & 10709.2 & 10550.4 & 9487.3 & 8414.4 \\
\hline \multirow[t]{2}{*}{ E85 Split HEV } & Total Energy & 1123.2 & 1099.8 & 1037.4 & 990.6 \\
\hline & Usable Energy & & & & \\
\hline \multirow[t]{2}{*}{ E85 Split HEV PHEV10 } & Total Energy & 3867.4 & 3864.0 & 3475.4 & 2714.5 \\
\hline & Usable Energy & 2320.5 & 2318.4 & 2085.2 & 1900.2 \\
\hline \multirow[t]{2}{*}{ E85 Split HEV PHEV20 } & Total Energy & 7627.3 & 7589.2 & 6734.9 & 5344.8 \\
\hline & Usable Energy & 4576.4 & 4553.5 & 4040.9 & 3741.4 \\
\hline \multirow[t]{2}{*}{ E85 Series HEV PHEV30 } & Total Energy & 13074.7 & 12816.2 & 11597.0 & 8857.3 \\
\hline & Usable Energy & 7844.8 & 7689.7 & 6958.2 & 6200.1 \\
\hline \multirow[t]{2}{*}{ E85 Series HEV PHEV40 } & Total Energy & 17639.8 & 17403.7 & 15598.1 & 11842.1 \\
\hline & Usable Energy & 10583.9 & 10442.2 & 9358.9 & 8289.5 \\
\hline \multirow[t]{2}{*}{$\mathrm{H}_{2}$ Split HEV } & Total Energy & 1099.8 & 1076.4 & 1014.0 & 959.4 \\
\hline & Usable Energy & & & & \\
\hline \multirow[t]{2}{*}{$\mathrm{H}_{2}$ Split HEV PHEV10 } & Total Energy & 3912.0 & 3895.8 & 3496.1 & 2727.9 \\
\hline & Usable Energy & 2347.2 & 2337.5 & 2097.6 & 1909.6 \\
\hline \multirow[t]{2}{*}{$\mathrm{H}_{2}$ Split HEV PHEV20 } & Total Energy & 7467.7 & 7435.0 & 6751.3 & 5267.1 \\
\hline & Usable Energy & 4480.6 & 4461.0 & 4050.8 & 3687.0 \\
\hline \multirow[t]{2}{*}{$\mathrm{H}_{2}$ Series HEV PHEV30 } & Total Energy & 12906.0 & 12623.6 & 11320.7 & 8703.0 \\
\hline & Usable Energy & 7743.6 & 7574.1 & 6792.4 & 6092.1 \\
\hline \multirow[t]{2}{*}{$\mathrm{H}_{2}$ Series HEV PHEV40 } & Total Energy & 17389.4 & 17121.2 & 15358.0 & 11630.5 \\
\hline & Usable Energy & 10433.6 & 10272.7 & 9214.8 & 8141.4 \\
\hline
\end{tabular}




\begin{tabular}{lccccc}
\hline & & \multicolumn{2}{c}{ Battery Energy (Wh) } \\
\hline & & $\mathbf{2 0 0 8}$ & \multicolumn{2}{c}{$\mathbf{2 0 1 5}$} \\
& & Reference & Low & Average & High \\
\hline FC HEV & Total Energy & 1146.6 & 1107.6 & $\mathbf{1 0 6 8 . 6}$ & 1029.6 \\
\hline & Usable Energy & & & & \\
FC HEV PHEV10 & Total Energy & 4318.0 & 4275.4 & $\mathbf{3 8 1 1 . 4}$ & 2937.5 \\
\hline \multirow{2}{*}{ FC HEV PHEV20 } & Usable Energy & 2590.8 & 2565.2 & $\mathbf{2 2 8 6 . 9}$ & 2056.3 \\
& Total Energy & 8475.5 & 8382.4 & $\mathbf{7 5 6 8 . 3}$ & 5882.4 \\
\hline FC HEV PHEV30 & Usable Energy & 5085.3 & 5029.4 & $\mathbf{4 5 4 1 . 0}$ & 4117.7 \\
& Total Energy & 12696.7 & 12656.4 & $\mathbf{1 1 3 4 1 . 2}$ & 8640.3 \\
\hline FC HEV PHEV40 & Usable Energy & 7618.0 & 7593.8 & $\mathbf{6 8 0 4 . 7}$ & 6048.2 \\
& Total Energy & 17061.7 & 16890.8 & $\mathbf{1 5 1 0 5 . 3}$ & 11543.8 \\
\hline & Usable Energy & 10237.0 & 10134.5 & $\mathbf{9 0 6 3 . 2}$ & 8080.7 \\
\hline & Total Energy & 68522.1 & 67838.5 & $\mathbf{6 0 1 7 4 . 4}$ & 43868.7 \\
\hline
\end{tabular}




\section{Vehicle Weight}

\begin{tabular}{|c|c|c|c|c|c|}
\hline & & \multicolumn{4}{|c|}{ Vehicle Test Weight (kg) } \\
\hline & & \multirow{2}{*}{$\begin{array}{c}2008 \\
\text { Reference }\end{array}$} & \multicolumn{3}{|c|}{2015} \\
\hline & & & Low & Average & High \\
\hline \multirow[t]{2}{*}{ SI Conv } & Vehicle Mass & 1580 & 1578 & 1500 & 1445 \\
\hline & $\%$ of glider mass & 62.7 & 62.7 & 61.1 & 59.9 \\
\hline \multirow[t]{2}{*}{ CI Conv } & Vehicle Mass & 1645 & 1644 & 1567 & 1514 \\
\hline & $\%$ of glider mass & 60.2 & 60.2 & 58.4 & 57.2 \\
\hline \multirow{2}{*}{$\mathrm{H}_{2}$ Conv } & Vehicle Mass & 1720 & 1771 & 1563 & 1470 \\
\hline & $\%$ of glider mass & 57.6 & 55.9 & 58.6 & 58.9 \\
\hline \multirow[t]{2}{*}{ E85 Conv } & Vehicle Mass & 1581 & 1580 & 1503 & 1447 \\
\hline & $\%$ of glider mass & 62.6 & 62.7 & 60.9 & 59.9 \\
\hline \multirow[t]{2}{*}{ SI Split HEV } & Vehicle Mass & 1687 & 1659 & 1567 & 1485 \\
\hline & $\%$ of glider mass & 58.7 & 59.7 & 58.4 & 58.3 \\
\hline \multirow[t]{2}{*}{ SI Split HEV PHEV10 } & Vehicle Mass & 1688 & 1661 & 1568 & 1484 \\
\hline & $\%$ of glider mass & 58.6 & 59.6 & 58.4 & 58.4 \\
\hline \multirow[t]{2}{*}{ SI Split HEV PHEV20 } & Vehicle Mass & 1719 & 1691 & 1596 & 1503 \\
\hline & $\%$ of glider mass & 57.6 & 58.5 & 57.4 & 57.6 \\
\hline \multirow[t]{2}{*}{ SI Series HEV PHEV30 } & Vehicle Mass & 1931 & 1874 & 1758 & 1631 \\
\hline & $\%$ of glider mass & 51.3 & 52.8 & 52.1 & 53.1 \\
\hline \multirow[t]{2}{*}{ SI Series HEV PHEV40 } & Vehicle Mass & 1973 & 1916 & 1792 & 1658 \\
\hline & $\%$ of glider mass & 50.2 & 51.7 & 51.1 & 52.2 \\
\hline \multirow[t]{2}{*}{ CI Split HEV } & Vehicle Mass & 1784 & 1748 & 1657 & 1572 \\
\hline & $\%$ of glider mass & 55.5 & 56.6 & 55.3 & 55.1 \\
\hline \multirow[t]{2}{*}{ CI Split HEV PHEV10 } & Vehicle Mass & 1789 & 1759 & 1666 & 1578 \\
\hline & $\%$ of glider mass & 55.3 & 56.3 & $\mathbf{5 5 . 0}$ & 54.9 \\
\hline \multirow[t]{2}{*}{ CI Split HEV PHEV20 } & Vehicle Mass & 1820 & 1789 & 1693 & 1600 \\
\hline & $\%$ of glider mass & 54.4 & 55.3 & 54.1 & 54.1 \\
\hline \multirow[t]{2}{*}{ CI Series HEV PHEV30 } & Vehicle Mass & 1968 & 1910 & 1792 & 1664 \\
\hline & $\%$ of glider mass & 50.3 & 51.8 & 51.1 & 52.1 \\
\hline \multirow[t]{2}{*}{ CI Series HEV PHEV40 } & Vehicle Mass & 2011 & 1953 & 1828 & 1692 \\
\hline & $\%$ of glider mass & 49.2 & 50.7 & 50.1 & 51.2 \\
\hline \multirow[t]{2}{*}{$\mathrm{H}_{2}$ Split HEV } & Vehicle Mass & 1667 & 1652 & 1516 & 1421 \\
\hline & $\%$ of glider mass & 59.4 & 59.9 & 60.4 & 61.0 \\
\hline \multirow[t]{2}{*}{$\mathrm{H}_{2}$ Split HEV PHEV10 } & Vehicle Mass & 1677 & 1663 & 1525 & 1424 \\
\hline & $\%$ of glider mass & 59.0 & 59.5 & 60.0 & 60.8 \\
\hline \multirow[t]{2}{*}{$\mathrm{H}_{2}$ Split HEV PHEV20 } & Vehicle Mass & 1707 & 1692 & 1551 & 1447 \\
\hline & $\%$ of glider mass & 58.0 & 58.5 & 59.0 & 59.9 \\
\hline \multirow[t]{2}{*}{$\mathrm{H}_{2}$ Series HEV PHEV30 } & Vehicle Mass & 1912 & 1873 & 1705 & 1566 \\
\hline & $\%$ of glider mass & 51.8 & 52.9 & 53.7 & 55.3 \\
\hline \multirow[t]{2}{*}{$\mathrm{H}_{2}$ Series HEV PHEV40 } & Vehicle Mass & 1954 & 1915 & 1741 & 1590 \\
\hline & $\%$ of glider mass & 50.7 & 51.7 & 52.6 & 54.5 \\
\hline
\end{tabular}




\begin{tabular}{|c|c|c|c|c|c|}
\hline & & \multicolumn{4}{|c|}{ Vehicle Test Weight (kg) } \\
\hline & & \multirow{2}{*}{$\begin{array}{c}2008 \\
\text { Reference }\end{array}$} & \multicolumn{3}{|c|}{2015} \\
\hline & & & Low & Average & High \\
\hline \multirow[t]{2}{*}{ E85 Split HEV } & Vehicle Mass & 1689 & 1657 & 1566 & 1485 \\
\hline & $\%$ of glider mass & 58.6 & 59.7 & 58.5 & 58.3 \\
\hline \multirow[t]{2}{*}{ E85 Split HEV PHEV10 } & Vehicle Mass & 1688 & 1661 & 1568 & 1484 \\
\hline & $\%$ of glider mass & 58.6 & 59.6 & 58.4 & 58.4 \\
\hline \multirow[t]{2}{*}{ E85 Split HEV PHEV20 } & Vehicle Mass & 1720 & 1691 & 1595 & 1505 \\
\hline & $\%$ of glider mass & 57.6 & 58.5 & 57.4 & 57.6 \\
\hline \multirow[t]{2}{*}{ E85 Series HEV PHEV30 } & Vehicle Mass & 1931 & 1874 & 1758 & 1631 \\
\hline & $\%$ of glider mass & 51.3 & 52.8 & 52.1 & 53.1 \\
\hline \multirow[t]{2}{*}{ E85 Series HEV PHEV40 } & Vehicle Mass & 1973 & 1916 & 1792 & 1658 \\
\hline & $\%$ of glider mass & 50.2 & 51.7 & 51.1 & 52.2 \\
\hline \multirow[t]{2}{*}{ FC HEV } & Vehicle Mass & 1793 & 1809 & 1582 & 1440 \\
\hline & $\%$ of glider mass & 55.2 & 54.7 & 57.9 & 60.2 \\
\hline \multirow[t]{2}{*}{ FC HEV PHEV10 } & Vehicle Mass & 1765 & 1771 & 1557 & 1429 \\
\hline & $\%$ of glider mass & 56.1 & 55.9 & 58.8 & 60.6 \\
\hline \multirow[t]{2}{*}{ FC HEV PHEV 20} & Vehicle Mass & 1801 & 1810 & 1591 & 1451 \\
\hline & $\%$ of glider mass & 55.0 & 54.7 & 57.6 & 59.7 \\
\hline \multirow[t]{2}{*}{ FC HEV PHEV30 } & Vehicle Mass & 1899 & 1900 & 1679 & 1526 \\
\hline & $\%$ of glider mass & 52.1 & 52.1 & 54.5 & 56.8 \\
\hline \multirow[t]{2}{*}{ FC HEV PHEV40 } & Vehicle Mass & 1943 & 1948 & 1715 & 1550 \\
\hline & $\%$ of glider mass & 51.0 & 50.8 & 53.4 & 55.9 \\
\hline \multirow[t]{2}{*}{ EV } & Vehicle Mass & 2111 & 2063 & 1896 & 1669 \\
\hline & $\%$ of glider mass & 46.9 & 48.0 & 48.3 & 51.9 \\
\hline
\end{tabular}



Argonne

Energy Systems Division

Argonne National Laboratory

9700 South Cass Avenue, Bldg. 362

Argonne, IL 60439-4815

www.anl.gov 